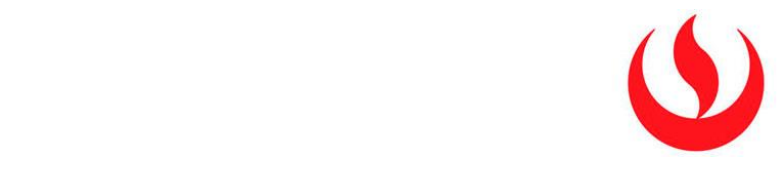

UNIVERSIDAD PERUANA DE CIENCIAS APLICADAS

FACULTAD DE INGENIERÍA

PROGRAMA ACADÉMICO DE INGENIERÍA DE SISTEMAS DE

INFORMACIÓN

\title{
MODELO DE REFERENCIA PARA LA IMPLEMENTACIÓN DE UNA SOLUCIÓN E- COMMERCE EN PYMES PERUANAS DEL SECTOR RETAIL
}

\begin{abstract}
TESIS
PARA OPTAR POR EL TÍTULO DE INGENIERO DE SISTEMAS DE INFORMACIÓN
\end{abstract}

AUTORES

Cadillo Montesinos, Miguel Alexis (0000-0001-8397-0552)

Kauss Pérez, Julio André (0000-0003-3946-2854)

ASESOR

Velásquez Nuñez, Ángel Augusto (0000-0003-4702-2576)

Lima, Octubre 2018 
Esta tesis esta dedicada a nuestras familias, cuyo apoyo se mantuvo incondicional durante nuestra vida universitaria y crecimiento profesional.

Gracias por todo. 


\section{Resumen Ejecutivo}

El comercio electrónico es un modelo de negocio que permite a las empresas optimizar los procesos de compra, venta, transferencia de bienes e intercambio de servicios a través de redes de computadora o Internet. En el entorno peruano, sólo el 15\% de Pymes del Sector Retail utilizan el comercio electrónico, a pesar de que existe un crecimiento constante en el sector. Esta situación se debe, en parte a que no existe un modelo que permita a las empresas implementar una solución e-commerce, lo que conlleva a que la mayoría de Pymes no tengan el conocimiento adecuado, para adaptarse al comercio electrónico. En este trabajo, se propone un modelo de referencia, para la implementación de una solución de e-commerce en Pymes peruanas del Sector Retail, el cual se describe como un marco que abarca desde un inicio el conocimiento total de la actividad de la empresa, así como su entorno y objetivos. Luego brinda una herramienta que permite conocer el status de la organización previo a la implementación del comercio electrónico, para posteriormente realizar un modelado de negocio que involucre los procesos claves de la organización (en su estado actual y futuro). En un tercer paso describe todo el proceso de implementación de la solución, la puesta en marcha y capacitación. Finalmente, permite a la empresa analizar los resultados obtenidos utilizando indicadores de éxito para medir el cumplimiento de sus objetivos. El presente modelo se validó en una Pyme del sector Retail peruano mediante una implementación de una plataforma de comercio electrónico, con la cual la empresa aumentó sus ventas a través del canal delivery en $10 \%$ en el primer mes de despliegue. Este resultado mostró que el modelo es fácil de implementar, es económico y ágil. Además, permitió a la empresa aumentar su oferta de negocio, adaptarse al e-commerce y fidelizar de una mejor forma a sus clientes.

Palabras claves: e-commerce, Pymes, Retail. 


\begin{abstract}
E-commerce is a business model that allows companies to optimize the processes of purchase, sale, transfer of goods and exchange of services through computer networks or the Internet. In the Peruvian environment, only $15 \%$ of SMEs in the Retail Sector use electronic commerce, despite the fact that there is constant growth in the sector. This situation is due, in part, to the fact that there is no model that allows companies to implement an e-commerce solution, which means that most SMEs do not have the adequate knowledge to adapt to electronic commerce. In this work, a reference model is proposed, for the implementation of an e-commerce solution in Peruvian SMEs of the Retail Sector, which is described as a framework that includes from the beginning, the total knowledge of the activity of the company, as well as its environment and objectives. Then it provides a tool that allows the knowledge of the status of the organization prior to the implementation of electronic commerce, to subsequently conduct a business modeling that involves the key processes of the organization (in its current and future state). In a third step it describes the entire process of implementation of the solution, the start-up and training. Finally, it allows the company to analyze the results obtained using success indicators to measure the fulfillment of its objectives. This model was validated in a SME in the Peruvian retail sector through an implementation of an electronic commerce platform, with which the company increased its sales through the delivery channel by $10 \%$ in the first month of deployment. This result showed that the model is easy to implement, it is economical and agile. In addition, it allowed the company to increase its business offer, adapt to e-commerce and improve customer loyalty in a better way
\end{abstract}

Key words: e-commerce, SME's, Retail. 


\section{Tabla de Contenido}

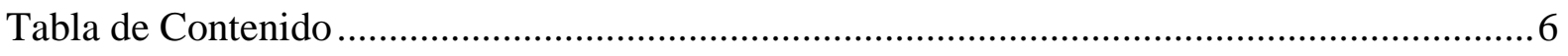

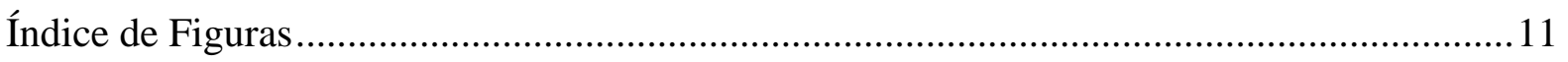

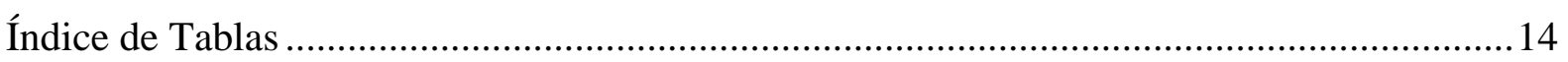

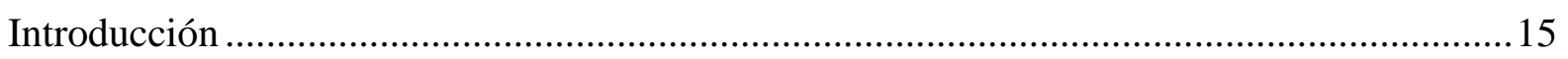

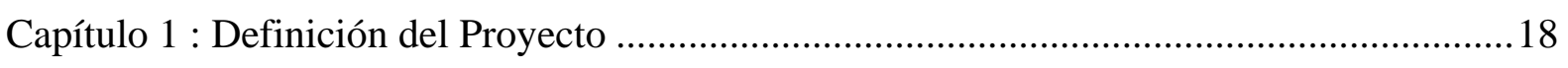

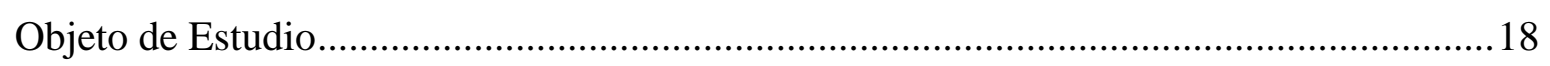

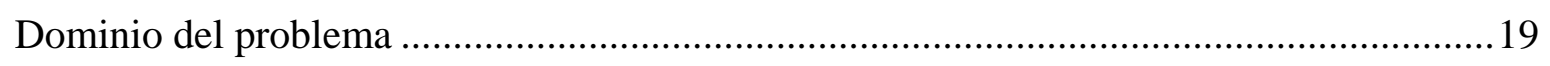

Importancia del problema ...................................................Error! Marcador no definido.

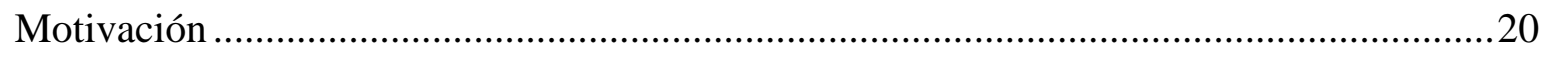

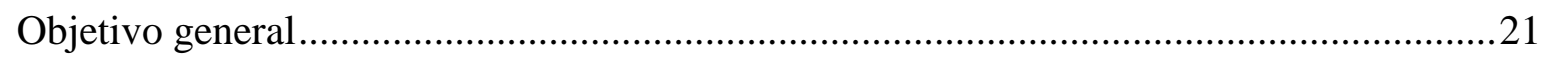

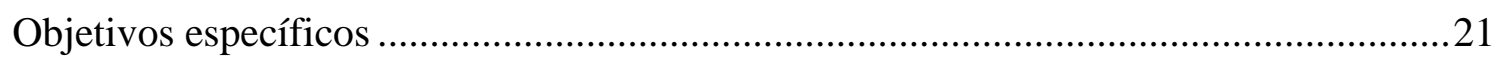

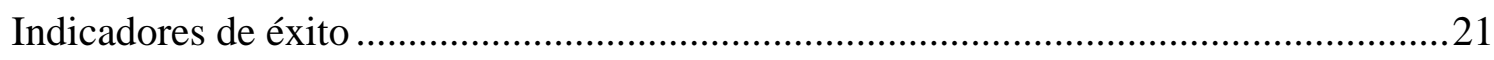

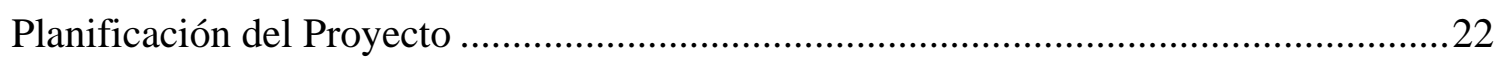

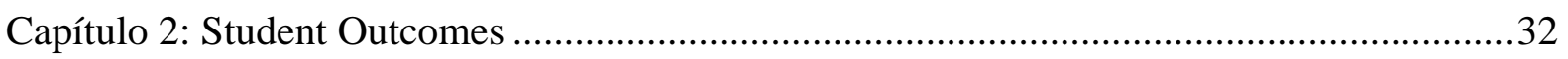

Student Outcome A ...........................................................Error! Marcador no definido.

Definición .........................................................................Error! Marcador no definido.

The Open Group Architecture Framework ..........................EFror! Marcador no definido.

Student Outcome B ..........................................................Error! Marcador no definido.

Definición ...........................................................................Error! Marcador no definido.

Modelo Propuesto ...............................................................Error! Marcador no definido.

Validación del Modelo.......................................................... ¿Error! Marcador no definido.

Student Outcome C ...........................................................Error! Marcador no definido.

Definición ......................................................................... Error! Marcador no definido.

Modelo Propuesto .................................................................Error! Marcador no definido.

Student Outcome D ....................................................... E Error! Marcador no definido.

Definición .......................................................................... E Error! Marcador no definido.

Representantes de municipalidades ....................................EFror! Marcador no definido.

Abogados ........................................................................... ¿Error! Marcador no definido. 
Ingenieros. ..¡Error! Marcador no definido.

Student Outcome E ... Error! Marcador no definido.

Definición ¡Error! Marcador no definido.

Análisis de Gobierno Electrónico ¡Error! Marcador no definido.

Análisis de la situación actual. ... Error! Marcador no definido.

Análisis de casos de éxito del gobierno electrónico ¡Error! Marcador no definido. Investigación sobre metodologías. ...¿Error! Marcador no definido.

Student Outcome F ..¡Error! Marcador no definido.

Definición ...¡Error! Marcador no definido.

Análisis del tema. ¡Error! Marcador no definido.

Modelo propuesto ..¡Error! Marcador no definido.

Referencias bibliográficas ... Error! Marcador no definido.

Student Outcome G. ..jError! Marcador no definido.

Definición ...¿Error! Marcador no definido.

Reuniones con el profesor cliente y profesor gerente ...Error! Marcador no definido. Reuniones de municipalidades ...jError! Marcador no definido.

Especialistas en el tema ..Error! Marcador no definido.

Actas de reunión ..¡Error! Marcador no definido.

Exposición frente al comité ... Error! Marcador no definido.

Memoria profesional ¡Error! Marcador no definido.

Student Outcome H. ¡Error! Marcador no definido. Definición ..¡Error! Marcador no definido.

Modelo propuesto ¡Error! Marcador no definido.

Student Outcome I ¡.Error! Marcador no definido.

Definición ¡Error! Marcador no definido.

The Open Group Architecture Framework ¡. ¿Error! Marcador no definido.

Papers de investigación ¡Error! Marcador no definido.

Investigación sobre metodologías. ¡.Error! Marcador no definido. Student Outcome J ...Error! Marcador no definido.

Definición ¡Error! Marcador no definido.

Modelo propuesto ¡.Error! Marcador no definido.

Student Outcome K ..¡Error! Marcador no definido. Definición ...¿Error! Marcador no definido. The Open Group Architecture Framework ¡Error! Marcador no definido. 
LucidChart ¡Error! Marcador no definido.

Bizagi ..¡Error! Marcador no definido.

Metodología PMBOK ..¡Error! Marcador no definido.

Comunicación Escrita ..¡Error! Marcador no definido. Definición ¡. Error! Marcador no definido.

Comunicación Oral ¡.¡Error! Marcador no definido. Definición ..¡Error! Marcador no definido. Ciudadanía ...¿Error! Marcador no definido. Definición ..¡Error! Marcador no definido.

Pensamiento Innovador ..¡Error! Marcador no definido. Definición ¡.Error! Marcador no definido.

Pensamiento Crítico ¡._Error! Marcador no definido. Definición ..jError! Marcador no definido.

Razonamiento Cuantitativo ¡. ¿Error! Marcador no definido. Definición ¡Error! Marcador no definido.

Manejo de Información ¡.Error! Marcador no definido. Definición ..¡Error! Marcador no definido.

Capítulo 3: Estado del Arte .45

Revisión de la Literatura ¡.Error! Marcador no definido.

Framework ¡EError! Marcador no definido. Un marco de implementación para E-Government 2.0 ...¡Error! Marcador no definido. Diseño y validación del marco de cultura de seguridad de la información ¡Error! Marcador no definido.

Mapa ontológico de la arquitectura orientada a servicios para servicios de administración compartidos ¡Error! Marcador no definido.

Evaluación ¡. EError! Marcador no definido. Participación de los ciudadanos en los sitios de Facebook de los gobiernos locales. Un análisis empírico: El impacto de los diferentes tipos de medios y contenidos en Europa Occidental ..¡Error! Marcador no definido.

Sistema de recomendación de desarrollos de aplicaciones : una encuesta ¡Error! Marcador no definido.

Facilidad de uso y la credibilidad de los sitios web de gobierno electrónico ¡Error! Marcador no definido. 
La adminoistración electrónica en las ciudades de la sociedad del conocimiento. Una investigación empírica de los sitios web gubernamentales de Smart Cities ¡Error! Marcador no definido.

Modelo para la Calidad de los Servicios en Línea del Gobierno LocaliError! Marcador no definido.

Servicios Electrónicos ¡Error! Marcador no definido.

Investigando Discrepancias entre E-Services: Implementación o No - Iso 9001: Perspectivas de los Clientes en el Ejemplo de los Servicios Electrónicos en Cataluña (España) ¡Error! Marcador no definido.

Conclusiones ¡Error! Marcador no definido.

Capítulo 4. Marco Teórico. .62

Arquitectura Empresarial ¡Error! Marcador no definido. TOGAF ¡Error! Marcador no definido.

$\mathrm{ADM}$ ..¡Error! Marcador no definido.

E-Government ..¡Error! Marcador no definido.

PMBOK ..¿Error! Marcador no definido.

Municipalidad ¡Error! Marcador no definido.

E-Servicios ...jError! Marcador no definido.

Capítulo 5: Desarrollo del Proyecto. .73

Desarrollo del Modelo .73

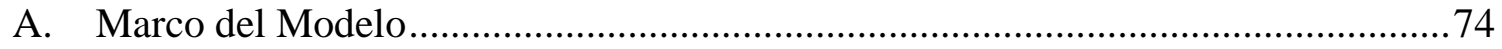

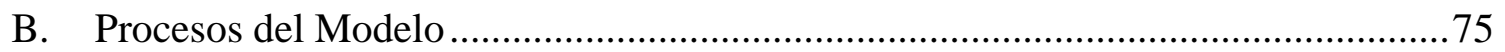

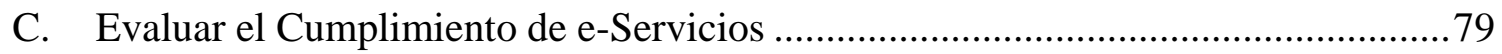

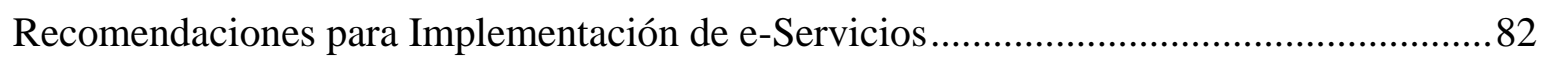

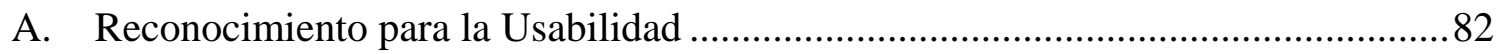

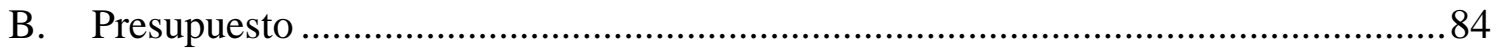

C. Restricciones Organizacionales - Leyes para Municipalidades y de Gobierno

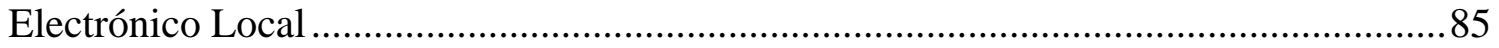

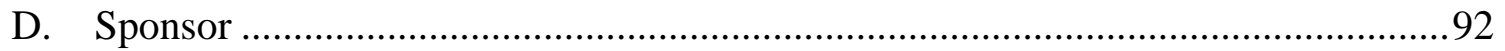

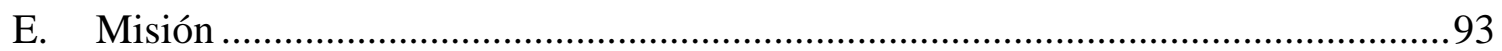

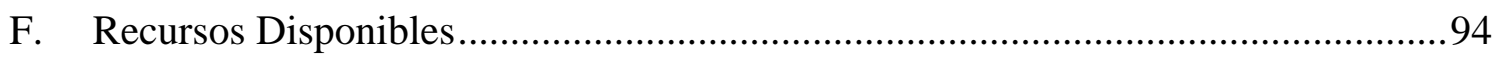

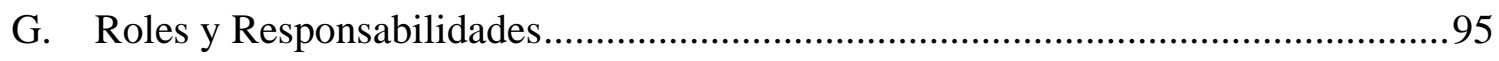

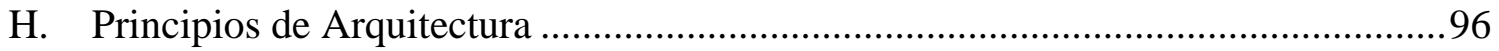

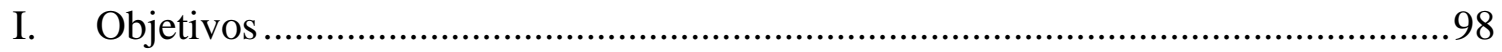




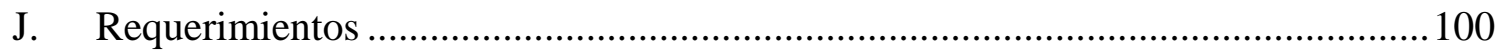

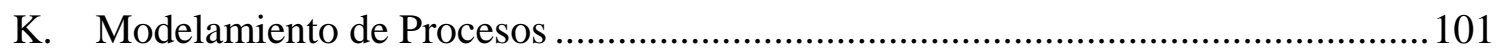

Recomendaciones para la Implementación de Arquitecturas ..............................................102

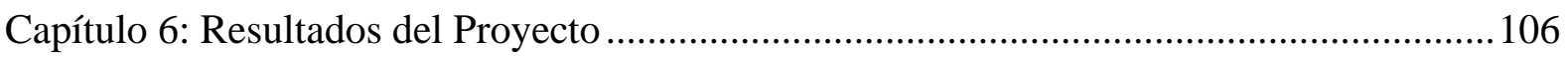

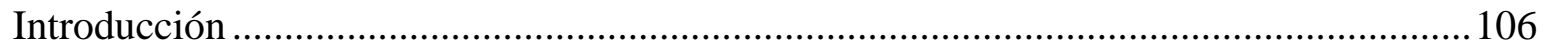

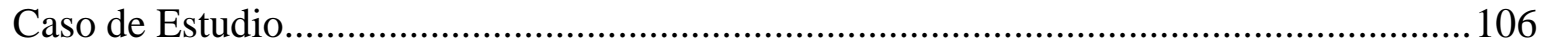

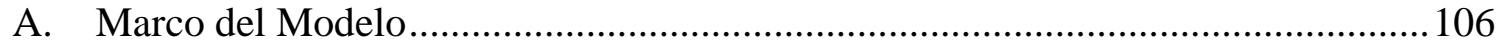

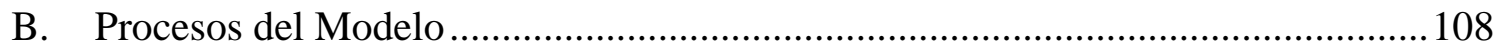

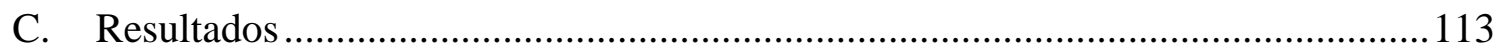

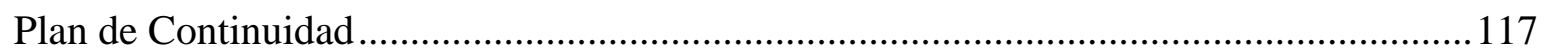

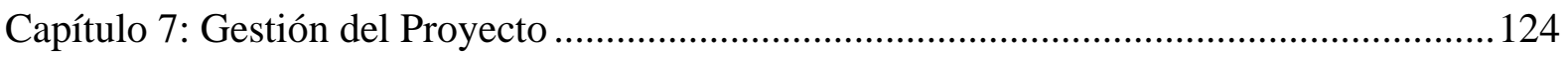

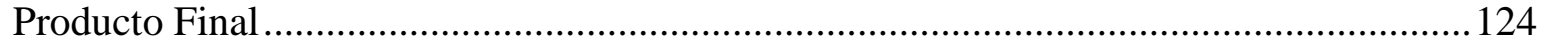

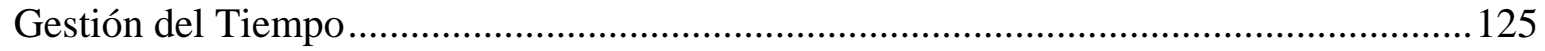

Gestión de los Recursos Humanos................................................................................131

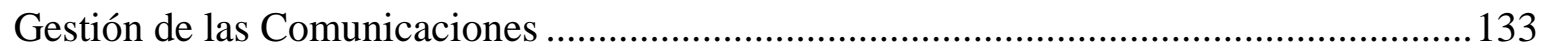

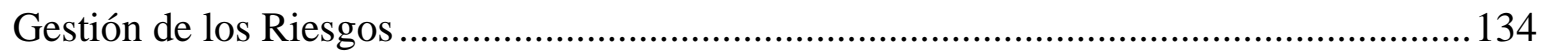

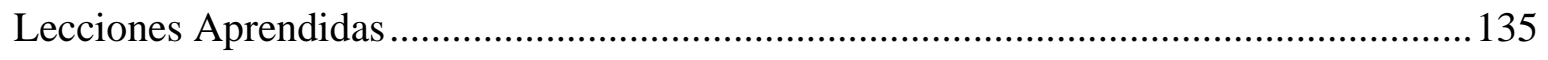

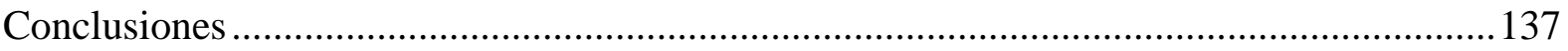

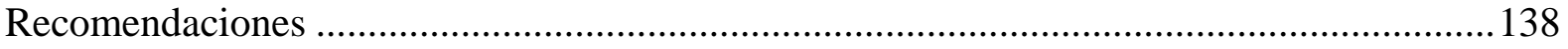

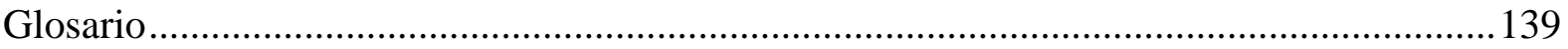

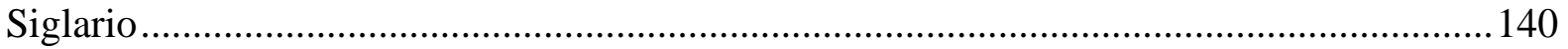

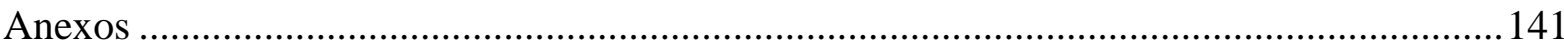

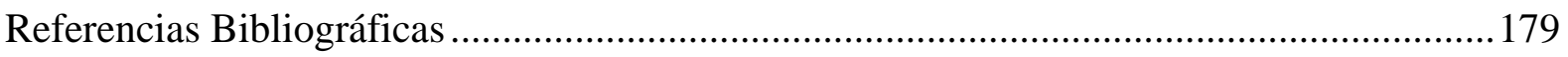




\section{Índice de Figuras}

Figure 1: Organigrama de Recursos Humanos ..¿Error! Marcador no definido.

Figure 2: Matriz de Riesgos - Identificación. ¡Error! Marcador no definido.

Figure 3: Matriz de Riesgos - Análisis ..¡Error! Marcador no definido.

Figure 4: Matriz de Riesgos - Estrategia de Respuesta. ¡Error! Marcador no definido.

Figure 5: Visión general del marco propuesto para el gobierno electrónico 2.0 ¡Error!

Marcador no definido.

Figure 6: Comparación de proyectos de gobierno electrónico con marco de e-Gobierno 2.0 ..¡Error! Marcador no definido.

Figure 7: Marco de cultura de seguridad de la información .....Error! Marcador no definido. Figure 8: Vista ontológica primaria de SOA para SSM ...........Error! Marcador no definido. Figure 9: El papel de Facebook en la comunicación G2C y C2G¡Error! Marcador no definido.

Figure 10: Métricas de Facebook para la participación de los interesados`Error! Marcador no definido.

Figure 11: Utilización de Facebook en gobiernos locales ........_Error! Marcador no definido.

Figure 12: Porcentaje de publicaciones por tipo de contenido y estilo de administración pública ¡Error! Marcador no definido.

Figure 13: Resumen de técnicas de recomendación en cada dominio de aplicación....... ¡Error! Marcador no definido.

Figure 14: Tareas asignadas a los usuarios antes de llenar el cuestionario¡Error! Marcador no definido.

Figure 15: Nielsen (1994) y las pautas de usabilidad ¡Error! Marcador no definido.

Figure 16: Fogg's (2002) y extensas pautas de credibilidad .....Error! Marcador no definido. Figure 17: Debilidad de la usabilidad ..¡Error! Marcador no definido.

Figure 18: Debilidad de la credibilidad ..¡Error! Marcador no definido.

Figure 19: Cinco pilares ... Error! Marcador no definido.

Figure 20: Madurez de 31 e-Gobiernos ..¿Error! Marcador no definido.

Figure 21: Dimensiones finales ... Error! Marcador no definido. 
Figure 22: Hoja de trabajo de evaluación para los servicios en línea del gobierno local¡Error! Marcador no definido.

Figure 23: E-Service quality fact ¡.Error! Marcador no definido.

Figure 24: Perceived value, loyalty intention and e-satisfaction factors;Error! Marcador no definido.

Figure 25: E-Service recovery factors ¡Error! Marcador no definido.

Figure 26: Características demográficas y perfil de los encuestados por bancos ¡Error! Marcador no definido.

Figure 27: Análisis de ANOVA y valor Eta por categoría ISO¡Error! Marcador no definido.

Figure 28: Medios por categoría ISO. ..¿Error! Marcador no definido.

Figure 29: Componentes de la Arquitectura Empresarial. ¡Error! Marcador no definido. Figure 30: Fases del ADM. ¡Error! Marcador no definido.

Figure 31: Secuencia de ejecución del modelo. .73

Figure 32: Entrada y salida del Sub Proceso de Análisis y Diseño del negocio.......................77

Figure 33: Entrada y salidas del Sub Proceso Análisis y Diseño de Datos .............................77

Figure 34: Entradas y salidas del Sub Proceso de Aplicaciones............................................78

Figure 35: Entradas y salidas del Sub Proceso de Análisis y Diseño de Infraestructura.........78

Figure 36: Componentes del Índice de Gobierno Electrónico Municipal ...............................79

Figure 37: Fases de Gobierno Electrónico Municipal propuestas por Esteves........................80

Figure 38: Modelo de Mejoras de e-Servicios Municipales ..................................................... 104

Figure 39: Gráfico Modelo de Mejoras de e-Servicios Municipales ..................................... 105

Figure 40: Comparación Trámite Actual vs Trámite Objetivo.............................................109

Figure 41: Extracto de Diagrama de Base de Datos ......................................................... 110

Figure 42: Extracto de Diagrama de Caso de Uso ............................................................... 111

Figure 43: Resultado de Reducción de Carga Procesal del Trámite de Licencia de

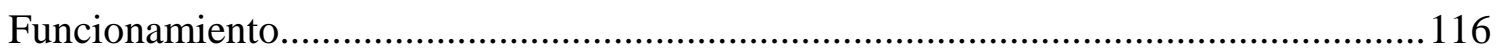

Figure 44: Resultado de Juicio de Expertos Municipales en Tecnología ...............................117

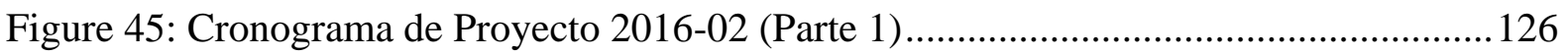

Figure 46: Cronograma de Proyecto 2016-02 (Parte 2) ....................................................... 127

Figure 47: Cronograma de Proyecto 2017-02 (Parte 1) ...................................................... 128

Figure 48: Cronograma de Proyecto 2017-02 (Parte 2) ....................................................... 129

Figure 49: Cronograma de Proyecto 2017-02 (Parte 3) ..................................................... 130

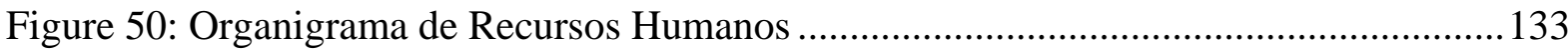


Figure 51: Proceso As-Is 141

Figure 52: Proceso To-Be 142

Figure 53: Caso de Uso 1 143

Figure 54: Caso de Uso 2. 144

Figure 55: Caso de Uso 3 146

Figure 56: Principios de Negocio 147

Figure 57: Principios de Datos 148

Figure 58: Principios de Aplicación 149

Figure 59: Principios de Tecnología 150

Figure 60: Principios de Seguridad. 151

Figure 61: Misión Municipalidad de Miraflores. 152

Figure 62: Sponsor 152

Figure 63: Objetivos 153

Figure 64: Requerimientos. 154

Figure 65: Roles 155

Figure 66: Roles - Responsabilidades (1) 156

Figure 67: Roles - Responsabilidades (2) 157

Figure 68: Trámite Dcoumentario 164

Figure 69: Licencia de Funcionamiento 165

Figure 70: Declaración Jurada 166

Figure 71: Declaración Jurada (2). 167

Figure 72: Solicitud de Declaración Jurada. 168

Figure 73: Licencia de Funcionamiento 169

Figure 74: Licencia de Funcionamiento (2) 170

Figure 75: Licencia de Funcionamiento (3) 171

Figure 76: Licencia de Funcionamiento (4) 172

Figure 77: Licencia de Funcionamiento (5) 173

Figure 78: Chat en Línea. 174

Figure 79: Chat en Línea (2) 175

Figure 80: Firma de Certificado 176

Figure 81: Memorandum ..... 177

Figure 82: Elaborar Documento 178 


\section{Índice de Tablas}

Tabla 1: Problema - Causas ..¿Error! Marcador no definido.

Tabla 2: Descripción de Riesgos ¡Error! Marcador no definido.

Tabla 3: Descripción de Roles ¡Error! Marcador no definido.

Tabla 4: Plan de Gestión del Tiempo ..¡Error! Marcador no definido.

Tabla 5: Procedimiento de Calidad. ..¡Error! Marcador no definido.

Tabla 6: Cuadro de Interesados ...¿Error! Marcador no definido.

Tabla 7: Temas Principales de Artículos ¡Error! Marcador no definido.

Tabla 8: Tipos de Arquitectura soportados por TOGAF ..¿Error! Marcador no definido.

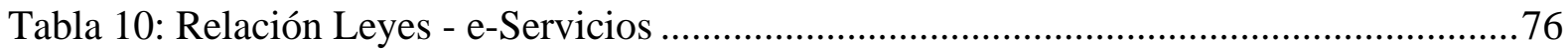

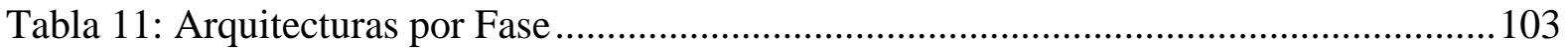

Tabla 12: Funcionalidades y e-Servicios que serán utilizados en el e-Trámite de Licencia de Funcionamiento. 108

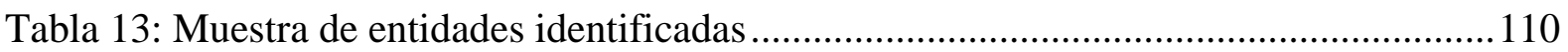

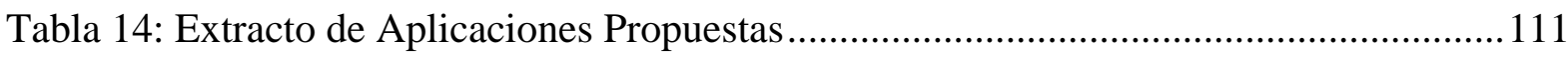

Tabla 15: Interacción del e-Trámite con las Otras Aplicaciones ...........................................112

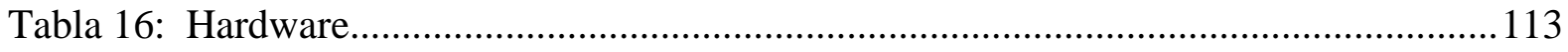

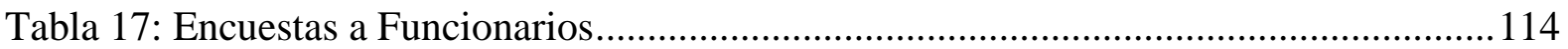

Tabla 18: Preguntas de Encuestas a Ciudadanos .................................................................... 114

Tabla 19: Resultado de Evaluación de Encuestas a Funcionarios ........................................... 114

Tabla 20: Resultado de Evaluación de Encuestas a Ciudadanos ...........................................115

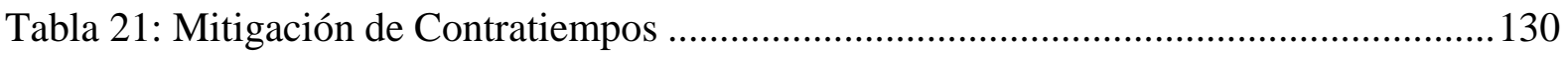

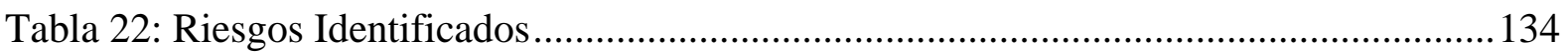




\section{Introducción}

En la actualidad, el sector Retail representa el 73,1\% del comercio total en el Perú [3], es un sector que está creciendo en promedio un $12 \%$ anual [1] ya que los Retails modernos llegan a alrededor de 8500 locales comerciales y sus ventas se incrementan con el pasar de los días. Es un sector que contiene en su mayoría a pequeñas y medianas empresas (Pymes), las cuales representan el 79.4\% de todo el segmento Pyme. Estas empresas enfocan su rubro de negocio en la venta física al cliente (mediante un local comercial) y ofrecen sus productos mediante una publicidad tradicional [7]. Una alternativa para romper el esquema tradicional es el comercio electrónico. El e-commerce permite a las Pymes romper el esquema tradicional de venta directa con el cliente y abrir su mercado a un número mayor de personas, las cuales están conectadas mediante internet y pueden ver a la empresa sin contactarse de forma física [ ]. Sin embargo, se necesita de un conocimiento técnico, factibilidad financiera, análisis del mercado, infraestructura de TI, entre otros factores para lograr la implementación del comercio electrónico. Diversos autores han desarrollado distintos modelos que permiten la adaptación de la empresa al comercio electrónico. Sin embargo, no existe actualmente un estándar definido que permita a las Pymes del Sector Retail implementar el comercio electrónico. Por lo tanto, este proyecto propone un modelo de referencia para la implementación de una solución e-commerce que pueda ser utilizado por las empresas y garantice la obtención tanto de los resultados esperados como de las ventajas que conlleva el uso de esta tecnología.

A continuación se realiza una breve descripción sobre los capítulos que comprende el proyecto:

\section{- Capítulo 1: Descripción del Proyecto}

El presente capitulo detalla el proyecto mediante la declaración del objeto de estudio a realizar, el problema que se busca resolver, y el motivo del estudio e implementación. Asimismo, se determina el objetivo general que busca responder la problemática, los objetivos específicos a lograr para lograrlo, y los indicadores de éxito que permiten medir su 
cumplimiento. Finalmente, presenta la planificación para el desarrollo del proyecto en base a las buenas prácticas del PMBOK.

\section{- $\quad$ Capítulo 2: Student Outcomes}

En el presente capítulo se describe como el proyecto cumple de manera exitosa los Students Outcomes, los cuales son criterios basados en las buenas prácticas de los estándares de calidad en programas de educación como ciencias, ingeniería, computación y tecnología.

\section{- Capítulo 3: Marco Teórico}

El presente capitulo detalla los conocimientos o conceptos básicos necesarios para un mejor entendimiento del desarrollo del proyecto. Primero, se empieza con la definición de ECommerce, sus tipos o modelos y ventajas con la finalidad de comprender las variantes de Ecommerce que existen dentro de las empresas y de lo importante que es contar con una de ellas. Posteriormente, se describe la clasificación de las PYMEs, la cual es necesaria para definir parámetros de evaluación para la Pyme en la cual se vaya a implementar la solución. Luego, se define el sector Retail. Finalmente, se presentan los casos de éxito de PYMEs que implementaron e-commerce, los cuales se entienden como un input para demostrar la viabilidad del comercio electrónico en PYMEs.

\section{- $\quad$ Capítulo 4: Estado del Arte}

En este cuarto capítulo se presenta una revisión de la literatura referida a la definición del Estado del Arte del proyecto modelo de referencia para la implementación de una solución ecommerce en una PYME del Sector Retail. Para este fin, se inicia la revisión con la descripción de la metodología elegida para la elección de los artículos que estén en relación con el tema desarrollado. Se presentarán 2 modelos de implementación de soluciones ecommerce, 2 modelos de arquitectura del comercio electrónico y, por último, 1 implementación de una solución e-commerce.

- $\quad$ Capítulo 5: Desarrollo del Proyecto

El presente capítulo explica el desarrollo del proyecto. El desarrollo del proyecto se basó en los estándares de la guía PMBOK (Project Management Body of Knowledge); por lo tanto, su desarrollo se encuentra en toda la fase de ejecución. Adicionalmente, se detalla los entregables del proyecto en sí y aquellos que aportaron valor dentro del mismo. 
- $\quad$ Capítulo 6: Resultados

El sexto capítulo está exclusivamente dirigido a mostrar los resultados de la solución de comercio electrónico implementada en una PYME del Sector Retail. Así como los costos que se utilizaron para el desarrollo del proyecto y por último, el plan de continuidad que permite garantizar la viabilidad en el tiempo de la solución.

- Capítulo 7: Gestión del Proyecto

El presente capítulo retoma el capítulo 1 sobre la planificación realizada en el proyecto y se verifica lo que se ejecutó en realidad contra lo que se planificó al principio. Asimismo, se muestra el resultado final del proyecto y los resultados de los planes de gestión del tiempo, de recursos humanos, de comunicaciones y de riesgos. Y la última sección explica sobre las lecciones aprendidas a lo largo del desarrollo del proyecto.

\section{Conclusiones}

Recomendaciones

Anexos

Glosario 


\section{Capítulo 1 : Definición del Proyecto}

El presente capitulo detalla el proyecto mediante la declaración del objeto de estudio a realizar, el problema que se busca resolver, y el motivo del estudio e implementación. Asimismo, se determina el objetivo general que busca responder la problemática, los objetivos específicos a lograr para lograrlo, y los indicadores de éxito que permiten medir su cumplimiento. Finalmente, presenta la planificación para el desarrollo del proyecto en base a las buenas prácticas del PMBOK.

\section{Objeto de Estudio}

El Proyecto describe la Implementación de una solución eCommerce para una Pyme del Sector Retail. Para llevar a cabo el proyecto, se ha realizado un análisis de la viabilidad del comercio electrónico en Pymes, un Benchmarking de las soluciones existentes de eCommerce a nivel mundial, la descripción de la arquitectura lógica y física de la solución y, por último, un modelo de implementación que servirá como Guía para que el desarrollo sea exitoso y pueda ser utilizado a futuro en las Pymes del Sector Retail.

En el Perú, las actividades económicas en las empresas se agrupan en tres categorías o sectores económicos de acuerdo a su gran variedad: sector Extractivo, sector Transformación y sector Servicios (INEI, 2016). Los 3 sectores tienen un sector en común que es el comercial, el cual se encarga de las actividades de compra y venta de bienes y/o servicios. El e-commerce es el proceso de compra y venta de bienes y servicios en internet a través de dispositivos electrónicos (Gartner,2017). Por lo tanto, al e-commerce estar involucrado en la optimización del proceso de ventas, afecta directamente al sector Comercial. Según la industria internacional uniforme (CIIU), considera la actividad de comercio en tres grupos de actividades: venta y reparación de vehículos, comercio al por mayor y comercio al por menor o Retail. De estas tres actividades, el comercio al por menor abarca una cantidad aproximadamente del $73,1 \%$ del comercio total en el Perú según el estudio realizado de la Instituto Nacional de Estadística e Informática (INEI, 2012). También, se puede observar que la cantidad de PYMES del sector Retail es del 79,4\% de todo el segmento empresarial. Por ende, este proyecto se enfoca en PYMES del sector retail como punto de estudio principal 
que a su vez tienen los recursos mínimo y necesario para gestionar la tecnología de eCommerce.

El presente proyecto demuestra cómo la implementación del eCommerce en una Pyme del Sector Retail incrementa las ventas de la empresa, amplía el mercado al tener un producto accesible a nivel mundial, optimiza el proceso de Marketing al tener herramientas digitales que permiten mejorar las campañas promocionales, elimina las barreras horarias al poder generarse una venta en cualquier momento del día y por último, genera un crecimiento en la empresa al aumentar la cantidad de transacciones mensuales (Cámara de Comercio de Lima, 2016). En adición, se espera que el Proyecto sea usado como un modelo para las Pymes del Sector Retail, ya que, al ser exitosa la implementación del comercio electrónico, demuestra que esta herramienta puede ser usada en más empresas del sector, permitiendo las ventajas ya descritas.

\section{Dominio del problema}

Anteriormente, las Pymes del Sector Retail vendían sus productos a través de tiendas físicas donde el cliente descubría los productos y servicios, y recibía la mejor atención posible. En la actualidad, la mayoría de las Pymes del Sector Retail en el Perú emplean el uso del ecommerce frecuentemente como una oportunidad para captar nuevos clientes y aumentar sus ventas en el mercado nacional e internacional. Sin embargo, en su mayoría no consiguen obtener los resultados esperados y por ende terminan fracasando (el Economista 2015); inclusive, algunas no pueden adquirir una solución para la implementación de eCommerce por los siguientes factores: la bancarización a través de medios de pago, la confianza por la existencia de empresas desconocidas e informales y la conectividad en zonas sin acceso a internet (Gestión, 2014). No obstante, existen casos de éxitos que indican que el eCommerce si es beneficioso (eCommerce Awards Perú 2016), y que el fracaso se debe al temor de dar el salto a la implementación.

El temor al dar el salto a la implementación se debe a siguientes causas principales:

Resistencia a tomar riesgos en las mejoras del negocio. Las PYMES tienden a actuar como las otras y la razón es el conformismo que paso el empresario peruano en la época de los 80's para sobrevivir - por la inflación. El 90\% de las PYMES dicen que es importante 
innovar, pero al preguntar si en sus empresas hay un planeamiento para generar innovación un $83 \%$ responden que no; eso quiere decir que existe conciencia, pero muy poca práctica. Por ejemplo, solo la mitad de las empresas investiga a sus clientes cuando van a innovar o lanzar un nuevo producto o servicio (Alfredo Torres, 2014).

Falta de conocimiento o de interés de las TIC. El 60\% de las PYMES aproximadamente no valoran el beneficio de las TIC (Google, 2015). por la escaza educación en tecnología; a pesar de que existen programas o cursos sobre TIC como CAPECE, Google, Cisco, etc.

Escaso aprovechamiento de las nuevas tecnologías de información y comunicaciones (TIC). En este aspecto, las PYMES no saben cómo explotar las tecnologías en la vanguardia como herramientas de venta y promoción internacional, por ejemplo: el uso de marketplaces B2B - que son plataformas online para la comercialización a través de un tercero. Por esta razón, el Perú se encuentra como el único miembro de la alianza del pacifico con el uso más pobre de las TIC. (WEF, 2015).

Para dar el salto a la implementación de comercio electrónico no basta con tener un sitio web y contar con una gran cartera de productos. Se necesitan una serie de herramientas que harán posible el funcionamiento de la tienda online, como una plataforma de comercio electrónico que permita potenciar y facilitar el proceso de venta de las Pymes del Sector Retail.

Bajo esta premisa, el proyecto tiene como finalidad implementar una solución eCommerce para una Pyme del Sector Retail.

\section{Motivación}

El eCommerce en el Perú tiene un crecimiento promedio de 15\% anual (Javier Álvarez, 2017). El Sector Retail crecerá hasta un 14\% en el año 2017 (Interetail, 2016). Estas fuentes nos confirman que la unión del eCommerce al Sector Retail tiene una tendencia al incremento. Todo indicaría que, si una Pyme implementa el eCommerce, estaría destinada al éxito. Revisando la información relevante para el proyecto, nos preguntamos: ¿Cuál es el número de Pymes que tienen éxito utilizando el comercio electrónico? La respuesta a la 
pregunta es clara y frustrante: Sólo el $15 \%$ de las Pymes que hay en el Perú tienen un éxito online (Agencia Andina,2015). Esta cifra nos lleva a la siguiente pregunta: ¿Qué pasa con el 85\% restante? Encontramos la respuesta: las demás Pymes no implementan el comercio electrónico debido a los siguientes factores: desconocimiento del tema (Google Perú, 2015), desconfianza al entrar en Internet (Gestión,2014), usabilidad (El Comercio, 2015) y la falta de recursos para la implementación.

De esta forma, se propone una implementación de una solución de eCommerce a una Pyme del Sector Retail, la cual va a demostrar que, una Pyme puede implementar el comercio electrónico y ser exitosa, de modo que cualquier PYME promedio del sector Retail pueda contar con esta solución tecnológica, obteniendo indicadores más exactos y precisos. Además, servirá como base a las futuras empresas de otros sectores para que tengan en consideración la tecnología de eCommerce en su negocio y puedan aumentar la participación e ingresos en el país.

\section{Objetivo general}

Implementar una Solución de e-commerce para una PYME del Sector Retail.

\section{Objetivos específicos}

Según el objetivo general planteado, se tiene con una serie de objetivos específicos (OE) que deben realizarse para alcanzarlo, y son los indicados a continuación:

* OE1: Analizar las diferentes soluciones eCommerce para PYMES del Sector Retail.

* OE2: Diseñar la arquitectura lógica y física de la Solución eCommerce.

OE3: Validar el modelo de implementación eCommerce propuesto en una PYME del sector retail.

* OE4: Elaborar un Plan de Continuidad al modelo de implementación, los cuales permitan garantizar su disponibilidad, retorno de inversión y mejoras al futuro.

\section{Indicadores de éxito}


Para poder sustentar el logro de cada Objetivo Específico, se debe cumplir con los siguientes Indicadores de Éxito (IE):

* IE1: Acta de aprobación del documento de viabilidad del comercio electrónico en Pymes presentes en el mercado por el cliente. (OE1)

* IE2: Acta de aprobación del análisis de opciones de eCommerce presentes en el mercado por el cliente. (OE1).

* IE3: Acta de aprobación del documento de la propuesta de arquitectura lógica y física de la solución eCommerce aprobado por el cliente. (OE2).

* IE4: Acta de aprobación del modelo definido para la implementación de la solución eCommerce aprobado por el cliente(OE3).

* IE5 Acta de aprobación de la implementación de una solución de eCommerce aprobado por el cliente. (OE3).

* IE6: Acta de aprobación del plan de continuidad de la solución ecommerce, los cuales permitan garantizar su disponibilidad, retorno de inversión y mejoras al futuro aprobado por el cliente. (OE4)

\title{
Planificación del Proyecto
}

\author{
Alcance \\ El alcance del proyecto comprende Implementar una solución de eCommerce para Pymes del \\ Sector Retail, definiendo una arquitectura, interfaz, análisis comparativo y los procesos \\ soportados. Asimismo, se han seguido los siguientes puntos para llevarlo a cabo: \\ - Se elaboró como resultados finales los siguientes entregables: \\ o Project Charter \\ o Cronograma del proyecto \\ o Entregables de Gestión del Proyecto (Plan de Alcance, Plan de RR. HH, \\ Matriz RAM y los demás documentos de gestión) \\ o Memoria del Proyecto
}


o Entregables de ingeniería del Proyecto (manuales, propuestas, modelos, etc.)

o Paper de Investigación

- Documento de viabilidad del comercio electrónico en Pymes del Sector Retail.

- Diseño y documentación del proceso de compra y venta de productos de eCommerce en el PYMES del sector retail.

- Análisis comparativo (benchmarking) de las soluciones tecnológicas de eCommerce para PYMES del sector retail que se encuentran disponibles en el mercado.

- Diseño y documentación de la arquitectura lógica y física de la solución eCommerce.

- Documentación de la implementación de la solución eCommerce desarrollada en el ciclo 2017-2, en base al modelo realizado.

- Documentación de las propuestas en el plan de continuidad que asegura la operatividad y escalabilidad de la solución desarrollada.

Las exclusiones del proyecto son las siguientes:

- Artefactos ajenos no especificados.

- No se desarrollará la programación de funcionalidades como modificación por solicitud de algún requerimiento realizado de alguno de los stakeholders del proyecto.

\section{Plan de Gestión del Tiempo}

En la gestión del tiempo, se exponen los hitos principales del proyecto, los cuales marcan los puntos clave del desarrollo del proyecto.

\begin{tabular}{|l|l|l|l|l|}
\hline \multicolumn{1}{|c|}{ Fases } & Hito del proyecto & $\begin{array}{c}\text { Fecha } \\
\text { Estimada }\end{array}$ & $\begin{array}{c}\text { Entregables } \\
\text { incluidos }\end{array}$ & \multicolumn{1}{|c|}{ Prioridad } \\
\hline Inicio & $\begin{array}{l}\text { Primera Reunión } \\
\text { con el Cliente }\end{array}$ & $28 / 03 / 2017$ & Project Charter & Media \\
\cline { 2 - 5 } & $\begin{array}{l}\text { Aprobación del } \\
\text { Charter por parte } \\
\text { del cliente y } \\
\text { profesor gerente }\end{array}$ & $21 / 04 / 2017$ & Project Charter & Alta \\
\hline
\end{tabular}




\begin{tabular}{|c|c|c|c|c|}
\hline Planificación & $\begin{array}{l}\text { Aprobación, por } \\
\text { parte del cliente y } \\
\text { profesor gerente, } \\
\text { de la planificación } \\
\text { del proyecto. }\end{array}$ & $26 / 05 / 2017$ & $\begin{array}{c}\text { Cronograma } \\
\text { Descripción de Roles } \\
\text { y Responsabilidades } \\
\text { Diccionario EDT } \\
\text { Matriz de } \\
\text { Comunicaciones } \\
\text { Matriz de Riesgos } \\
\text { Matriz de } \\
\text { Trazabilidad de } \\
\text { Requerimientos } \\
\text { Matriz RAM } \\
\text { Plan de Gestión de } \\
\text { Alcance } \\
\text { Plan de Gestión de } \\
\text { Calidad } \\
\text { Plan de Gestión de } \\
\text { Comunicaciones } \\
\text { Plan de Gestión de } \\
\text { Riesgos } \\
\text { Plan de Gestión de } \\
\text { RRHH } \\
\text { Plan de Gestión del } \\
\text { Cronograma } \\
\text { Registro } \\
\text { Interesados }\end{array}$ & Alta \\
\hline \multirow[t]{3}{*}{$\begin{array}{l}\text { Ejecución } \\
\text { control }\end{array}$} & 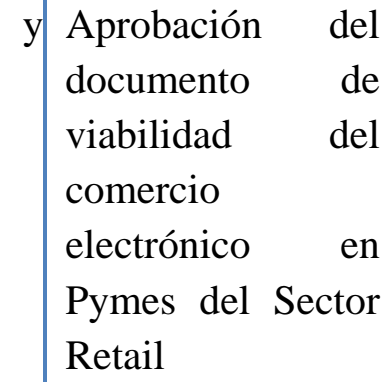 & $24 / 06 / 2017$ & $\begin{array}{lr}\text { Documento } & \text { de } \\
\text { Viabilidad } & \text { del } \\
\text { comercio electrónico } \\
\text { en Pymes del Sector } \\
\text { Retail. }\end{array}$ & Alta \\
\hline & $\begin{array}{lr}\text { Aprobación } & \text { del } \\
\text { documento } & \text { de } \\
\text { análisis } & \text { de } \\
\text { opciones } & \text { de } \\
\text { eCommerce } & \\
\text { presentes en } & \text { el } \\
\text { mercado. } & \end{array}$ & $24 / 06 / 2017$ & $\begin{array}{l}\text { Documento de análisis } \\
\text { de las opciones de } \\
\text { eCommerce presentes } \\
\text { en el mercado. }\end{array}$ & Alta \\
\hline & $\begin{array}{l}\text { Aprobación de la } \\
\text { arquitectura lógica } \\
\text { y física de la } \\
\text { solución } \\
\text { eCommerce }\end{array}$ & $24 / 06 / 2017$ & $\begin{array}{l}\text { Propuesta de } \\
\text { arquitectura lógica y } \\
\text { física de la solución } \\
\text { eCommerce. }\end{array}$ & Alta \\
\hline
\end{tabular}




\begin{tabular}{|c|c|c|c|c|}
\hline & $\begin{array}{l}\text { Implementación } \\
\text { de la propuesta } \\
\text { eCommerce }\end{array}$ & 06/10/2017 & $\begin{array}{l}\text { Informe de despliegue } \\
\text { de la solución } \\
\text { eCommerce. } \\
\text { Entregable final de la } \\
\text { solución eCommerce } \\
\text { implementada. }\end{array}$ & Alta \\
\hline & $\begin{array}{lr}\text { Aprobación } & \text { del } \\
\text { plan } & \text { de } \\
\text { continuidad } & \end{array}$ & $17 / 11 / 2017$ & $\begin{array}{l}\text { Plan de continuidad y } \\
\text { soporte al modelo } \\
\text { tecnológico. }\end{array}$ & Alta \\
\hline Cierre & $\begin{array}{l}\text { Aprobación final } \\
\text { del proyecto }\end{array}$ & $01 / 12 / 2017$ & 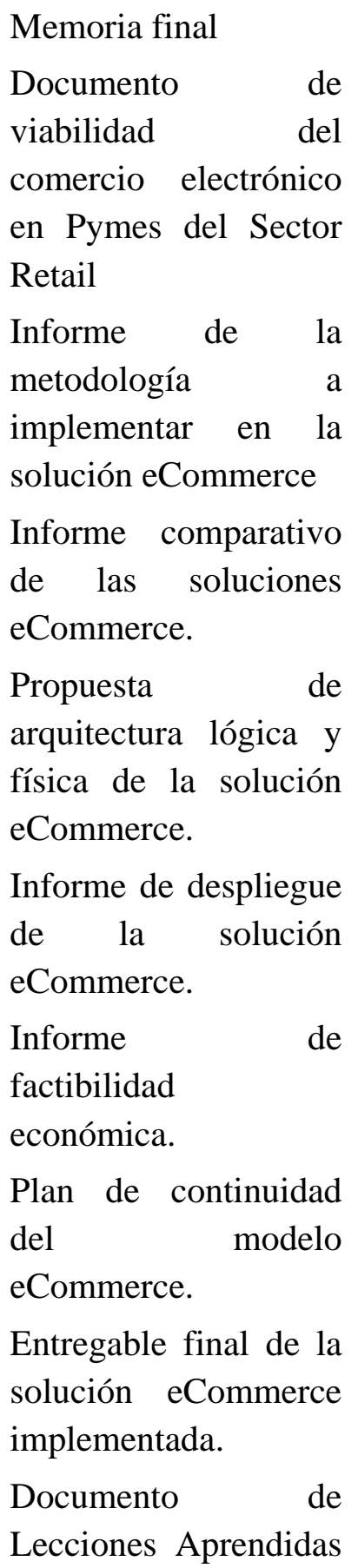 & Alta \\
\hline
\end{tabular}




\begin{tabular}{|l|l|l|l|}
\hline & & $\begin{array}{l}\text { y Oportunidades de } \\
\text { Mejora. } \\
\text { Acta de Aceptación y } \\
\text { Cierre de Proyecto. }\end{array}$ & \\
\hline
\end{tabular}

Tabla 1. Hitos y Entregables del Proyecto. (Fuente: Elaboración propia)

\section{Plan de Gestión de Recursos Humanos}

En este punto, se detallan las responsabilidades y los roles que se involucran con el proyecto.

\begin{tabular}{|c|c|c|}
\hline Rol & Miembro & Responsabilidades \\
\hline Comité de Proyecto & $\begin{array}{l}\text { - } \text { Rosario Villalta } \\
\text { - Jimmy Armas } \\
\text { - Pedro } \\
\text { - Shiguihara } \\
\text { - Victor Parasi }\end{array}$ & $\begin{array}{l}\text { - Aprobar los proyectos } \\
\text { profesionales. } \\
\text { - Monitorear el cumplimiento } \\
\text { de los entregables. } \\
\text { - Decidir la continuidad de los } \\
\text { proyectos. }\end{array}$ \\
\hline Jefe de Proyecto & - Miguel Cadillo & $\begin{array}{l}\text { - Realizar las funciones } \\
\text { necesarias para llevar a cabo } \\
\text { el cumplimiento del alcance e } \\
\text { implementación del Proyecto. }\end{array}$ \\
\hline Jefe de Proyecto & - Julio Kauss & $\begin{array}{l}\text { - Realizar las funciones } \\
\text { necesarias para llevar a cabo } \\
\text { el cumplimiento del alcance e } \\
\text { implementación del Proyecto. }\end{array}$ \\
\hline $\begin{array}{l}\text { Profesor Gerente de IT } \\
\text { Consulting }\end{array}$ & - Emilio Herrera & $\begin{array}{l}\text { - Monitorear y controlar las } \\
\text { actividades programadas del } \\
\text { proyecto. } \\
\text { - Aprobar la memoria en el } \\
\text { capítulo } 1,2 \text { y } 6 .\end{array}$ \\
\hline Profesor Cliente & - Roy Pérez & $\begin{array}{l}\text { - Brindar los requerimientos y } \\
\text { pautas del proyecto. } \\
\text { - Validar la calidad de los } \\
\text { documentos del proyecto. } \\
\text { - Aprobar la memoria en el } \\
\text { capítulo 5. }\end{array}$ \\
\hline $\begin{array}{l}\text { Recursos de Quality } \\
\text { Services }\end{array}$ & $\begin{array}{l}\text { - Recursos } \\
\text { asignados para } \\
\text { el ciclo 2017-02 }\end{array}$ & $\begin{array}{l}\text { - Brindar los servicios de } \\
\text { validación y verificación para } \\
\text { los documentos del proyecto. }\end{array}$ \\
\hline Revisor & - David Mauricio & - Revisar el avance de la \\
\hline
\end{tabular}




\begin{tabular}{|l|l|l|}
\hline & & $\begin{array}{l}\text { memoria. } \\
\bullet\end{array}$ \\
& $\begin{array}{l}\text { Encargarse de aprobar la } \\
\text { memoria en el capítulo 3 y 4. }\end{array}$ \\
\hline
\end{tabular}

Tabla 2. Roles y Responsabilidades. (Fuente: Elaboración propia)

Por otro lado, la estructura organizacional, según los roles y responsabilidades del proyecto, se define de la siguiente manera:

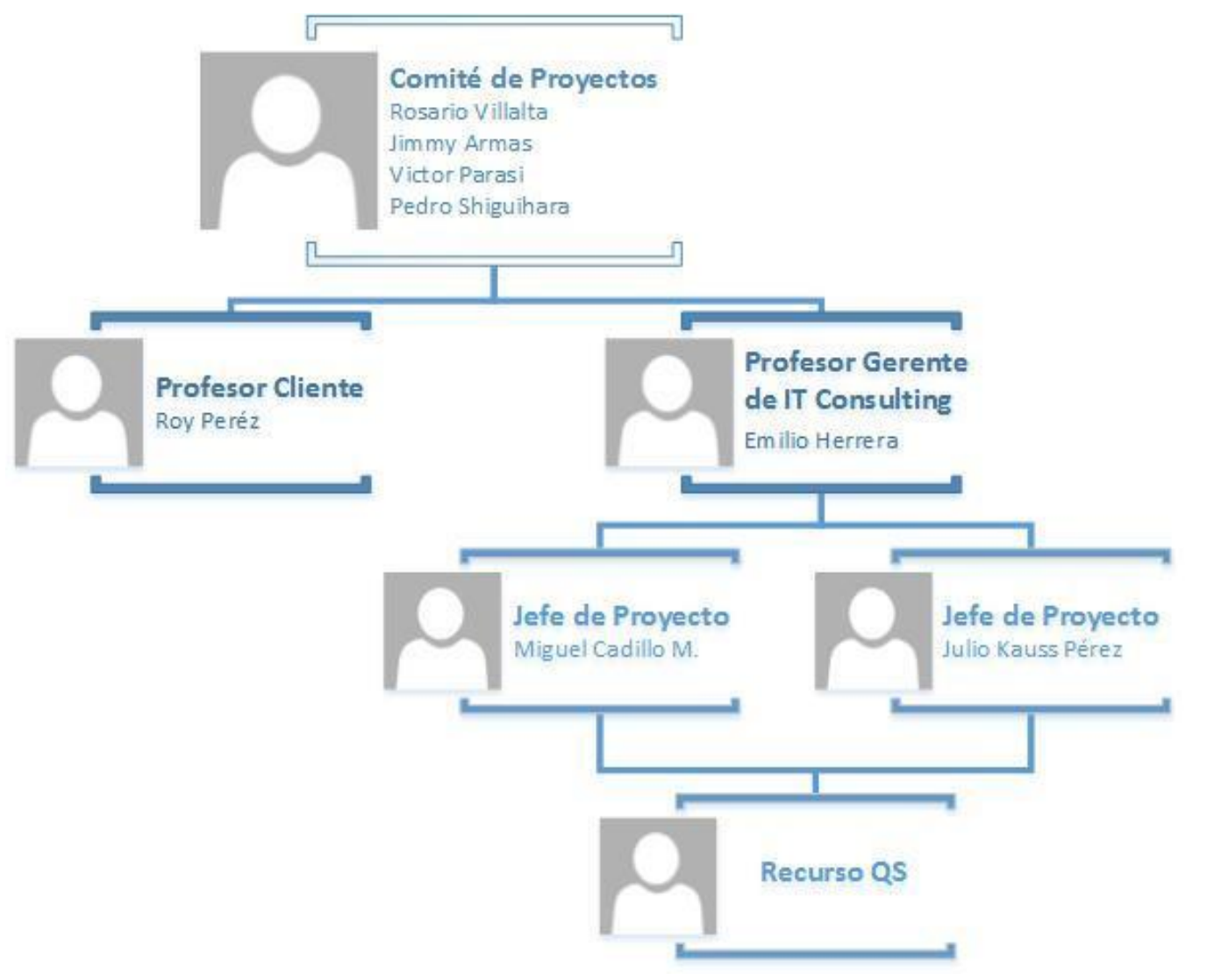

Ilustración 1. Estructura Organizacional del proyecto (Fuente: Elaboración propia)

\section{Plan de Comunicaciones}

En este documento de gestión se presentarán diversas guías que indicarán cómo se desplegará

el flujo de comunicación entre los stakeholders y los canales de comunicación que se llevarán a cabo en todo el proyecto.

\section{Guías para reuniones}

En ella, se detallarán las pautas de las reuniones:

- Se manejará una agenda para cada reunión de acuerdo a los temas de interés, 
tocando las tareas pendientes en las reuniones previas.

- Se cuenta con un horario específico para cada reunión, con previa coordinación y comunicación de los asistentes con un día como máximo.

- Al finalizar cada reunión se deberá recopilar lo tratado, resaltando los acuerdos para posteriormente elaborar el acta de reunión.

- Todas las actas de reunión deberán ser firmadas por todos los asistentes.

\section{Guías para correo electrónico}

Toda la remisión de correos electrónicos debe seguir las siguientes pautas:

- Cada correo electrónico debe ser redactado de una manera formal.

- Todo correo electrónico dirigido al cliente debe ser copiado al resto del equipo de proyecto.

\section{Guías para Codificación de Documentos}

La codificación de los documentos del proyecto será la siguiente:

- Cada documento o entregable del proyecto se identificará por un código único. Tendrá el siguiente estándar:

[Código de Proyecto]_[Nombre de documento]_v[Versión]

Por ejemplo:

SEPSR_Plan de Gestión de Comunicaciones_v1.0

- La duplicidad del código del proyecto no se dará bajo ninguna circunstancia.

\section{Guías para Almacenamiento de Documentos}

El almacenamiento de los documentos del proyecto deberá seguir las siguientes pautas:

- El almacenamiento de la documentación del proyecto se realiza bajo Google Drive como repositorio virtual, creado previamente por la empresa virtual.

- Cada nueva versión de un documento debe ser subida en la misma carpeta del documento origen.

\section{Guías para el Control de Versiones}

El control de las versiones de los entregables será de la siguiente forma:

- Cuando ocurra una entrega pactada, el entregable será codificado de la siguiente 
manera: 1.0, 2.0, 3.0 y así sucesivamente hasta que el proyecto finalice.

A continuación, se procede a mostrar la matriz de comunicaciones dónde se detalla la información como el contenido de la misma, el responsable de su elaboración, el método o canal de comunicación a ser usado, la frecuencia de ocurrencia, y finalmente el código de EDT asociado.

\begin{tabular}{|c|c|c|c|c|c|c|}
\hline $\begin{array}{l}\text { Inform sdión } \\
\text { Requerich }\end{array}$ & Conterido & $\begin{array}{l}\text { Responsable de } \\
\text { elaboración }\end{array}$ & $\begin{array}{c}\text { Para su entrege a las } \\
\text { stakeholders }\end{array}$ & Mét odo de com uriación a ut îner & Freauencia & Cóligo de EDT asociado \\
\hline Inicio & Project Charter & Jefes de Provecto & $\begin{array}{l}\text { - Ciente } \\
\text { - Profesor Gerente }\end{array}$ & \begin{tabular}{|l|} 
- Documento físico \\
- Documento digital
\end{tabular} & Semanal & 1.1 .1 .1 \\
\hline Planificación & $\begin{array}{l}\text { Documentos de Gestión } \\
\text { basados en la metodologí } \\
\text { PMBOK }\end{array}$ & Jefes de Proyecto & $\begin{array}{l}\text { - Ciente } \\
\text { - Profesor Gerentz }\end{array}$ & - Documento digital & Semanal & $\begin{array}{l}1.2 .1 .1 \\
1.2 .1 .2 \\
1.2 .2 .1 \\
1.2 .3 .1 \\
1.2 .3 .2 \\
1.2 .3 .3 \\
1.2 .3 .4\end{array}$ \\
\hline Ejecución & $\begin{array}{l}\text { Documento de via bilidad } \\
\text { del ecommerce en Pymes } \\
\text { del Sector Retail }\end{array}$ & Jefes de Provecto & - Ciente & \begin{tabular}{|l} 
- Documento físico \\
- Documento digital
\end{tabular} & Semanal & 1.3.1.2. \\
\hline Ejecución & $\begin{array}{l}\text { Documento de análisis de } \\
\text { opciones de ecommerce }\end{array}$ & Jefes de Proyecto & - Cliente & \begin{tabular}{|l|}
-Documento físico \\
- Documento digital
\end{tabular} & Semanal & 1.3.1.3. \\
\hline Ejecución & $\begin{array}{l}\text { Propuesta de arquitec tura } \\
\text { lógica y fisica de la } \\
\text { solución ecommerce }\end{array}$ & Lefes de Proyecto & - Ciente & \begin{tabular}{|l} 
- Documento físico \\
- Documento digital
\end{tabular} & Semanal & 1.3.1.4. \\
\hline Ejecución & $\begin{array}{l}\text { Informe de la metodol cogia a } \\
\text { implementar enla sol ución } \\
\text { ecommerce }\end{array}$ & Jefes de Proyecto & - Cliente & \begin{tabular}{|l} 
- Documento físico \\
- Documento digital
\end{tabular} & Semanal & 1.3.1.5. \\
\hline Ejecución & $\begin{array}{l}\text { Informe de desplies le de la } \\
\text { solución ecommerce }\end{array}$ & Jefes de Proyecto & - Ciente & - Documento digital & Semanal & 1.3.1.6. \\
\hline Ejecución & $\begin{array}{l}\text { Entrega ble firal de la } \\
\text { implementación de la } \\
\text { sol ución ecommerce }\end{array}$ & Jefes de Proyecto & - Ciente & - Documento digital & Semanal & 1.3.1.7. \\
\hline Ejecución & económica & Jefes de Proyecto & - Ciente & -Documento digital & Semanal & 1.3.1.8. \\
\hline Ejecución & $\begin{array}{l}\text { Plan de continuidad del } \\
\text { modelo ecommerce }\end{array}$ & Jefes de Proyecto & \begin{tabular}{|l|} 
- Ciente \\
-Profesor Gerente
\end{tabular} & \begin{tabular}{|l|}
-Documento físico \\
- Documento digital
\end{tabular} & Semanal & 1.3.1.9. \\
\hline Cierre & $\begin{array}{l}\text { aprendidas y } \\
\text { Oportunidades de Mejora }\end{array}$ & Lefes de Proyesto & \begin{tabular}{|l} 
- Ciente \\
-Profesor Gerente
\end{tabular} & \begin{tabular}{|l|} 
- Documento físico \\
- Documento digital
\end{tabular} & Semanal & 1.4.1.1. \\
\hline Cierre & Memoria del Proyecto & Jefes de Proyacto & \begin{tabular}{|l} 
- Ciente \\
-Profesor Gerente
\end{tabular} & \begin{tabular}{|l|} 
- Documento físico \\
- Documento digital
\end{tabular} & Semanal & 1.4 .1 .2 \\
\hline
\end{tabular}

Ilustración 2: Matriz de Comunicaciones del proyecto. (Fuente: Elaboración propia)

\section{Plan de Gestión de Riesgos}

Los riesgos del proyecto son cualquier eventualidad cuya ocurrencia afecta al desarrollo del proyecto y puede poner en peligro su exitosa culminación según lo planificado. En esta sección se detallan los riesgos importantes para el proyecto y se les asigna un nivel de probabilidad e impacto, y las estrategias de mitigación que buscan minimizar su probabilidad de salida (ver tabla 3 ).

\begin{tabular}{|c|l|c|c|c|}
\hline$\#$ & \multicolumn{1}{|c|}{ Riesgo } & $\begin{array}{r}\text { Probabili } \\
\text { dad }\end{array}$ & Impacto & Estrategia de mitigación \\
\hline 1 & $\begin{array}{l}\text { Escasez de } \\
\text { información para el } \\
\text { proyecto. }\end{array}$ & Media & Alto & $\begin{array}{l}\text { Reunirse con el cliente con el fin } \\
\text { de captar a mayor detalle los } \\
\text { requerimientos e información }\end{array}$ \\
\hline
\end{tabular}




\begin{tabular}{|c|c|c|c|c|}
\hline & & & & del proyecto. \\
\hline 2 & $\begin{array}{l}\text { Falta } \quad \text { de } \\
\text { disponibilidad de los } \\
\text { stakeholders. }\end{array}$ & Baja & Alto & $\begin{array}{l}\text { Coordinación para establecer un } \\
\text { cronograma de reuniones. }\end{array}$ \\
\hline 3 & $\begin{array}{ll}\begin{array}{l}\text { Retraso en } \\
\text { entregables }\end{array} & \text { des } \\
\text { proyecto. } & \end{array}$ & Baja & Alto & $\begin{array}{l}\text { Establecer un cronograma para } \\
\text { el proyecto que pueda generar } \\
\text { un mejor control de entregables } \\
\text { y modificarlo si existen cambios } \\
\text { en la fecha de entregables sin } \\
\text { perjudicar ni generar retrasos } \\
\text { en el cierre del proyecto. }\end{array}$ \\
\hline 4 & $\begin{array}{l}\text { Cancelación de las } \\
\text { reuniones con el } \\
\text { profesor gerente o } \\
\text { profesor cliente por } \\
\text { no cumplir con el } \\
\text { calendario } \\
\text { establecido. }\end{array}$ & Media & Alto & $\begin{array}{l}\text { Programar reuniones con los } \\
\text { stakeholders y planificar los } \\
\text { tiempos para que no haya } \\
\text { retrasos en las asistencias a las } \\
\text { reuniones. }\end{array}$ \\
\hline 5 & $\begin{array}{ll}\text { Falta } & \text { de } \\
\text { cumplimiento de } & \text { dabores por parte de } \\
\text { los recursos del } \\
\text { proyecto }\end{array}$ & Media & Media & $\begin{array}{l}\text { Se deberá seguir buscando el } \\
\text { recurso o los recursos } \\
\text { necesarios para culminar el } \\
\text { trabajo que se solicita. }\end{array}$ \\
\hline 6 & $\begin{array}{l}\text { Solicitud de cambio } \\
\text { de requerimientos o } \\
\text { alcance del proyecto } \\
\text { por parte del } \\
\text { profesor cliente. }\end{array}$ & Media & Alto & $\begin{array}{l}\text { Se realizará las modificaciones } \\
\text { de todos los documentos } \\
\text { afectados por el cambio de } \\
\text { requerimientos o alcance de } \\
\text { proyecto, a través del } \\
\text { procedimiento establecido por } \\
\text { el comité. }\end{array}$ \\
\hline 7 & $\begin{array}{lr}\text { Dificultad } & \text { para } \\
\text { configurar } & \text { la } \\
\text { herramienta } & \\
\text { propuesta } & \text { como } \\
\text { solución. } & \end{array}$ & Baja & Alto & $\begin{array}{l}\text { Leer los manuales de uso de la } \\
\text { herramienta y familiarizarse con ella } \\
\text { antes de la configuración }\end{array}$ \\
\hline 1 & $\begin{array}{lr}\text { Escasez } & \text { de } \\
\text { información para el } \\
\text { proyecto. }\end{array}$ & Media & Alto & $\begin{array}{l}\text { Reunirse con el cliente con el fin } \\
\text { de captar a mayor detalle los } \\
\text { requerimientos e información } \\
\text { del proyecto. }\end{array}$ \\
\hline 2 & $\begin{array}{l}\text { Falta } \\
\text { disponibilidad de los } \\
\text { stakeholders. }\end{array}$ & Baja & Alto & $\begin{array}{l}\text { Coordinación para establecer un } \\
\text { cronograma de reuniones. }\end{array}$ \\
\hline
\end{tabular}


Tabla 3: Riesgos del proyecto. (Fuente: Elaboración propia). 


\section{Capítulo 2: Student Outcomes}

En el presente capítulo se describirá como el proyecto cumple de manera exitosa los Students Outcomes, los cuales son criterios basados en las buenas prácticas basados en los estándares de calidad en programas de educación como ciencias, ingeniería, computación y tecnología. Adicionalmente, se muestra la evidencia del cumplimiento de las competencias generales que debe tener un profesional.

\section{Competencias Específicas}

\section{Student Outcome A}

Aplica conocimientos de matemática, ciencias, computación e ingeniería."

El Student Outcome A describe como el profesional cuenta con la capacidad para aplicar todos los conocimientos adquiridos durante los primeros años universitarios; es decir, aplicar conocimientos de ciencias exactas como matemáticas, cursos de carrera o ingeniería.

Considerando la descripción anterior, el presente proyecto ha logrado cumplir con el Student Outcome A de la siguiente manera:

- Durante la fase de Planificación, los Jefes de Proyecto elaboran un cronograma o plan de trabajo, el cual deberá ser ejecutado y seguido de manera rigurosa. Para la realización del cronograma, se ha usado los conceptos de PMBOK (Project Management Body of Knowledge) para determinar o calcular los esfuerzos en realizar las actividades del proyecto teniendo en cuenta la triple restricción según la disciplina: recurso, tiempo y dinero. Asimismo, usando las ciencias exactas, se pudo determinar la cantidad de recursos como los tiempos de las actividades con la finalidad de poder cumplir los tiempos de compromiso pactados con el comité de la carrera.

A continuación, se evidenciará mediante los siguientes documentos:

- Cronograma del proyecto

- Diccionario EDT del proyecto

- Plan de Gestión de Cronograma

- Durante la fase de análisis, se ha realizado un estudio de benchmarking de las diferentes soluciones eCommerce según las definiciones de Forrester y como resultado se ha 
obtenido una herramienta ganadora bajo diferentes criterios. Para la elaboración de este entregable, se ha usado como base los conocimientos de ciencias y computación, porque se definieron atributos o criterios que por medio de validaciones se otorgaría un puntaje que posteriormente nos apoyaría en la elección de la mejor solución e-commerce. Esto se evidenciará en el siguiente entregable:

- Informe de Benchmarking de las soluciones e-commerce

En conclusión, mediante la suma de evidencias presentadas anteriormente se logró cumplir con el Student Outcome A mediante los resultados del proyecto y es así donde se evidencia que se utilizaron los conocimientos adquiridos de los distintos cursos para la ejecución del proyecto.

\section{Student Outcome B}

\section{"Diseña y conduce experimentos en base al análisis e interpretación de datos."}

El Student Outcome B hace mención en como el profesional puede realizar pruebas para la validación y posteriormente a ello, tomar decisiones en base al análisis de los resultados obtenidos.

Considerando la descripción anterior, el presente proyecto ha logrado cumplir con el Student Outcome B de la siguiente manera:

Durante el análisis del proyecto, se identificó la herramienta e-commerce más apropiada para las pymes que es el Magento; es por ello, que al realizar el benchmarking de las herramientas se describieron varios criterios para la mejor elección y en base a los cuadros elaborados en base a las diferentes modalidades de las herramientas, precios de las soluciones, cantidad de Plugins free y pagados y la cantidad de funcionalidades e-commerce que cuentan las herramientas. Esto se puede evidenciar en las siguientes entregable:

- $\quad$ Lista de Herramientas e-commerce

- Informe de comparativo de las soluciones e-commerce

En la etapa de validación, se realizó la validación de la plataforma elegida, mediante un informe de pruebas funcionales (Descrito en el capítulo 5 de la memoria), En el cual se realiza un análisis profundo a la herramienta y se define cuáles son los puntos correctos y cuales tienen que mejorar. 
En conclusión, mediante la suma de evidencias presentadas anteriormente se logró cumplir con el Student Outcome B mediante los resultados del proyecto y es así donde se evidencia que el equipo de proyecto diseño y realizo las pruebas en los documentos presentados, y finalmente se llegaron a tomar decisiones realizando un análisis de los mismos.

\section{Student Outcome C}

\section{"Diseña sistemas, componentes o procesos para encontrar soluciones en la atención de necesidades teniendo en cuenta restricciones económicas, sociales, políticas, éticas de salud y seguridad y otras propias del entorno empresarial."}

El Student Outcome $C$ hace referencia a la manera o forma en que el profesional diseña una propuesta de sistemas teniendo en cuenta la realidad actual de la empresa en sus diferentes aspectos coyunturales.

En base a la descripción anterior, el presente proyecto ha logrado cumplir con el Student Outcome C de la siguiente manera:

Se realizó un análisis completo de la empresa Distribuciones Técnicas S.A.C., diseñando sus procesos ASIS y To Be para poder definir cómo el comercio electrónico impactaría en la empresa. Adicionalmente a este análisis, se definieron roles en la empresa, los cuales interactuarían con la plataforma de comercio electrónico. Se diseñó la infraestructura actual de la empresa y la infraestructura de TI futura que se tendría con la implementación de la plataforma de eCommerce. Todos los entregables mencionados anteriormente se utilizaron en el Modelo de Negocio, para poder entender cómo el comercio electrónico afectaría a la empresa en los procesos involucrados.

Adicionalmente, se diseñó el modelo de referencia para la implementación de una solución eCommerce, que engloba los entregables anteriormente mencionados, para luego desarrollar la implementación de la solución y permite a la empresa obtener resultados como la ampliación de oferta, la adaptación tecnológica y fidelización del cliente. 


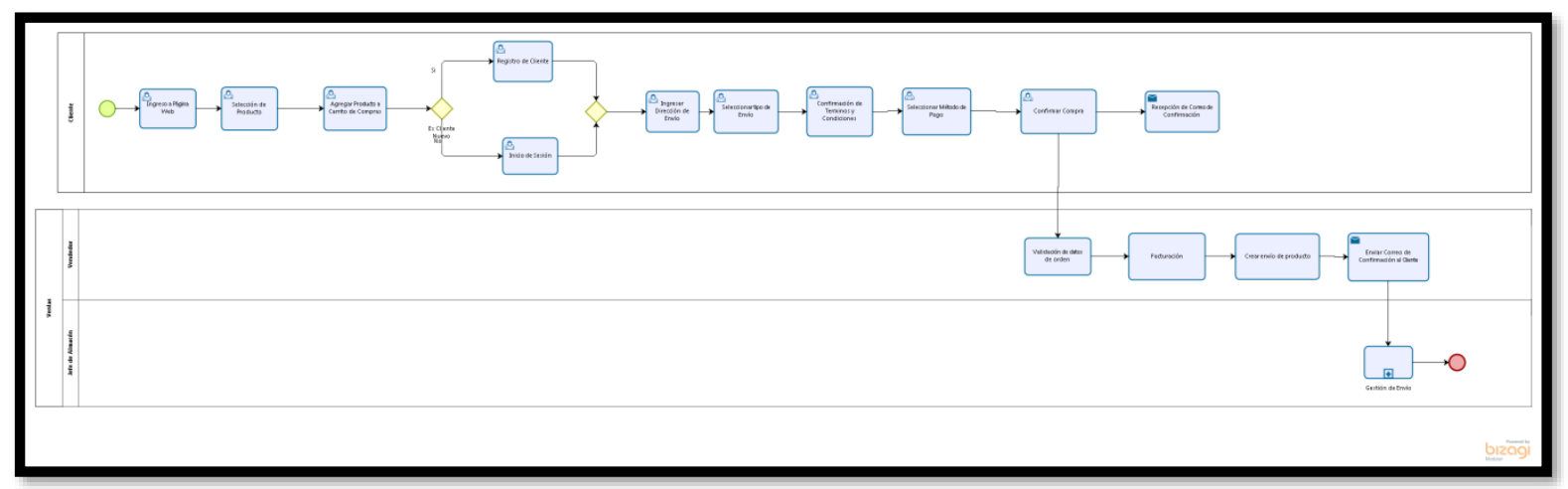

Ilustración 3: Proceso de Gestión de Ventas-E-Commerce. (Fuente: Elaboración propia)

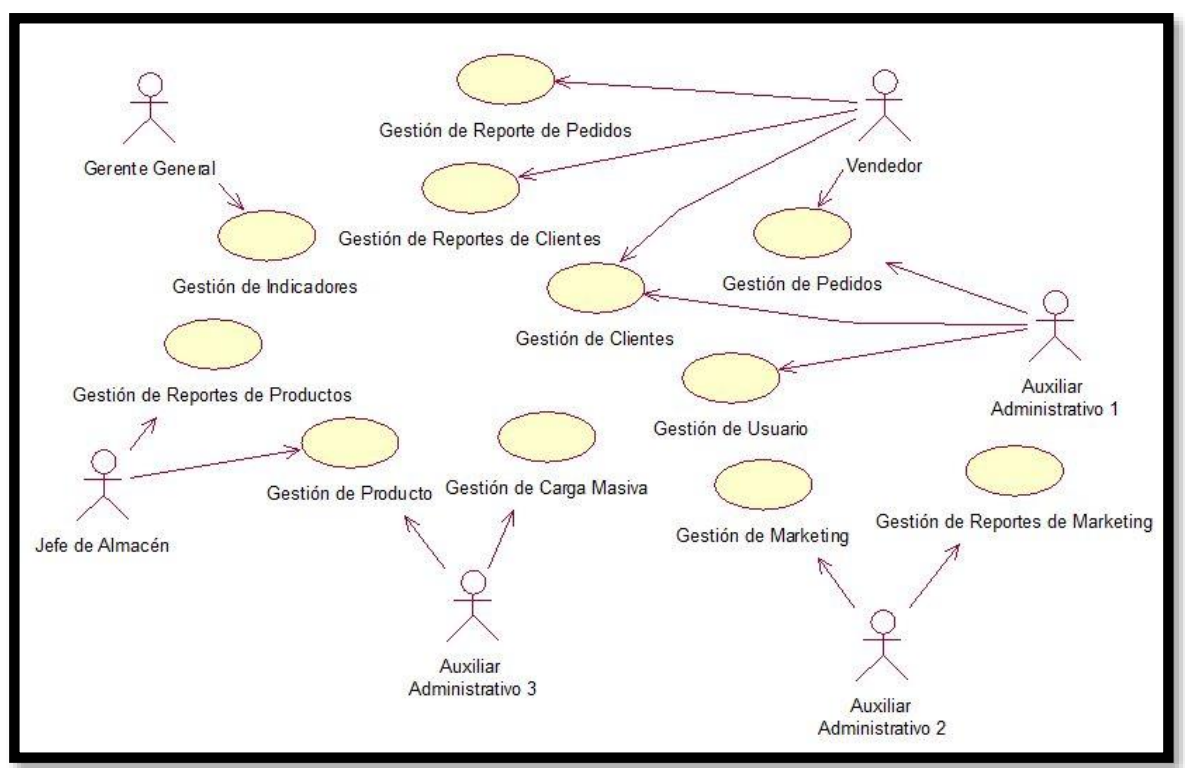

Ilustración 4: Diagrama de casos de uso. (Fuente: Elaboración propia) 


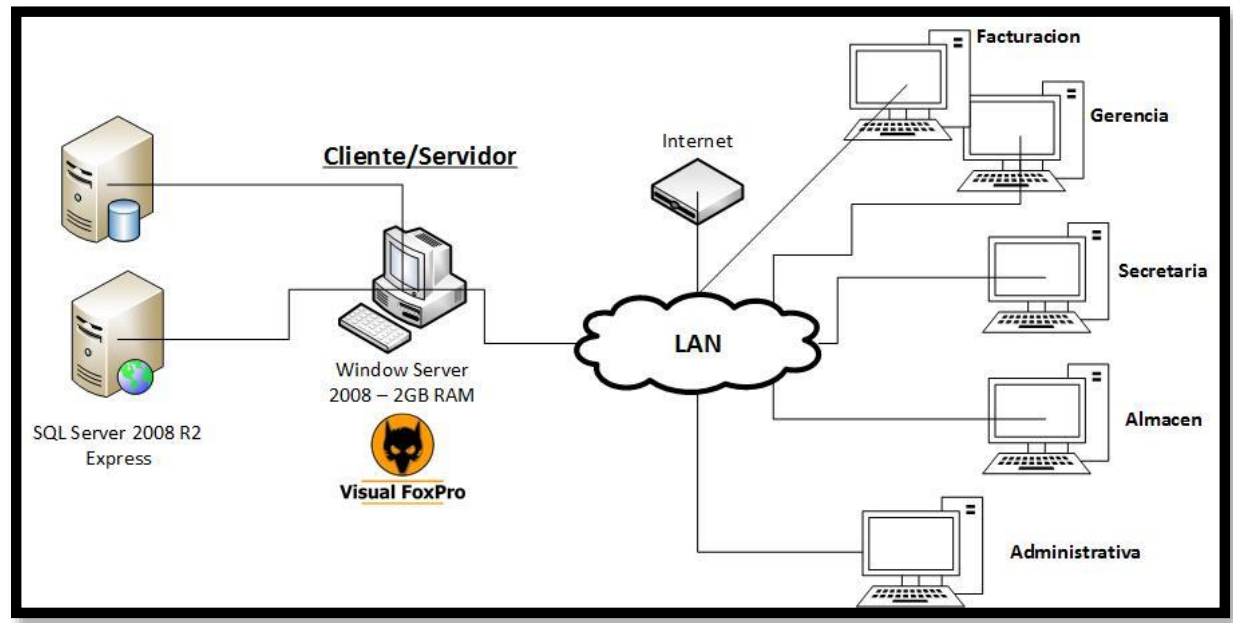

Ilustración 5: Infraestructura de TI - Distribuciones Técnicas S.A.C. (Fuente: Elaboración Propia).

\section{MODELO MISEP}

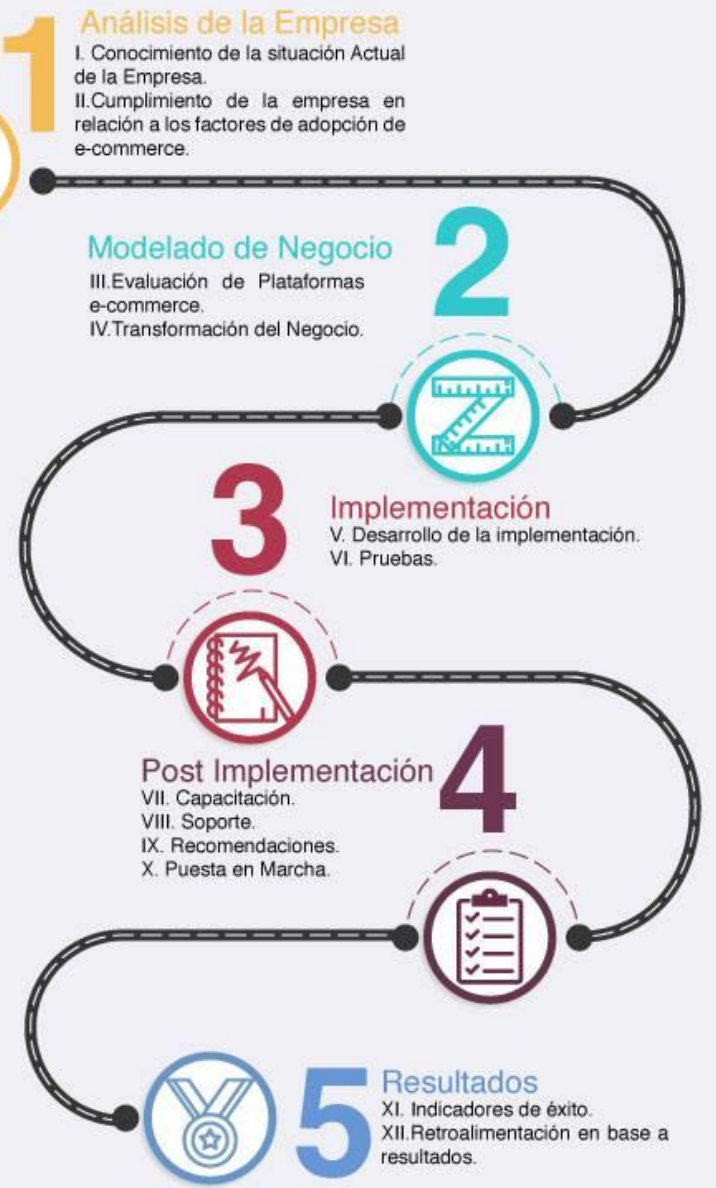

Ilustración 6: Modelo de Referencia para la Implementación de una Solución E-Commerce en una Pyme del Sector Retail (Fuente: Elaboración Propia). 


\section{Student Outcome D}

"Participa en equipos multidisciplinarios desarrollando sus tareas con profesionales de diferentes especialidades o dominio de aplicación."

El Student Outcome D hace mención a la capacidad de realizar trabajos y reuniones con profesionales de diferente campo de aplicación.

En base a la definición anterior, el proyecto ha cumplido con el Student Outcome D de la siguiente manera:

En el cronograma del proyecto, se han planeado reuniones con los interesados del proyecto; es decir, reuniones con el Profesor Gerente cuyas reuniones son todos los viernes; con el Profesor Cliente, cuyas reuniones son todos los domingos y con el co-autor, cuyas reuniones son los días jueves. De esta manera, el equipo de proyecto programó las reuniones con algunos especialistas en su rubro para darle seguimiento constante de los avances del desarrollo del proyecto. Asimismo, estas reuniones se especifican en los documentos de gestión según el PMBOK. Esto se ha evidenciado en los siguientes entregables:

- Cronograma del proyecto

- Plan de Comunicaciones

Para realizar la validación del modelo propuesto, se recurrió al CEO de la agencia MK, una agencia de marketing. El señor Luis Navarro, licenciado en Marketing, tuvo el rol de Juicio Experto dentro de la validación, y ayudó con el proyecto al definir los indicadores que se usaron para presentar los resultados finales.

Adicionalmente, para validar el modelo propuesto, se implementó la solución de comercio electrónico en la empresa Distribuciones Técnicas S.A.C., teniendo un contacto directo con la Gerenta General de la empresa, la Señora Ana Pérez García, licenciada en contabilidad, quien brindó su experiencia en el rubro automotriz y brindó los requerimientos para que la solución se lleve a cabo.

Asimismo, durante el desarrollo del proyecto, también se ha tenido interacción con no profesionales para la validación. Para esto, se ha contado con la Empresa IT Service, la cual se tuvo coordinaciones con el Gerente Alumno: Catriel Cruz y los recursos asignados al proyecto para la validación de los documentos o entregables que son desarrollados en los dos ciclos académicos. Para evidenciar esto, se brindará el siguiente documento:

- Certificado de QS 
Sumando lo antes descrito, el equipo de trabajo ha presentado las evidencias suficientes para cubrir el Student Outcome D y así, poder participar con equipos multidisciplinarios para realizar las tareas profesionales.

\section{Student Outcome E}

\section{"Identifica, formula y resuelve problemas de ingeniería."}

El Student Outcome E hace mención a analizar las situaciones y proponer soluciones a problemas de ingeniería.

Tomando en cuenta lo antes descrito, el presente proyecto ha logrado cumplir el Student Outcome E de la siguiente manera:

Según el ciclo de vida de los sistemas de información se plantea el análisis del proyecto por medio de comparativas e investigación de tecnologías por las cuales de comparan buenas prácticas, marcos de trabajo, soluciones e-commerce y pruebas de las validaciones. De esta manera se identificó las mejores opciones para el desarrollo del proyecto. Esto se ha evidenciado en los documentos que fueron considerados como entregables:

- Informe de benchmarking de soluciones e-commerce.

Luego del análisis, se plantea el diseño de la solución e-commerce con la finalidad de resolver el problema del poco éxito en implementación de soluciones de comercio electrónico. De esta manera se diseñan procesos, aplicaciones y arquitectura que permitieron que la empresa Distribuciones Técnicas pueda aumentar un canal de ventas y aumentar su oferta de negocio. Esto se puede evidenciar en el capítulo 5 de la Memoria, en el cual se describe el Modelo de referencia para la implementación de una solución eCommerce en Pymes del Sector Retail.

Finalmente, para la implementación y validación del modelo e-commerce que abarca todo lo relacionado a la resolución del problema identificado al inicio del proyecto, el modelo es la respuesta más adecuada para las Pymes retail. De esta forma, se resuelve el problema planteado mediante una solución que nace desde un concepto de ingeniería.

\section{Student Outcome F}

\section{"Propone soluciones a problemas de ingeniería con responsabilidad profesional y ética."}

El Student Outcome F hace mención a poder realizar un proyecto teniendo en cuenta la confidencialidad y la responsabilidad de cumplir tiempos de compromisos pactados. 
Bajo la descripción antes mencionada, el presente proyecto ha logrado cumplir con el Student Outcome F de la siguiente manera:

Como profesionales, el equipo de proyecto ha sido responsable en respetar los tiempos de compromiso pactados de forma que se cumpla con las actividades planificadas en el cronograma de trabajo desde el inicio del proyecto. De esta manera, se ha ejecutado las fases del proyecto de manera metódica y constante. A pesar de tener dificultades durante el desarrollo del cronograma, se pudieron manejar encontrando una alternativa que no retrase los tiempos pactados.

Para la validación del Student Outcome F, se realizaron los siguientes entregables:

- Cronograma del proyecto

- Plan de Gestión del Cronograma del proyecto

- Diccionario EDT

- Actas de Reunión con el Profesor Gerente y Profesor Cliente

En estas actas de reunión se da el compromiso de cumplir con las fechas establecidas y entregar los documentos los días que se han mencionado sin faltar al cumplimiento de los acuerdos.

\section{Student Outcome G}

\section{“Comunica ideas o resultados de manera oral o escrita con claridad y efectividad."}

En el presente proyecto se ha logrado cubrir el Student Outcome G de la siguiente manera:

Durante el desarrollo del proyecto, el equipo de proyecto ha plasmado sus ideas y conceptos en una serie de entregables. Los entregables, que pueden ser entregables de ingeniería o documentos de gestión y estos fueron revisados por el equipo de proyecto y personas interesadas en el proyecto como un juicio de experto, una persona o empresa que cuente con alguna pyme sobre el cual se realizara la validación del proyecto.

Para poder ser entendidos por distintas personas de diferentes roles dentro del proyecto, fue necesario contar con una comunicación oral y escrita efectiva para poder comunicar las ideas del equipo de proyecto de una manera simple y no compleja. Y este punto es sumamente importante debido que al tener un modelo e-commerce como entregable final entonces se busca que este sea usado por diversas pymes y bajo este enfoque, la claridad y la simplicidad son necesarios al momento de explicar el modelo planteado es básico para que pueda ser fácilmente comprendido, tanto al momento de exponer las ideas como cuando lean los documentos del proyecto. 
Por todo lo antes mencionado, para el equipo de proyecto es de suma importancia contar con constancias o certificados de revisión de todos sus entregables, por personal experto en la materia correspondiente, con el cual se asegurará la calidad de estos. Por ello, dentro del proyecto se cuenta con constancias de revisión del trabajo que se evidencia en:

- Constancia de revisión de toda la documentación por ciclo por QS

- Constancia de las actas de reuniones con las partes interesadas

- Constancia de revisión y aprobación de Paper

Con esta constancia se asegurará que el Paper del proyecto fue elaborado, finalizado y revisado de una manera exhaustiva con el objetivo de proponer el Paper a diferentes congresos internacionales, donde la comunicación escrita es de suma importancia porque será revisado por entes internacionales.

- Acta de validación por el juicio de experto- Agencia de Marketing

Esta constancia asegura que se realizó una reunión con el CEO de la agencia MK, en la cual la persona pudo validar el modelo de referencia.

- Para poder sostener una comunicación clara, se sostuvieron 4 exposiciones frente a un comité dentro del campo de la ingeniería, software y computación, el cual evalúan y realizan las consultas necesarias al equipo de proyecto y finalmente, dar los resultados de las exposiciones orales.

\section{Student Outcome H}

"Identifica el impacto de las soluciones de ingeniería en el contexto global, económico y del entorno de la sociedad."

El presente proyecto ha logrado cubrir el Student Outcome H de las siguientes maneras:

Para lograr la identificación de impacto del proyecto, inicialmente se evaluó dentro del documento Project Chárter. Este documento es el primero en documentarse en proyecto y consolida temáticas como el problema a solucionar, siendo necesario para proponerlo, conocer un problema con impacto y trascendencia dentro de la sociedad, como es la no implementación de soluciones de comercio electrónico por parte de las Pymes del Sector Retail.

Finalmente, en el Paper del proyecto se detalla de una manera mucho más detallada el impacto de la solución planteada a nivel global, debido al estudio realizado y en la consideración de Papers de diversos países, sobre los cuales se han efectuado varias indagaciones dentro de casos de éxito de modelos similares en otras sociedades del mundo. 


\section{Student Outcome I}

\section{"Reconoce la necesidad de mantener sus conocimientos actualizados."}

El presente proyecto ha logrado cubrir el Student Outcome I de las siguientes maneras:

Durante el desarrollo del proyecto, se realizaron diversos estudios, dando como resultado el entregable final, que es un modelo e-commerce para lo cual se ha tenido que recaudar fuentes de Paper de diferentes autores y países que puedan colaborar en el desarrollo del modelo y siempre considerando un periodo de 4 años como máximo. Y esto se evidencia en el Paper del proyecto.

Adicionalmente, durante la etapa de análisis del proyecto, se ha contado con estudios de las funcionalidades del e-commerce tomados en cuenta de los informes de Forrester y Gartner de los últimos años para que pueda dar la tendencia de las herramientas e-commerce más usadas a nivel global. Esto se puede evidenciar en el entregable de Benchmarking de las soluciones de comercio electrónico.

El soporte tecnológico empleado en el proyecto, por concepto es un componente variable, teniendo en cuenta los grandes avances tecnológicos que se dan en el día a día. De esta manera tener conocimiento tecnológico actualizado para el modelo e-commerce, es fundamental dentro de su buen funcionamiento en la pyme. Para mantener actualizados los conocimientos tecnológicos, se elaboró el informe de benchmarking de las soluciones ecommerce como parte de los entregables del proyecto.

De esta manera, se reconoce la necesidad de mantener los conocimientos actualizados.

\section{Student Outcome J}

\section{"Analiza hechos del mundo contemporáneo identificando el impacto en el desempeño profesional de ingeniería."}

El presente proyecto ha logrado cubrir el Student Outcome J de la siguiente manera:

Se realizó una investigación sobre los factores que permiten la adopción al comercio electrónico, en artículos que tienen menos de 4 años de antigüedad y en los cuales, se propone modelos de adopción del comercio electrónico que se aplican en un contexto real. Al revisar los artículos, se observó que no existe un modelo estándar, de referencia para la implementación de soluciones de comercio electrónico en Pymes. Es por eso que, se propone el modelo el cual se desarrolló en una Pyme, obteniendo como entrada la información de la empresa, sus procesos actuales y dando como resultado un aumento en ventas, lo cual se da en un contexto real y no de pruebas. 


\section{Student Outcome K}

\section{"Utiliza técnicas, herramientas y metodologías necesarios para la práctica de ingeniería."}

El presente proyecto ha logrado cumplir el Student Outcome K de la siguiente manera:

En el desarrollo del proyecto, se utilizaron diversas técnicas y herramientas, que fueron de gran utilidad al momento de poner en práctica la ingeniería en el modelo e-commerce propuesto. Durante la fase de planificación, se elaboró un cronograma que cumple la función de planificador de todas las actividades por realizar en el durante el proyecto que fue de gran utilidad porque permitió medir tiempos y dividir las actividades según la metodología PMBOK (Project Management Body of Knowledge).

Con respecto a herramientas utilizadas y para estar a la vanguardia tecnológica, dentro de los entregables del modelo se ha considerado el estudio de 7 herramientas e-commerce de la lista que ya se contaba: Magento, Volusion, Prestahop, Shopify, OsCommerce, Bigcommerce y Lemonstand donde se ha podido acceder a todas las herramientas y poder validar sus funcionalidades básicas. Luego, gracias a este paso realizado, se ha podido realizar el informe de benchmarking de soluciones e-commerce y así poder definir que herramienta, plugin, modalidad más apropiada para las pymes. Adicionalmente, se revisaron las metodologías existentes para la adopción del comercio electrónico. Para obtener los datos de los resultados del modelo, se utilizaron herramientas como Google Analytics y Google Forms. Todas las metodologías y herramientas utilizadas fueron debidamente aprobadas por el Profesor Cliente y esto se evidencia en las actas de reunión.

\section{Student Outcome L}

\section{“Comprende y brinda soporte para el uso, entrega y gestión de sistemas de información dentro de un entorno de sistemas de información." \\ El presente proyecto ha logrado cumplir el Student Outcome L de la siguiente manera: Como parte de la implementación de la solución de comercio electrónico, se ha brindado a la empresa Distribuciones Técnicas los siguientes documentos:}

Manual de usuario. Manual de usuario que brinda al gerente general y a los usuarios de la plataforma dentro de la empresa la guía necesaria para desarrollar correctamente sus funciones. 
Documento de Soporte. En este entregable, se brindan los errores frecuentes, de tal forma que la empresa pueda solucionarlos y no tenga que contactarse con el proveedor de soporte. Adicionalmente, se detalla en este documento a la persona de contacto para soporte.

Recomendaciones. En este entregable, se brindan las recomendaciones a la empresa previo al despliegue de la plataforma de comercio electrónico. Por ejemplo, se brinda la recomendación de desarrollar una estrategia de Marketing con la cual se pueda promocionar de una forma más adecuada y eficiente a la solución de e-commerce de cara a los clientes de la empresa.

Resultados. En el presente entregable, se brindan los resultados a la empresa, con la finalidad de que se dé a conocer los beneficios reales de la implementación de la solución de comercio electrónico.

\section{Competencias Generales}

\section{Comunicación Escrita}

Esta competencia se evidencia en la redacción de la memoria completa y el Paper.

\section{Comunicación Oral}

Esta competencia se desarrolló durante las exposiciones que se han realizado en el tiempo del proyecto, así como en las reuniones con el Cliente, en las cuales se explicaban los avances del proyecto y se planteaban nuevas iniciativas. Adicionalmente, el proyecto se expuso en el congreso nacional COPIOS, frente a un público diverso, en el que se destacaba la presencia de conferencistas internacionales, los cuales cuentan con el grado de doctor.

\section{Ciudadanía}

Esta competencia se desarrolló al realizar la validación del proyecto en un trabajo conjunto con la empresa Distribuciones Técnicas S.A.C. Se respetaron los horarios de la organización, el ambiente laboral al momento de la toma de requerimientos y al momento de la capacitación del personal. Se establecieron acuerdos en las reuniones con la gerencia y se cumplió de forma ordenada con cada uno de los puntos. 


\section{Pensamiento innovador}

El modelo propuesto en el proyecto muestra la innovación al ser un estándar sin precedentes. Se propuso el modelo para brindar una referencia a las empresas que deseen implementar el comercio electrónico, marcando pautas necesarias para el éxito con el comercio electrónico.

\section{Pensamiento crítico}

Se criticó a los modelos de adopción del comercio electrónico, y a los modelos de implementación, se mostraron sus falencias a través del desarrollo de la investigación. Cuando se realizó el benchmarking para elegir a la plataforma más adecuada para la implementación del comercio electrónico, se criticó de forma específica a cada una de las alternativas.

\section{Razonamiento cuantitativo}

Esta competencia se desarrolló, en parte al desarrollar la tabla de cumplimiento de la empresa a través de los factores de adopción del comercio electrónico, en la cual se debe marcar valores entre 1 a 3 si la empresa cumple o no cumple con estos factores. Al final de la tabla, se obtiene un resultado, el cual lleva a la decisión si la empresa está apta o no para implementar el comercio electrónico.

\section{Manejo de la información}

Esta competencia se evidencia al investigar sobre el comercio electrónico y sus aplicaciones en un entorno global. Se revisaron más de 20 artículos que hacen referencia al tema y se clasificaron en grupos de acuerdo con su enfoque. Adicionalmente, se realizó un manejo de información al recibir los detalles de los productos de la empresa, al clasificarlos en categorías según lo explicado por la empresa y al elaborar una plantilla de importación para la carga masiva en la plataforma de comercio electrónico. 


\section{Capítulo 3: Estado del Arte}

En este tercer capítulo se presenta una revisión de la literatura referida a la definición del Estado del Arte del proyecto Implementación de una solución eCommerce para una Pyme del Sector Retail. Para este fin, se inicia la revisión con la descripción de la metodología elegida para la elección de los artículos que estén en relación con el tema desarrollado. Se presentarán 2 modelos de implementación de soluciones eCommerce, 2 modelos de arquitectura del comercio electrónico y, por último, 1 implementación de una solución eCommerce.

\section{Metodología de elección de artículos}

Para realizar la selección de artículos, se consultaron los repositorios de revistas científicas, dentro de bancos de información como ScienceDirect, IEEE Xplore y ACM library, los papers se validaron como relevantes a través de la página Scimago Journal \& Country Rank. Se utilizaron las siguientes palabras clave en cada uno de los bancos de revistas científicas: eCommerce, Modelo de implementación de eCommerce, eCommerce en Pymes, eCommerce Architecture, eCommerce model for SME'S, Implementation of eCommerce, Advantages of eCommerce, eCommerce en Perú, Modelo de adopción de eCommerce, Soluciones de eCommerce y tipos de eCommerce.

Como resultado de la búsqueda en los bancos mencionados se encontraron los siguientes papers, de los cuales se utilizarán 5 como aportes al proyecto en cuestión:

\begin{tabular}{|c|c|l|l|}
\hline Autor & Título & Journal & Año \\
\hline Tarazona B. & Buenas prácticas & & \\
Giovanny, Gómez & para la & & \\
R. Maribel y & implementación del & Visión Electrónica, & 2012 \\
Montenegro M. & comercio & Número 2 p. 31-45 & \\
Carlos & electrónico en & & \\
& Pymes & & \\
& & & \\
\hline
\end{tabular}




\begin{tabular}{|c|c|c|c|}
\hline $\begin{array}{l}\text { Luchuan Liu, } \\
\text { Guopeng Yin }\end{array}$ & $\begin{array}{l}\text { IT Organization } \\
\text { Transformation in } \\
\text { Enterprise } \\
\text { eCommerce }\end{array}$ & $\begin{array}{c}\text { Second } \\
\text { International } \\
\text { Symposium on } \\
\text { Electronic } \\
\text { Commerce and } \\
\text { Security }\end{array}$ & 2009 \\
\hline $\begin{array}{c}\text { Rima Fayad \& } \\
\text { David Paper }\end{array}$ & $\begin{array}{l}\text { The Technology } \\
\text { Acceptance Model } \\
\text { E-Commerce } \\
\text { Extension: A } \\
\text { Conceptual } \\
\text { Framework }\end{array}$ & $\begin{array}{c}\text { Procedia } \\
\text { Economics and } \\
\text { Finance }\end{array}$ & 2015 \\
\hline $\begin{array}{c}\text { Caroline Chan \& } \\
\text { Paula M.C. } \\
\text { Swatman }\end{array}$ & $\begin{array}{l}\text { Management and } \\
\text { business issues for } \\
\text { B2B eCommerce } \\
\text { implementation }\end{array}$ & $\begin{array}{l}\text { IEEE Computer } \\
\text { Society }\end{array}$ & 2002 \\
\hline $\begin{array}{c}\text { Zhu Mingqiang \& } \\
\text { Zou Zuxu }\end{array}$ & $\begin{array}{l}\text { The Analysis of } \\
\text { Knowledge } \\
\text { Management's } \\
\text { Functions in E- } \\
\text { Commerce } \\
\text { Implementation }\end{array}$ & $\begin{array}{l}\text { IEEE Computer } \\
\text { Society }\end{array}$ & 2009 \\
\hline $\begin{array}{c}\text { Tizana Guzzo, } \\
\text { Fernando Ferri \& } \\
\text { Patrizia Grifoni }\end{array}$ & $\begin{array}{c}\text { A model of e- } \\
\text { commerce adoption } \\
\text { (MOCA): }\end{array}$ & Behaviour \& & \\
\hline
\end{tabular}




\begin{tabular}{|c|c|c|c|}
\hline & $\begin{array}{c}\text { consumer's } \\
\text { perceptions and } \\
\text { behaviours }\end{array}$ & $\begin{array}{l}\text { Information } \\
\text { Technology }\end{array}$ & 2016 \\
\hline $\begin{array}{l}\text { Yuan-Jin Tseng, } \\
\text { Chin-Chin Chang } \\
\text { \& Judy C.R. Tseng }\end{array}$ & $\begin{array}{c}\text { Modeling and } \\
\text { Implementation of } \\
\text { Object-Oriented E- } \\
\text { Commerce } \\
\text { Platform }\end{array}$ & $\begin{array}{c}\text { IEEE Computer } \\
\text { Society }\end{array}$ & 2007 \\
\hline $\begin{array}{c}\text { Sherah Kurnia, } \\
\text { Jyoti Choudrie, } \\
\text { Rahim Md \& Basil } \\
\text { Alzagooul }\end{array}$ & $\begin{array}{c}\text { E-commerce } \\
\text { technology } \\
\text { adoption: A } \\
\text { Malaysian grocery } \\
\text { SME }\end{array}$ & $\begin{array}{l}\text { Journal of Business } \\
\text { Research }\end{array}$ & 2015 \\
\hline $\begin{array}{l}\text { Sun Lin \& Xu } \\
\text { WenZheng }\end{array}$ & $\begin{array}{l}\text { E-commerce } \\
\text { personalized } \\
\text { recommendation } \\
\text { system based on } \\
\text { Web mining } \\
\text { technology design } \\
\text { and } \\
\text { implementation }\end{array}$ & $\begin{array}{c}\text { International } \\
\text { Conference on } \\
\text { Intelligent } \\
\text { Transportation, Big } \\
\text { Data \& Smart City }\end{array}$ & 2015 \\
\hline $\begin{array}{l}\text { Saeed Solaymani, } \\
\text { Kiomars Sohaili \& } \\
\text { Esmaeil Akhlaghi }\end{array}$ & $\begin{array}{c}\text { Adoption and use } \\
\text { of e-commerce in } \\
\text { SME's }\end{array}$ & $\begin{array}{c}\text { Electron Commer } \\
\text { Res }\end{array}$ & 2012 \\
\hline
\end{tabular}




\begin{tabular}{|c|c|c|c|}
\hline $\begin{array}{l}\text { Huang XiaoQin, } \\
\text { Huang LinPeng, } \\
\text { Chen Lin \& Li } \\
\text { Minglu }\end{array}$ & $\begin{array}{c}\text { Design and } \\
\text { Implementation of } \\
\text { an Agent-based } \\
\text { Web Services } \\
\text { Platform for } \\
\text { Electronic } \\
\text { Commerce }\end{array}$ & $\begin{array}{l}\text { IEEE Computer } \\
\text { Society }\end{array}$ & 2004 \\
\hline $\begin{array}{l}\text { Anil Kini \& Joobin } \\
\text { Choobineh }\end{array}$ & $\begin{array}{c}\text { Trust in Electronic } \\
\text { Commerce: } \\
\text { Definition and } \\
\text { Theor }\end{array}$ & IEEE Xplore & 1998 \\
\hline $\begin{array}{l}\text { K.J. Lin \& Yan } \\
\text { Wang }\end{array}$ & $\begin{array}{c}\text { E-Commerce } \\
\text { Technology, Back } \\
\text { to a Prominent } \\
\text { Future }\end{array}$ & E-Commerce Track & 2008 \\
\hline $\begin{array}{c}\text { Guotao Zhuang \& } \\
\text { Junwei Du }\end{array}$ & $\begin{array}{c}\text { MDA-based } \\
\text { Modeling and } \\
\text { Implementation of } \\
\text { E-Commerce Web } \\
\text { Applications in } \\
\text { WebML }\end{array}$ & $\begin{array}{l}\text { IEEE Computer } \\
\text { Society }\end{array}$ & 2009 \\
\hline $\begin{array}{c}\text { Tarazona B. } \\
\text { Giovanny, Medina } \\
\text { G. Victor \& }\end{array}$ & $\begin{array}{c}\text { Modelo de } \\
\text { Implementación de } \\
\text { soluciones de }\end{array}$ & $\begin{array}{c}\text { Revista Ingenierías } \\
\text { Universidad de }\end{array}$ & 2013 \\
\hline
\end{tabular}




\begin{tabular}{|c|c|c|c|}
\hline Giraldo Lylliana & $\begin{array}{l}\text { Comercio } \\
\text { Electrónico }\end{array}$ & Medellín & \\
\hline $\begin{array}{l}\text { Fatima Ajmal \& } \\
\text { Norizan Mohd Y. }\end{array}$ & $\begin{array}{c}\text { Model for } \\
\text { Electronic } \\
\text { Commerce } \\
\text { Adoption for Small } \\
\text { and Medium Sized } \\
\text { Enterprises }\end{array}$ & $\begin{array}{c}\text { International } \\
\text { Journal of } \\
\text { Innovation, } \\
\text { Management and } \\
\text { Technology }\end{array}$ & 2012 \\
\hline $\begin{array}{c}\text { Fabian Aulkemeier, } \\
\text { Milan Schramm, } \\
\text { Maria-Eugenia } \\
\text { Iacob \& Jos van } \\
\text { Hillegersberg }\end{array}$ & $\begin{array}{l}\text { A Service-Oriented } \\
\text { E-Commerce } \\
\text { Reference } \\
\text { Architecture }\end{array}$ & $\begin{array}{c}\text { Journal of } \\
\text { Theoretical and } \\
\text { Applied Electronic } \\
\text { Commerce } \\
\text { Research }\end{array}$ & 2016 \\
\hline $\begin{array}{c}\text { Damian } \\
\text { Fijalkowski \& } \\
\text { Radoslaw Zatoka }\end{array}$ & $\begin{array}{l}\text { An Architecture of } \\
\text { a Web } \\
\text { recommender } \\
\text { system using social } \\
\text { network user } \\
\text { profiles for e- } \\
\text { commerce }\end{array}$ & $\begin{array}{l}\text { Proceedings of the } \\
\text { Federated } \\
\text { Conference on } \\
\text { Computer Science } \\
\text { and Information } \\
\text { Systems }\end{array}$ & 2011 \\
\hline $\begin{array}{c}\text { Chen Lyu, Lefei Li } \\
\text { \& Tao Pan }\end{array}$ & $\begin{array}{c}\text { A Smart B2C e- } \\
\text { Commerce System } \\
\text { Based on ACP } \\
\text { Approach }\end{array}$ & $\begin{array}{l}\text { Cyber-Physical- } \\
\text { Social Systems }\end{array}$ & 2014 \\
\hline
\end{tabular}


Tabla 4: Lista de papers. (Fuente: Elaboración propia)

De los artículos encontrados, se ha definido 3 grandes áreas de investigación: Modelos, Arquitectura e Implementación. Para tal fin, se describirá el aporte de 2 papers por área de investigación.

\section{Revisión de la literatura}

El impacto del comercio electrónico en la estructura organizacional, con lleva que las empresas se vean obligadas a implementar cambios para aprovechar al máximo las oportunidades que les brinda el comercio electrónico.

Giovanny Tarazona Bermúdez, Víctor Hugo Medina García, Lylliana Giraldo definen un modelo de evaluación de aspectos críticos al momento de implementar una solución de comercio electrónico, con el objetivo de disminuir el fracaso que implican inversiones no planificadas en tecnologías,

Ajmal y Yasin proponen un modelo de adopción de eCommerce en Pymes, en la cual nos ayuda a definir cuáles son los factores que afectan el éxito de eCommerce en Pymes, estás se dividen en internos y externos.

Se puede concluir, que tanto los artículos de Giovanny Tarazona Bermúdez, Víctor Hugo Medina García, Lylliana Giraldo y Ajmal \& Yasin nos muestran un proceso detallado de cuáles son los pasos a seguir para la implementación de una solución eCommerce, sino también definir parámetros para culminar con el conocimiento de la empresa, y de esa manera evaluarla.

\section{Modelo de Implementación de soluciones eCommerce}

\section{Modelo de Implementación de soluciones de comercio electrónico para pymes de Giovanny Tarazona Bermúdez, Víctor Hugo Medina García, Lylliana Giraldo}

Giovanny Tarazona Bermúdez, Víctor Hugo Medina García, Lylliana Giraldo identificó que las empresas se ven obligadas a implementar cambios en su organización para aprovechar las oportunidades que les brinda el comercio electrónico.; de lo contrario, se verán forzados a la quiebra. Por lo tanto, proponen un modelo de organización para la planeación estratégica del eCommerce: Modelo PESCE, el cual facilita si la empresa es apta o no para implementar una solución de comercio electrónico coherente con su plan de negocio. 
Este modelo de organización viabiliza una implementación favorable para la empresa y así garantizar el éxito de la implementación de soluciones de comercio electrónico. El procedimiento de evaluaciones de condiciones se desarrolla en tres etapas que se detallan en la Ilustración 3.
$\checkmark$ Formulación
$\checkmark$ Organización
$\checkmark$ Implementación 


\section{Modelo PESCE}

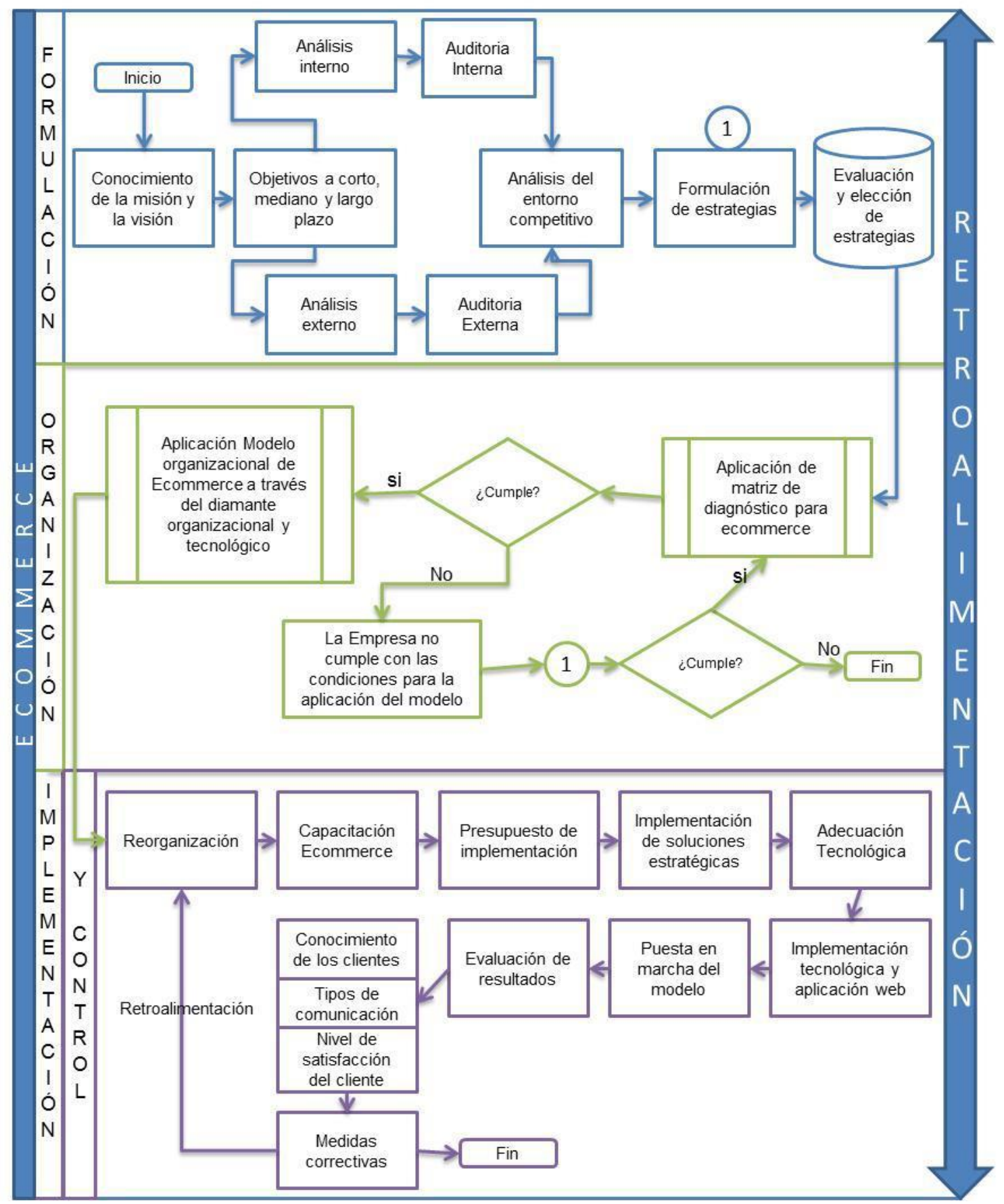

Ilustración 7: Modelo PESCE - Planeación Estratégica del eCommerce

El primer paso es la Formulación, esto inicia con el conocimiento de la empresa a través de la misión y la visión, seguido por la formulación de objetivos a corto mediano y largo plazo se propone un análisis interno y externo de la empresa.

En la siguiente etapa que es la Organización, luego de los resultados obtenidos en la fase de formulación los datos son empleados para la aplicación de la matriz de diagnóstico, esta matriz establece si la empresa tiene o no condiciones para la implementación de una solución de comercio electrónico. 
En la última etapa que es la Implementación y Control, es la adopción de las estrategias que posibilitan la implementación de plataformas de comercio electrónico en cualquier tipo de organización; en ella se deben tener en cuenta criterios como: Capacitación, Presupuesto de implementación, Implementación de soluciones de comercio electrónico y Adecuación tecnológica al modelo de negocio.

Finalmente, para validar este modelo se realizaron una encuesta para detectar la apropiación tecnológica en el sector textil de Bogotá, Colombia. Asimismo, se realizó un formulario virtual a una muestra de 62 empresas pertenecientes al sector textil. Con los datos obtenidos, se procesaron que se encontró que del total de empresas el $8 \%$ está en el rango de implementar una solución de comercio electrónico sin ningún problema. El $71 \%$ tiene condiciones para la implementación y el $21 \%$ no cuenta con las condiciones para llevarla a cabo.

\section{Modelos de adopción de eCommerce para pymes de Ajmal \& Yasin}

Ajmal \& Yasin identifican que existen factores que perjudican el éxito del eCommerce en Pymes. Los factores que afectan el éxito de eCommerce en Pymes se dividen en internos y externos. Por lo tanto, proponen un modelo para la adopción de eCommerce en Pymes para evaluar el éxito de eCommerce.

Los autores en el modelo presentan un grupo de factores son divididos en Factores Independientes que son: Organizacional, Administración, Tecnológico, Individual, Implementación, Confianza y Ambiental. Cada factor independiente consiste de factores variables o dependientes (contribuyentes), como se puede apreciar en la Ilustración 4.

\begin{tabular}{|c|c|c|c|c|c|c|}
\hline Organizational & Management & Technological & Individual & Implementación & Environmental & Trust \\
\hline $\begin{array}{l}\text { (01) Enterprise } \\
\text { resources } \\
(02) \text { Firm size }\end{array}$ & $\begin{array}{l}\text { M1) Resources } \\
\text { commitment } \\
\text { (International } \\
\text { web use) } \\
\text { (M2) good } \\
\text { Project mana- } \\
\text { gement team }\end{array}$ & $\begin{array}{l}\text { (T1) Technical } \\
\text { Infraestructura } \\
\text { (T2) Business } \\
\text { Infrastructure } \\
\text { (T3) Commu- } \\
\text { nication }\end{array}$ & $\begin{array}{l}\text { (11) IT Skill \& } \\
\text { Expertise } \\
\text { (12) Education } \\
\text { \& awareness }\end{array}$ & $\begin{array}{l}\text { (IM1) Product } \\
\text { \& services } \\
\text { (IM3) Usefulness } \\
\text { (IM4) Ease of use } \\
\text { (IM5) Customer } \\
\text { Service / Client } \\
\text { interface }\end{array}$ & $\begin{array}{l}\text { (E1) Goverment } \\
\text { Support } \\
\text { (E2) Industry } \\
\text { (E3) National } \\
\text { (E4) Competitive }\end{array}$ & $\begin{array}{l}\text { (T1) Secunity } \\
\text { (T2) Privacy } \\
\text { (T3) Loyalty }\end{array}$ \\
\hline
\end{tabular}

Ilustración 8: Factores de éxito para la adopción de eCommerce [Ajmal \& Yasin] 
En el artículo se señalan que los Factores Organizacionales, conocidos como factores internos de la empresa, son tamaño, calidad de SI, soporte de gestión y recursos de la empresa.

En el estudio los autores indican que los Factores de Administración, la capacidad de innovación del CEO y su conocimiento de TI, tienen un impacto positivo en la adopción de eCommerce.

Según Ajmal \& Yasin, los Factores Tecnológicos, involucran varias tecnologías de Internet, tecnologías de redes y sistemas de apoyo como sistemas para toma de decisiones y aplicaciones distribuidas, etc. que amplíen o mejoren las aplicaciones de eCommerce.

Los autores explican que los Factores Individuales están conformados por los clientes, empleados y gerentes, ya que ellos son los principales afectados por la adopción de eCommerce.

Para los Factores de Implementación se debe considerar un buen funcionamiento del sitio web, los clientes deben poder registrarse y ordenar sus productos y servicios, también pagar con cualquier medio de pago desde el sitio web.

Para los Factores Ambientales se considera la presión competitiva, pues mientras más empresas usan inter- net para dar servicios a los clientes, esto impactará en la competitividad y acelerará la adopción de eCommerce por las pymes. El apoyo gubernamental es necesario pues puede simplificar normas y regulaciones. Las diferencias culturales y la infraestructura tecnológica pueden variar entre países y esto puede afectar la habilidad para usar y adoptar eCommerce.

Como Factores de Confianza se consideran la percepción del cliente respecto a los asuntos de privacidad y seguridad. También la confianza del cliente en el uso del sitio, sus productos y servicios. La lealtad es una necesidad económica y competitiva, ya que conseguir nuevos clientes resulta muy caro.

Finalmente, los autores concluyen que en los últimos años hay un crecimiento sobre la adopción de diferentes tecnologías, entre ellas eCommerce. El gran problema de la adopción de eCommerce por las Pymes de los países en crecimiento, se debe al impacto que tienen en las operaciones de negocios de la organización; como la reducción de costos de sus procesos, apertura a nuevos mercados, mejora en la atención y la facilidad para captar nuevos clientes. Además, el modelo propuesto incluye una cantidad importante de variables, dado que corresponde a un modelo teórico sobre el que no se han realizado pruebas y está pendiente de validación. 


\section{Arquitectura de eCommerce.}

\section{Arquitectura de referencia eCommerce orientada al servicio de Fabian Aulkemeier, Milan Schramm, Maria Eugenia Iacob y Jos van Hillegersberg.}

Fabian Aulkemeier, Milan Schramm, Maria Eugenia Iacob y Jos van Hillegersberg identifican que el comercio electrónico está volviéndose más y más importante en la rutina de las personas al comprar, es necesario integrar las ventas tradicionales con el internet para ampliar el mercado y aumentar considerablemente los ingresos de una empresa. Por tal razón, los modelos de referencia existentes en el campo del eCommerce sólo se enfocan en los procesos de negocio, pero ignoran la arquitectura de la empresa, por lo tanto, en su artículo proponen un modelo de referencia para arquitectura de eCommerce que esté orientada al servicio, revisando las actuales tendencias y las mejores prácticas en el comercio electrónico. La Arquitectura que proponen está basada en cuatro modelos de referencia, el modelo de Becker para el retail, el cual describe once factores que están dentro de los tres grandes grupos de adquisiciones, almacenamiento y distribución. El modelo Frank's E-MEMO, el cual contiene una biblioteca de 85 modelos de procesos de negocio divididos en nueve funciones. La investigación de Burt \& Sparks que hace referencia al impacto del eCommerce en el proceso de Retail, la cual describe actividades, propiedad, costos y eficiencia del eCommerce comparado con el Retail tradicional. Por último, el modelo de Gunasekaran, que describe 8 funciones del Negocio involucradas en el comercio electrónico. Después de describir los modelos, se entrega una propuesta de arquitectura de referencia eCommerce extendida y muestra tres capas, así como su relación dentro y a través de ellas (véase la figura). Las capas son: el proceso de retail en línea -definen funciones de negocio de la solución eCommerce, el servicio de aplicación y componentes -definen artefactos de software utilizados por los usuarios para alcanzar sus objetivos, y el servicio de tecnología y componentes - definen infraestructuras y servicios de tecnología activa. 


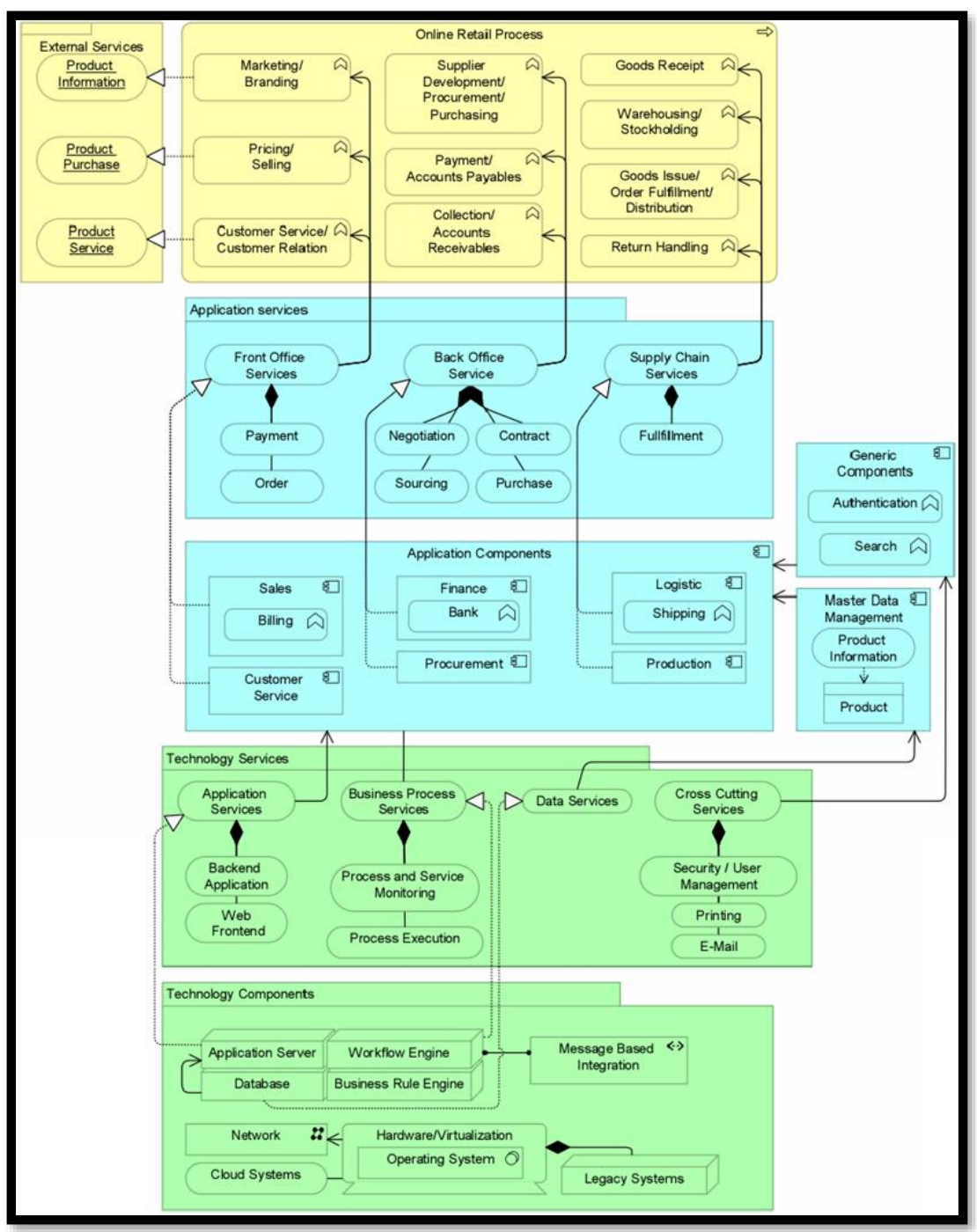

Ilustración 9: Modelo de Arquitectura [Fabian Aulkemeier, Milan Schramm, Maria Eugenia Iacob y Jos van Hillegersberg]

Para validar el modelo de arquitectura extendida se llevó a cabo un caso de estudio, el cual tenía como meta introducir la arquitectura dentro de un caso de la realidad para poder identificar posibles brechas en el modelo. Se definió cuatro procesos clave del Retail y se explicó el cómo la arquitectura de aplicaciones pudo soportar cada uno de los procesos, a través de funcionalidades, o módulos del eCommerce. Se tuvo como resultado que cada componente de aplicaciones de la arquitectura podría soportar a los procesos del caso de estudio, demostrando la viabilidad del modelo.

\section{Arquitectura eCommerce de un sistema B2C basado en ACP de Chen Lyu, Lefei Li, y Tao Pan.}

Chen Lyu, Lefei Li, y Tao Pan explican que el comercio electrónico se ha vuelto una parte esencial de la vida en China. Las ventas anuales a través del eCommerce han tenido un 
aumento del 40\% en el 2013 alcanzando 0.3 trillones de dólares americanos. Identifican que, para aumentar las ganancias de una empresa, los proveedores de eCommerce están teniendo interés en el desarrollo de sistemas de recomendación, los cuales pueden estimular a los usuarios a ver más productos, y posiblemente comprarlos. Por lo tanto, con el fin de proponer un mejor servicio B2C (Business to Comerce), proponen un framework con 6 componentes tal como se muestra:

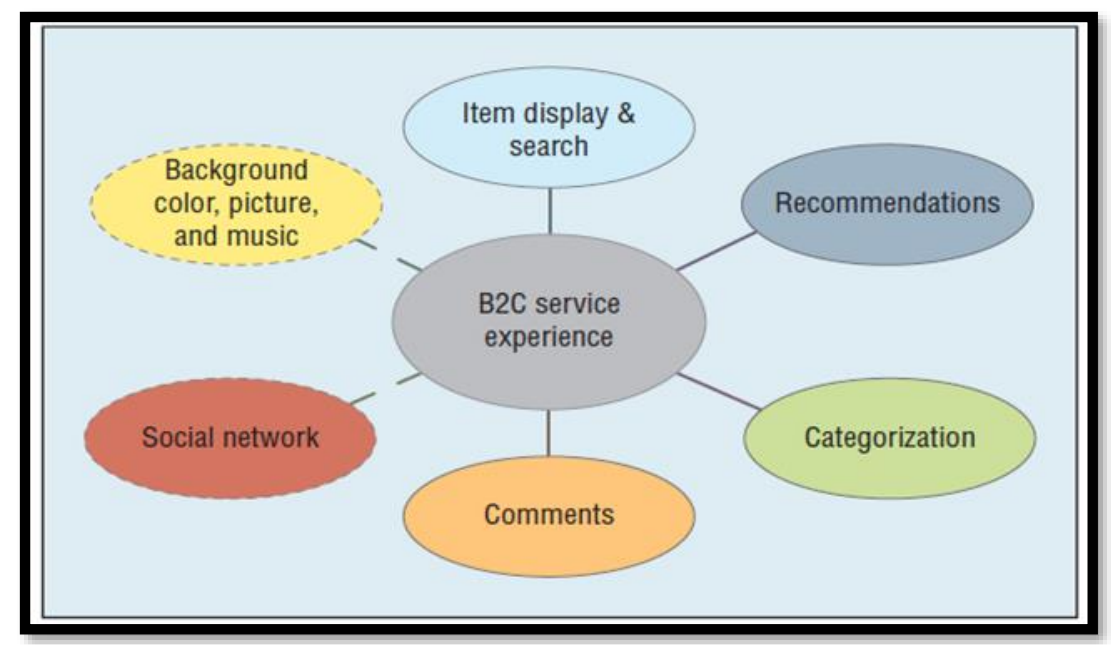

Ilustración 10: Framework de la experiencia de servicio de negocio a consumidor (B2C). [Fabian Aulkemeier, Milan Schramm, Maria Eugenia Iacob y Jos van Hillegersberg]

Los 6 componentes que se definieron sirven como base para el desarrollo del sistema ARS, un pequeño sistema eCommerce construido con 3 acciones: diseño de base de datos, interfaz de usuario y diseño de experimentos. El sistema funciona de la siguiente forma: el usuario se registra y comparte información sobre sus preferencias en sus acciones (Páginas web visitadas y compras), luego, estas acciones sirven como input para el sistema artificial, el cual busca recomendar productos relacionados a sus acciones con el fin de cerrar una venta. Para soportar el modelo presentado, se definió la arquitectura de la siguiente forma: 


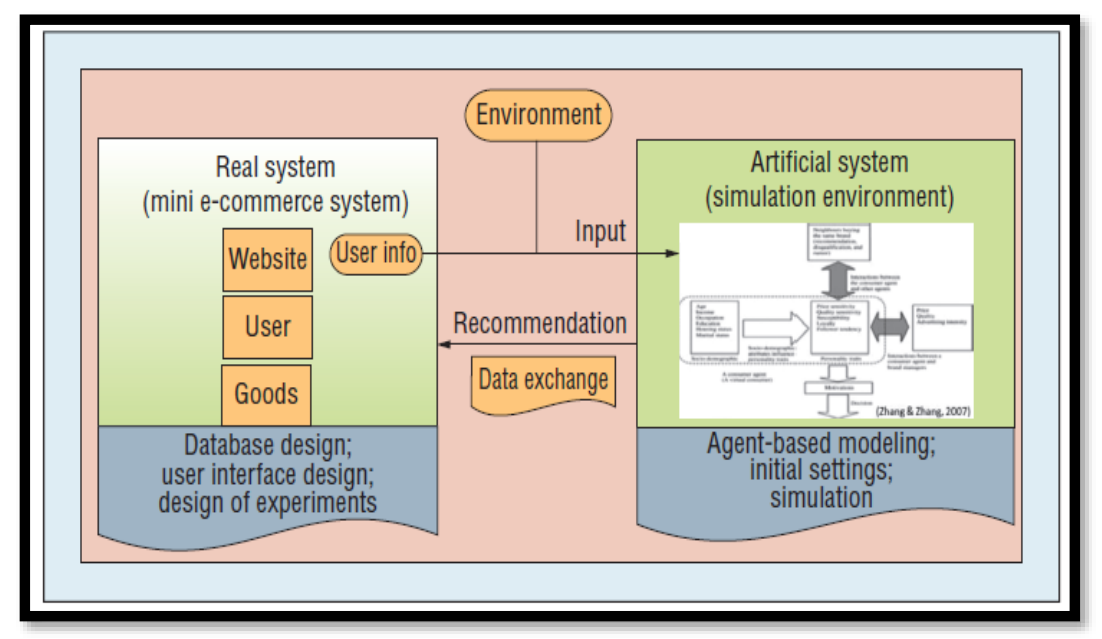

Ilustración 11: Sistema de arquitectura del sistema de recomendación basado en los sistemas artificiales, experimentos computacionales y ejecución paralela (ACP). [Fabian Aulkemeier, Milan Schramm, Maria Eugenia Iacob y Jos van Hillegersberg]

Los autores realizaron la validación del modelo y la arquitectura presentada como un experimento de laboratorio, en el cual se necesitó la ayuda de 22 estudiantes. Una vez que los estudiantes utilizaban el sitio web B2C, el sistema ARS captaba sus preferencias y presentaba una serie de productos recomendados, se encontró que existe una diferencia significativa entre las opiniones de los usuarios sobre los productos recomendados y los productos presentados por el enfoque de más vendidos. En pocas palabras, el sistema ARS recomienda una cantidad mayor de productos que los sistemas tradicionales que únicamente presentan a los productos más vendidos.

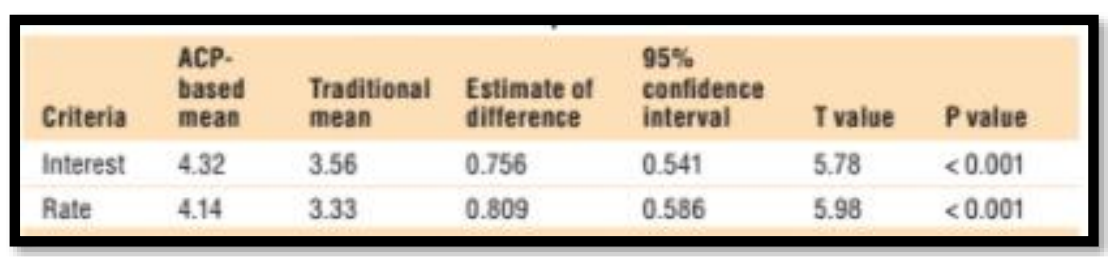

Ilustración 12: Resultado del experimento de laboratorio. [Fabian Aulkemeier, Milan Schramm, Maria Eugenia Iacob y Jos van Hillegersberg]

\section{Implementación de eCommerce}

\section{Modelado e Implementación de la Plataforma de Comercio Electrónico Orientada a Objetos de Yuan-Jin Tseng, Chin-Chih Chang y Judy Tseng.}

Yuan-Jin Tseng, Chin-Chih Chang y Judy Tseng indican que la tecnología de objetos ha sido reconocida como un modelo para la construcción de un sitio web de eCommerce. Una 
plataforma de eCommerce en Internet, se ha convertido en esencial para cualquier empresa, a fin de satisfacer a los usuarios y compartir el mercado online, estrategias de marketing flexible y diversificar los métodos de promoción son importantes para un exitoso sitio de eCommerce. Los autores proponen un método que incorpora la herencia y el polimorfismo en el proceso de diseño e implementación de eCommerce. Este método no sólo facilita el diseño y la implementación de un sitio Web de eCommerce, sino también hacer la gestión de mantenimiento y ampliación de un sitio Web eCommerce más eficiente.

La propuesta del método consta de cuatros fases: Análisis de requisitos del sistema, Diseño del Modelo Conceptual, Diseño del Modelo de Navegación, Diseño de la interfaz del Sistema como se muestra en la Ilustración 9.

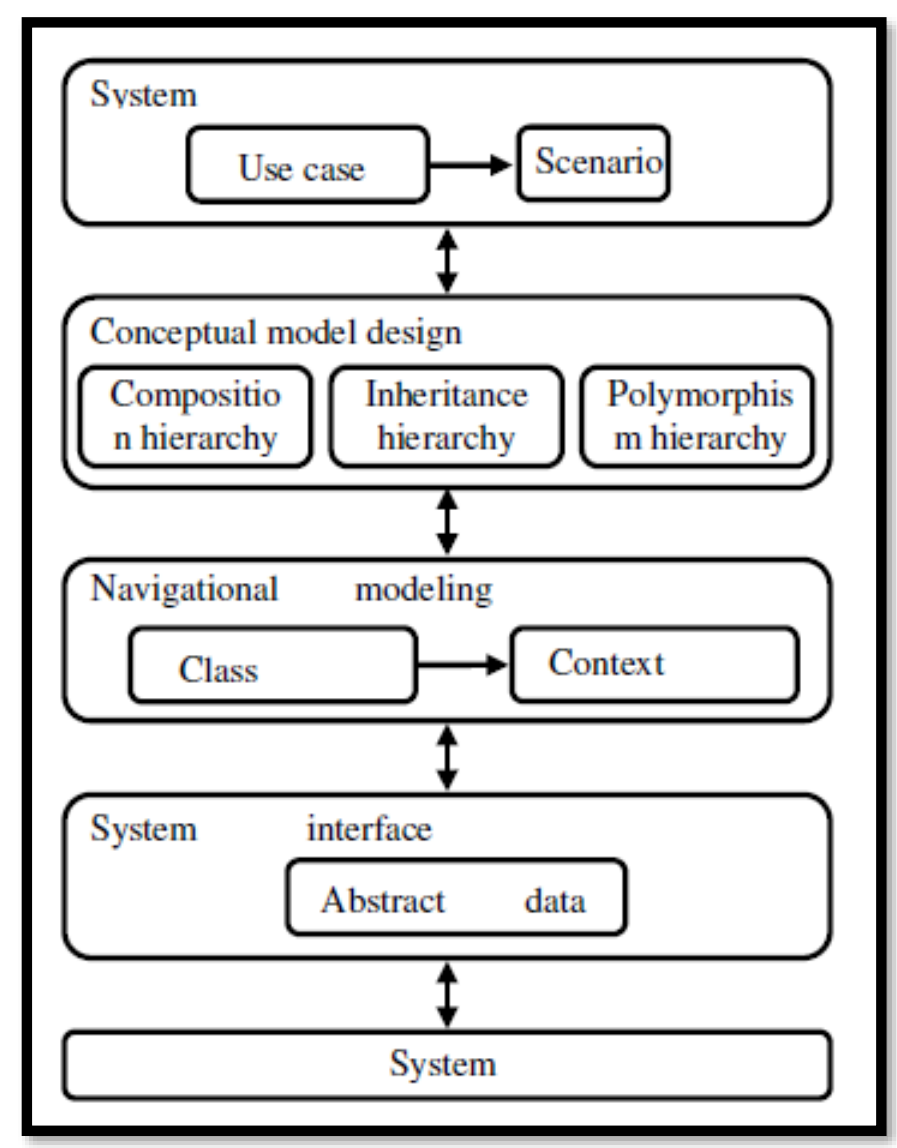

\section{Ilustración 13: Desarrollo de procesos utilizando OOECDM [Yuan-Jin Tseng, Chin-Chih Chang y Judy Tseng]}

La fase de análisis de requisitos del sistema está orientado al usuario. Los objetivos del usuario son analizados por los casos de uso, y luego los escenarios modelados por un diagrama secuencial.

La fase de diseño del modelo conceptual se analiza un sitio Web desde diferentes perspectivas. La UML es utilizado para definir las clases de sistema y las relaciones entre las 
clases. En esta fase, los casos de uso y los escenarios obtenidos en la fase de análisis de requisitos del sistema son modelados como objetos.

En la fase de diseño del modelo de navegación, un modelo de clase de navegación se utiliza para definir una vista sobre el modelo conceptual. Se centra en cómo presentar la información y los servicios prestados por el modelo conceptual. Cuatro requisitos de un sistema de información basado en la Web son considerados en esta fase: navegación, computación, comunicación y cooperación.

En la fase de Diseño de la Interfaz del Sistemas, la interfaz de usuario de cada página Web está diseñada y las relaciones de la transmisión de mensajes a través de estas páginas Web están definidos. En consecuencia, los elementos y datos presentados en cada página Web están planificadas.

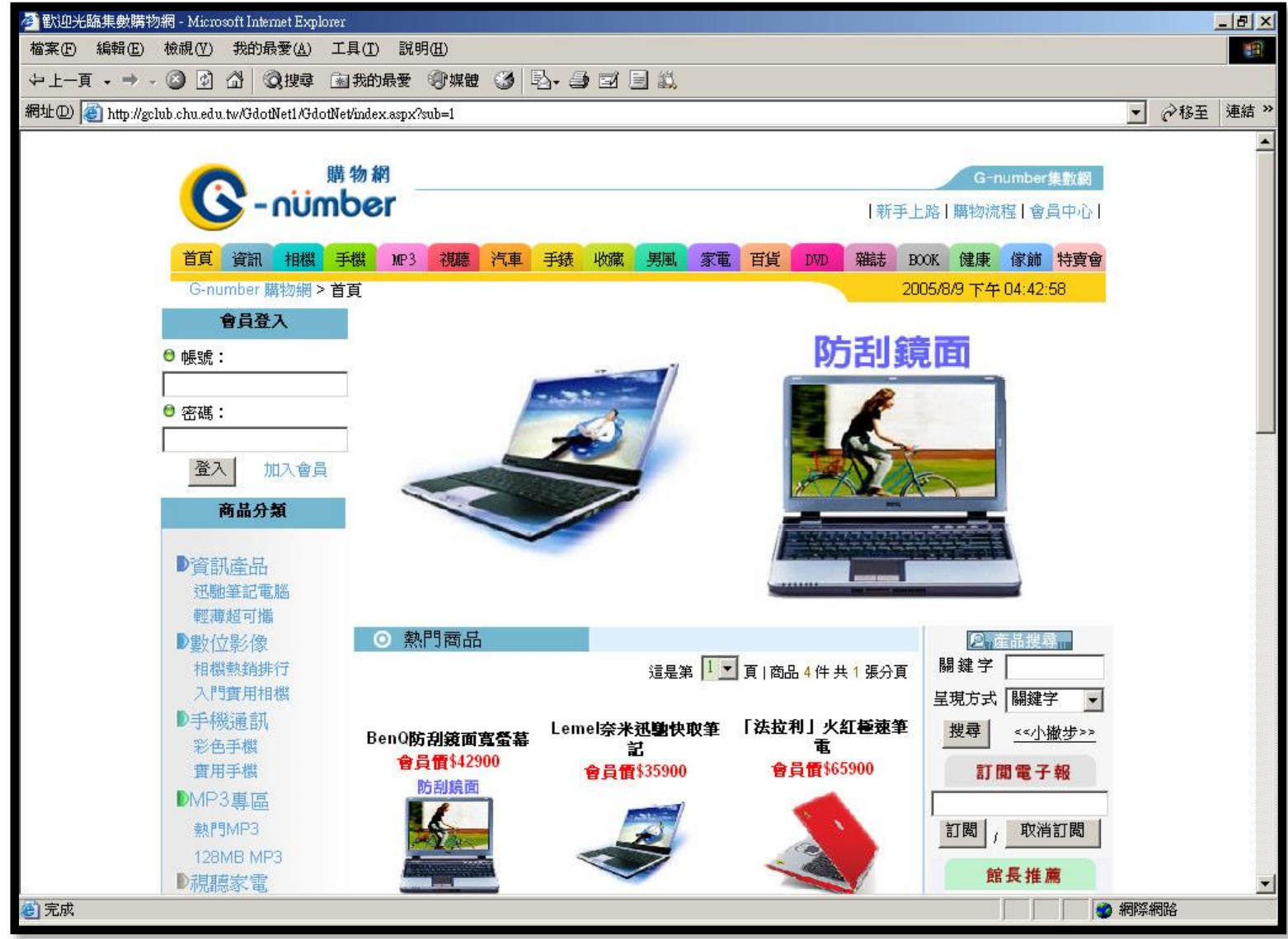

Ilustración 14: Objeto de sistema de producto [Yuan-Jin Tseng, Chin-Chih Chang y Judy Tseng] 


\begin{tabular}{||c|c|c|}
\hline Method Item & Function X & Function Y \\
\hline $\begin{array}{c}\text { Procedural Design } \\
\text { Method (PO } \\
\text { Web) }\end{array}$ & Designer A & Designer B \\
\hline Design Time & 36 Hours & 10 Hours \\
\hline Coding Time & 72 Hours & 22 Hours \\
\hline $\begin{array}{c}\text { OOECM(OO } \\
\text { Web) }\end{array}$ & Designer B & Designer A \\
\hline Design Time & 42 Hours & 16 Hours \\
\hline Coding Time & 64 Hours & 12 Hours \\
\hline
\end{tabular}

Ilustración 15: Resultados experimentales [Yuan-Jin Tseng, Chin-Chih Chang y Judy Tseng]

Los resultados muestran que el método de diseño orientado a objetos tomó menos tiempo de codificación que método de diseño procesal, aunque tardó más tiempo de diseño. Por lo tanto, podemos deducir que el OOECDM puede hacer funcionar la expansión más rápida y fácil. Esto permitirá que un sitio de comercio electrónico es capaz de adaptarse a los rápidos cambios del marketing. 


\section{Capítulo 4. Marco Teórico}

El presente capitulo detalla los conocimientos o conceptos básicos necesarios para un mejor entendimiento del desarrollo del proyecto. Primero, se empieza con la definición de eCommerce, sus tipos o modelos y ventajas con la finalidad de comprender las variantes de eCommerce que existen dentro de las empresas y de lo importante que es contar con una de ellas. Posteriormente, se describe la clasificación de las Pymes, la cual es necesaria para definir parámetros de evaluación para la Pyme en la cual se vaya a implementar la solución. Luego, se define el sector Retail. Finalmente, se presentan los casos de éxito de Pymes que implementaron eCommerce, los cuales se entienden como un input para demostrar la viabilidad del comercio electrónico en Pymes.

\section{E-commerce}

Se realizó una investigación teniendo como referencia 10 artículos, que explican la definición del comercio electrónico, permitiendo así, tener un concepto final del término.

\section{Comercio electrónico Según Forrester:}

El término eCommerce hace alusión a aquellas actividades en que las empresas o consumidores utilizan el Internet para identificar suministros, seleccionar los productos y servicios, realizar las transacciones financieras y obtener servicios. En cuanto a la entrega, esta puede ser en línea o fuera de la red.

\section{Comercio electrónico Según Tarazona G., Gómez M. y Montenegro, C. (2012):}

Comercio electrónico: Abarca las cuestiones suscitadas por toda relación de índole comercial, sea o no contractual, estructurada a partir de la utilización de uno o más mensajes de datos o de cualquier otro medio similar. Las relaciones de índole comercial comprenden, sin limitarse a ellas, las siguientes operaciones: toda operación comercial de suministro o intercambio de bienes o servicios; todo acuerdo de distribución; toda operación de representación o mandato comercial; todo tipo de operaciones financieras, bursátiles y de seguros; de construcción de obras; de consultoría; de ingeniería; de concesión de licencias; todo acuerdo de concesión o explotación de un servicio público; de empresa conjunta y otras formas de cooperación 
industrial o comercial; de transporte de mercancías o de pasajeros por vía aérea, marítima y férrea, o por carretera.

\section{Comercio electrónico Según Turban E., King D., Mckay J., Marshall P. \& Lee J. (2008):}

Definen al eCommerce como el proceso de compra, venta, transferencia o intercambio de productos, servicios y/o información por medio de redes de computadoras incluyendo Internet. Además, distinguen entre eCommerce con Internet y sin Internet. El eCommerce sin Internet incluye, por ejemplo, la compra y pago de servicios y productos con tarjetas inteligentes a través de máquinas de ventas y/o transacciones realizadas vía redes, como redes de área local (LAN), usando intranet o aún una máquina computarizada.

\section{Comercio electrónico Según Chaffey, D., Ellis-Chadwic, F., Mayer, R. \& Jhonston, K. (2009):}

El comercio electrónico (comercio electrónico) se suele pensar simplemente en referirse a la compra y venta usando el Internet; La gente piensa de inmediato en las compras minoristas de las empresas como Amazon. Sin embargo, el comercio electrónico implica mucho más que Transacciones entre organizaciones y clientes. El comercio electrónico debe considerarse como todas las transacciones realizadas electrónicamente entre una organización y cualquier tercero que trata con ella. Con esta definición, las transacciones no financieras tales como las solicitudes de información también se consideraría parte del comercio electrónico.

Comercio electrónico Según Vaithianathan, S. (2010):

El comercio electrónico puede definirse como "el uso de Internet Y otras tecnologías de redes para realizar transacciones comerciales. No sólo implica la venta y compra en línea, sino que también implica una actividad de la cadena de valor de la empresa como la promoción de productos / servicios Web, integrando la facturación y el pago de los clientes, transacciones seguras y manejo de consultas de los clientes en línea.

\section{Comercio electrónico Según Rincón Cárdenas, Erick:}

Cuando se trata de comercio electrónico, estamos frente a una nueva forma de comercio que tiene unas características muy especiales, que lo diferencian del comercio tradicional.

Las diferencias radican esencialmente en los siguientes aspectos:

- Las operaciones se realizan por vía electrónica o digital, a través de un mensaje de datos. 
- El lugar donde se encuentran las partes es, en principio, irrelevante.

- No quedan rastros del acuerdo o del pago en papel.

- El bien que se importa no pasa por ninguna aduana ni inspección.

- Se disminuyen los intermediarios

- Cada empresa, por pequeña que sea, puede tener presencia mundial, pues su acceso y presencia en los diferentes mercados es ilimitada.

Comercio electrónico es el uso de las tecnologías computacionales y de telecomunicaciones que se realiza entre empresas o bien entre vendedores y compradores, para apoyar el comercio de bienes y servicios.

Comercio electrónico Según Romero, M. y Mauricio, D. (2012):

eCommerce es el proceso de compra, venta, transferencia o intercambio de productos, servicios y/o información por medio de redes de computadoras incluyendo Internet.

\section{Comercio electrónico Según Gartner (2016):}

Define a eCommerce como la compra y venta de bienes y servicios en internet a través de dispositivos electrónicos con el propósito de realizar una transacción.

\section{Comercio electrónico Según Kendall, J. D., Tung, L.L., Chua, K.H. (2001):}

El Comercio Electrónico (EC) es la combinación de los procesos de negocio y las tecnologías de internet, reflejado en las interacciones entre los clientes y proveedores.

\section{Comercio electrónico Según TutorialsPoint:}

Comercio electrónico es un modelo de negocio moderno que se ocupa de la necesidad de las organizaciones empresariales, proveedores y clientes para reducir los costos y mejorar la calidad de los bienes y servicios al tiempo que aumenta la velocidad de entrega.

\section{Conclusión:}

A partir de todas las definiciones previamente descritas, se concluye que el eCommerce es un el modelo de negocio que involucra los procesos de compra, venta, transferencia o intercambio de productos e incluye todo tipo de operaciones que se den por medio de dispositivos electrónicos.

\section{Modelos de Ecommerce}

A continuación, se describirá los tipos de eCommerce desde las definiciones de Forrester:

\section{- B2B (Business to Business)}

En este tipo de modelo de Ecommerce implica interacciones y/o transacciones entre una empresa y sus socios comerciales tales como proveedores, colaboradores, filiales y grandes clientes institucionales. 


\section{- B2C (Business to Customer)}

Este tipo de modelo realiza ventas directas al cliente a través de un catálogo de ventas de una página web.

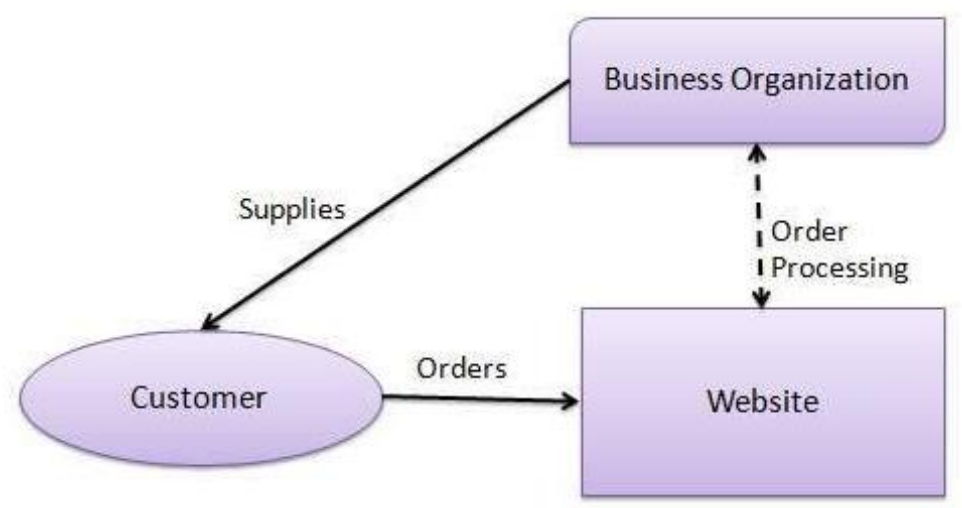

Ilustración 16: Proceso B2C. (Fuente: TutorialPoint, 2016)

\section{- C2C (Customer to Customer)}

Este tipo de modelo de Ecommerce apoya a los consumidores a vender sus activos tales como casas, automóviles, motocicletas, alquiler de cuartos, etc. a través de una publicación en el sitio web. Un ejemplo de este modelo es OLX, Mercado Libre entre otros más.

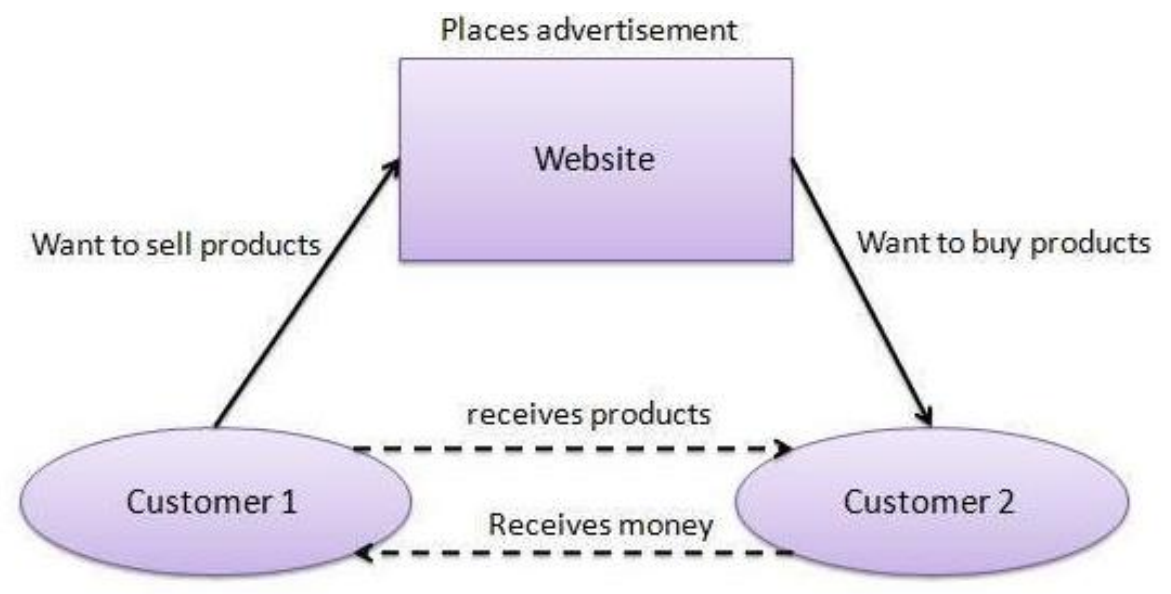

Ilustración 17: Proceso C2C. (Fuente: TutorialPoint, 2016) 


\section{- C2B (Customer to Business)}

Este modelo hace referencia cuando el consumidor recurre a una determinada página web, la cual muestra varias organizaciones para un determinado servicio.

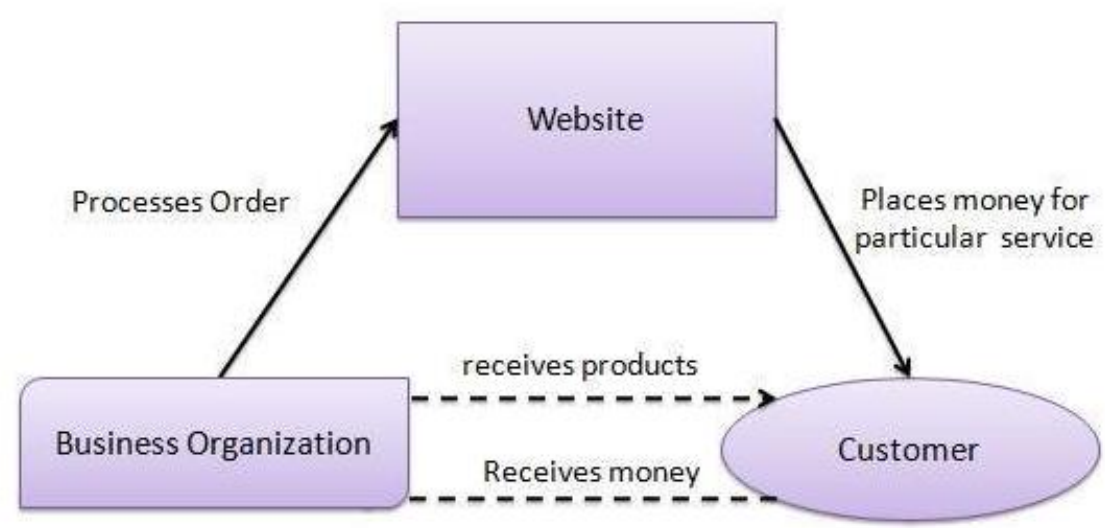

Ilustración 18: Proceso C2B. (Fuente: TutorialPoint, 2016)

\section{- B2G (Business to Goverment)}

Este modelo es una variante del modelo B2B. Las páginas de web de este tipo de modelo son usadas por el Gobierno para realizar comercio e intercambio de información con las diferentes organizaciones.

\section{- G2B (Goverment to Business)}

Modelo en el que el Gobierno usa un sitio web bajo el modelo B2G con la finalidad de acercarse a las organizaciones empresariales. Estos sitios son compatibles con las subastas, concursos, etc.

\section{- G2C (Goverment to Customer)}

Modelo en que el Gobierno usa una página web de este tipo para acercase a los ciudadanos en general. Unos ejemplos de este modelo son aquellos que cuentan con los servicios de registros de certificados de actas de nacimientos, matrimonios, defunciones, etc.

\section{- B2E (Business to Employee)}

Este modelo se encarga de la disciplina aplicada a servicios. 


\section{Ventajas del Ecommerce}

- Expandir la base de clientes al entrar a un mercado más amplio.

- Extender el horario de venta a 24 horas al día, los 7 días a la semana, 365 días al año.

- Mayor comodidad para el comprador y vendedor debido que una transacción puede realizarse desde el hogar.

- Reducción de los costos de producción, capital, administración entre otros más.

- Mejorar la calidad y eficiencia en el servicio de la atención al cliente.

- Disminución de los costes en la comunicación debida que se usara el internet como canal de comunicación (UPF Barcelona School of Management, 2015).

\section{Clasificación de Pymes}

Se realizó una investigación de 3 fuentes peruanas, las cuales clasifican a las Pymes en rangos de ventas y número de trabajadores:

\section{Clasificación de Pymes según SUNAT:}

- MICROEMPRESA:

Número de trabajadores: de uno hasta diez trabajadores.

Ventas anuales: Hasta 150 UIT (1 UIT= S/.4050), S/. 607,500.

\section{- PEQUEÑA EMPRESA:}

Número de trabajadores: de uno hasta 100 trabajadores.

Ventas anuales: Hasta 1700 UIT (S/. 6,885,000)

\section{Clasificación de Pymes según Jorge Arbulú:}

La legislación peruana define a la PYME como: la unidad económica constituida por una persona natural o jurídica, bajo cualquier forma de organización o gestión empresarial contemplada en la legislación vigente, que tiene como objeto desarrollar actividades de extracción, transformación, producción, comercialización de bienes o prestación de servicios, debiendo contar con las siguientes características:

- MICROEMPRESA:

Número total de trabajadores entre uno y 10. 
Niveles de venta anuales no mayores a 150 UIT.

\section{- PEQUEÑA EMPRESA:}

Número total de trabajadores: hasta un máximo de 50.

Niveles de ventas anuales: entre 51 y 850 UIT.

EL 99.5\% de empresas en el Perú son PYME (formales e informales).

El $97.9 \%$ son microempresas (formales e informales).

\section{Clasificación de Pymes según INEI:}

\section{- MICROEMPRESA:}

De 1 a 10 trabajadores.

Hasta \$125,000 en ventas anuales.

Hasta 25,000 Activos Fijos.

\section{- PEQUEÑA EMPRESA:}

De 11 a 50 trabajadores.

De $\$ 125,000$ hasta $\$ 1,500,000$ dólares en ventas anuales.

Hasta 300,000 Activos Fijos

\section{- MEDIANA EMPRESA:}

De 51 a 200 trabajadores.

De $\$ 1,500,000$ hasta $\$ 20,000,000$ en ventas anuales.

Hasta 4,000,000 de activos fijos

\section{Clasificación final de PYME:}

Las PYMES en el mercado peruano:

- Capacidad máxima de 100 trabajadores.

- Ventas anuales hasta 1700 UIT. 


\section{Definición del Sector Retail}

Podemos definir al sector Retail como el sector en el que operan tanto grandes y pequeñas empresas que dirigen un producto hacia un cliente final. Es el sector que engloba a las empresas mayoristas y minoristas, destinadas a la venta de productos.

\section{Casos de éxito de Pymes que implementaron eCommerce.}

El eCommerce day es concurso que premia a las mejores Pymes en implantar el comercio electrónico del Perú (Cámara de Comercio de Lima, 2016). Para la presente investigación se tomó como referencia a los nominados y ganadores del concurso en el año 2015 y 2016, con el objetivo de investigar la metodología usada por cada empresa y la herramienta que soporta su página web.

El eCommerce day es un evento patrocinado por la cámara de comercio de lima y el instituto latinoamericano de comercio electrónico.

\section{Florerías Unidas}

Florerías Unidas apostó por un site creativo y eficiente que sea la base de su ecosistema digital, que logre la conexión entre el comprador y la marca, pero sobre todo que proporcione información sobre los productos del catálogo online. Este mismo fue optimizado para todos los buscadores aplicando técnicas especiales de SEO de la mano de planners de medios especializados del lado de la agencia (La república, 2016).

Según detalla la agencia EXEPERÚ.COM, uno de los retos fue aumentar el tráfico de la web, y esto se logró aplicando estrategias que involucren otras plataformas en las que la marca también tiene presencia como: Facebook, que actualmente es deriva al público a la web a través de una Brand Voice renovada y anuncios pagados que refuerzan el concepto propuesto. Por último, la marca ganó en la categoría porque logró aumentar las ventas en el canal web, que creció en un considerable 90\% en los primeros seis meses del 2016 con respecto al 2015. Otro aumento significativo fue el de los pedidos, que aumentaron en un $70 \%$ con respecto al 2015.

\section{Qempo}

Anson Tou (25), egresado de la carrera de negocios internacionales de la Universidad Internacional de Florida y estudiante de Emprendimiento e Innovación en Stanford, es el 
CEO y fundador de Qempo, una empresa que con solo 4 miembros realizó ventas el 2013 por un valor de US\$ 400 mil.

"Lo que hacemos en Qempo es recibir de nuestros clientes el enlace de un producto de distintas tiendas en Estados Unidos (Amazon, eBay, por ejemplo). Analizamos el producto, le enviamos la cotización y previo pago nos encargamos de llevarlo hasta la puerta de su casa a Perú”, explicó Anson Tou a El Comercio.

En los últimos tres años, Qempo se ha concentrado en mejorar su servicio reduciendo el tiempo de entrega del producto y facilitando los sistemas de pago: actualmente sus clientes pueden pagar vía Internet con Visa, PayPal y también en efectivo.

La start-up recibe 100 pedidos mensuales y el ticket promedio de compra es de 320 dólares. Entre los productos más solicitados por los usuarios de Qempo figuran los de la categoría tecnología, es decir, laptops y celulares que no llegan a Perú, así como calzados y artículos de todo tipo.

\section{Bus Portal}

Busportal es considerado dentro de los casos de éxito, ya que, gracias a la implementación del eCommerce, se ha estimado que la empresa podría triplicar sus ventas en el transcurso del año. Esto debido, en gran parte, a la inversión obtenida del líder mundial en ventas online de pasajes de bus, RedBus.

RedBus es el mayor servicio de compra de pasajes de bus por internet, usado por más de 8 millones de viajeros en el mundo. Su plataforma ingresó al Perú, luego de adquirir a Busportal.pe -líder local en venta de pasajes de bus- cambiándose el nombre de Busportal.pe por redBus.pe, en un esfuerzo conjunto por mejorar la calidad del servicio y brindar mayores beneficios a todos los usuarios. A través de su nueva página web y moderna aplicación móvil (IOS/Android), RedBus ofrece pasajes de bus para las rutas más importantes de Latinoamérica (Perú y Colombia).

Según explicó el cofundador y gerente, el rápido aumento en las cifras de la empresa se explica por la ampliación de las rutas y empresas de transportes afiliadas al portal en el último año, además de la inversión en la mejora de la funcionalidad de la plataforma.

"Busportal se presenta como la mejor alternativa para comprar un pasaje de bus en el Perú. Ofrecemos en tiempo real los asientos disponibles de más de 40 empresas de bus, incluyendo a las más importantes del país; además, los usuarios pueden comprar los pasajes en la web al mismo precio que en la terminal”, indicó Bourgi. 
El emprendedor agregó que, si bien el número de viajeros que compran por internet va en aumento, la mayoría de los pasajes de bus son comprados de manera presencial, ya que gran porcentaje del público aún siente temor de usar su tarjeta para compras por internet.

En la empresa Busportal, se implementó el comercio electrónico de la siguiente forma: un portal web que permita al cliente reservar el asiento online y pagar de forma presencial en agentes bancarios. "Esta opción ayuda a los clientes a comprar, sin el temor de los fraudes electrónicos"

\section{Mejores Pymes de eCommerce Perú 2015}

El eCommerce day presenta a las Mejores Pymes que implementaron eCommerce en el Perú de forma anual, en el año 2016, se nominaron a las siguientes:
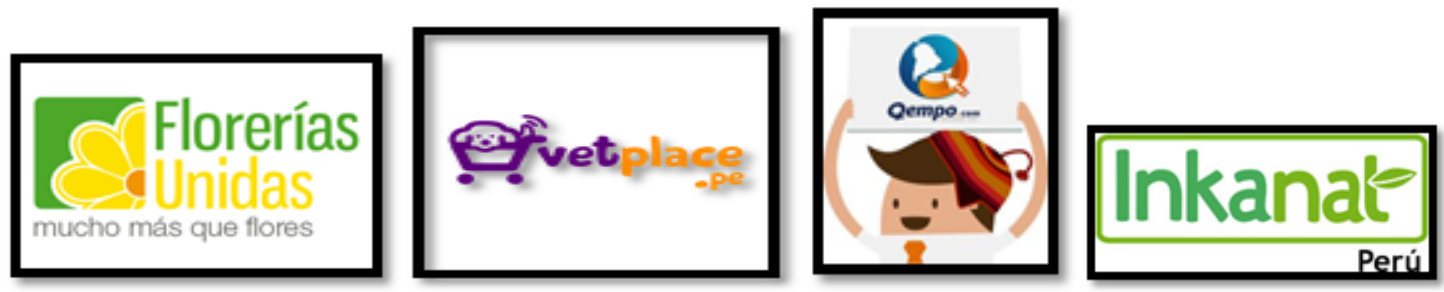

Ilustración 19: Mejores Pymes de eCommerce Perú 2015. (Fuente: eCommerce Day 2015

\section{Mejores Pymes de eCommerce Perú 2016}

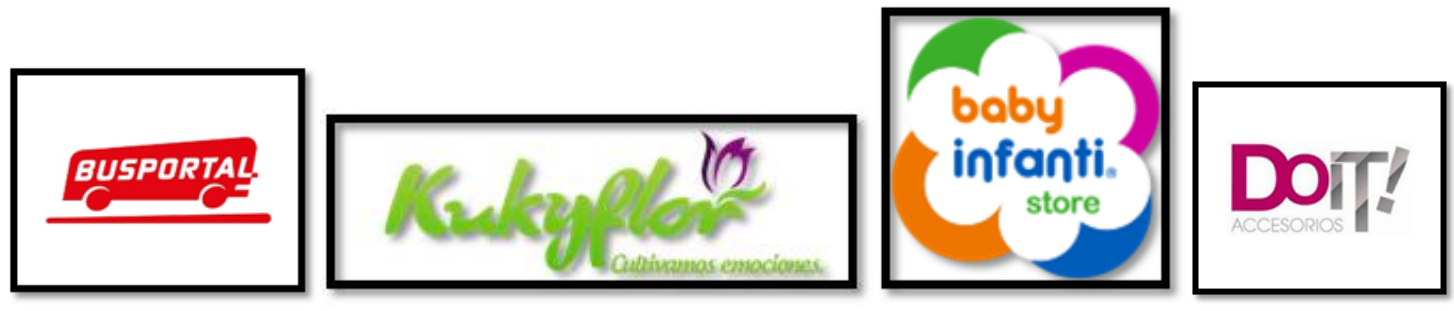

Ilustración 20: Mejores Pymes de eCommerce Perú 2016. (Fuente: eCommerce Day 2016)

\section{Criterios de evaluación de eCommerce Awards}

Para definir a los nominados de la categoría mejor Pyme en implementar el comercio electrónico, la Cámara de Comercio de Lima definió una serie de criterios que sirven como rúbrica para poder calificar a cada empresa. 


\begin{tabular}{|lll|}
\hline FACTOR DE SELECCIÓN & CARACTERÍSTICA & PUNTUACIÓN \\
\hline Estético & Diseño general del sitio visual y funcional & 10 pts \\
Criterios Funcionales & Usabilidad - Navegabilidad & 20 pts \\
Criterios de seguridad y privacidad & Buenas prácticas-uso de SSL, etc. & 20 pts \\
Tecnologia utilizada & Servicios de apoyo y uso de tecnologia & 20 pts \\
Estrategia comercial y de marketing & Campañas-Innovación - Multicanales-Logistica & 30 pts \\
& TOTAL & 100 PTS \\
\hline
\end{tabular}

Ilustración 21: Criterios de Evaluación para la Calificación. (Fuente: eCommerce Day 2016) 


\section{Capítulo 5: Desarrollo del Proyecto}

En este capítulo se explica las secciones del modelo propuesto, tales como las fases de gobierno electrónico y su objetivo; los e-Servicios que están alineados a las leyes peruanas y su clasificación en las fases propuestas; el índice de Gobierno Electrónico Municipal (GEM) y su importancia para el cumplimiento del modelo. Para el diseño del e-Servicio, en el capítulo se detalla un conjunto de consideraciones que deben estar presentes al momento de su realización en el modelo, tales como el presupuesto, el equipo del proyecto, los principios de arquitectura, la usabilidad, los objetivos del negocio que se desean alcanzar, las leyes peruanas a considerar y los recursos disponibles que cuenta la municipalidad; para luego poder explicar la ejecución de los cuatro procesos de análisis y diseño que permiten el desarrollo de un e-Servicio basado en las cuatro arquitecturas. Estas son la arquitectura de negocios, datos, aplicaciones e infraestructura.

\section{Desarrollo del Modelo}

El modelo de mejoras de e-Servicios municipales peruanas busca que las entidades gubernamentales locales implementen de manera exitosa el Gobierno Electrónico, mediante la digitalización de los servicios municipales que utilizan los ciudadanos.

Figure 1: Secuencia de ejecución del modelo

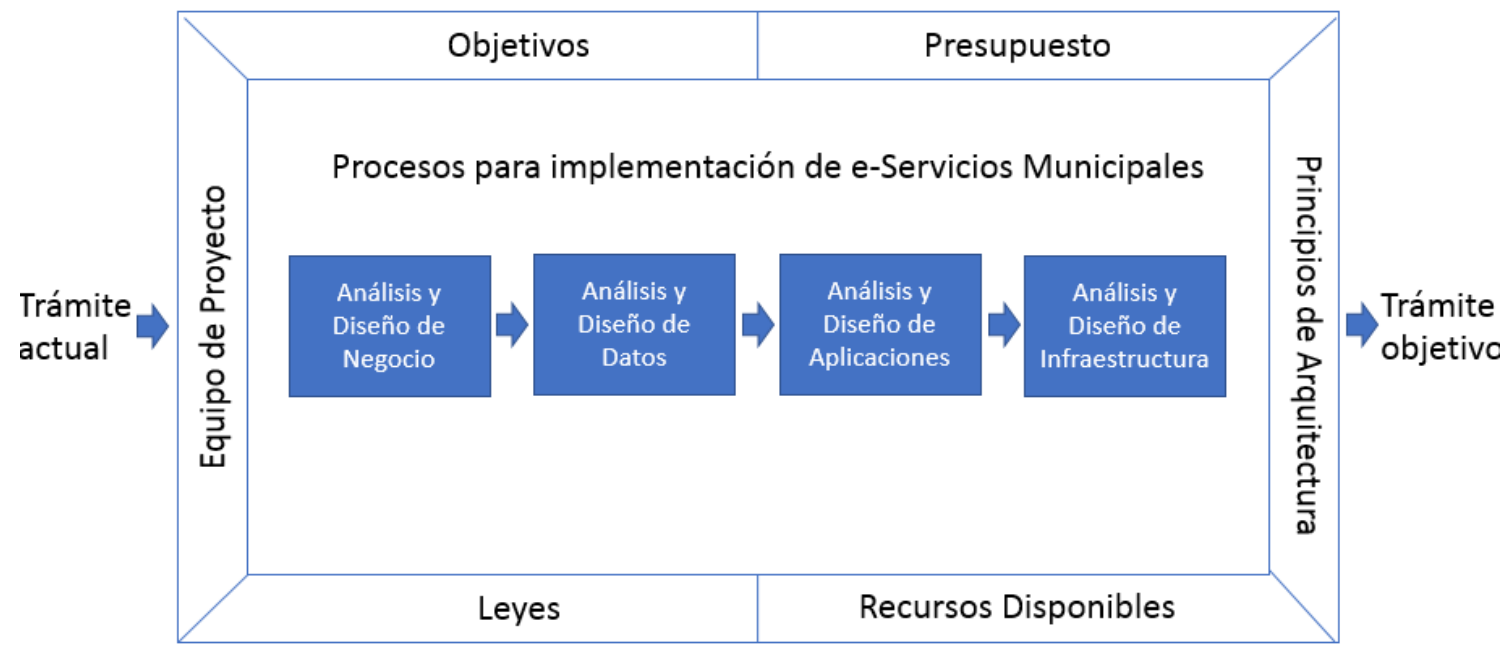

Fuente: Elaboración Propia 
Para la elaboración del modelo se han tomado las buenas prácticas de TOGAF, las cuales han sido adaptadas al contexto municipal peruano. La propuesta se ha dividido en dos partes para su correcto desarrollo. El primero es el marco del modelo, el cual contiene las consideraciones que se deben tener en cuenta a lo largo del proyecto. Estos son: objetivos, equipo de proyecto, leyes, recursos disponibles, principios de arquitectura y presupuesto. El segundo es el conjunto de procesos que van a transformar el actual proceso orientado a los ciudadanos en un proceso basado en e-Servicios. Estos son: análisis y diseño de negocio, análisis y diseño de datos, análisis y diseño de aplicaciones y; análisis y diseño de infraestructura.

El modelo propuesto busca complementar el trabajo de investigación "Modelo de Desarrollo de Sitios Web Municipales basado en Benchmarking y Segmentación”, el cual recomienda eServicios distribuidos en cinco fases. Esto permitirá una mejor percepción de la municipalidad por parte del ciudadano, con respecto a la transparencia y confianza hacia la misma. Se propone un índice de Gobierno Electrónico Municipal (GEM), que permita medir el cumplimiento de e-Servicios, usabilidad y la correcta implementación de estos. Este índice permite medir el cumplimiento de los objetivos de una municipalidad.

\section{A. Marco del Modelo}

Antes de utilizar el modelo, se debe conocer cuál va a ser su entrada. Dicha entrada es lo que el modelo propuesto va a transforma, es decir, un proceso tradicional de la municipalidad que desea que sea llevado a la web. Dicho proceso puede ser ejecutado de forma total o parcialmente manual.

El marco del modelo es la parte inicial del proyecto de gobierno electrónico, los cuales deben ser elaborados y tomados en cuenta a lo largo del proyecto. Este consta de seis partes que son detallados a continuación:

\section{Objetivos}

Son los objetivos municipales que deben encontrarse orientados a los objetivos planteados por el Estado. Estos, serán cumplidos de manera parcial o por completo con ayuda del proyecto. (Ver Recomendaciones para Implementación de e-Servicios - Objetivos)

\section{Equipo de Proyecto}


Son los roles que utilizarán el modelo para la elaboración del e-Trámite. (Ver Recomendaciones para Implementación de e-Servicios - Roles y Responsabilidades)

3. Recursos disponibles

Son los recursos tecnológicos, software y hardware, con los que cuenta la municipalidad antes del inicio del proyecto. (Ver Recomendaciones para Implementación de e-Servicios Recursos Disponibles)

\section{Leyes}

Los e-Servicios están basados en leyes peruanas de gobierno electrónico. (Ver Recomendaciones para Implementación de e-Servicios - Restricciones organizacionales Leyes para Municipalidades y de Gobierno Electrónico Local)

5. Principios de arquitectura:

Son los principios que se deben cumplir en todas las fases del proyecto, estos son de arquitectura de negocio, arquitectura de datos, arquitectura de aplicaciones, arquitectura de redes. (Ver Recomendaciones para Implementación de e-Servicios - Principios de Arquitectura)

6. Presupuesto:

Se debe asignar un presupuesto al proyecto. (Ver Recomendaciones para Implementación de e-Servicios - Presupuesto)

\section{B. Procesos del Modelo}

1. Análisis y Diseño del Negocio

En este punto se analiza el actual proceso municipal que debe ser orientado a los ciudadanos, el cual debe ser elegido para satisfacer el cumplimento de sus objetivos. Dicho proceso debe ser diagramado para poder identificar los puntos de mejora en su flujo de actividades (Ver Recomendaciones para Implementación de e-Servicios - Modelamientos de Procesos). Posteriormente, plantear los e-Servicios que van a contribuir en el incremento de su eficiencia y eficacia. Cabe resaltar que, la municipalidad puede plantear nuevos servicios electrónicos 
en base al marco legal vigente. Estos deben ser clasificados en una de las cinco fases propuestas según sus características.

Al conocerlos, dependerá de la entidad si selecciona el total o parcial de e-Servicios determinados anteriormente. Dichos servicios deben encontrarse alineados a las leyes peruanas como se muestra en la Tabla 17. Se diagrama el e-Trámite objetivo (Ver Recomendaciones para Implementación de e-Servicios - Modelamientos de Procesos), el cual servirá como entrada para la siguiente fase.

Tabla 1: Relación Leyes - e-Servicios

\begin{tabular}{|c|c|}
\hline Leyes & e-Servicios \\
\hline \multirow{3}{*}{$\begin{array}{l}\text { LEY N. }{ }^{\circ} 27806 \text { - } \\
\text { Acceso de Transparencia y } \\
\text { a la Información Pública }\end{array}$} & Formulario \\
\hline & Actas de consejo \\
\hline & Portal de transparencia \\
\hline \multirow{3}{*}{$\begin{array}{l}\text { LEY N. }{ }^{\circ} 28976 \text { - Ley Marco de Licencia } \\
\text { De Funcionamiento y los Formatos de } \\
\text { Declaración Jurada }\end{array}$} & Agenda municipal \\
\hline & Autoridades comunales \\
\hline & TUPA \\
\hline \multirow{3}{*}{$\begin{array}{l}\text { LEY N. }{ }^{\circ} 27972 \text { - Ley Orgánica de } \\
\text { Municipalidades }\end{array}$} & E-mail \\
\hline & Teléfono \\
\hline & Respuesta e-mail \\
\hline \multirow{2}{*}{$\begin{array}{l}\text { LEY N. }{ }^{\circ} 29733 \text { - Ley de Protección de } \\
\text { Datos } \\
\text { Personales }\end{array}$} & Trámite en línea \\
\hline & Pago en línea \\
\hline \multirow{4}{*}{$\begin{array}{l}\text { LEY N. }{ }^{\circ} 27269-\text { Ley de Firmas y } \\
\text { Certificados } \\
\text { Ley N. } .^{\circ} 27444 \text { - Ley del Procedimiento } \\
\text { Administrativo General }\end{array}$} & Certificado y firmas digitales \\
\hline & Carpeta del ciudadano \\
\hline & Seguimiento \\
\hline & Celular \\
\hline $\begin{array}{l}\text { RESOLUCIÓN MINISTERIAL N. }{ }^{\circ} \text { 126- } \\
\text { 2009-PCM }\end{array}$ & PIDE \\
\hline $\begin{array}{l}\text { LEY N. }{ }^{\circ} 27972-\text { Ley Orgánica de } \\
\text { Municipalidades }\end{array}$ & Chat online \\
\hline $\begin{array}{l}\text { LEY N. }^{\circ} 28976 \text { - Ley Marco de Licencia de } \\
\text { Funcionamiento y los Formatos de } \\
\text { Declaración Jurada }\end{array}$ & Foro \\
\hline
\end{tabular}

Fuente: Elaboración Propia 
Figure 2: Entrada y salida del Sub Proceso de Análisis y Diseño del negocio

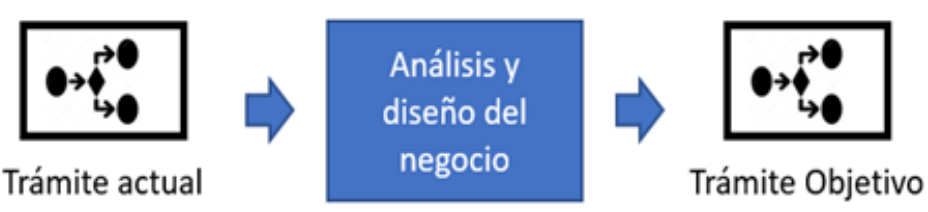

Fuente: Elaboración Propia

Para hacer esta actividad, se debe llenar la plantilla MMEM - Análisis de Situación Actual de Servicios Municipales y MMEM - Plantilla de e-Servicios Afectados por Servicios.

\section{Análisis y Diseño de Datos}

Al determinar qué e-Servicios se van a implementar y conociendo el nuevo flujo del proceso para su ejecución, se procede a identificar los datos que van a viajar por él. Esto con el fin de poder diseñar una base de datos que soporte la propuesta. Se debe evitar la redundancia de datos, de manera que se cuente con un diseño de base de datos más eficiente. (Ver Recomendaciones para Implementación de Arquitectura - Catálogo de Portafolio de Entidades, Matriz Entidad de Datos - Función de Negocio y Diagrama de Base de Datos).

Figure 3: Entrada y salidas del Sub Proceso Análisis y Diseño de Datos

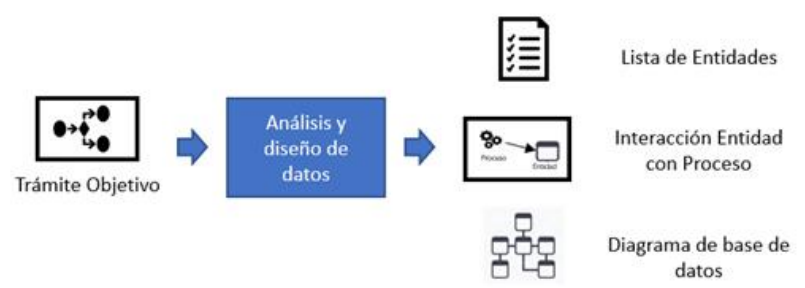

Fuente: Elaboración Propia

\section{Análisis y Diseño de Aplicaciones}

Con los resultados de los temas anteriormente, se puede realizar tres puntos. El primero, conocer qué nuevos aplicativos servirán de apoyo a los e-Servicios que van a ser implementados en el proceso identificado. En segundo lugar, identificar la interacción de los e-Servicios con el nuevo proceso y de esta manera, diseñar los entregables necesarios. En 
tercer lugar, identificar la interacción de todas las aplicaciones entre sí. (Ver Recomendaciones para Implementación de Arquitectura - Catálogo de Portafolio de Aplicaciones, Matriz Aplicaciones - Función de Negocio, Diagrama de Caso de Uso y Matriz de Interacción de Aplicaciones).

Figure 4: Entradas y salidas del Sub Proceso de Aplicaciones

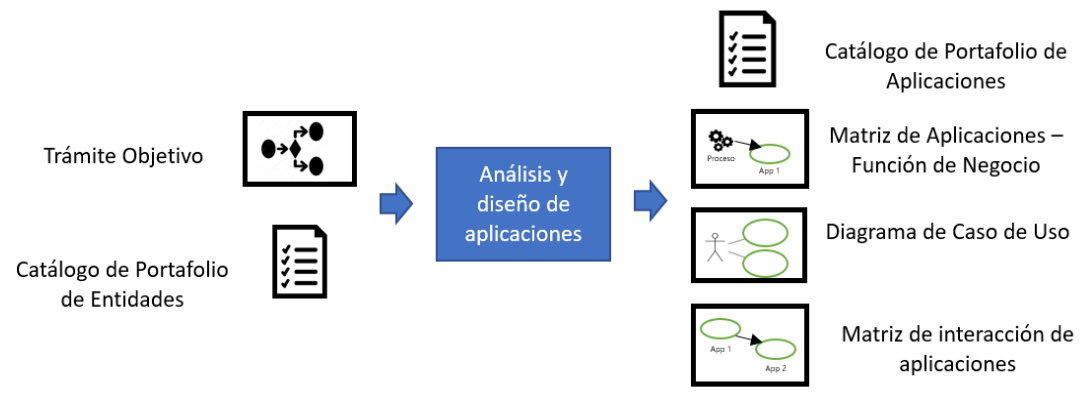

Fuente: Elaboración Propia

\section{Análisis y Diseño de Infraestructura}

Se recibe como entrada las aplicaciones identificadas en el punto anterior, de manera que se elabore una infraestructura tecnológica que la soporte. El primer proceso de arquitectura entregará el flujo del trámite objetivo para determinar la interacción de toda la infraestructura con dicho trámite. (Ver Recomendaciones para Implementación de Arquitectura - Catálogo de Portafolio de Tecnología, Diagrama de Red y Matriz de Tecnología).

Figure 5: Entradas y salidas del Sub Proceso de Análisis y Diseño de Infraestructura

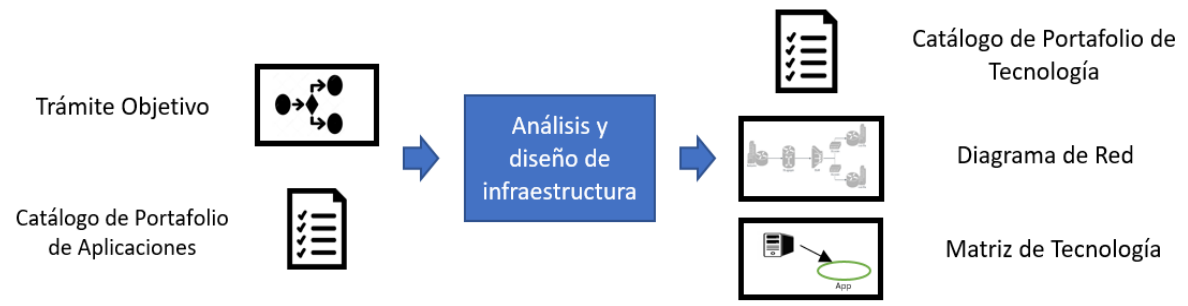

Fuente: Elaboración Propia 


\section{Evaluar el Cumplimiento de e-Servicios}

En este punto, el modelo permitirá un auto diagnóstico del e-Servicio que se desea implementar por parte de la municipalidad mediante el índice del Gobierno Electrónico Municipal (GEM). De esta manera, se puede conocer si estos cumplen con los criterios del modelo propuesto, los cuales son: la implementación del e-Servicio, usabilidad de este y que se encuentre basado en un enfoque de arquitectura empresarial.

El índice de Gobierno Electrónico Municipal contempla tres subíndices que se definen a continuación:

1. Índice de e-Servicios: Evalúa los servicios electrónicos de cada fase propuesto. Este indicador equivale al 60\% del Índice de Gobierno Electrónico Municipal.

2. Índice de Usabilidad: Evalúa la usabilidad de la web municipal. Este indicador representa el 15\% del Índice de Gobierno Electrónico Municipal.

3. Índice de AE: Mide las buenas prácticas de arquitectura empresarial propuestas, el cual se encuentra basada en TOGAF. Este índice representa el 25\% del Gobierno Electrónico Municipal.

Figure 6: Componentes del Índice de Gobierno Electrónico Municipal

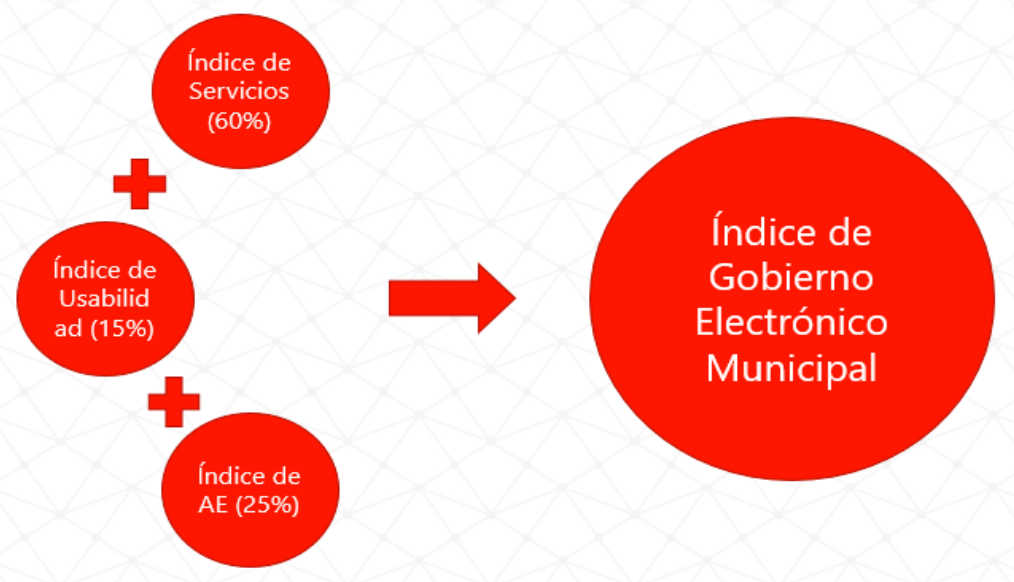

Fuente: Elaboración Propia

Para la medición de dichos índices se cuenta con tres encuestas. En cada encuesta se colocó un puntaje por pregunta para, posteriormente, lograr determinar el índice de 
Gobierno Electrónico Municipal. Para ver las encuestas, se encuentra la plantilla MMEM - Evaluación.

Por otro lado, las fases recomendadas ayudan a que una municipalidad conozca el impacto generado en los ciudadanos de los e-Servicios recomendados o propuestos.

Figure 7: Fases de Gobierno Electrónico Municipal propuestas por Esteves

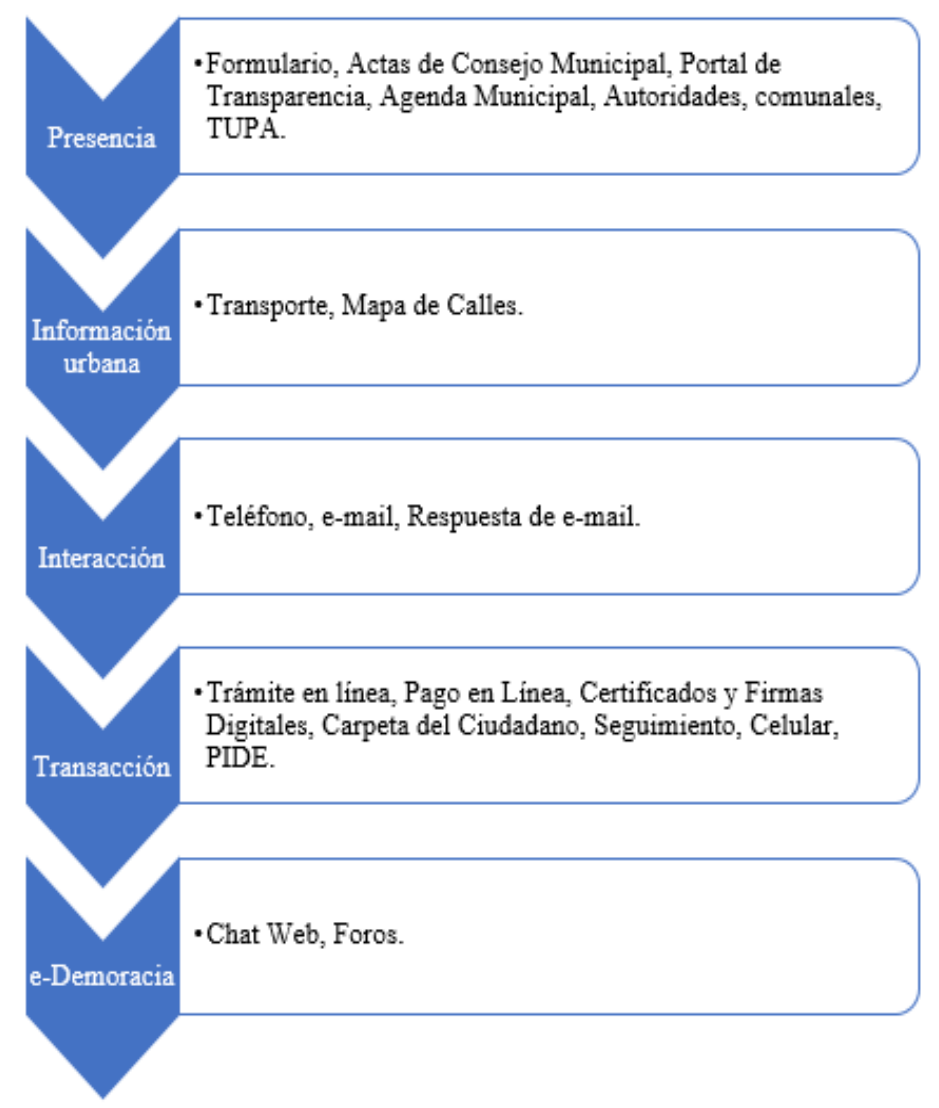

Fuente: Elaboración Propia

A continuación, se detalla los e-Servicios planteados:

Presencia:

- Formulario: Documentos necesarios para la ejecución de un trámite.

- Actas de Consejo Municipal: Es el documento que contiene los temas tocados y los acuerdos llegados por el consejo municipal.

- Portal de transparencia: Es una sección de la web que debe tener toda municipalidad según la ley de transparencia.

- Agenda Municipal: Es el documento que contiene todas las actividades que va a realizar la municipalidad en la comuna. 
- Autoridades comunales: Contiene información de dichas autoridades, ya sea nombre, cargo, entre otros.

- TUPA: Es el Texto Único de Procesos Administrativos, el cual contiene todos los procesos que realiza la municipalidad, sus requerimientos, tiempos de ejecución, entre otros.

Información Urbana:

- Mapa municipal: Son los planos municipales donde se puede conocer la zonificación de usos de suelos, planos de altura de edificación, entre otros.

- Transporte Urbano: Muestra las rutas de las líneas de transporte público.

Interacción:

- E-mail: Permite una comunicación vía correo electrónico.

- Teléfono: Permite una comunicación directa por teléfono con el ciudadano.

- Respuesta de e-mail: La municipalidad debe responder por correo electrónico a cualquier pregunta o solicitud que inicio por este medio.

Transacción:

- Trámite en línea: Permite que el ciudadano pueda realizar sus trámites por medio de la web, estos están contenidos en el TUPA.

- Pago en Línea: Los trámites realizados tienen un costo por su ejecución, dichos cobros, entre otros, deben ser pagados por medio de la web.

- Certificados y firmas digitales: Permite firmar digitalmente documentos del mismo tipo.

- Carpeta del Ciudadano: Es una carpeta que almacena los trámites y pagos realizados por el ciudadano. Permite ver sus datos históricos.

- Seguimiento: El ciudadano podrá ver el estado de sus expedientes inconclusos, en que área orgánica se encuentra, entre otros.

- Celular: Todos los servicios anteriores deben ser utilizados desde una aplicación de un dispositivo móvil.

- PIDE: Conectarse con la plataforma de interoperabilidad del estado peruano para poder adquirir y suministrar información a otras entidades del gobierno para tener un proceso más completo.

e-Democracia:

- Chat Web: Permite una interacción directa entre el funcionario y el ciudadano para absolver sus dudas. 
- Foros: Brinda una ventana para que la ciudadanía pueda opinar o participar en un tema de importancia para la comuna.

\section{Recomendaciones para Implementación de e-Servicios}

\section{A. Reconocimiento para la Usabilidad}

Bórquez propone la usabilidad como parte de su guía de recomendaciones, en donde incluye una evaluación de este concepto a partir de un subconjunto de recomendaciones del gobierno chileno. Los componentes considerar se pueden agrupar en las siguientes dimensiones:

- Identidad corporativa: qué tan bien refleja el sitio Web la pertenencia a la institución. Se busca si en el sitio web se encuentran presentes los elementos propios de la imagen institucional de un municipio. Se evalúan las siguientes variables:

○ Identidad del municipio reflejada en la página principal.

- Uso de elementos de la imagen corporativa en la portada del sitio como el logo o escudo).

- Repetición de la imagen corporativa en todas las páginas (vale decir, si en la totalidad de las páginas, la aparición de la imagen corporativa era consistente).

○ Información de contactos (e-mail, teléfono) al pie o encabezado de la página.

- Facilidad del sitio Web: qué tan útil es el sitio Web para el visitante. Se mide evaluando qué tan fácil es encontrar la información de los servicios más importantes entregados por el municipio en la página principal. Se considera que en un sitio en el cual no sea fácil encontrar tal información, es poco útil, desde el punto de vista del ciudadano.

- Navegación: qué tan fácil es navegar dentro del sitio. Se mide a través de las siguientes variables:

○ Rapidez o fluidez de la navegación

- Qué tan intuitiva es la navegación

○ Organización de temas del sitio

- Facilidad para encontrar contenidos 
○ Posición del menú de navegación

- Facilidad para ver el menú de navegación (Visibilidad)

○ Coherencia y consistencia de la navegación

○ Distinción de botones y links

- Posibilidad para rehacer o deshacer operaciones

- Visibilidad del estado del sistema: qué tanta información del estado del sitio Web se le proporciona al usuario. Esta dimensión se obtiene midiendo las siguientes variables:

- Información acerca del sitio que se está visitando.

○ Información de pasos faltantes para terminar un trámite en línea.

- Ayuda: qué tanta ayuda sobre el sitio Web se le proporciona al usuario. Se mide la presencia de teléfonos de soporte web, o mesa de ayuda, presencia de un FAQ6, y una sección de ayuda, ofreciendo una explicación de cómo utilizar el sitio.

- Feedback: cómo puede el usuario proporcionar feedback a los responsables del sitio Web. Se mide la presencia de una instancia de contacto (sea en formulario, teléfono o mail) con el Web Master7, y el estado de funcionamiento de los formularios de contacto, en caso de que corresponda.

- Estética y diseño: cómo estos factores ayudan o confunden al usuario dentro del sitio. Se mide fundamentalmente la presencia de jerarquías visuales que permitan determinar los elementos más importantes.

- Actualización: qué tan actualizados el usuario percibe los contenidos del sitio. Se mide la presencia de la publicación de información acerca de contenidos nuevos en la portada, con fecha de publicación.

- Otros componentes esenciales: características deseables de un sitio web municipal. Se miden aspectos tales como:

- Garantía de respuesta a solicitudes.

- Presencia de párrafos largos en textos. 
- Políticas de confidencialidad.

○ Presencia de exceso de elementos en la página principal.

- Uso de pop ups.

- Uso de sitios Web separados para información del municipio y para los trámites municipales.

\section{B. Presupuesto}

Para el proyecto el presupuesto es un punto muy importante, ya que se refiere a la proyección de los movimientos económicos, monetarios y financieros relacionadas a las actividades del proyecto. En caso se presenten dudas, se procede desarrolla este punto.

El presupuesto abarca toda actividad financiera respecto al proyecto, en donde, los ingresos se determinan en base a los objetivos planteados y los gastos se obtienen de la cantidad de gastos operativos e inversión. Este presupuesto debe ser proyectado para la duración del proyecto, debe ser lo más exacto, detallado y sincero posible. Además, debe incluir costos directos, indirectos, contingencias que puedan existir y las ganancias que se espera obtener.

Para elaborar el presupuesto debemos realizar lo siguiente:

- Estimar los ingresos y los gastos, dependiendo de lo que se espera realizar con el proyecto.

- Calcular el costo del proyecto.

- Realizar la asignación de los recursos financieros.

- Tener en cuenta y solicitar de acuerdo a la jerarquía establecida la aprobación del Presupuesto Institucional de las Municipalidades.

- Al poner en ejecución el presupuesto estimado del proyecto, se concretará los ingresos, se ejecutarán los gastos previstos y se realizarán modificaciones financieras que sean necesarias.

- Tener en cuenta que luego de la ejecución, se deberá realizar una evaluación con respecto al presupuesto proyectado, en donde se muestra el avance financiero de la ejecución presupuestal, y el grado de cumplimiento de lo proyectado. 
- Tener en cuenta que se debe llevar un control periódico del resultado del proyecto.

\section{Restricciones Organizacionales - Leyes para Municipalidades y de Gobierno Electrónico Local}

Para la elaboración del proyecto se debe tener en cuenta las leyes referentes al gobierno electrónico implementadas en el Perú. En caso no se haya tomado en cuenta estas leyes o se presenten dudas al respecto, se pasa a presentar estas leyes.

\section{LEY Na 27444 - Ley del Procedimiento Administrativo General}

\section{TÍTULO PRELIMINAR}

Hace referencia a las siguientes entidades del estado.

1. El Poder Ejecutivo, incluyendo Ministerios y Organismos Públicos Descentralizados

2. El Poder Legislativo

3. El Poder Judicial

4. Los Gobiernos Regionales

5. Los Gobiernos Locales

6. Los Organismos a los que la Constitución Política del Perú y las leyes confieren autonomía.

7. Las demás entidades y organismos, proyectos y programas del Estado, cuyas actividades se realizan en virtud de potestades administrativas $\mathrm{y}$, por tanto, se consideran sujetas a las normas comunes de derecho público, salvo mandato expreso de ley que las refiera a otro régimen.

8. Las personas jurídicas bajo el régimen privado que prestan servicios públicos o ejercen función administrativa, en virtud de concesión, delegación o autorización del Estado, conforme a la normativa de la materia ${ }^{1}$.

\footnotetext{
${ }^{1}$ Cfr. Indecopi $(2017: 1,5,6)$
} 
DECRETO LEGISLATIVO $\mathrm{N}^{\circ} 1353$ - Decreto Legislativo que crea la Autoridad Nacional de Transparencia y Acceso a la Información Pública, Fortalece el Régimen de Protección de Datos Personales y la Regulación de la Gestión de Intereses

Indica que todas las entidades que se encuentran en el Artículo I Título Preliminar de la Ley $\mathrm{N}^{\circ}$ 27444, Ley del Procedimiento Administrativo General, empresas del estado y personas jurídicas deben proponer políticas, emitir directivas, supervisar su cumplimiento, absolver consultas que las entidades, personas jurídicas o naturales, fomenten una cultura, puedan solicitar información que considere necesarias de otras entidades sobre materia de transparencia y acceso a la información pública. Además, se debe presenta un informe anual al congreso de la república sobre dicho tema.

\section{DECRETO LEGISLATIVO $\mathbf{N}^{\circ} 1246$ - Decreto Legislativo que Aprueba Diversas Medidas de Simplificación Administrativa}

La presente ley busca simplificar, optimizar y eliminar procedimientos administrativos de todas las entidades que se encuentran en el Artículo I Título Preliminar de la Ley $N^{\circ} 27444$. Se desea tomar en cuenta 3 servicios sociales en los 3 niveles del gobierno.

a. Normas generales y específicas para la estandarización de los procedimientos administrativos.

b. Dictar medidas para la optimización de servicios en las entidades públicas del estado.

c. Contribuir el fortalecimiento institucional y la calidad del servicio al ciudadano.

Por otro lado, manera gratuita, las entidades en mención deben permitir el acceso o suministrar información o bases de datos actualizadas que administren, posean, entre otros, respecto a los usuarios o administrados a las demás entidades requieran necesariamente y de acuerdo con la ley, para la tramitación de sus procesos administrativos y para sus actos de administración interna. Si la información requerida necesita datos protegidos por la ley $\mathrm{N}^{\circ}$ 29733, Ley de Protección de Datos Personales, estas deben ser autorizadas por el administrado o usuario.

\section{LEY Na 27269 - Ley de Firmas y Certificados Digitales}


Según el artículo 1 de la presente ley, tiene como objetivo regular la utilización de la firma electrónica otorgándole la misma validez y eficacia jurídica que el uso de una firma manuscrita u otra análoga que el conlleve manifestación de voluntad.

La firma digital es aquella firma electrónica que utiliza una técnica de cristología asimétrica, basada en el uso de un par de claves únicos, asociada a una clave privada y una clave pública relacionadas matemáticamente entre sí, de forma que las personas que conocen la clave pública no puedan llegar a la privada.

El certificado digital es el documento electrónico generado y formado digitalmente por una entidad de certificación, la cual vincula un par de claves con una persona determinada confirmando su identidad.

\section{DECRETO SUPREMO $\mathrm{N}^{\circ}$ 026-2016-PCM - Aprueban Medidas para el} Fortalecimiento de la Infraestructura Oficial de Firma Electrónica y la Implementación Progresiva de la Firma Digital en el Sector Público y Privado

Según el artículo 1, tiene como objeto aprobar las medidas para el fortalecimiento de la Infraestructura Oficial de Firma Electrónica - IOFE y la implementación progresiva de la firma digital en el sector público y privado.

Detalla los pasos a seguir para que las entidades de Certificación que cumplan con estándares técnicos internacionales o sellos de confianza internacional sean reconocidas oficialmente por el estado peruano.

La Infraestructura Oficial de Firma Electrónica (IOFE) es un concepto macro que se refiere al sistema confiable, acreditado, regulado y supervisado por la AAC; es decir, por la Comisión de Reglamentos Técnicos y Comerciales del INDECOPI. Entidad designada para tales efectos por el artículo $36^{\circ}$ del Reglamento, concordante con el artículo $2^{\circ}$ del Decreto Supremo que lo aprueba ${ }^{2}$.

RESOLUCIÓN MINISTERIAL No 244-2007-PCM - Aprueban Uso Obligatorio de la Norma Técnica Peruana “Ntp-Iso/ Iec 17799:2007 Edi. Tecnología de la Información. Código de Buenas Prácticas para la Gestión de la Seguridad de la Información. 2a. Edición” en Todas las Entidades Integrantes del Sistema Nacional de Informática

\footnotetext{
${ }^{2}$ Cfr. Indecopi (2017:12)
} 
NTP-ISO/IEC 17799:2007 EDI. TECNOLOGÍA DE LA INFORMACIÓN. CÓDIGO DE BUENAS PRÁCTICAS PARA LA GESTIÓN DE LA SEGURIDAD DE LA INFORMACIÓN. $2^{\text {a }}$ EDICIÓN

"Esta norma ofrece recomendaciones para realizar la gestión de a seguridad de la información que pueden utilizarse por los responsables de iniciar, implementar o mantener y mejorar la seguridad en una organización. Persigue proporcionar una base común para desarrollar normas de seguridad dentro de las organizaciones y ser una práctica eficaz de la gestión de la seguridad"3.

DECRETO LEGISLATIVO No 1211 - Decreto Legislativo que Aprueba Medidas para el Fortalecimiento e Implementación de Servicios Públicos Integrados a Través de Ventanillas Únicas e Intercambio de Información entre Entidades Públicas

Según el artículo 1 del presente decreto legislativo establece el marco normativo que promueve la integración de los servicios y procedimientos del Estado, bajo las modalidades presenciales y virtuales, a través del diseño, desarrollo e implementación de ventanillas únicas y el intercambio de información entre entidades públicas, facilitando el comercio, el desarrollo productivo y eliminando las regulaciones excesivas.

El presente decreto legislativo es aplicable a las entidades públicas previstas en el artículo I del Título Preliminar de la Ley No 27444, Ley del Procedimiento Administrativo General.

\section{RESOLUCIÓN MINISTERIAL No 241-2014-PCM - Aprueban Directiva No 001-2014- Pcm/ Ongei, "Directiva Sobre Estándares de Servicios Web de Información Georreferenciada para el Intercambio de Datos entre Entidades de la Administración Pública}

La directiva tiene como objetivo "definir los estándares de los servicios web para el intercambio de información georreferenciada entre entidades de la Administración Pública, en el marco de la Política Nacional de Gobierno Electrónico"4.

Debe ser cumplido por "todas las entidades de la Administración Pública a que se refiere el Artículo I del Título Preliminar de la Ley 27444, Ley del Procedimiento Administrativo

\footnotetext{
${ }^{3}$ Cfr. Ongei (2007:13)

${ }^{4}$ Cfr. Ongei (2014:6)
} 
General, que en el marco de sus funciones y competencias administren datos georreferenciados"

DECRETO SUPREMO $\mathrm{N}^{\circ}$ 133-2013-PCM - Decreto Supremo Mediante el cual se establece el Acceso e Intercambio de Información Especial entre Entidades de la Administración Pública

Establece los lineamientos y mecanismos de aplicación nacional que facilitan el acceso e intercambio de información especial o georreferenciar entre las entidades de la administración pública. Las entidades públicas que deben aplicarla son las que refiere el Artículo I del Título Preliminar de la Ley $N^{\circ} 2744$, Ley del Procedimiento Administrativo General que utilicen, produzcan o financien la producción de datos especiales o georreferénciales.

\section{LEY N2 30096 - Ley de Delitos Informáticos}

La presente Ley tiene por objeto prevenir y sancionar las conductas ilícitas que afectan los sistemas y datos informáticos y otros bienes jurídicos de relevancia penal, cometidas mediante la utilización de tecnologías de la información o de la comunicación, con la finalidad de garantizar la lucha eficaz contra la ciberdelincuencia.

\section{DECRETO SUPREMO $\mathrm{N}^{\mathrm{o}}$ 004-2013-PCM - Aprueba la Política Nacional de Modernización de la Gestión Pública}

Apruébese la Política Nacional de Modernización de la Gestión Pública, la cual forma parte integrante del presente Decreto Supremo como Anexo, siendo el principal instrumento orientador de la modernización de la gestión pública en el Perú, que establecerá la visión, los principios y lineamientos para una actuación coherente y eficaz del sector público, al servicio de los ciudadanos y el desarrollo del país.

RESOLUCIÓN MINISTERIAL No. 073-2004-PCM - Aprueban Guía para la Administración Eficiente del Software Legal en la Administración Publica

“Aprobar la Guía para la Administración Eficiente del Software Legal en la Administración Pública elaborada coordinadamente por el Instituto Nacional de Defensa de la Competencia y

\footnotetext{
${ }^{5}$ Cfr. Ongei (2014:6)
} 
de la Protección de la Propiedad Intelectual - INDECOPI y la Oficina Nacional de Gobierno Electrónico e Informática - ONGEI, que forma parte de la presente resolución”“6.

"La Guía explica la importancia de realizar un inventario detallado y la forma apropiada de elaborarlo. Asimismo, determina cómo identificar copias ilegales de software y describe los pasos necesarios para verificar que el uso del software se realice de acuerdo con los términos de la licencia. Por otra parte, se identifican herramientas útiles para realizar el inventario, aunque, si usted no tiene acceso a una aplicación de inventario de software, hallará instrucciones detalladas para identificar el software instalado en sus computadoras"7.

\section{RESOLUCIÓN MINISTERIAL No 139-2004-PCM - Aprueban Documento "Guía} Técnica Sobre Evaluación de Software para la Administración Pública”

"Las entidades de la Administración Pública, integrantes del Sistema Nacional de Informática, deberán aplicar lo establecido en la "Guía Técnica Sobre Evaluación de Software para la Administración Pública" en los productos de software que desarrollen o adquieran a partir de la fecha de publicación de la presente Resolución."

La presente guía consta de las siguientes partes:

a. Modelo de la calidad: Se describe un modelo de calidad para los productos de software, dividido en dos partes:

a. Calidad interna y externa

b. Calidad en uso.

b. Métricas

c. Proceso de evaluación de software

\section{LEY No 286121 - Ley que Norma el Uso, Adquisición y Adecuación del Software en la Administración Pública}

"La presente Ley tiene por objeto establecer las medidas que permitan a la administración pública la contratación de licencias de software y servicios informáticos en condiciones de

\footnotetext{
${ }^{6}$ Cfr. Ongei (2004:2)

${ }^{7}$ Cfr. Ongei (2004:8)

${ }^{8}$ Cfr. Ongei (2004:1)
} 
neutralidad, vigencia tecnológica, libre concurrencia y trato justo e igualitario de proveedores"9.

"La evaluación técnica de los recursos de software y hardware requeridos por la administración pública se sujetará a las normas dictadas por el ente rector del Sistema Nacional de Informática" ${ }^{10}$.

RESOLUCIÓN JEFATURAL N 088-2003-INEI - Aprueban Directiva sobre "Normas Para el Uso del Servicio de Correo Electrónico en las Entidades de la Administración Pública"

La norma pretende "Dar lineamientos para el uso correcto del servicio de correo electrónico oficia"11.

DECRETO SUPREMO $\mathbf{N}^{\circ}$ 063-2010-PCM - Decreto Supremo que Aprueba la Implementación del Portal de Transparencia Estándar en las Entidades de la Administración Pública

“Aprobar la implementación del Portal de Transparencia estándar en las entidades de la administración pública. Dicha herramienta informática contiene formatos estándares bajo los cuales cada entidad registrará y actualizará su información de gestión de acuerdo a lo establecido por la Ley de Transparencia y Acceso a la información Pública y a los plazos establecidos en ella, sin perjuicio de la información adicional que la Entidad considere pertinente publicar. Dicha herramienta se presenta en una versión amigable con definiciones expresadas en un lenguaje claro y sencillo para un mejor entendimiento de la ciudadanía en general" 12 .

"El presente Decreto Supremo de obligatorio cumplimiento será de aplicación a todas las entidades públicas, entendiéndose como tales, a aquellas referidas en el Artículo I del Título Preliminar de la Ley $N^{\circ}$ 27444, Ley del Procedimiento Administrativo General”"13.

\section{LEY N ${ }^{\circ} 29733$ - Ley de Protección de Datos Personales}

\footnotetext{
${ }^{9}$ Cfr. UNAC.edu.pe $(2005: 1)$

${ }^{10}$ Cfr. UNAC.edu.pe $(2005: 1)$

${ }^{11}$ Cfr. Inei (2003:2)

${ }^{12}$ Cfr. El Peruano (2010:2)

${ }^{13}$ Cfr. El Peruano (2010:2)
} 
La presente ley tiene el objetivo de garantizar el derecho fundamental a la protección de los datos personales, previsto en el artículo 2 numeral 6 de la Constitución Política del Perú, a través de su adecuado tratamiento, en un marco de respeto de los demás derechos fundamentales que en ella se reconoce.

\section{DECRETO SUPREMO No 081-2006-PCM - Exoneran del Pago de Derechos, Tasas o} Precios Públicos a Entidades que Requieran Información de otra Entidad de la Administración Pública

"Mediante el presente Decreto Supremo se exonera del pago de derechos, tasas o precios públicos a las entidades de la Administración Pública, que requieran información a otra entidad de la Administración Pública a efecto de facilitar los procesos de interconexión e integración entre las mismas"14.

\section{RESOLUCIÓN JEFATURAL No 207-2002-INEI - Aprueban Directiva «Normas Técnicas para la Asignación de Nombres de Dominio de las Entidades de la Administración Pública»}

La presente norma tiene como objetivo "Uniformizar los nombres de dominio en las entidades de la Administración Pública a nivel nacional"15.

\section{Sponsor}

En este punto se desarrollará el sponsor, en caso no se tenga claro o se presenten dudas al respecto. El sponsor es una persona u organización que patrocina, apoya o financia el proyecto. Idealmente, quien asume este rol debe ser de alguien lo suficientemente responsable para poder tomar decisiones grandes e importantes, es responsable de facilitar el éxito del proyecto, establece prioridades, proporciona recursos y e el portavoz del proyecto. Es por esto, que el que asuma este rol debe ser de gran autoridad dentro del proyecto. Un sponsor debe contar con las siguientes características:

- El sponsor debe ser alguien con autoridad jerárquica dentro del proyecto.

- El sponsor debe ser líder del proyecto.

\footnotetext{
${ }^{14}$ Cfr. Softwarepublico.gob.pe (2006:2)

${ }^{15}$ Cfr. Inei (2002:2)
} 
- El sponsor debe demostrar y transmitir confianza y credibilidad a todos los miembros del equipo del proyecto.

- El sponsor debe contar con habilidades de comunicación.

- El sponsor debe participar en el éxito del proyecto y debe encontrarse disponible cuando se lo requiera.

Debe llevarse un registro de las personas que asumen el rol de sponsor dentro del proyecto, por lo que se definen los siguientes puntos:

- ID: Identificador

- Nombre: Nombre completo del Sponsor

- Organización: Nombre de la organización a la que pertenece el sponsor

- Posición: Posición que el sponsor tiene en la organización

- Email: Correo electrónico del sponsor

- Teléfono: Número de teléfono del sponsor

*Ver plantilla MMEM-Sponsor

\section{E. Misión}

La misión describe el rol que la organización desempeña para el logro de la visión, permite establecer objetivos, formular estrategias y ejecutar tareas. La misión es de vital importancia, ya que explica la razón de ser de la organización o del proyecto y sirve de referencia para la toma de decisiones, ya que indica que es lo que la organización o proyecto hace y qué es lo que la diferencia del resto. En el caso en que la misión no se encuentre desarrollada ni documentada o se presenten dudas al respecto, en este punto se trata acerca de este tema.

La misión debe tener las siguientes características:

- Debe ser clara y comprensible para todos los miembros.

- Decir en pocas palabras en qué consiste el negocio.

- Distinguir la organización de las demás.

- No debe provocar confusiones sobre lo que hace la empresa.

- No debe limitar el accionar de los miembros del equipo. 
Para lograr establecer una correcta misión debemos respondernos las siguientes preguntas:

- ¿Cuál es nuestra razón de ser?

- ¿Quiénes somos?

- ¿Qué buscamos?

- ¿Qué hacemos?

- ¿Dónde lo hacemos?

- ¿Por qué lo hacemos?

- ¿Para quién trabajamos?

- ¿Quiénes son nuestros clientes?

- ¿Cuáles son nuestros principales productos o servicios?

- ¿Cuáles son nuestros mercados?

- ¿Cuál es nuestra diferenciación o mayor ventaja competitiva?

Ejemplos:

"Contribuir a mejorar la vida de nuestros clientes, modificando sus formas de trabajar, de aprender y de comunicarse, a través de delicados productos de cómputo personal e innovadores servicios.”

"Ayudar a nuestros clientes a alcanzar sus metas de negocio proveyéndoles servicios y soluciones innovadoras."

*Ver plantilla MMEM-Misión

\section{F. Recursos Disponibles}

En todo proyecto se debe contar con un listado de los recursos, elementos que cuenta la organización, es por esto que se elabora una plantilla para contar con dicha información. Los recursos son aquellos activos, elementos, insumos y/o bienes tangibles o intangibles que contribuyen en el funcionamiento de la organización y a lograr los objetivos. Los recursos disponibles de la empresa pueden ser de tipo financiero, tecnológico, material o humanos. Contar con esta descripción es muy importante, ya que de esta manera podremos saber con qué recursos se dispone y cuáles se necesitan. 
Los recursos son:

- Recursos Financieros: Referido al recurso monetario de la empresa y ajeno con que la empresa cuenta para el desarrollo de las actividades de la organización. Este puede ser: dinero en efectivo, utilidades, acciones, préstamo, créditos, entre otros.

- Recursos Tecnológicos: Referido al medio tecnológico tangibles o intangibles por el cual las empresas desarrollan sus actividades.

- Recursos Materiales: Relacionado a los bienes tangibles de la empresa como muebles, enseres, edificios, terrenos, herramientas, entre otros.

- Recursos Humanos: Relacionado a los servicios que ofrecen las personas a la empresa, en cuanto a sus habilidades, conocimientos, realización de actividades y toma de decisiones para el funcionamiento de la empresa.

*Ver plantilla MMEM-Recursos Disponibles

Se proponen puntos o recomendaciones se serán tomados por cada fase del esquema de eGovernment. A continuación, se pasará a desarrollar dichos puntos.

\section{G. Roles y Responsabilidades}

En este punto se desarrollará o aclarará ciertas dudas con respecto a los roles y responsabilidades de los miembros del equipo de proyecto.

Para el proyecto a desarrollar, es importante contar con una lista de roles y responsabilidades definidas; de esta manera, se tendrá conocimiento de quiénes participan y qué papeles ocupan para llevar a cabo el proyecto. La definición de los roles y las responsabilidades de cada miembro del equipo es una parte muy importante para el proyecto, ya que proporciona una descripción definida de las tareas que va a realizar cada recurso humano, comprobar que no existen vacíos y evitar ambigüedades de cada rol. Esta definición nos permite responder a las siguientes preguntas:

- ¿Quiénes forman parte del equipo?

- ¿Qué funciones se atribuyen a cada una de ellas? 
- ¿Cuáles son sus responsabilidades específicas?

- ¿Qué obligaciones deben cumplir?

- ¿Cuál es la información de contacto de cada uno de los miembros del equipo?

Para definir los roles y responsabilidades del equipo de trabajo se debe considerar lo siguiente:

- Definir los roles del proyecto y la cantidad de personal que demandará.

- Definir las responsabilidades de cada rol.

- Elaborar un documento llamado "Descripción del Trabajo". En este documento se describe detalladamente las responsabilidades específicas de cada rol.

- Identificar e iniciar el proceso de reclutamiento, en donde se convoca a candidatos para cubrir los roles establecidos.

- Designar al personal a cada rol.

*Ver plantilla MMEM-Roles y Responsabilidades

\section{H. Principios de Arquitectura}

Es necesario proponer principios para el proyecto a desarrollar, ya que los principios definen las normas y directrices para el uso y despliegue de los recursos y activos de TI. En caso no se haya propuesto principios o se presenten dudas al respecto; a continuación, se desarrolla dicho punto.

Los principios reflejan un nivel de consenso entre los distintos elementos de la empresa, y constituyen la base para la toma de futuras decisiones de TI. Son reglas generales y pautas, destinadas a ser duraderas y poco modificadas, que informan y apoyan la forma en que una organización se pone a cumplir su misión. A su vez, los principios pueden ser solo un elemento de un conjunto estructurado de ideas que definen y guían colectivamente la organización, desde los valores hasta las acciones y los resultados. Un buen conjunto de principios se fundará en las creencias y valores de la organización y se expresará en un lenguaje que la empresa entiende y utiliza. Los principios deben ser pocos en número, orientados al futuro, y respaldados y defendidos por la alta dirección. Proporcionan una base firme para tomar decisiones de arquitectura, enmarcar políticas, procedimientos y estándares, y apoyar la resolución de situaciones contradictorias. Un conjunto de principios pobres se 
desvanecerá rápidamente, y las arquitecturas, políticas y estándares resultantes carecerán de credibilidad. Esencialmente, los principios conducen el comportamiento.

Existen cinco criterios que distinguen un buen conjunto de principios:

- Comprensible: los principios subyacentes pueden ser rápidamente comprendidos y entendidos por los individuos en toda la organización. La intención del principio es clara y sin ambigüedades.

- Robusto: Cada principio debe ser suficientemente preciso para apoyar una toma de decisiones coherente en situaciones complejas y potencialmente polémicas.

- Completo: Los principios cubren cada situación percibida.

- Consistente: El conjunto de principios debe expresarse de una manera que permita un equilibrio de interpretaciones entre los principios. Estos no deben ser contradictorios hasta el punto de que adherirse a un principio violaría el espíritu de otro. Cada palabra en una declaración de principios debe ser cuidadosamente elegida para permitir una interpretación coherente y flexible.

- Estable: los principios deben ser duraderos, pero capaces de acomodar los cambios. Debería establecerse un proceso de enmienda para agregar, remover o alterar principios después de haber sido ratificados inicialmente.

Tener en cuenta que debemos definir 4 tipos de principios los cuales son:

- Los principios de negocio definen las directrices para el negocio, ya sean procesos, reglas de negocio, roles y responsabilidades, entro otros.

- Los principios de datos definen las directrices para los datos ya sea para su almacenamiento, formato, etc.

- Los principios de aplicaciones definen las directrices para los softwares que se utilizan o están en desarrollo.

- Los principios de tecnología definen las directrices para los software y hardware de la municipalidad. 
- Los principios de seguridad definen las directrices para los procedimientos de seguridad de software y hardware de la municipalidad.

Para la elaboración de los principios se debe tener en cuenta lo siguiente.

- ID: Identificador

- Nombre: Nombre del Principio

- Declaración: La declaración debe comunicar brevemente y sin ambigüedad la regla fundamental. Es vital que la declaración de principios sea inequívoca.

- Fundamento: El fundamento explica o detalla la regla definida en la declaración. En este punto se puede mencionar los beneficios del negocio de adherirse al principio, las circunstancias para su aplicación, entro otros. Si es necesario, se debe describir las situaciones en las que un principio tendría prioridad o tendría más peso que otro para tomar una decisión.

- Implicaciones: Las implicaciones son las condiciones deben existir o acciones que se deben de realizar, en términos de recursos, costos y tareas, para el cumplimiento del principio, tanto para el negocio como para TI. E impacto en el negocio y las consecuencias de la adopción de un principio deben ser claramente establecidos. El lector debe discernir fácilmente la respuesta a: ¿Cómo me afecta esto?" Es importante no simplificar, trivializar o juzgar el mérito del impacto. Algunas de las implicaciones se identificarán como posibles impactos solamente, y pueden ser especulativas en lugar de ser analizadas en su totalidad.

- Fecha: Fecha de creación o modificación del principio.

- Creador: Creador o propietario

*Ver plantilla MMEM-Catálogo de Principios

\section{Objetivos}

Para el proyecto se debe tener definido los objetivos, en caso no se tenga desarrollado o se presenten dudas al respecto; a continuación, se desarrolla dicho punto. 
Los objetivos son resultados que una organización desea alcanzar en un período de tiempo y empleando recursos, de los cuales dispone o pretende disponer. Deben determinar qué es lo que se desea lograr y encontrarse relacionados con la misión. Son esenciales, ya que establece un curso a seguir para llegar al éxito de la organización, y permite enfocar los esfuerzos hacia una dirección.

Los objetivos deben contar con las siguientes características:

- Deben ser medibles y deben estar ligados a un límite de tiempo.

- Deben ser claros, precisos y entendibles.

- Deben encontrarse dentro de las posibilidades de la organización, teniendo en cuenta el tiempo y los recursos que dispone.

- Deben ser realistas y desafiantes.

- Deben encontrarse alineados con otros objetivos, con la misión, visión, política y valores de la organización.

- Los objetivos pueden ser: generales, específicos, estratégicos, tácticos, operacionales, de largo, mediano y corto plazo.

Ejemplo Objetivo General: "Ser una marca que los demandantes reconozcan por su variedad de productos."

Ejemplo Objetivo Específico: “Aumentar las ventas en un 20\% en los próximos 12 meses, para poder empezar la ampliación de nuestra nueva planta."

Ejemplo Objetivo Específico: “Adquirir 2 nuevas maquinarias para el segundo semestre.” Ejemplo Objetivo Específico: “Abrir 3 tiendas para el primer trimestre del próximo año.” *Ver plantilla MMEM-Objetivos 


\section{J. Requerimientos}

Para el proyecto es necesario definir lo requerimientos. En caso no se cuenten con requerimientos definidos o exista alguna duda. A continuación, se desarrolla dicho punto.

Un requerimiento es una necesidad del contenido o funcionalidad del proyecto, producto o servicio. Como parte de la funcionalidad o contenido identifica los atributos, las características o las cualidades que debe cumplir el producto, servicio o proyecto para brindar un valor o utilidad. Los requerimientos se dividen en:

- Requerimientos funcionales: que determina lo que debe hacer, con las relaciones que debe tener, teniendo en cuenta lo que no se debe hacer.

- Requerimientos no funcionales: referente a las cualidades y/o función que debe cumplir.

Para la definición de los requerimientos debemos tener en cuenta que:

- Debe cumplir con las necesidades definidas.

- Deben ser claros y concretos.

- Deben ser redactados de manera que pueda ser comprensible por todos.

- Deben estar organizados de manera jerárquica.

- No debe contradecir a cualquier otro requerimiento.

- No debe ser obsoleto con el paso del tiempo.

- No debe ser ambiguo y debe poder ser implementado.

Ejemplo: "El jefe del área de Recursos Humanos debe ser capaz de actualizar el listado de empleados que existe en la organización, indicando los nuevos ingresantes."

*Ver plantilla MMEM-Requerimientos 


\section{K. Modelamiento de Procesos}

Un proceso, es un conjunto de actividades secuenciales con el fin de lograr un resultado determinado. Contar con la documentación de estos procesos de la organización es clave, ya que permite obtener información específica acerca de los pasos que se deben realizar para completarlos. Por lo que, se debe identificar los procesos de la organización y pasar a documentarlos.

La documentación de procesos brinda uniformidad para realizar las actividades de los procesos, funciona como un mapa de ruta de la organización y sirve de guía para empleados y directores. Además, ayuda a saber cómo se encuentra actualmente el proceso, permite identificar posibles mejoras para el mismo y, posibilita el monitoreo y supervisión. Esta documentación permite también, que el conocimiento quede en la empresa y no se vaya con los empleados que dejan la organización. Adicional a esto, permite que los empleados nuevos y antiguos entiendan su rol dentro de la organización.

Documentación de procesos permite:

- Corregir y eliminar errores.

- Reducir tiempos en el desarrollo de las tareas de los procesos.

- Reducir recursos y disminuir costos.

- Mejorar la eficiencia y calidad de los procesos.

- Aumentar la satisfacción de los usuarios.

Es por esto, que se propone la utilización de la gestión de procesos, el cual es una metodología que permite diseñar, modelar, documentar, controlar y optimizar los procesos de la organización. Business Process Management (BPM) es un sistema de gestión enfocado a perseguir la mejora continua en el funcionamiento de las actividades empresariales mediante la identificación, selección, descripción, documentación y mejora de procesos, partiendo del despliegue de la estrategia de la organización, asegurando la misión empresarial y alineada a la visión de la empresa. BPM se alinea con la estrategia, con la gestión de recursos humanos, con la gestión financiera, con la gestión de la información, con la gestión de la calidad y con las disciplinas tradicionales de gestión definiendo indicadores de funcionamiento y objetivos, 
que incrementen la mejora y estén alineados, en tiempo real, con los objetivos estratégicos y tengan en cuenta las necesidades y expectativas de los clientes ${ }^{16}$.

Para el desarrollo de la gestión de los procesos de la organización, la cual es una entidad pública, se debe tener en cuenta que cualquier cambio realizado se debe considerar las regulaciones brindadas por el Estado y se tomarán las plantillas desarrolladas en la tesis Modelo de Implementación de una Solución BPM con Open Source para Pymes desarrollada por Renzo Hohagen y Renato Chapeyquén.

\section{Recomendaciones para la Implementación de Arquitecturas}

Para la realización de las arquitecturas planteadas se tomaron las buenas prácticas del marco de trabajo TOGAF, la cual proporciona un enfoque para el diseño, la planificación, implementación y gobierno de esta. Se plantean cuatro arquitecturas que cubren cuatro fases de gobierno electrónico municipal, las cuales son Presencia, Información Urbana, Interacción y Transacción. Cada fase tiene un nivel de cumplimiento diferente, ya sea por contenido de información registrada o por entregables desarrollados. A continuación, explicaremos estos últimos para una mejor comprensión de su utilización.

1. Diagrama de Casos de Uso: Un diagrama de casos de uso del sistema muestra las relaciones entre consumidores y proveedores de servicios de aplicaciones. Los servicios de aplicaciones son consumidos por los agentes u otros servicios. Es decir, describe el comportamiento de un sistema al afrontar una tarea de negocio. Es por esta razón porque la que se debe contar con este documento, la municipalidad de conocer las funcionalidades que va a tener su sub y quienes van a interactuar con ella. Esto beneficia al momento de hacer un cambio, ya se conoce como va a importar y a quienes.

2. Catálogo de Portafolio de Aplicaciones: Identifica una lista de todas las aplicaciones. Esta lista ayuda a definir el propósito de las iniciativas de cambio que pueden impactar en los tipos de aplicaciones ${ }^{17}$.

3. Catálogo de Portafolio de Entidades: Identifica la lista de entidades con las que va a contar el sistema propuesto. Permite evitar redundancias de información.

\footnotetext{
${ }^{16}$ Cfr. Libro del BPM 2011:6-7

${ }^{17}$ Crf Andrés Felipe García Osorio (2014)
} 
4. Matriz de interacción de aplicaciones: Muestra la relación de comunicación que tienen las aplicaciones con otras.

5. Catálogo de Portafolio de Tecnología: El propósito de este catálogo es identificar y mantener una lista de toda la tecnología en uso en toda la empresa, incluyendo hardware, software de infraestructura y software de aplicación. El catálogo de portafolio de tecnología proporciona una base sobre la cual basar las matrices y diagramas restantes.

6. Diagrama de Red: Muestra la relación de los componentes de infraestructura. Como va a estar diseñada la red de la municipalidad.

7. Matriz de Tecnología: Mapea la relación entre las aplicaciones con los componentes tecnológicos.

8. Matriz Entidad de Datos - Función de Negocio: Su propósito es describir la relación entre entidades de datos y funciones empresariales dentro de la empresa. Las funciones empresariales están soportadas por servicios empresariales con límites definidos explícitamente y serán soportadas y realizadas por procesos empresariales.

9. Matriz de Aplicaciones - Función de Negocio: Su propósito es describir la relación entre las aplicaciones y las funciones empresariales dentro de la empresa ${ }^{18}$.

10. Diagrama de Base de Datos: Su propósito es mostrar la lógica de la base de datos, sus relaciones, como se almacena los datos y como se accede a ellos. Cuentan con reglas que deben ser cumplidas, tales como evitar la redundancia, duplicidad de llaves, entre otros.

Tabla 2: Arquitecturas por Fase

\begin{tabular}{|l|l|l|l|l|}
\hline \multicolumn{1}{|c|}{ Presencia } & \multicolumn{1}{|c|}{ Información urbana } & Transacción \\
\hline \multicolumn{2}{|c|}{ Fase C } & Caso de uso & Caso de uso \\
\hline $\begin{array}{l}\text { Caso de uso } \\
\text { Aplicálogo de Portafolio de }\end{array}$ & $\begin{array}{l}\text { Catálogo de Portafolio de } \\
\text { Aplicaciones }\end{array}$ & $\begin{array}{l}\text { Catálogo de Portafolio de } \\
\text { Aplicaciones }\end{array}$ & $\begin{array}{l}\text { Catálogo de Portafolio de } \\
\text { Aplicaciones }\end{array}$ \\
\hline Catálogo de Portafolio de & Catálogo de Portafolio de & Catálogo de Portafolio de & Catálogo de Portafolio de \\
\hline
\end{tabular}

${ }^{18}$ Crf. Open Group 


\begin{tabular}{|l|l|l|l|}
\hline Entidades & Entidades & Entidades & Entidades \\
\hline $\begin{array}{l}\text { Matriz de Interacción de } \\
\text { Aplicaciones }\end{array}$ & $\begin{array}{l}\text { Matriz de Interacción de } \\
\text { Aplicaciones }\end{array}$ & $\begin{array}{l}\text { Matriz de Interacción de } \\
\text { Aplicaciones }\end{array}$ & $\begin{array}{l}\text { Matriz de Interacción de } \\
\text { Aplicaciones }\end{array}$ \\
\hline & & & $\begin{array}{l}\text { Matriz Entidad de Datos - } \\
\text { Función de Negocio }\end{array}$ \\
\hline $\begin{array}{l}\text { Catálogo de Portafolio de } \\
\text { Tecnología }\end{array}$ & $\begin{array}{l}\text { Catálogo de Portafolio de } \\
\text { Tecnología }\end{array}$ & $\begin{array}{l}\text { Catálogo de Portafolio de } \\
\text { Tecnología }\end{array}$ & $\begin{array}{l}\text { Catálogo de Portafolio de } \\
\text { Función de Negocio }\end{array}$ \\
\hline $\begin{array}{l}\text { Diagrama de Red } \\
\text { Matriz de Tecnología }\end{array}$ & Magrama de Red & Diagrama de Red & Diagrama de Red \\
\hline
\end{tabular}

Fuente: Elaboración Propia

Figure 8: Modelo de Mejoras de e-Servicios Municipales

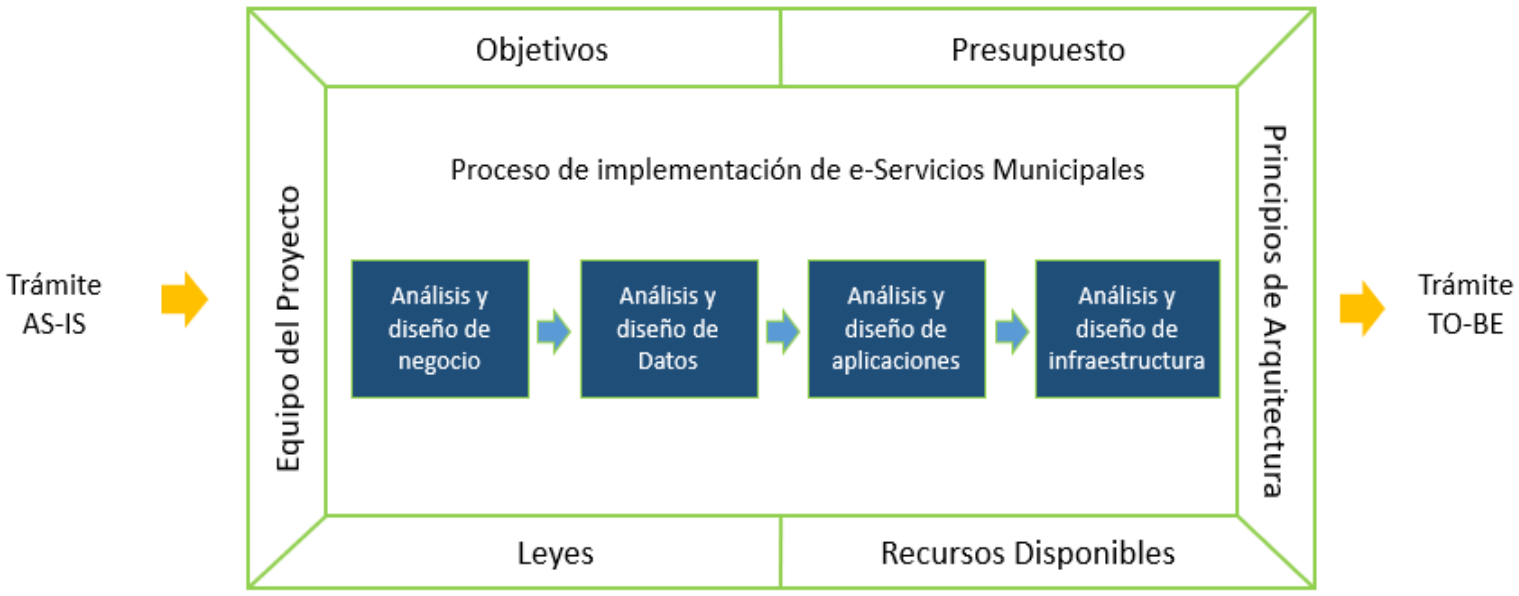

Fuente: Elaboración Propia 
Figure 9: Gráfico Modelo de Mejoras de e-Servicios Municipales
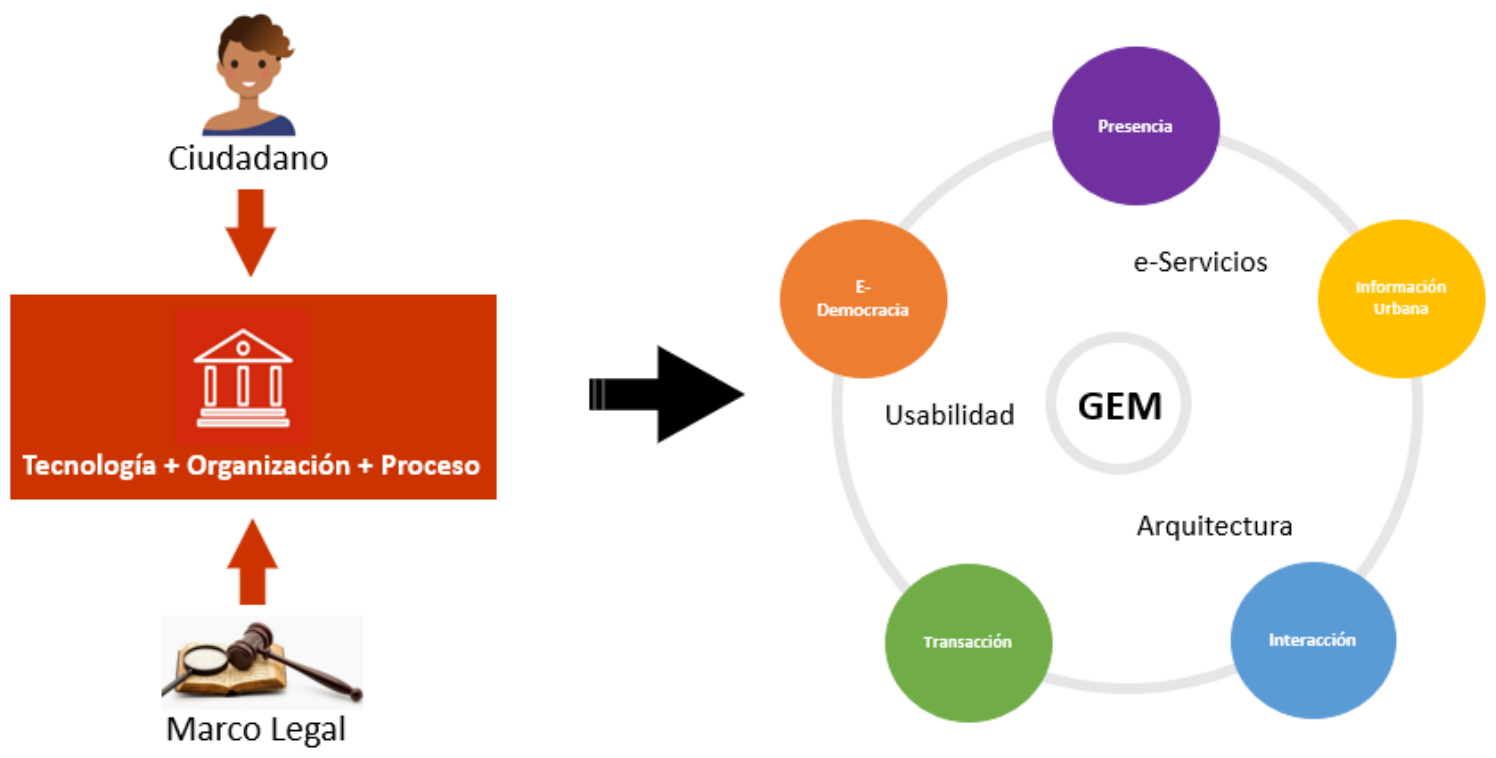

Fuente: Elaboración Propia 


\section{Capítulo 6: Resultados del Proyecto}

En este capítulo se realiza la validación del caso de estudio, para esto se elabora el eServicio llamado Trámite Documentario Electrónico utilizando el modelo propuesto. La validación se realiza por medio de encuestas a tres grupos, los cuales son expertos en el área de tecnología de municipalidades, ciudadanos y funcionarios públicos. Estas encuestas se desarrollaron por medio de la escala de Likert, el cual se ha definido en 5 niveles: 1 Muy Alto, 2 Alto, 3 Medio, 4 Bajo, 5 Nada.

\section{Introducción}

Para el presente proyecto, existen dos tipos de validación. El primero es un caso de estudio donde se utilizó el modelo en la municipalidad de Surco. El objetivo es que la entidad diseñe su gobierno electrónico en base a e-Servicios y, de esta manera, se le facilite su implementación. Para lograrlo, se identificó un trámite que sea utilizado por muchos ciudadanos para que el impacto de la propuesta sea alto. El trámite tiene relación con muchos otros e-Servicios de la fase objetivo y otros de fases anteriores. Para obtener los resultados, se elaboraron prototipos y una encuesta que mostraban los beneficios del nuevo trámite, tanto a los funcionarios que participan en el mismo como a los ciudadanos que tienen un local con licencia de funcionamiento. El segundo es una validación por juicio de expertos, una encuesta para especialista de tecnología que pertenezcan a una municipalidad. Los expertos son Sub Gerentes de las municipalidades de Santiago de Surco, Barranco, Miraflores, Villa María del Triunfo y Chorrillos. A continuación, se explica el desarrollo del proceso de ambos tipos de validación empezando por el caso de estudio.

\section{Caso de Estudio}

El caso de estudio se realizó en la municipalidad de Santiago de Surco, con el trámite de licencia de funcionamiento. Según el informe de la entidad, este proceso ha sido el más solicitado entre los años 2016 - 2017 por la ciudadanía. Su traslado a la web disminuiría considerablemente la carga procesal de la municipalidad.

\section{A. Marco del Modelo}

Antes de empezar la ejecución del modelo en el trámite, se realiza el marco propuesto. 
1. Objetivos: Los objetivos que se alinean a la misión planteada.

*Ver Anexo - MMEM-Objetivos

2. Equipo de Proyecto: Los funcionarios que participan en el trámite se muestran en la siguiente tabla.

*Ver Anexo - MMEM-Roles y Responsabilidades

3. Recursos disponibles

4. Leyes: Se basa en el marco legal vigente.

5. Principios de arquitectura: Se han definido los cinco grupos de arquitectura, las cuales son de negocio, aplicaciones, datos, tecnología y seguridad.

*Ver Anexo - MMEM-Catálogo de Principios

6. Presupuesto: No aplica para el caso de estudio.

Se realizaron las siguientes recomendaciones planteadas en el modelo:

7. Misión: Se propone una misión para que este alineada a una propuesta de gobierno electrónico.

*Ver Anexo - MMEM-Misión

8. Sponsor: Si bien para la presente evaluación se contó con un sponsor, se dejan las propuestas de posibles en la municipalidad de Surco.

*Ver Anexo - MMEM-Sponsor

9. Requerimientos: Son los requerimientos identificados para el cumplimiento de la propuesta.

*Ver Anexo - MMEM-Requerimientos 


\section{B. Procesos del Modelo}

La entrada del proceso propuesto es el trámite de licencia de funcionamiento como se encuentra actualmente. Para su ejecución, el ciudadano debe acercarse a la entidad y entregar dos solicitudes firmadas. Al ser aceptadas, se programa una fecha de inspección para que el personal de Defensa Civil se acerque a la dirección indicada. Luego, el Gerente de Desarrollo Urbano firma la licencia de funcionamiento. En paralelo, se realiza la inspección y es el inspector quien ingresa los resultados al sistema. Al ser aprobado, la inspección técnica es firmada por la Sub Gerencia de Defensa Civil y es entregada al Gerente de Desarrollo Urbano. Tanto la licencia de funcionamiento como la inspección técnica son entregadas al ciudadano solicitante.

\section{*Ver Anexo - MMEM-Proceso-Actual}

\section{Análisis y Diseño del Negocio}

Al conocer cómo funciona el proceso de licencia de funcionamiento, se debe analizar las oportunidades de mejora para el proceso e identificar qué e-Servicios de la propuesta pueden ser consumidos por él.

Tabla 3: Funcionalidades y e-Servicios que serán utilizados en el e-Trámite de Licencia de Funcionamiento

\begin{tabular}{|c|c|c|}
\hline & Actividades & Funcionalidad \\
\hline \multirow{6}{*}{ 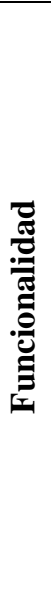 } & Envíos de información & $\begin{array}{c}\text { Enviar información de la sesión del } \\
\text { usuario }\end{array}$ \\
\hline & Archivar expediente & $\begin{array}{c}\text { Registrar documentos en el servidor } \\
\text { de archivos }\end{array}$ \\
\hline & $\begin{array}{l}\text { Registro de información en } \\
\text { otros sistemas }\end{array}$ & $\begin{array}{c}\text { Intercambiar información con otros } \\
\text { sistemas }\end{array}$ \\
\hline & Recibir documentos & Cargar documentos \\
\hline & Verificar requerimientos & Verificar documentos \\
\hline & $\begin{array}{l}\text { Programar fecha de inspección } \\
\text { ocular }\end{array}$ & Programar fecha de inspección \\
\hline \multirow{4}{*}{ 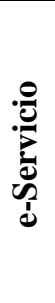 } & Pago por derecho a trámite & Pago en línea \\
\hline & Firma de documentos & Firma y certificado digital \\
\hline & Asesorías al ciudadano & Chat en línea \\
\hline & & \\
\hline
\end{tabular}




\begin{tabular}{|c|c|c|} 
Entrega de formatos & Formatos en línea \\
\cline { 2 - 3 } & Consultar TUPA web & TUPA en línea \\
\hline
\end{tabular}

Fuente: Elaboración Propia

En base a la información analizada, se brinda una propuesta del trámite objetivo. En el nuevo proceso, el ciudadano puede cargar las solicitudes desde la web de la municipalidad. El sistema valida la información y registra en la base de datos. Se programa automáticamente la inspección. Al concluir esta tarea, el sistema calcula el pago por derecho a trámite y le muestra al ciudadano el importe y los medios de pago. Una vez el ciudadano realiza el pago, se confirma la inspección. El sistema elabora licencia de funcionamiento con la información del ciudadano y se almacena en el servidor de archivos hasta que se apruebe la inspección técnica. Al ser aprobada por el área de Sub Gerencia de Defensa Civil, el sistema elabora la inspección técnica, la cual es firmada digitalmente por el Sub Gerente de dicha área para luego ser enviada a la cuenta del ciudadano previamente creada. En todo momento se podrá monitorear el estado del trámite.

Figure 10: Comparación Trámite Actual vs Trámite Objetivo

\begin{tabular}{|c|c|c|c|c|c|}
\hline & Ciudadano & Inspector & Sub Gerente & Sub Gerente & Asesor CAS \\
\hline 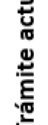 & $\begin{array}{c}\text { Entregar } \\
\text { documentos en } \\
\text { ventanilla }\end{array}$ & $\begin{array}{l}\text { Programar } \\
\text { inspección }\end{array}$ & $\Rightarrow \begin{array}{c}\text { Firmar licencia } \\
\text { de } \\
\text { funcionamiento }\end{array}$ & $\begin{array}{l}\text { Firmar } \\
\text { inspección } \\
\text { técnica }\end{array}$ & $\begin{array}{c}\text { Entregar } \\
\text { documentos en } \\
\text { ventanilla }\end{array}$ \\
\hline \multirow{2}{*}{ 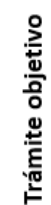 } & Ciudadano & Sistema & Sub Gerente & Sub Gerente & Sistema \\
\hline & $\begin{array}{c}\text { Cargar } \\
\text { documentos } \\
\text { por la web }\end{array}$ & $\begin{array}{l}\text { Programar } \\
\text { inspección }\end{array}$ & $\vec{c} \begin{array}{c}\text { Firma } \\
\text { electrónica en } \\
\text { licencia de } \\
\text { funcionamiento }\end{array}$ & $\begin{array}{c}\text { Firma } \\
\text { electrónica en } \\
\text { inspección } \\
\text { técnica }\end{array}$ & $\begin{array}{c}\text { Entrega de } \\
\text { documentos en } \\
\text { carpeta del } \\
\text { ciudadano }\end{array}$ \\
\hline
\end{tabular}

Fuente: Elaboración Propia

*Ver Anexo - MMEM-Proceso-Objetivo

\section{Análisis y Diseño de Datos}

Luego de saber qué funcionalidades y e-Servicios se van a implementar, se procede a identificar las entidades necesarias para su desarrollo. Algunos de ellos se encuentran en la siguiente tabla. 
Tabla 4: Muestra de entidades identificadas

\begin{tabular}{|c|l|}
\hline Entidad & \multicolumn{1}{|c|}{ Descripción } \\
\hline Formulario & Almacena los formularios ingresados por el ciudadano o funcionario. \\
\hline TUPA & Se encuentran los requerimientos del TUPA. \\
\hline Comprobante & Información de los pagos realizados por la web y de manera presencial. \\
\hline Trámite_Formulario_Firma & $\begin{array}{l}\text { Almacena la relación entre los documentos legales, el trámite y los usuarios } \\
\text { que la han firmado. }\end{array}$ \\
\hline
\end{tabular}

Fuente: Elaboración Propia

\section{*Ver Anexo - MEMM-EDM-05-Catálogo de Entidades}

Luego, se elabora la Matriz Entidad de Datos - Función de Negocio donde muestra la relación de las entidades con el negocio, la cual permite entender qué entidades van a ser consumidas por el proceso propuesto y por los demás.

Para contar el diseño de la base de datos, se realiza un diagrama de base de datos donde se encuentra todas las entidades identificadas anteriormente. La siguiente figura muestra un extracto del planteado.

Figure 11: Extracto de Diagrama de Base de Datos

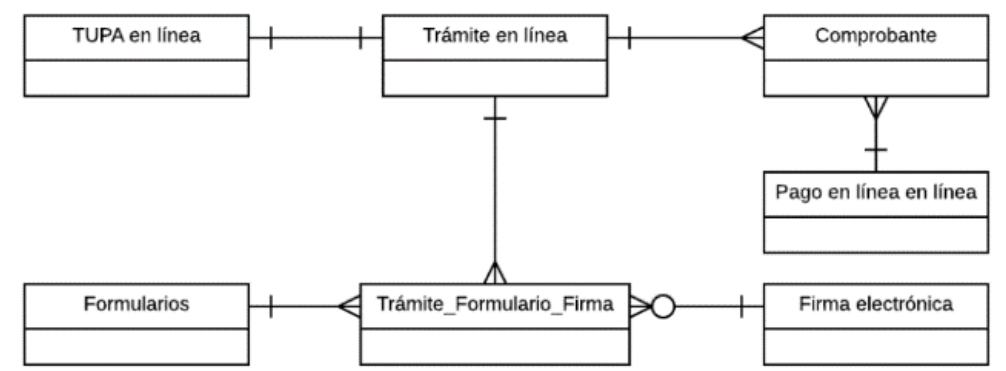

Fuente: Elaboración Propia

\section{Análisis y Diseño de Aplicaciones}

Al contar con el proceso objetivo y las entidades para la propuesta, podemos definir las aplicaciones que se deben desarrollar para implementar el trámite objetivo. Algunas de las aplicaciones identificadas se encuentran en la siguiente tabla. 
Tabla 5: Extracto de Aplicaciones Propuestas

\begin{tabular}{|c|l|}
\hline Aplicación & \multicolumn{1}{|c|}{ Descripción } \\
\hline Formulario & $\begin{array}{l}\text { Permite elaborar un documento para que se inicie un trámite, este será } \\
\text { llenado por el ciudadano o el funcionario de manera digital. La información } \\
\text { restante, será llenada por el sistema. }\end{array}$ \\
\hline Pago online & Permite realizar el pago por medio de la web con tarjeta de crédito o débito. \\
\hline $\begin{array}{c}\text { Trámite de emisión de } \\
\text { licencia de funcionamiento } \\
\text { menor a } 100 \mathrm{~m} 2\end{array}$ & $\begin{array}{l}\text { Permite la ejecución de un trámite de licencia de funcionamiento de un } \\
\text { establecimiento menor a } 100 \mathrm{~m} 2 \text { desde la web sin que el ciudadano tenga } \\
\text { que ir a la municipalidad }\end{array}$ \\
\hline
\end{tabular}

\section{Fuente: Elaboración Propia}

\section{*Ver Anexo - MEMM-EDM-06-Catálogo de aplicaciones}

Al conocer las aplicaciones necesarias para alcanzar el proceso objetivo, se debe conocer cómo estas van a interactuar con los roles que participan en el proceso. En la siguiente figura se muestra un extracto del diagrama de caso de uso del trámite de licencia de funcionamiento.

Figure 12: Extracto de Diagrama de Caso de Uso

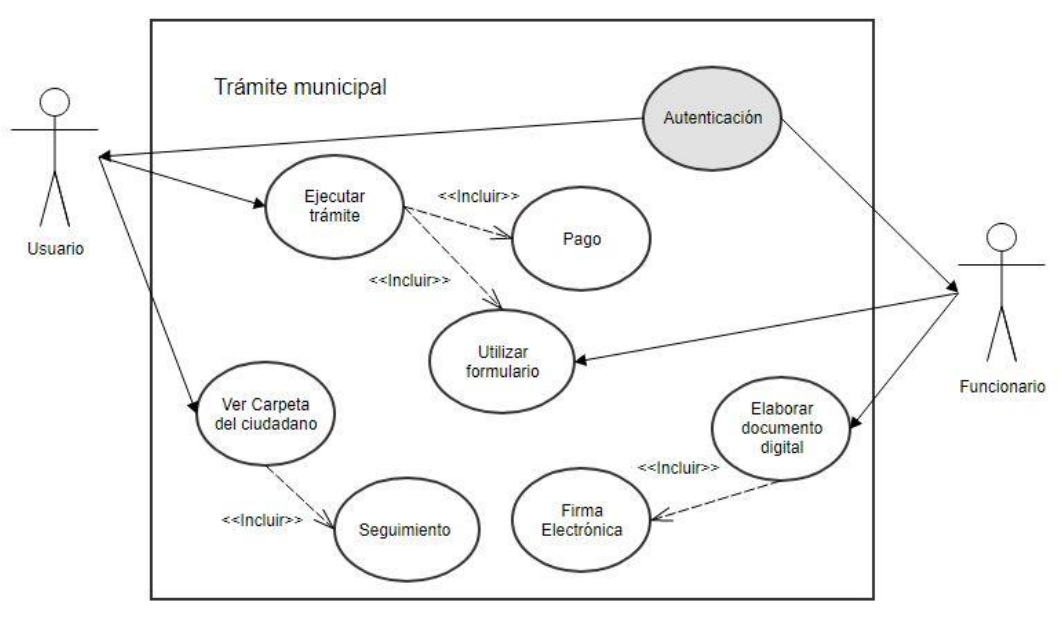

Fuente: Elaboración Propia

*Ver Anexo - MEMM-EDM-07-Caso de uso - Trámite Municipal

*Ver Anexo - MEMM-EDM-08-Caso de uso - Información Municipal

*Ver Anexo - MEMM-EDM-09-Caso de uso - Contacto con el Ciudadano 
Para entender cómo van a interactuar las aplicaciones entre ellas, se utiliza en artefacto matriz interacción entre aplicaciones. Se muestra una parte de la matriz mostrando como se relaciona el e-Trámite con otras aplicaciones. La siguiente tabla muestra dos columnas, la primera es Consume, la cual se refiere a las aplicaciones utilizadas por el sistema para ejecutar una función, mientras que la columna Comunica se refiere al intercambio de información con otra aplicación.

Tabla 6: Interacción del e-Trámite con las Otras Aplicaciones

\begin{tabular}{|c|c|}
\hline Consume & Comunica \\
\hline Mapa web & Chat en línea \\
\hline Llama IP & Tupa en línea \\
\hline & Carpeta del ciudadano \\
\hline & Formulario \\
\hline & Pago en línea \\
\hline
\end{tabular}

Fuente: Elaboración Propia

*Ver Anexo - MEMM-EDM-03-Matriz de interacción de aplicaciones

Si bien las aplicaciones identificadas van a ser consumidas por el proceso, se debe mapear como estas van a interactuar con todo el negocio. Por lo que, se debe realizar una relación entre los procesos con todas las aplicaciones de la entidad municipal.

Debido a que no se cuenta con el acceso a la información de todas las aplicaciones de la municipalidad de Santiago de Surco, no se elabora el documento.

\section{Análisis y Diseño de Infraestructura}

Como último paso, se debe determinar qué infraestructura va a soportar la propuesta. Primero, se identifica la parte lógica, es decir los sistemas que va a necesitar la infraestructura para que pueda ejecutar su función correctamente. Para esto, se usará un sistema gestor de base de datos, el cual permite el almacenamiento, modificación y extracción de la información en una base de datos; y un servidor web, referido a un programa informático que procesa una aplicación del lado del servidor realizando conexiones bidireccionales y/o unidireccionales y, síncronas o asíncronas con el cliente generando o cediendo una respuesta en cualquier lenguaje o aplicación del lado del cliente. 
Si bien ya se conoce la parte lógica, se procede a identificar la parte física de la infraestructura. Esta viene a ser el hardware necesario para alcanzar el objetivo.

Tabla 7: Hardware

\begin{tabular}{|c|c|}
\hline Nombre & Descripción \\
\hline & $\begin{array}{l}\checkmark \text { Procesadores: Hasta dos procesadores Intel } \AA \text { Xeon }{ }^{\mathrm{TM}} \text { con Tecnología de } 64 \text { bits de } \\
\text { memoria ampliada Intel de hasta } 3,6 \mathrm{GHz} \\
\checkmark \text { Memoria: } 12 \text { GB DDR2 } 400 \text { SDRAM; } 12 \text { GB con disponibilidad de } \\
\text { rack único de } 2 \text { GB DIMMS1 } \\
\checkmark \text { Unidad de disco: Ocho unidades de } 1 \text { “ + Dos unidades de } 1 \text { “ SCSI Ultra320 de conexión } \\
\text { en caliente con soporte de unidad de cinta interna } \\
\checkmark \text { Almacenamiento interno máximo: Hasta } 1,46 \text { TB de } 300 \text { GB } \\
\text { Unidades de disco duro: } 300 \text { GB2 Ultra320 SCSI } \\
\checkmark \text { Tarjeta de interfaz de red: Incorporado doble Intel } 1000 \text { Gigabit NIC; Intel PRO/1000 MT }\end{array}$ \\
\hline
\end{tabular}

Fuente: Elaboración Propia

*Ver Anexo - MEMM-EDM-03-Matriz de interacción de aplicaciones

*Ver Anexo - MEMM-EDM-12-Catálogo de portafolio de tecnología

Al utilizar el modelo con el proceso actual de licencia de funcionamiento, el resultado es el etrámite de licencia de funcionamiento listo para su implementación, analizado y diseñado con las buenas prácticas de la arquitectura empresarial TOGAF.

\section{Resultados}

Para validar el caso de estudio, se elaboran prototipos que fueron mostrados a los ciudadanos con licencia de funcionamiento para su local y a los participantes del trámite actual. La validación se realiza por medio de dos encuestas, una para cada grupo. Estas encuestas fueron desarrollas por medio de la escala de Likert, el cual se ha definido en 5 niveles: 1 Muy Alto, 2 Alto, 3 Medio, 4 Bajo, 5 Nada.

Además, se calcula la reducción de carga procesal mediante las actividades del flujo del proceso, midiendo los tiempos del trámite actual vs objetivo.

Las encuestas realizadas a los funcionarios contaron con cinco preguntas las cuales se detallan en la siguiente tabla. 
Tabla 8: Encuestas a Funcionarios

\begin{tabular}{|c|l|}
\hline Código & \multicolumn{1}{|c|}{ Pregunta } \\
\hline FP1 & $\begin{array}{l}\text { ¿Considera que la propuesta presentada disminuye la carga procesal de los } \\
\text { funcionarios? }\end{array}$ \\
\hline FP2 & ¿Considera que la propuesta presentada facilitaría al ciudadano a realizar sus trámites? \\
\hline FP3 & $\begin{array}{l}\text { ¿Considera que la propuesta presentada contribuye a mejorar la relación entre el ciudadano y } \\
\text { la municipalidad? }\end{array}$ \\
\hline FP4 & $\begin{array}{l}\text { ¿Considera que la propuesta presentada contribuye a que los procesos de la municipalidad } \\
\text { sean más transparentes para el ciudadano? }\end{array}$ \\
\hline FP5 & \begin{tabular}{l} 
En general, ¿Cómo considera la propuesta? \\
\hline
\end{tabular} \\
\hline
\end{tabular}

\section{Fuente: Elaboración Propia}

Por otro lado, las preguntas realizadas a los ciudadanos en la encuesta se pueden acontinuación.

Tabla 9: Preguntas de Encuestas a Ciudadanos

\begin{tabular}{|c|l|}
\hline Código & \multicolumn{2}{|c|}{ Pregunta } \\
\hline CP1 & $\begin{array}{l}\text { ¿Considera que la propuesta presentada le facilita solicitar una licencia de } \\
\text { funcionamiento? }\end{array}$ \\
\hline CP2 & ¿Considera que la municipalidad debería utilizar una solución como esta? \\
\hline CP3 & $\begin{array}{l}\text { ¿Considera que la propuesta presentada contribuye a mejorar la relación entre el } \\
\text { ciudadano y la municipalidad? }\end{array}$ \\
\hline CP4 & ¿Considera que la propuesta beneficiaría a los ciudadanos? \\
\hline CP5 & En general, ¿cómo considera la propuesta? \\
\hline
\end{tabular}

Fuente: Elaboración Propia

En primer lugar, se valida el trámite objetivo en cuatro municipalidades de Lima, las cuales fueron Chorrillos, Villa María del Triunfo, Barranco y Santiago de Surco. En estas, se encuestaron a 15 funcionarios públicos que participan en el proceso. Los resultados se muestran en la siguiente tabla.

Tabla 10: Resultado de Evaluación de Encuestas a Funcionarios

\begin{tabular}{|l|l|l|l|l|l|l|l|}
\hline Cód/Puntaje & 1 & 2 & 3 & 4 & 5 & Media & Análisis \\
\hline
\end{tabular}




\begin{tabular}{|c|c|c|c|c|c|c|c|}
\hline FP1 & 0 & 0 & 0 & 6 & 9 & 4.6 & Muy aceptable \\
\hline FP2 & 0 & 1 & 2 & 5 & 7 & 4.2 & Aceptable \\
\hline FP3 & 0 & 0 & 0 & 3 & 12 & 4.8 & Muy aceptable \\
\hline FP4 & 0 & 0 & 3 & 5 & 7 & 4.3 & Aceptable \\
\hline FP5 & 0 & 0 & 0 & 6 & 9 & 4.6 & Muy aceptable \\
\hline
\end{tabular}

Fuente: Elaboración Propia

Como se puede apreciar, en la pregunta FP5, el 60\% de los funcionarios entrevistados indican que es muy aceptable la propuesta mostrada, mientras que el $40 \%$ lo consideran como aceptable. En términos generales, la propuesta de licencia de funcionamiento tuvo muy buena aceptación.

En segundo lugar, la siguiente encuesta se realiza a 25 ciudadanos que cuentan con un local y una licencia de funcionamiento para del mismo, de las municipalidades antes mencionadas, obteniendo el resultado que se muestra a continuación.

Tabla 11: Resultado de Evaluación de Encuestas a Ciudadanos

\begin{tabular}{|c|c|c|c|c|c|c|c|}
\hline Cód/Puntaje & $\mathbf{1}$ & $\mathbf{2}$ & $\mathbf{3}$ & $\mathbf{4}$ & $\mathbf{5}$ & Media & Análisis \\
\hline CP1 & 0 & 0 & 1 & 4 & 20 & 4.8 & Muy aceptable \\
\hline CP2 & 0 & 0 & 0 & 2 & 23 & 4.9 & Muy aceptable \\
\hline CP3 & 0 & 0 & 0 & 1 & 24 & 5.0 & Muy aceptable \\
\hline CP4 & 0 & 0 & 1 & 3 & 21 & 4.8 & Muy aceptable \\
\hline CP5 & 0 & 0 & 0 & 0 & 25 & 5.0 & Muy aceptable \\
\hline
\end{tabular}

Fuente: Elaboración Propia

La tabla muestra que el $92 \%$ de los ciudadanos encuestados considera en la pregunta CP5 que la propuesta, es muy aceptable y el $8 \%$ lo considera aceptable. Por lo cual, se demuestra que la ciudadanía considera que un trámite de licencia de funcionamiento que se pueda ejecutar desde la web es una propuesta muy atractiva.

Para demostrar la reducción de carga procesal, se contabiliza las actividades ejecutadas por los funcionarios públicos tanto en el trámite actual como en el objetivo. La ventaja de este último es que hay un Sistema que ejecuta actividades que antes eran manuales para facilitar el trabajo a los funcionarios. La siguiente figura muestra el resultado obtenido. 
Figure 13: Resultado de Reducción de Carga Procesal del Trámite de Licencia de Funcionamiento

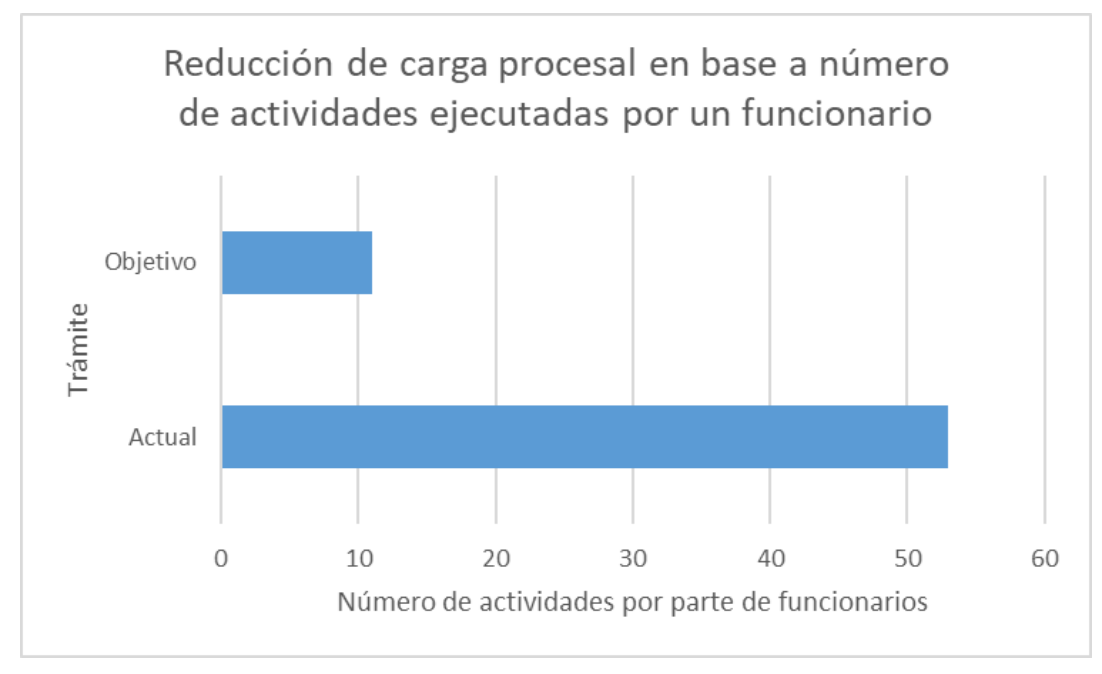

Fuente: Elaboración Propia

Las actividades en el trámite actual son de 54 para que se entregue la licencia de funcionamiento. La mayoría de estas son ejecutadas por los trabajadores recibiendo un pequeño apoyo de sistemas con los que cuenta la entidad. Por otro lado, el trámite objetivo cuenta con 11 actividades ejecutadas por los funcionarios públicos. Las demás han sido automatizadas por funcionalidades o e-Servicios. Esta diferencia representa una reducción de carga procesal del $79.63 \%$, lo cual evidencia una mejora sustancial en las actividades municipales.

\section{Juicio de Expertos}

Para la validación de juicio de expertos, se muestra el modelo a 6 profesionales en el área de tecnología de las municipalidades de Santiago de Surco, Barranco, Chorrillos, Miraflores y Villa María del Triunfo. Luego de la explicación del modelo y de los artefactos, se realiza una encuesta donde se obtuvo el siguiente resultado. 
Figure 14: Resultado de Juicio de Expertos Municipales en Tecnología

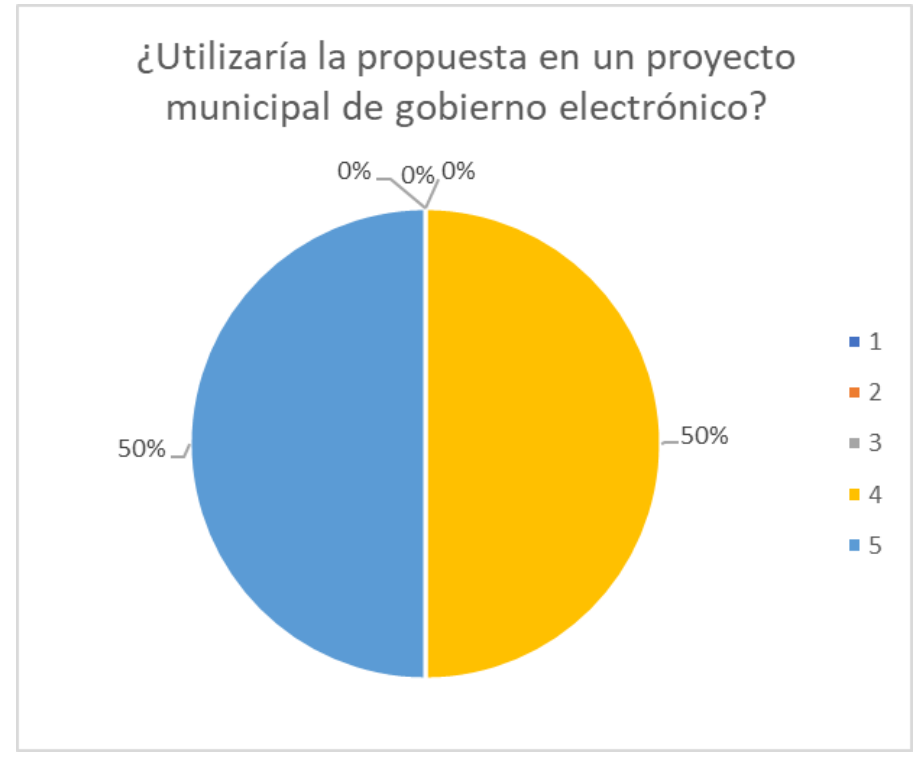

Fuente: Elaboración Propia

Como se puede apreciar, el 50\% de los expertos califican como "Muy aceptable" a la pregunta si utilizaría la propuesta en un proyecto de implementación de gobierno electrónico, mientras que el otro 50\% lo considera como "Aceptable". Estos resultados muestran una gran aceptación de la propuesta por parte de los expertos municipales de tecnología.

\section{Plan de Continuidad}

1. Framework de Implementación de Gobierno Electrónico Municipal enfocado en la fase e-Democracia

Problemática

Creciente interés de las municipalidades por una incentiva participación de los ciudadanos en las actividades del municipio y una relación más cercana con los mismos.

Causas

- No existe un framework de implementación de gobierno electrónico, específicamente de una de sus fases.

- El estado busca la modernización de sus instituciones.

- Las áreas de la municipalidad no se encuentran interconectados 
- La mayoría de las municipalidades no cuentan con información integrada.

Objetivos del Proyecto

Objetivo General: Proponer un framework de implementación de la fase de eDemocracia del Gobierno Electrónico Municipal.

OE1: Analizar el contexto actual del Gobierno Electrónico, en especial del gobierno electrónico municipal

OE2: Diseñar el framework de implementación de gobierno electrónico municipal enfocado en la fase de eDemocracia

OE3: Validar el framework de implementación de gobierno electrónico municipal enfocado en la fase de eDemocracia

OE4: Definir una cartera de proyectos que aseguran el éxito del modelo

Entregable o Resultado

Framework de implementación de gobierno electrónico municipal enfocado en la fase de eDemocracia

Paper

- eParticipation research: Systematizing the field (ISSN: 0740-624X)

En este paper se realiza un estudio de literatura de publicaciones conceptuales sobre el tema de eParticipation / eDemocracy en el período de tiempo 2007-2009, para poder rastrear el desarrollo teórico reciente en el campo, revelar las restricciones y limitaciones del área, y ofrecer algunas sugerencias para una mayor investigación. Los resultados del estudio muestran que la mayoría de las teorías actualmente utilizadas en la investigación conceptual eParticipation provienen de los campos de Ciencias Políticas, Medios y Estudios de Comunicación. Pero junto con esto, los autores contemporáneos de eParticipation contribuyen a fortalecer el campo con algunos modelos y marcos "internos" también. Los problemas centrales con la investigación eParticipation se refieren a la inmadurez del campo, las brechas tópicas y las suposiciones sesgadas. La revisión muestra que los temas de las publicaciones recientes se pueden agrupar en tres categorías principales: partes interesadas, 
medio ambiente y aplicaciones y herramientas. También encuentra algunas interconexiones entre estas categorías; sin embargo, en general, la tecnología de acoplamiento-stakeholders(participativos) es débil.

- The shape of eParticipation: Characterizing an emerging research area (ISSN: 0740$624 \mathrm{X})$

En este paper se realiza la revisión de literatura, identificando 131 artículos científicos considerados importantes para el desarrollo teórico del campo. Esta muestra proporciona el punto de partida para un análisis fundamentado que conduce al desarrollo de un modelo general: el campo de eParticipation visto desde la perspectiva de un investigador. El modelo proporciona una estructura para comprender la forma emergente del campo, así como una indicación inicial de su contenido. También proporciona la base para desarrollar agendas de investigación para el futuro.

- Characterizing eParticipation (ISSN: 0268-4012)

En este paper se traza algunas de las teorías y disciplinas académicas que aborda el área de eParticipation, utilizando técnicas de estudio de la literatura convencional, se identifican 99 artículos que se consideran altamente relevantes para eParticipation. Desarrollan un esquema de definición que sugiere diferentes formas de entender un área de investigación emergente, y usan este esquema para identificar artículos académicos clave que ayudan a definir eParticipation. Adaptam Deetz's, una taxonomía de los discursos en la ciencia organizacional para proporcionar un esquema general de categorización para la investigación en el área, y mapear la literatura. El artículo contribuye así a una imagen en desarrollo que ayudará a los futuros investigadores a comprender y navegar el área de investigación.

2. Seguridad de la Información para la fase e-Democracia del Gobierno Electrónico Municipal

Problemática

Creciente necesidad de las municipalidades por introducir la participación ciudadana, usando para este caso el voto electrónico, el cual es parte de la fase e-Democracia del gobierno electrónico municipal. 


\section{Causas}

- Se requiere implementar la última fase de gobierno electrónico municipal, el cual incluye la participación ciudadana.

- El voto electrónico es parte de la participación ciudadana, en donde los ciudadanos pueden participar en decisiones de la municipalidad y poder llegar a un consenso.

- Creciente demanda de transparencia de los procesos gubernamentales por parte de la ciudadanía.

- Se busca la incorporación de los gobiernos locales con los ciudadanos.

Objetivos del Proyecto

Objetivo General: Proponer un modelo de gestión de seguridad de la información para la fase de e-Democracia del Gobierno Electrónico Municipal

OE1: Analizar el contexto actual del uso de seguridad de la información

OE2: modelo de gestión de seguridad de la información para la fase de e-Democracia del Gobierno Electrónico Municipal.

OE3: modelo de gestión de seguridad de la información para la fase de e-Democracia del Gobierno Electrónico Municipal.

OE4: Definir una cartera de proyectos que aseguran el éxito del esquema.

Entregable o Resultado

Modelo de gestión de seguridad de la información para la fase de e-Democracia del Gobierno Electrónico Municipal

Paper

- Trading old errors for new errors? The impact of electronic voting technology on party label votes in Brazil (ISSN: 0261-3794)

En este paper se emplea un diseño de discontinuidad de regresión similar al de estudios previos de la tecnología de votación electrónica brasileña para mostrar que la tecnología 
electrónica también causó un fuerte aumento en los votos de etiqueta de partido que solo pueden explicarse por error de votación. Se muestra, además, que este error compensa una gran parte de las ganancias en el derecho al voto, destacando el hecho de que incluso los cambios generalmente positivos en los procedimientos de votación pueden tener efectos negativos. Los resultados sugieren que los votos de etiqueta del partido no se deben considerar una medida de la fuerza del partido en el contexto brasileño.

- A practical, secure, and auditable e-voting system (ISSN: 2214-2126)

En este paper se propone un sistema de votación electrónica criptográfica que reemplaza el método tradicional de votación, ampliamente utilizados en la mayoría de los países en desarrollo en la región de Medio Oriente y el Norte de África. El sistema de votación electrónica propuesto se basa en el concepto de Prêt àVoter, que es un esquema de voto electrónico en papel. Los esquemas de votación electrónica basados en MixNet, como Prêt àVoter, usan servidores de mezcla para crear canales anónimos. El esquema de votación electrónica propuesto elimina la necesidad de canales anónimos para anonimizar los votos en los esquemas de voto electrónico basados en Mixnet, pero proporciona un nivel comparable de seguridad y anonimato de voto con menos complejidad del sistema. El esquema de votación electrónica propuesto utiliza boletas de papel, debido a su familiaridad entre el público, pero con fuertes algoritmos criptográficos con funciones de seguridad comprobadas, para proporcionar un nivel mejorado de secreto de la boleta, verificabilidad y seguridad.

- Full privacy preserving electronic voting scheme (ISSN: 1005-8885)

En este paper se toca el tema de privacidad en el voto electrónico, más específicamente privacidad total, no solo la privacidad de los votantes, sino también la de los candidatos. Se presenta la preservación de la privacidad de la arquitectura de las elecciones electrónicas sin ningún tercero de confianza y también se proporciona una técnica general para la elección kout-of-m basada en el cifrado distribuido de ElGamal y el mix-match. Los votantes pueden calcular el resultado por sí mismos sin revelar su voluntad y el voto de los candidatos perdedores. Además, si el voto del candidato ganador es más de la mitad se puede verificar directamente. Este esquema satisface el patrón de "votar y continuar" y logra una privacidad total. La corrección y la seguridad también se analizan.

3. Aplicación de DataMining como aporte a la fase e-Democracia del Gobierno Electrónico Municipal 


\section{Problemática}

Las municipalidades cuentan con una gran cantidad de datos de información y requiere de esta información para la realización de sus trámites y procesos.

Causas

- Las municipalidades cuentan con gran cantidad de información.

- La información de las municipalidades se encuentra en documentos físicos.

- Las instituciones públicas como las municipalidades se deben encontrar asociados a la transparencia, eficiencia y eficacia.

- Búsqueda de las instituciones públicas de brindar facilidades al ciudadano para obtener información pública.

Objetivos del Proyecto:

Objetivo General: Proponer un modelo de aplicación de DataMining para el Gobierno Electrónico Municipal

OE1: Analizar el contexto DataMining

OE2: Diseñar el modelo de aplicación de DataMining para el desarrollo del Gobierno Electrónico Municipal

OE3: Validar el modelo de aplicación de DataMining para el desarrollo del Gobierno Electrónico Municipal

OE4: Definir una cartera de proyectos que aseguran el éxito del modelo

Entregable o Resultado

Modelo de aplicación de DataMining para el desarrollo del Gobierno Electrónico Municipal.

Paper

- Enhancing usability testing through datamining techniques: A novel approach to detecting usability problem patterns for a context of use (ISSN: 0950-5849) 
En este paper se presenta un nuevo enfoque de usabilidad, aquí se utilizan dos técnicas de datamining (reglas de asociación y árboles de decisión) para extender el proceso de prueba de usabilidad cualitativa existente a fin de proporcionar un diagnóstico de usabilidad general de un contexto dado de uso de un punto de vista cualitativo Para validar nuestra propuesta, los patrones de problemas de usabilidad pertenecientes a páginas web académicas en países de habla hispana se evalúan procesando 3450 registros que almacenan información cualitativa recopilada mediante una Evaluación Heurística.

- Class dependent feature scaling method using naive Bayes classifier for text datamining (ISSN: 0167-8655)

Una parte crítica de la selección de características es clasificar las características según su importancia. El clasificador ingenuo de Bayes se ha usado ampliamente en la categorización de texto. Se ha desarrollado un nuevo método de escalado de funciones, ponderación de características dependientes de la clase (CDFW) usando el clasificador Naive Bayes (NB). Un nuevo método de escalado de funciones, CDFW-NB-RFE, combina CDFW y eliminación de características recursivas (RFE). Los resultados experimentales mostraron que CDFWNB-RFE superó a otros esquemas de clasificación de características populares utilizados en conjuntos de datos de texto.

- Accounting and Financial Data Analysis Data Mining Tools (ISSN: 2067-9211)

En este paper los autores analizan los sistemas de contabilidad computarizados de los últimos años, los cuales han aumentado la complejidad debido al entorno económico competitivo, pero con ayuda de soluciones de análisis de datos como OLAP y Data Mining pueden ser datos multidimensionales, asegurando que dicha información sea útil para la toma de decisiones dentro de la organización. Realizan la literatura acerca de la definición de minería de datos, pero encuentran que todo se reduce a la misma idea: el proceso se lleva a cabo para extraer nueva información de grandes colecciones de datos difíciles de obtener. La información obtenida por el proceso de minería de datos tiene la ventaja de que solo responde a la pregunta de qué sucede, pero al mismo tiempo argumenta y muestra por qué ciertas cosas están sucediendo. En este documento, presentan técnicas avanzadas para el análisis y la explotación de datos almacenados en una base de datos multidimensional. 


\section{Capítulo 7: Gestión del Proyecto}

En este capítulo se da a conocer la gestión del proyecto luego de haberlo realizado. Este se desarrolló bajo la metodología PMBOK. Se detalla el tiempo empleado con la planificación, la gestión para la realización del proyecto, tales como la gestión de los recursos humanos, comunicaciones y riesgos; y las lecciones aprendidas obtenidas al finalizar la elaboración del proyecto.

\section{Producto Final}

El producto resultante es un modelo de mejora de servicios electrónicos municipales, el cual se encuentra basado por buenas prácticas del gobierno electrónico y para el cual se analiza la selección de artefactos del ADM. Este esquema permitirá que una municipalidad pueda autoevaluarse con respecto al nivel de gobierno electrónico que presenta y brinda una guía de implementación de este. Con este modelo se busca mejorar la calidad, eficiencia y eficacia de los servicios brindados a los ciudadanos y otras empresas.

El producto que se obtendrá estará alineado totalmente al alcance planteado al inicio del proyecto y contempla lo siguiente:

- Realización de un estudio acerca de definición de e-Government, sus características y sus ventajas.

- Realización de un estudio de casos de éxito en otros países.

- Realización de un estudio del estado actual del Perú con respecto al gobierno electrónico.

- Análisis de entregables y artefactos de las fases Requerimientos, Preliminar, A Visión de la Arquitectura, B - Arquitectura de Negocio, C - Arquitectura de Sistemas de Información y D - Arquitectura Tecnológica del ADM.

- Realización de análisis de Retorno de Inversión (ROI) que evidencie la rentabilidad del proyecto de implementación. 
Así mismo, el proyecto no abarcó:

- La realización de las fases E, F, G y H de TOGAF para el esquema de e-Government.

- No se implementará el esquema propuesto de e-Government.

\section{Gestión del Tiempo}

Se detalla el cronograma que ha sido elaborado al inicio del proyecto, el cual es actualizado conforme el avance de este. El cronograma elaborado a inicio del proyecto es el siguiente: 
Figure 15: Cronograma de Proyecto 2016-02 (Parte 1)

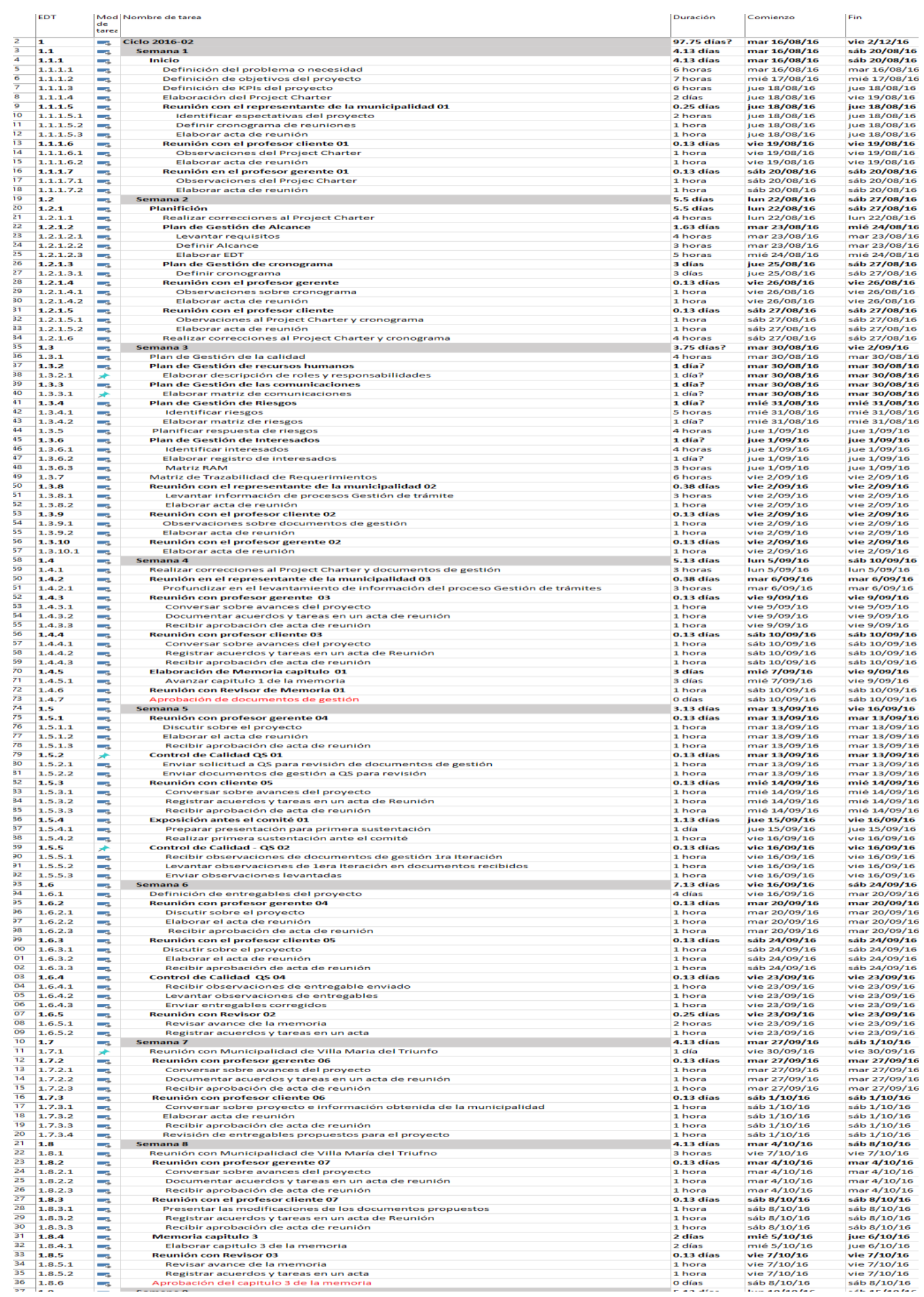

Fuente: Elaboración Propia 
Figure 16: Cronograma de Proyecto 2016-02 (Parte 2)

\begin{tabular}{|c|c|c|c|c|c|c|}
\hline 1ـ، & 1.9 & $\mathbf{5}$ & semanta y & 5.13 ulas & $\operatorname{sun} 10 / 10 / 10$ & Sav $13 / 10 / 10$ \\
\hline 138 & 1.9.1 & 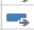 & Elaboración de la primera versión del proceso de la municipalidad & 2 días & Iun 10/10/16 & $\operatorname{mar} 11 / 10 / 16$ \\
\hline 139 & 1.9.2 & - & Reunión con Municipalidad de Villa María del Triunfo & 3 horas & vie $14 / 10 / 16$ & vie $14 / 10 / 16$ \\
\hline 140 & 1.9 .3 & $=$ & Reunión con profesor gerente 08 & 0.13 días & mar 11/10/16 & $\operatorname{mar} 11 / 10 / 16$ \\
\hline 141 & 1.9.3.1 & - & Conversar sobre avances del proyecto & 1 hora & $\operatorname{mar} 11 / 10 / 16$ & $\operatorname{mar} 11 / 10 / 16$ \\
\hline 142 & 1.9.3.2 & 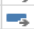 & Documentar acuerdos y tareas en un acta de reunión & 1 hora & $\operatorname{mar} 11 / 10 / 16$ & $\operatorname{mar} 11 / 10 / 16$ \\
\hline 143 & 1.9.3.3 & $\Rightarrow$ & Recibir aprobación de acta de reunión & 1 hora & $\operatorname{mar} 11 / 10 / 16$ & $\operatorname{mar} 11 / 10 / 16$ \\
\hline 144 & 1.9.4 & $\Rightarrow$ & Reunión con cliente 08 & 0.13 dias & sáb 15/10/16 & sáb 15/10/16 \\
\hline 145 & 1.9.4.1 & -5 & Conversar sobre el proyecto & 1 hora & sáb 15/10/16 & sáb 15/10/16 \\
\hline 146 & 1.9.4.2 & $\Rightarrow$ & Registrar acuerdos y tareas en un acta de Reunión & 1 hora & sáb 15/10/16 & sáb 15/10/16 \\
\hline 147 & 1.9.4.3 & $\Rightarrow$ & Recibir aprobación de acta de reunión & 1 hora & sáb 15/10/16 & sáb 15/10/16 \\
\hline 148 & 1.10 & $\Rightarrow$ & Semana 10 & 5 días? & mar 18/10/16 & sáb 22/10/16 \\
\hline 149 & 1.10 .1 & $=$ & Reunión con Municipalidad de Villa María del Triunfo & 3 horas & vie $21 / 10 / 16$ & vie $21 / 10 / 16$ \\
\hline 150 & 1.10 .2 & $=$ & Reunión con profesor gerente 09 & 0.13 dias & mar 18/10/16 & $\operatorname{mar} 18 / 10 / 16$ \\
\hline 151 & 1.10.2.1 & $\Rightarrow$ & Conversar sobre avances del proyecto v1.0 & 1 hora & mar 18/10/16 & $\operatorname{mar} 18 / 10 / 16$ \\
\hline 152 & 1.10.2.2 & $\Rightarrow$ & Documentar acuerdos y tareas en un acta de reunión & 1 hora & mar 18/10/16 & $\operatorname{mar} 18 / 10 / 16$ \\
\hline 153 & 1.10 .2 .3 & $\Rightarrow$ & Recibir aprobación de acta de reunión & 1 hora & mar 18/10/16 & $\operatorname{mar} 18 / 10 / 16$ \\
\hline 154 & 1.10 .3 & -5 & Reunión con profesor cliente 09 & 1 día? & sáb 22/10/16 & sáb 22/10/16 \\
\hline 155 & 1.10.3.1 & -5 & Conversar sobre el proyecto & 1 hora & sáb 22/10/16 & sáb 22/10/16 \\
\hline 156 & 1.10.3.2 & $\Rightarrow$ & Registrar acuerdos y tareas en un acta de Reunión & 1 hora & sáb 22/10/16 & sáb 22/10/16 \\
\hline 157 & 1.10.3.3 & $\Rightarrow$ & Recibir aprobación de acta de reunión & 1 hora & sáb 22/10/16 & sáb 22/10/16 \\
\hline 158 & 1.10.3.4 & त? & Revisión de la primera versión del proceso & & & \\
\hline 159 & 1.10 .4 & -5 & Memoria capitulo 4 & 0.38 días & mié 19/10/16 & mié 19/10/16 \\
\hline 160 & 1.10.4.1 & $=$ & Elaborar capitulo 4 de la memoria & 3 horas & mié 19/10/16 & mié 19/10/16 \\
\hline 161 & 1.10 .5 & $=$ & Reunión con Revisor 04 & 0.13 días & vie 21/10/16 & vie $21 / 10 / 16$ \\
\hline 162 & 1.10.5.1 & 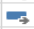 & Revisar avance de la memoria & 1 hora & vie $21 / 10 / 16$ & vie $21 / 10 / 16$ \\
\hline 163 & 1.10 .5 .2 & $\Rightarrow$ & Registrar acuerdos y tareas en un acta & 1 hora & vie $21 / 10 / 16$ & vie $21 / 10 / 16$ \\
\hline 164 & 1.11 & -9 & Semana 11 & 5 días? & mar 25/10/16 & sáb 29/10/16 \\
\hline 165 & 1.11.1 & $\Rightarrow$ & Elaboración de segunda versión del proceso & 1 día & mié 26/10/16 & mié $26 / 10 / 16$ \\
\hline 166 & 1.11.2 & - & Reunión con Munícipalidad de Villa María del Triunfo & 3 horas & mar 25/10/16 & $\operatorname{mar} 25 / 10 / 16$ \\
\hline 167 & 1.11 .3 & - & Reunión con el profesor gerente 10 & 0.13 días & mar 25/10/16 & $\operatorname{mar} 25 / 10 / 16$ \\
\hline 168 & 1.11.3.1 & 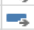 & Conversar sobre avances del proyecto & 1 hora & mar 25/10/16 & $\operatorname{mar} 25 / 10 / 16$ \\
\hline 169 & 1.11.3.2 & $\Rightarrow$ & Documentar acuerdos y tareas en un acta de reunión & 1 hora & mar 25/10/16 & $\operatorname{mar} 25 / 10 / 16$ \\
\hline 170 & 1.11.3.3 & $\Rightarrow$ & Recibir aprobación de acta de reunión & 1 hora & mar 25/10/16 & $\operatorname{mar} 25 / 10 / 16$ \\
\hline 171 & 1.11 .4 & $\Rightarrow$ & Reunión con el profesor cliente 10 & 1 día? & sáb 29/10/16 & sáb 29/10/16 \\
\hline 172 & 1.11.4.1 & $\Rightarrow$ & Conversar sobre el proyecto & 1 hora & sáb 29/10/16 & sáb 29/10/16 \\
\hline 173 & 1.11.4.2 & $\Rightarrow$ & Registrar acuerdos y tareas en un acta de Reunión & 1 hora & sáb 29/10/16 & sáb 29/10/16 \\
\hline 174 & 1.11.4.3 & $\Rightarrow$ & Recibir aprobación de acta de reunión & 1 hora & sáb 29/10/16 & sáb 29/10/16 \\
\hline 175 & 1.11.4.4 & ते & Aprobación de segunda versión del proceso & & & \\
\hline 176 & 1.12 & $\Rightarrow$ & Semana 12 & 6 días? & Iun 31/10/16 & sáb 5/11/16 \\
\hline 177 & 1.12 .1 & $\Rightarrow$ & Reunión con Municipalidad de Villa María del Triunfo & 3 horas & Iun $31 / 10 / 16$ & Iun $31 / 10 / 16$ \\
\hline 178 & 1.12 .2 & 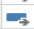 & Elaboración de primera versión de segundo proceso & 2 dias & $\operatorname{mar} 1 / 11 / 16$ & mié $2 / 11 / 16$ \\
\hline 179 & 1.12 .3 & -5 & Reunión con profesor gerente 11 & 0.13 días & $\operatorname{mar} 1 / 11 / 16$ & $\operatorname{mar} 1 / 11 / 16$ \\
\hline 180 & 1.12.3.1 & $\Rightarrow$ & Conversar sobre avances del proyecto & 1 hora & $\operatorname{mar} 1 / 11 / 16$ & $\operatorname{mar} 1 / 11 / 16$ \\
\hline 181 & 1.12.3.2 & -5 & Documentar acuerdos y tareas en un acta de reunión & 1 hora & $\operatorname{mar} 1 / 11 / 16$ & $\operatorname{mar} 1 / 11 / 16$ \\
\hline 182 & 1.12 .3 .3 & -5 & Recibir aprobación de acta de reunión & 1 hora & $\operatorname{mar} 1 / 11 / 16$ & $\operatorname{mar} 1 / 11 / 16$ \\
\hline 183 & 1.12 .4 & -5 & Reunión con profesor cliente 11 & 1 día? & sáb 5/11/16 & sáb 5/11/16 \\
\hline 184 & 1.12.4.1 & $\Rightarrow$ & Conversar sobre el proyecto & 1 hora & sáb 5/11/16 & sáb 5/11/16 \\
\hline 185 & 1.12.4.2 & -5 & Registrar acuerdos y tareas en un acta de Reunión & 1 hora & sáb 5/11/16 & sáb 5/11/16 \\
\hline 186 & 1.12.4.3 & $\Rightarrow$ & Recibir aprobación de acta de reunión & 1 hora & sáb 5/11/16 & sáb 5/11/16 \\
\hline 187 & 1.12.4.4 & t? & Revisión de primera versión del segundo proceso & & & \\
\hline 188 & 1.13 & $\Rightarrow$ & Semana 13 & 6.25 días? & sáb 5/11/16 & sáb 12/11/16 \\
\hline 189 & 1.13 .1 & -5 & Reunión con Municipalidad de Villa María del Triunfo & 3 horas & Iun $7 / 11 / 16$ & Iun $7 / 11 / 16$ \\
\hline 190 & 1.13.2 & 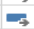 & Elaboración de segunda versión del segundo proceso & 3 días & sáb 5/11/16 & mié $9 / 11 / 16$ \\
\hline 191 & 1.13 .3 & $\Rightarrow$ & Reunión con profesor gerente 12 & 0.13 días & $\operatorname{mar} 8 / 11 / 16$ & $\operatorname{mar} 8 / 11 / 16$ \\
\hline 192 & 1.13.3.1 & $\Rightarrow$ & Conversar sobre avances del proyecto & 1 hora & $\operatorname{mar} 8 / 11 / 16$ & $\operatorname{mar} 8 / 11 / 16$ \\
\hline 193 & 1.13.3.2 & $\Rightarrow$ & Documentar acuerdos y tareas en un acta de reunión & 1 hora & $\operatorname{mar} 8 / 11 / 16$ & $\operatorname{mar} 8 / 11 / 16$ \\
\hline 194 & 1.13.3.3 & $\Rightarrow$ & Recibir aprobación de acta de reunión & 1 hora & $\operatorname{mar} 8 / 11 / 16$ & $\operatorname{mar} 8 / 11 / 16$ \\
\hline 195 & 1.13 .4 & $\Rightarrow$ & Reunión con cliente 12 & 1 día? & sáb 12/11/16 & sáb 12/11/16 \\
\hline 196 & 1.13.4.1 & $\Rightarrow$ & Conversar sobre el proyecto & 1 hora & sáb 12/11/16 & sáb 12/11/16 \\
\hline 197 & 1.13.4.2 & $\Rightarrow$ & Registrar acuerdos y tareas en un acta de Reunión & 1 hora & sáb 12/11/16 & sáb 12/11/16 \\
\hline 198 & 1.13.4.3 & $\Rightarrow$ & Recibir aprobación de acta de reunión & 1 hora & sáb 12/11/16 & sáb 12/11/16 \\
\hline 199 & 1.13.4.4 & t? & Revisión de segunda versión del segundo proceso & & & \\
\hline 200 & 1.14 & $\Rightarrow$ & Semana 14 & 5.38 días? & sáb 12/11/16 & sáb 19/11/16 \\
\hline 201 & 1.14 .1 & $\Rightarrow$ & Solicitud de cambio de nombre del proyecto & 1 día? & sáb 12/11/16 & Iun $14 / 11 / 16$ \\
\hline 202 & 1.14.1.1 & $\Rightarrow$ & Aprobación del profesor gerente & 6 horas & sáb 12/11/16 & Iun $14 / 11 / 16$ \\
\hline 203 & 1.14.1.2 & $\Rightarrow$ & Aprobación del profesor cliente & 4 horas & sáb 12/11/16 & Iun $14 / 11 / 16$ \\
\hline 204 & 1.14.1.3 & t? & Aprobación de comité & & & \\
\hline 205 & 1.14.2 & $\Rightarrow$ & Reunión con profesor gerente 13 & 0.13 días & $\operatorname{mar} 15 / 11 / 16$ & $\operatorname{mar} 15 / 11 / 16$ \\
\hline 206 & 1.14.2.1 & $\Rightarrow$ & Conversar sobre avances del proyecto & 1 hora & $\operatorname{mar} 15 / 11 / 16$ & $\operatorname{mar} 15 / 11 / 16$ \\
\hline 207 & 1.14.2.2 & $\Rightarrow$ & Documentar acuerdos y tareas en un acta de reunión & 1 hora & $\operatorname{mar} 15 / 11 / 16$ & $\operatorname{mar} 15 / 11 / 16$ \\
\hline 208 & 1.14 .2 .3 & $\Rightarrow$ & Recibir aprobación de acta de reunión & 1 hora & $\operatorname{mar} 15 / 11 / 16$ & $\operatorname{mar} 15 / 11 / 16$ \\
\hline 209 & 1.14 .3 & $\Rightarrow$ & Reunión con profesor cliente 13 & 0.13 días & sáb 19/11/16 & sáb 19/11/16 \\
\hline 210 & 1.14.3.1 & 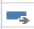 & Conversar sobre el proyecto & 1 hora & sáb 19/11/16 & sáb 19/11/16 \\
\hline 211 & 1.14.3.2 & 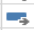 & Registrar acuerdos y tareas en un acta de Reunión & 1 hora & sáb 19/11/16 & sáb 19/11/16 \\
\hline 212 & 1.14.3.3 & $\Rightarrow$ & Recibir aprobación de acta de reunión & 1 hora & sáb 19/11/16 & sáb 19/11/16 \\
\hline 213 & 1.15 & $\Rightarrow$ & Semana 15 & 5 días? & mar 22/11/16 & sáb 26/11/16 \\
\hline 214 & 1.15 .1 & 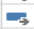 & Reunión con profesor gerente 14 & 0.13 días & mar 22/11/16 & $\operatorname{mar} 22 / 11 / 16$ \\
\hline 215 & 1.15.1.1 & - & Conversar sobre avances del proyecto & 1 hora & mar 22/11/16 & $\operatorname{mar} 22 / 11 / 16$ \\
\hline 216 & 1.15.1.2 & $\Rightarrow$ & Documentar acuerdos y tareas en un acta de reunión & 1 hora & mar 22/11/16 & $\operatorname{mar} 22 / 11 / 16$ \\
\hline 217 & 1.15.1.3 & $\Rightarrow$ & Recibir aprobación de acta de reunión & 1 hora & mar 22/11/16 & $\operatorname{mar} 22 / 11 / 16$ \\
\hline 218 & 1.15.2 & $\Rightarrow$ & Reunión con profesor cliente 14 & 1 día? & sáb 26/11/16 & sáb 26/11/16 \\
\hline 219 & 1.15.2.1 & $\Rightarrow$ & Conversar sobre el proyecto & 1 hora & sáb 26/11/16 & sáb 26/11/16 \\
\hline 220 & 1.15.2.2 & $\Rightarrow$ & Registrar acuerdos y tareas en un acta de Reunión & 1 hora & sáb 26/11/16 & sáb 26/11/16 \\
\hline 221 & 1.15.2.3 & $\Rightarrow$ & Recibir aprobación de acta de reunión & 1 hora & sáb 26/11/16 & sáb 26/11/16 \\
\hline 222 & 1.15.2.4 & त? & Exposición ante profesor cliente & & & \\
\hline 223 & 1.16 & $\Rightarrow$ & Semana 16 & 5.25 días & sáb 26/11/16 & vie $2 / 12 / 16$ \\
\hline 224 & 1.16 .1 & $\Rightarrow$ & Exposición antes el comité 02 & 5.25 dias & sáb 26/11/16 & vie $2 / 12 / 16$ \\
\hline 225 & 1.16.1.1 & $\Rightarrow$ & Preparar presentación para sustentación final & 8 horas & vie $2 / 12 / 16$ & vie $2 / 12 / 16$ \\
\hline 226 & 1.16.1.2 & $\boldsymbol{\sigma}$ & Realizar primera sustentación ante el comité final & 1 hora & sáb 26/11/16 & sáb 26/11/16 \\
\hline 227 & 1.16 .2 & - & Aprobación de Primera parte del Proyecto & O días & sáb 26/11/16 & sáb 26/11/16 \\
\hline
\end{tabular}

Fuente: Elaboración Propia 
A continuación, se presenta el cronograma desarrollado para el ciclo 2017-2.

Figure 17: Cronograma de Proyecto 2017-02 (Parte 1)

\begin{tabular}{|c|c|}
\hline 232 & 2.1 \\
\hline 233 & 2.1 .1 \\
\hline 234 & 2.1.1.1 \\
\hline 235 & 2.1.1.2 \\
\hline 236 & 2.1.1.3 \\
\hline 237 & 2.1.1.4 \\
\hline 238 & 2.1 .2 \\
\hline 239 & 2.1.2.1 \\
\hline 240 & 2.1 .2 .2 \\
\hline 241 & 2.1 .2 .3 \\
\hline 242 & 2.2 \\
\hline 243 & 2.2 .1 \\
\hline 244 & 2.2.1.1 \\
\hline 245 & 2.2 .1 .2 \\
\hline 246 & 2.2 .1 .3 \\
\hline 247 & 2.2 .2 \\
\hline 248 & 2.2 .2 .1 \\
\hline 249 & 2.2 .3 \\
\hline 250 & 2.2 .3 .1 \\
\hline 251 & 2.2 .3 .2 \\
\hline 252 & 2.2 .3 .3 \\
\hline 253 & 2.2 .4 \\
\hline 254 & 2.2 .4 .1 \\
\hline 255 & 2.2 .4 .2 \\
\hline 256 & 2.2.4.3 \\
\hline 257 & 2.2 .4 .4 \\
\hline 258 & 2.2 .5 \\
\hline 259 & 2.2 .5 .1 \\
\hline 260 & 2.2 .5 .2 \\
\hline 261 & 2.2 .5 .3 \\
\hline 262 & 2.2 .5 .4 \\
\hline 263 & 2.2 .5 .5 \\
\hline 264 & 2.2 .5 .6 \\
\hline 265 & 2.2 .5 .7 \\
\hline 266 & 2.2 .5 .8 \\
\hline 267 & 2.2 .5 .9 \\
\hline 268 & 2.3 \\
\hline 269 & 2.3.1 \\
\hline 270 & 2.3.1.1 \\
\hline 271 & 2.3 .1 .2 \\
\hline 272 & 2.3.1.3 \\
\hline 273 & 2.3 .2 \\
\hline 274 & 2.3.2.1 \\
\hline 275 & 2.3 .3 \\
\hline 276 & 2.3.3.1 \\
\hline 277 & 2.3.3.2 \\
\hline 278 & 2.3.3.3 \\
\hline 279 & 2.3.3.4 \\
\hline 280 & 2.3 .4 \\
\hline 281 & 2.3 .4 .1 \\
\hline 282 & 2.3.4.2 \\
\hline 283 & 2.3.4.3 \\
\hline 284 & 2.3.4.4 \\
\hline 285 & 2.3 .4 .5 \\
\hline 286 & 2.3.4.6 \\
\hline 287 & 2.3.4.7 \\
\hline 288 & 2.3 .5 \\
\hline 289 & 2.3 .5 .1 \\
\hline 290 & 2.3 .5 .2 \\
\hline 291 & 2.3 .5 .3 \\
\hline 292 & 2.3 .5 .4 \\
\hline 293 & 2.3.5.5 \\
\hline 294 & 2.3 .5 .6 \\
\hline 295 & 2.3 .5 .7 \\
\hline 296 & 2.3 .5 .8 \\
\hline 297 & 2.3.5.9 \\
\hline 298 & 2.3 .5 .9 .1 \\
\hline 299 & 2.3 .5 .9 .2 \\
\hline 300 & 2.3.5.9.3 \\
\hline 301 & 2.3.5.9.4 \\
\hline 302 & 2.4 \\
\hline 303 & $\begin{array}{l}2.4 \\
2.4 .1\end{array}$ \\
\hline 304 & 2.4.1.1 \\
\hline 305 & 2.4 .1 .2 \\
\hline 306 & 2.4 .1 .3 \\
\hline 307 & 2.4.1.4 \\
\hline 308 & 2.4 .1 .5 \\
\hline 309 & 2.4 .1 .6 \\
\hline 310 & 2.4 .1 .7 \\
\hline 311 & 2.4.1.1.8 \\
\hline 312 & 2.4 .1 .9 \\
\hline 313 & 2.4.1.10 \\
\hline 314 & 2.4.1.10.1 \\
\hline 315 & 2.4 .1 .10 .2 \\
\hline 316 & 2.4.1.10.3 \\
\hline 317 & 2.4.1.11 \\
\hline 318 & 2.4.1.11.1 \\
\hline 319 & 2.4.1.12 \\
\hline 320 & 2.4 .1 .12 .1 \\
\hline 321 & 2.4.1.12.2 \\
\hline 322 & 2.4.1.12.3 \\
\hline 323 & 2.4.1.12.4 \\
\hline 324 & 2.4.1.12.5 \\
\hline 325 & 2.4 .1 .12 .5 \\
\hline 326 & 2.4.1.12.5 \\
\hline 327 & 2.4.1.12.5 \\
\hline 328 & 2.4.1.12.5 \\
\hline
\end{tabular}

Fuente: Elaboración Propia 
Figure 18: Cronograma de Proyecto 2017-02 (Parte 2)

\begin{tabular}{|c|}
\hline$\ldots$ \\
\hline 329 \\
\hline 330 \\
\hline 331 \\
\hline 332 \\
\hline 333 \\
\hline 334 \\
\hline 335 \\
\hline 336 \\
\hline 337 \\
\hline 338 \\
\hline 339 \\
\hline 340 \\
\hline 341 \\
\hline 342 \\
\hline 343 \\
\hline 344 \\
\hline 345 \\
\hline 346 \\
\hline 347 \\
\hline 348 \\
\hline 349 \\
\hline 350 \\
\hline 351 \\
\hline 352 \\
\hline 353 \\
\hline 354 \\
\hline 355 \\
\hline 356 \\
\hline 357 \\
\hline 358 \\
\hline 359 \\
\hline 360 \\
\hline 361 \\
\hline 362 \\
\hline 363 \\
\hline 364 \\
\hline 365 \\
\hline 366 \\
\hline 367 \\
\hline 368 \\
\hline 369 \\
\hline 370 \\
\hline 371 \\
\hline 372 \\
\hline 373 \\
\hline 374 \\
\hline 375 \\
\hline 376 \\
\hline 377 \\
\hline 378 \\
\hline 379 \\
\hline 380 \\
\hline 381 \\
\hline 382 \\
\hline 383 \\
\hline 384 \\
\hline 385 \\
\hline 386 \\
\hline 387 \\
\hline 388 \\
\hline 389 \\
\hline 390 \\
\hline 391 \\
\hline 392 \\
\hline 393 \\
\hline 394 \\
\hline 395 \\
\hline 396 \\
\hline 397 \\
\hline 398 \\
\hline 399 \\
\hline 400 \\
\hline 401 \\
\hline 402 \\
\hline 403 \\
\hline 404 \\
\hline 405 \\
\hline 406 \\
\hline 407 \\
\hline 408 \\
\hline 409 \\
\hline 410 \\
\hline 411 \\
\hline 412 \\
\hline 413 \\
\hline 414 \\
\hline 415 \\
\hline 416 \\
\hline 417 \\
\hline 418 \\
\hline 419 \\
\hline 420 \\
\hline 421 \\
\hline 422 \\
\hline 423 \\
\hline 424 \\
\hline 425 \\
\hline
\end{tabular}

Fuente: Elaboración Propia 
Figure 19: Cronograma de Proyecto 2017-02 (Parte 3)

\begin{tabular}{|c|c|c|}
\hline & & \\
\hline 426 & 2.10 & \\
\hline 27 & 2.10 .1 & \\
\hline 28 & 2.10 .2 & \\
\hline 29 & 2.10 .2 .1 & \\
\hline 30 & 2.10 .2 .2 & \\
\hline 431 & 2.10 .2 .3 & \\
\hline 432 & 2.10 .3 & \\
\hline 433 & 2.10 .3 .1 & \\
\hline 434 & 2.10 .4 & \\
\hline 435 & 2.10 .4 .1 & \\
\hline 436 & 2.10 .4 .2 & \\
\hline 437 & 2.10 .4 & \\
\hline 438 & 2.10 .4 & \\
\hline 439 & 2.11 & \\
\hline 440 & 2.11.1 & \\
\hline 441 & 2.11.1.1 & \\
\hline 442 & 2.11.1.2 & \\
\hline 443 & 2.11.1. & \\
\hline 444 & 2.11 .2 & \\
\hline 445 & 2.11.2. & \\
\hline 446 & 2.11 .3 & \\
\hline 447 & 2.11 .3 & \\
\hline 448 & 2.11 & \\
\hline 449 & 2.11 & \\
\hline 450 & 2.11 .4 & \\
\hline 451 & 2.12 & \\
\hline 452 & 2.12 .1 & \\
\hline 453 & 2.12 . & \\
\hline 454 & 2.12 . & \\
\hline 455 & 2.12 .1 & \\
\hline 456 & 2.12 .2 & \\
\hline 457 & 2.12 .2 & \\
\hline 458 & 2.12 .3 & \\
\hline 459 & 2.12 & \\
\hline 460 & 2.12 .3 & \\
\hline 461 & 2.12.3. & \\
\hline 462 & 2.13 & \\
\hline 463 & 2.13.1 & \\
\hline 464 & 2.13 .2 & \\
\hline 465 & 2.13 .2 & \\
\hline 466 & 2.13.2 & \\
\hline 467 & 2.13 . & \\
\hline 468 & 2.13 .3 & \\
\hline 469 & 2.13 . & \\
\hline 470 & 2.13. & \\
\hline 471 & 2.13 . & \\
\hline 472 & 2.13 . & \\
\hline 473 & 2.13. & \\
\hline 474 & 2.14 & \\
\hline 475 & 2.14 & \\
\hline 476 & 2.14 & \\
\hline 477 & 2.14 .3 & \\
\hline 478 & 2.14 .3 & \\
\hline 479 & 2.14. & \\
\hline 480 & 2.14.4 & \\
\hline 481 & 2.14 .5 & \\
\hline 482 & 2.14 & \\
\hline 483 & 2.14 .5 & \\
\hline 484 & 2.14 .5 & \\
\hline 485 & 2.15 & \\
\hline 486 & 2.15 & \\
\hline & & \\
\hline
\end{tabular}

\begin{tabular}{|c|c|}
\hline Semana 10 & 5.19 días \\
\hline Corrección observaciones del parcial & 3 días \\
\hline Reunión con profesor gerente & 0.13 días \\
\hline Conversar sobre avances del proyecto & 1 hora \\
\hline Documentar acuerdos y tareas en un acta de reunión & 1 hora \\
\hline Recibir aprobación de acta de reunión & 1 hora \\
\hline Clase de taller de paper & 0.13 días \\
\hline Recibir asesoría de Paper & 1 hora \\
\hline Reunión con profesor cliente & 0.19 días \\
\hline Conversar sobre el proyecto & 1.5 horas \\
\hline Aprobación corrección de observaciones & 1.5 horas \\
\hline Registrar acuerdos y tareas en un acta de Reunión & 1.5 horas \\
\hline Recibir aprobación de acta de reunión & 1.5 horas \\
\hline Semana 11 & 5.19 días \\
\hline Reunión con profesor gerente & 0.13 días \\
\hline Conversar sobre avances del proyecto & 1 hora \\
\hline Documentar acuerdos y tareas en un acta de reunión & 1 hora \\
\hline Recibir aprobación de acta de reunión & 1 hora \\
\hline Clase de taller de paper & 0.13 días \\
\hline Recibir asesoría de Paper & 1 hora \\
\hline Reunión con profesor cliente & 0.19 días \\
\hline Conversar sobre el proyecto & 1.5 horas \\
\hline Registrar acuerdos y tareas en un acta de Reunión & 1.5 horas \\
\hline Recibir aprobación de acta de reunión & 1.5 horas \\
\hline Correcciones adicionales & 5 días \\
\hline Semana 12 & 2.19 días \\
\hline Reunión con profesor gerente & 0.13 días \\
\hline Conversar sobre avances del proyecto & 1 hora \\
\hline Documentar acuerdos y tareas en un acta de reunión & 1 hora \\
\hline Recibir aprobación de acta de reunión & 1 hora \\
\hline Clase de taller de paper & 0.13 días \\
\hline Recibir asesoría de Paper & 1 hora \\
\hline Reunión con cliente & 0.19 días \\
\hline Conversar sobre el proyecto & 1.5 horas \\
\hline Registrar acuerdos y tareas en un acta de Reunión & 1.5 horas \\
\hline Recibir aprobación de acta de reunión & 1.5 horas \\
\hline Semana 13 & 2.19 días \\
\hline Entrega Final del DVD del proyecto & 1 hora \\
\hline Reunión con profesor gerente & 0.13 días \\
\hline Conversar sobre avances del proyecto & 1 hora \\
\hline Documentar acuerdos y tareas en un acta de reunión & 1 hora \\
\hline Recibir aprobación de acta de reunión & 1 hora \\
\hline Clase de taller de paper & 0.13 días \\
\hline Recibir asesoría de Paper & 1 hora \\
\hline Reunión con cliente 27 & 0.19 días \\
\hline Conversar sobre el proyecto & 1.5 horas \\
\hline Registrar acuerdos y tareas en un acta de Reunión & 1.5 horas \\
\hline Recibir aprobación de acta de reunión & 1.5 horas \\
\hline Semana 14 & 6.25 días \\
\hline Poster & 2 días \\
\hline Actas de cierre (capacitación y conformidad) & 3 días \\
\hline Reunión con profesor gerente & 0.19 días \\
\hline Exposición con el profesor gerente & 1.5 horas \\
\hline Clase de taller de paper & 0.13 días \\
\hline Recibir asesoría de Paper & 1 hora \\
\hline Reunión con profesor cliente & 0.19 días \\
\hline Conversaciones finales acerca del proyecto & 1.5 horas \\
\hline Registrar acuerdos y tareas en un acta de Reunión & 1.5 horas \\
\hline Recibir aprobación de acta de reunión & 1.5 horas \\
\hline Semana 15 & 1.19 días \\
\hline Exposición antes el comité 02 & 1.19 días \\
\hline Preparar presentación para susten & 1 día \\
\hline
\end{tabular}
lun 16/10/17 lun $16 / 10 / 17$ vie $20 / 10 / 17$ vie $20 / 10 / 17$ vie $20 / 10 / 17$ vie $20 / 10 / 17$ jue 19/10/17 jue 19/10/17 sáb 21/10/17 sáb 21/10/17 sáb $21 / 10 / 17$ sáb 21/10/17 sáb 21/10/17 lun $23 / 10 / 17$ vie $27 / 10 / 17$ vie $27 / 10 / 17$ vie $27 / 10 / 17$ vie $27 / 10 / 17$ jue 26/10/17 jue $26 / 10 / 17$ sáb 28/10/17 sáb 28/10/17 sáb 28/10/17 sáb 28/10/17 Iun $23 / 10 / 17$ jue 2/11/17 vie $3 / 11 / 17$ vie $3 / 11 / 17$ vie $3 / 11 / 17$ vie $3 / 11 / 17$ jue $2 / 11 / 17$ jue $2 / 11 / 17$ sáb 4/11/17 sáb $4 / 11 / 17$ sáb $4 / 11 / 17$ sáb 4/11/17 jue 9/11/17 vie $10 / 11 / 17$ vie 10/11/17 vie $10 / 11 / 17$ vie $10 / 11 / 17$ vie $10 / 11 / 17$ jue $9 / 11 / 17$ jue $9 / 11 / 17$ sáb $11 / 11 / 17$ sáb $11 / 11 / 17$ sáb $11 / 11 / 17$ sáb $11 / 11 / 17$ sáb 11/11/17 sáb 11/11/17 sáb 11/11/17 vie 17/11/17 vie $17 / 11 / 17$ jue 16/11/17 jue $16 / 11 / 17$ sáb 18/11/17 sáb 18/11/17 sáb $18 / 11 / 17$ sáb 18/11/17 lun 20/11/17 Iun 20/11/17 sáb 21/10/17 mié $18 / 10 / 17$ vie $20 / 10 / 17$ vie $20 / 10 / 17$ vie $20 / 10 / 17$ vie $20 / 10 / 17$ jue 19/10/17 jue $19 / 10 / 17$ sáb 21/10/17 sáb 21/10/17 sáb 21/10/17 sáb $21 / 10 / 17$ sáb $21 / 10 / 17$ sáb 28/10/17 vie $27 / 10 / 17$ vie $27 / 10 / 17$ vie $27 / 10 / 17$ vie $27 / 10 / 17$ jue $26 / 10 / 17$ jue $26 / 10 / 17$ sáb 28/10/17 sáb 28/10/17 sáb $28 / 10 / 17$ sáb $28 / 10 / 17$ vie $27 / 10 / 17$ sáb 4/11/17 vie $3 / 11 / 17$ vie $3 / 11 / 17$ vie $3 / 11 / 17$ vie $3 / 11 / 17$ jue 2/11/17 jue $2 / 11 / 17$ sáb 4/11/17 sáb 4/11/17 sáb $4 / 11 / 17$ sáb $4 / 11 / 17$ sáb 11/11/17 vie $10 / 11 / 17$ vie 10/11/17 vie $10 / 11 / 17$ vie $10 / 11 / 17$ vie $10 / 11 / 17$ jue $9 / 11 / 17$ jue $9 / 11 / 17$ sáb 11/11/17 sáb $11 / 11 / 17$ sáb 11/11/17 sáb 11/11/17 sáb 18/11/17 lun $13 / 11 / 17$ mar $14 / 11 / 17$ vie $17 / 11 / 17$ vie $17 / 11 / 17$ jue 16/11/17 jue 16/11/17 sáb 18/11/17 sáb 18/11/17 sáb 18/11/17 sáb 18/11/17 mar 21/11/17 mar 21/11/17 Iun 20/11/17

Fuente: Elaboración Propia

Existieron algunos contratiempos que no se tuvieron previstos y las cuales se detallan.

Tabla 12: Mitigación de Contratiempos

Mitigación de Contratiempos 


\begin{tabular}{|c|c|c|}
\hline Semana $2,3,4$ & $\begin{array}{l}\text { Problemas para contactar con la } \\
\text { municipalidad de VMT para la cual se } \\
\text { realiza el proyecto }\end{array}$ & $\begin{array}{l}\text { - Conversar con el comité del proyecto } \\
\text { para cambiar de municipalidad. } \\
\text { - Comunicación con el contacto de la } \\
\text { municipalidad por medio de correos y } \\
\text { llamadas telefónicas. } \\
\text { - Solicitud de carta de presentación de la } \\
\text { universidad para poder obtener acceso a } \\
\text { la información. }\end{array}$ \\
\hline Semana 33 & Actualización de entregables planteados & $\begin{array}{l}\text { - Se revisaron los entregables y llegó a la } \\
\text { conclusión que debían desestimarse } \\
\text { algunos de los ya seleccionados } \\
\text { anteriormente. } \\
\text { - Se determinó que los documentos a } \\
\text { realizar serían plantillas adaptadas a los } \\
\text { requerimientos del proyecto. }\end{array}$ \\
\hline
\end{tabular}

Fuente: Elaboración Propia

\section{Gestión de los Recursos Humanos}

A lo largo del desarrollo del proyecto se llevó los siguientes roles, según lo acordado.

- Comité de Proyectos

Son los encargados de aprobar la correcta realización del proyecto y se encargan de evaluar, asesorar y calificar el proyecto los avances del proyecto. Conformado por la directora de la Escuela de Ingeniería de Sistemas y Computación y los coordinadores de las carreras de Ingeniería de Sistemas de Información, Ingeniería de Software y Ciencias de la Computación.

- Profesor Gerente ITConsulting

Es el encargado de establecer y cumplir los objetivos principales de la empresa ITConsulting; con respecto a la participación en el proyecto, el profesor gerente realizará las siguientes funciones:

- Presentar oportunidades de mejora para el cumplimiento de objetivos de la empresa ITConsulting en base a los proyectos propuestos.

- Realizar un seguimiento del proyecto con el fin de evaluar si se cumple con lo estipulado de acuerdo con el cronograma establecido. 
- Brindar comentarios y observaciones de los entregables realizados para su mejora y levantamiento antes de la presentación de estos al cliente y comité.

\section{- Profesor Cliente}

Es el rol que corresponde al cliente del proyecto, encargado de la solicitud de requerimientos para el desarrollo y ejecución del proyecto, y de la orientación para la realización de los entregables.

\section{- Profesor Revisor}

Este rol corresponde al revisor de la memoria profesional del proyecto, por lo que su función es validar y certificar que este documento se encuentre alineada a la tesis desarrollada.

- Jefe de Proyecto

Este es el rol que corresponde a los encargados de planificar, ejecutar y controlar el avance del proyecto cumpliendo lo que se estableció en el cronograma. Encargados de la investigación y documentación de lo requerido por el proyecto. Realizan las coordinaciones respectivas con los involucrados en el proyecto.

\section{- Analista de Calidad QS}

Es el rol correspondiente al personal de QS, encargado de la revisión y aseguramiento de la calidad de los entregables de gestión. 
Figure 20: Organigrama de Recursos Humanos

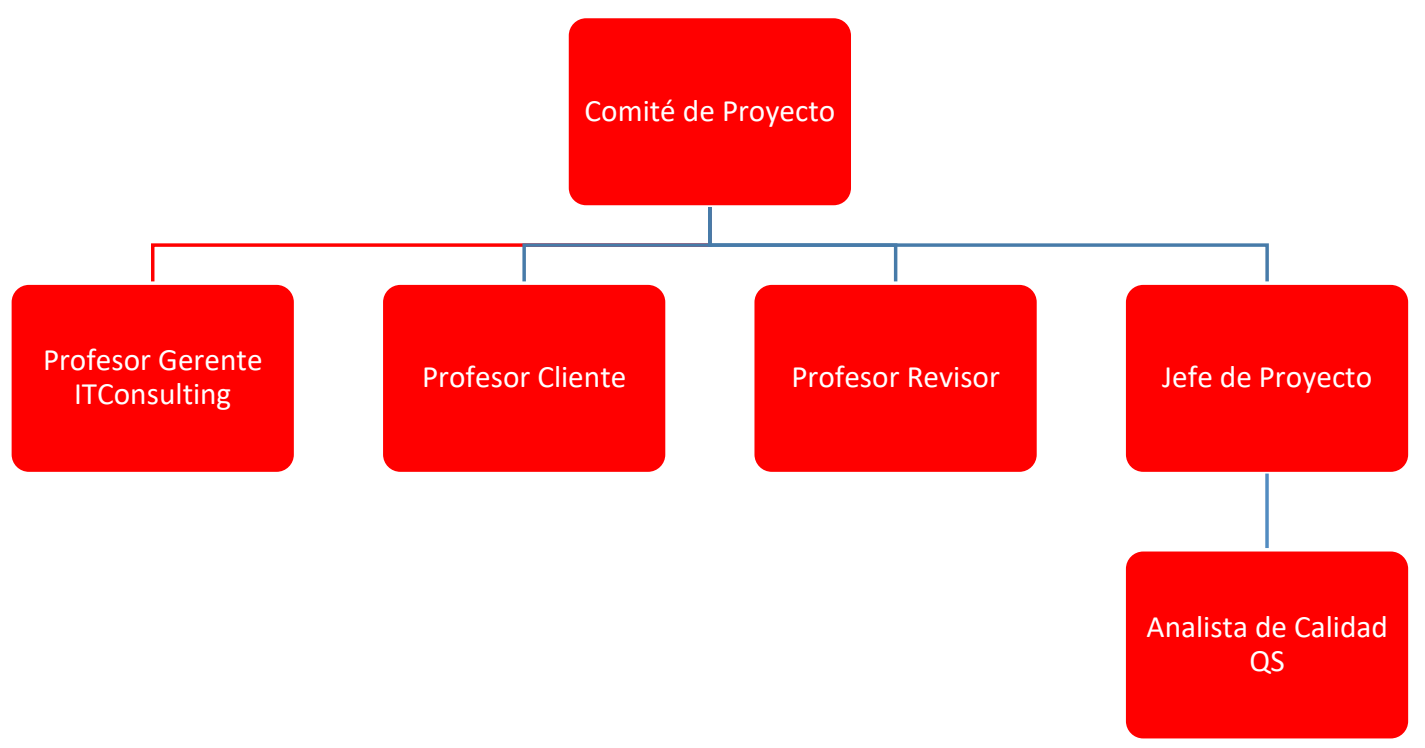

Fuente: Elaboración Propia

\section{Gestión de las Comunicaciones}

El plan de gestión de comunicaciones tiene como finalidad definir los lineamientos de comunicación, tanto interna como externa, con los involucrados en el proyecto. Este plan se cumplió según lo acordado.

Guía para las reuniones:

- En caso de tener un nuevo miembro en cada reunión, se hará la respectiva presentación de este ante los asistentes.

- Se manejará una agenda para cada reunión de acuerdo a los temas de interés a tratarse, así como también las tareas pendientes de reuniones anteriores. Para este caso, se debe tener en cuenta el entregable a realizar según el diccionario EDT.

- Cada punto de la agenda contará con un nivel de prioridad a ser tratado.

- Se cuenta con un horario específico para cada reunión, sin embargo, será necesario confirmar/recordar la reunión vía correo electrónico un día antes como máximo. 
- En caso se deba postergar una reunión, se deberá justificar y además acordar el nuevo día de esta.

- Al finalizar cada reunión se deberá recopilar lo tratado, resaltando los acuerdos para posteriormente elaborar el acta de reunión.

- Todas las actas de reunión deberán ser firmadas por el jefe de proyecto, asistente de proyecto y gerente general o cliente, respectivamente.

Guías para el correo electrónico:

- Cada correo electrónico debe ser redactado de una manera formal.

- Todo correo electrónico al cliente debe ser copiado a todo el equipo de proyecto; en especial a gerente, jefe, asistente de proyecto.

- Los correos electrónicos entre el gerente de la empresa y el cliente, deberá ser enviado por el jefe de proyecto para establecer un estándar en la conexión.

- En caso de envíos de solicitud de servicios a empresas externas, se debe copiar al correo de la empresa.

\section{Gestión de los Riesgos}

En relación con lo planteado al inicio del proyecto se presentó un riesgo adicional (9), el cual pudo impactar de manera importante si no se aplicaba la estrategia de mitigación adecuada. A continuación, se detallan los riesgos identificados para el proyecto con sus respectivas estrategias de mitigación.

Tabla 13: Riesgos Identificados

\begin{tabular}{|c|l|c|c|c|}
\hline$\#$ & \multicolumn{1}{|c|}{ Riesgo } & Probabilidad & Impacto & Estrategia de mitigación \\
\hline 1 & $\begin{array}{l}\text { El cliente no define } \\
\text { correctamente los requisitos del } \\
\text { proyecto. Esto puede causar } \\
\text { demoras en el levantamiento de } \\
\text { información. }\end{array}$ & Baja & Muy Alto & $\begin{array}{l}\text { Informar al cliente sobre los } \\
\text { problemas encontrados y } \\
\text { definir los requisitos con él. }\end{array}$ \\
\hline 2 & $\begin{array}{l}\text { Poca disponibilidad de tiempo } \\
\text { del cliente debido a sus }\end{array}$ & Alta & Muy Alto & Realizar con cronograma de \\
reuniones con el cliente.
\end{tabular}




\begin{tabular}{|c|c|c|c|c|}
\hline$\#$ & Riesgo & Probabilidad & Impacto & Estrategia de mitigación \\
\hline & funciones municipales. & & & \\
\hline 3 & $\begin{array}{l}\text { Abandono del proyecto por } \\
\text { parte de un integrante del } \\
\text { equipo. }\end{array}$ & Baja & Muy Alto & $\begin{array}{l}\text { Mantener una comunicación } \\
\text { constante entre los } \\
\text { participantes del equipo }\end{array}$ \\
\hline 4 & $\begin{array}{l}\text { Cambios en el alcance del } \\
\text { proyecto propuestos por el } \\
\text { comité o por el cliente. }\end{array}$ & Baja & Muy Alto & $\begin{array}{l}\text { Gestionar adecuadamente la } \\
\text { holgura del proyecto. }\end{array}$ \\
\hline 5 & $\begin{array}{l}\text { No cumplir con las expectativas } \\
\text { del cliente }\end{array}$ & Medio & Muy Alto & $\begin{array}{l}\text { Realizar encuestas de } \\
\text { satisfacción al cliente de } \\
\text { manera periódica. }\end{array}$ \\
\hline 6 & $\begin{array}{l}\text { Inadecuado seguimiento y } \\
\text { control hacia los recursos. }\end{array}$ & Bajo & Alto & $\begin{array}{l}\text { Realizar reuniones de } \\
\text { seguimiento. }\end{array}$ \\
\hline 7 & $\begin{array}{l}\text { Cambio de cliente luego de } \\
\text { haber iniciado el proyecto. }\end{array}$ & Muy Bajo & Muy Alto & $\begin{array}{l}\text { Realizar análisis procesos } \\
\text { estándares en las } \\
\text { municipalidades. }\end{array}$ \\
\hline 8 & $\begin{array}{l}\text { No contar con el documento de } \\
\text { presentación por parte de la } \\
\text { universidad por lo que } \\
\text { imposibilita } \\
\text { municipalidad no brinde la } \\
\text { información. }\end{array}$ & Bajo & Muy Alto & $\begin{array}{l}\text { Solicitar el documento de } \\
\text { presentación a algún } \\
\text { miembro del comité de } \\
\text { proyecto. }\end{array}$ \\
\hline 9 & $\begin{array}{l}\text { Cambio de proyecto propuesto } \\
\text { por el comité o por el cliente. }\end{array}$ & Medio & Muy Alto & $\begin{array}{l}\text { Informar al contacto sobre el } \\
\text { proyecto de estudio a } \\
\text { realizar y realizar un } \\
\text { cronograma de reuniones } \\
\text { con el contacto. }\end{array}$ \\
\hline
\end{tabular}

Fuente: Elaboración Propia

\section{Lecciones Aprendidas}

Se procede a detallar las lecciones aprendidas a lo largo del desarrollo del proyecto, las cuales se recomiendan tomar en cuenta para posteriores proyectos de tesis.

- Es fundamental tener un entendimiento acerca del tema del proyecto para un adecuado levantamiento de información y elaboración de entregables. En caso se 
presente alguna duda, es necesario realizar las preguntas respectivas con los responsables.

- La actualización del cronograma del proyecto es importante para la reasignación de tiempo y recursos para las actividades actualizadas y las nuevas actividades.

- Es importante determinar a tiempo si el proyecto continúa o procede con algún cambio, ya que esto afecta de algún modo o a gran medida al proyecto inicial.

- Es importante contar con una trazabilidad en cuanto a los entregables del proyecto para garantizar la calidad del proyecto.

- Es importante tener conocimiento de los entregables y artefactos de las fases de Togaf usados para el proyecto, ya que estos serán usados como base para el proyecto y deben ser realizados adecuadamente. 


\section{Conclusiones}

- En este trabajo se introduce una forma de implementación de trámites digitales basadas en e-Servicios para municipalidades distritales peruanas urbanas utilizando las buenas prácticas del marco de trabajo de arquitectura empresarial TOGAF.

- El modelo permite a una municipalidad urbana implementar los e-Trámites basándose en e-Servicios Municipales que se encuentran alineados a las leyes peruanas. Esto, mediante un conjunto de entregables con los cuales se puede ir a la etapa de desarrollo e implementar el trámite propuesto de una forma ordenada.

- Al realizar la evaluación de juicio de expertos se concluye que su utilización permite una mejor implementación de los e-Trámites y que el 100\% se encuentra dispuesto a utilizar el modelo para su siguiente proyecto de trámite electrónico, el 50\% lo considera como "Muy aceptable" y el otro 50\% como "Aceptable".

- Los funcionarios de la municipalidad brindan una gran aceptación al modelo propuesto, ya que el $60 \%$ lo califica como "Muy aceptable" y el 40\% como "Aceptable", lo cual indica como prometedor los de e-Trámites.

- Por otro lado, el $92 \%$ de los ciudadanos encuestados lo califican como "Muy aceptable" y el 8\% como "Aceptable", lo cual muestra una gran aceptación por parte de la ciudadanía, que son las personas más importantes en una propuesta de gobierno electrónico.

- Los resultados encontrados muestran una gran ventaja respecto a las otras guías de implementación encontradas en la literatura. Esto se debe, a que se ha unido exitosamente las buenas prácticas de arquitectura empresarial con los e-Servicios que cumplen con las leyes peruanas. 


\section{Recomendaciones}

Las recomendaciones obtenidas del proyecto son las siguientes :

- Se recomienda tener en cuenta el punto de marco de modelo para iniciar el proyecto de implementación.

- Para la implementación del modelo, se debe elaborar todas las plantillas propuestas y en el orden recomendado, debido a que esto garantiza las buenas prácticas de TOGAF.

- El equipo de proyecto debe encontrarse al tanto de las tecnologías emergentes para proponer e-Servicios innovadores.

- Se recomienda analizar los costos del proyecto de acuerdo a la realidad de la municipalidad. 


\section{Glosario}

A continuación, se listan los términos pocos comunes en el proyecto.

- STUDENT OUTCOMES: Competencias técnicas y blandas que deben ser alcanzadas por los alumnos de la carrera. Estas son definidas por la acreditadora ABET.

- TOGAF: The Open Group Architecture Framework, conjunto de herramientas de apoyo para el desarrollo de una Arquitectura Empresarial, proporciona un enfoque para el diseño, planificación, implementación y gobierno de una arquitectura empresarial.

- ADM: Architecture Development Method, compuesto por diferentes fases en forma cíclica y conforme se vaya desarrollando cada etapa la madurez de la Arquitectura Empresarial va aumentando.

- E-Government: Gobierno electrónico, se refiere a la interacción entre los gobiernos de distintos países y sus ciudadanos o personas que tengan contacto con ellos. Consiste en la realización de las actividades que cumple el gobierno haciendo uso de las tecnologías de información.

- PMBOK: Project Management Body of Knowledge, presenta estándares, pautas y normas para la gestión de proyectos

- E-Servicios: Los servicios electrónicos se refiere a los servicios prestados mediante el internet. Estas se encuentran automatizadas y requieren de una intervención mínima humana. 


\section{Siglario}

A continuación, se listan los acrónimos que son usados en el proyecto.

- UNESCO: United Nations Educaional, Scientific and Cultural Organization

- EDT: Estructura de Descomposición de Trabajo

- PMBOK: Project Management Body of Knowledge

- ADM: Architecture Development Metod (Método de Desarrollo de la Arquitectura)

- TOGAF: The Open Group Architecture Framework

- OE: Objetivo Específico

- IE: Indicadores de Éxito 
Anexos

Anexo 1: Emisión de Licencia de Funcionamiento (As-Is)

Figure 21: Proceso As-Is

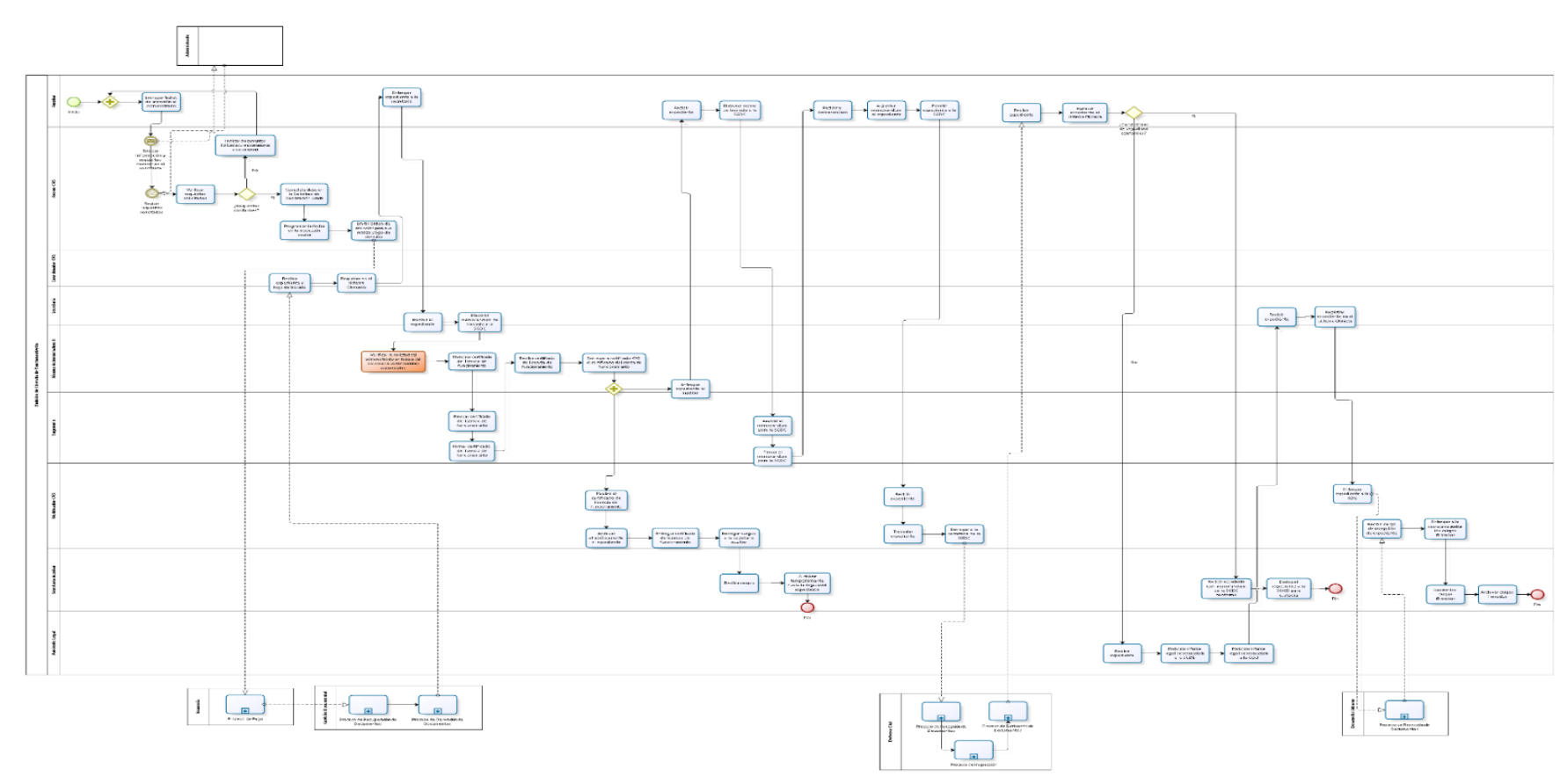


Fuente : Elaboración Propia

Anexo 2: Emisión de Licencia de Funcionamiento (To-Be)

Figure 22: Proceso To-Be

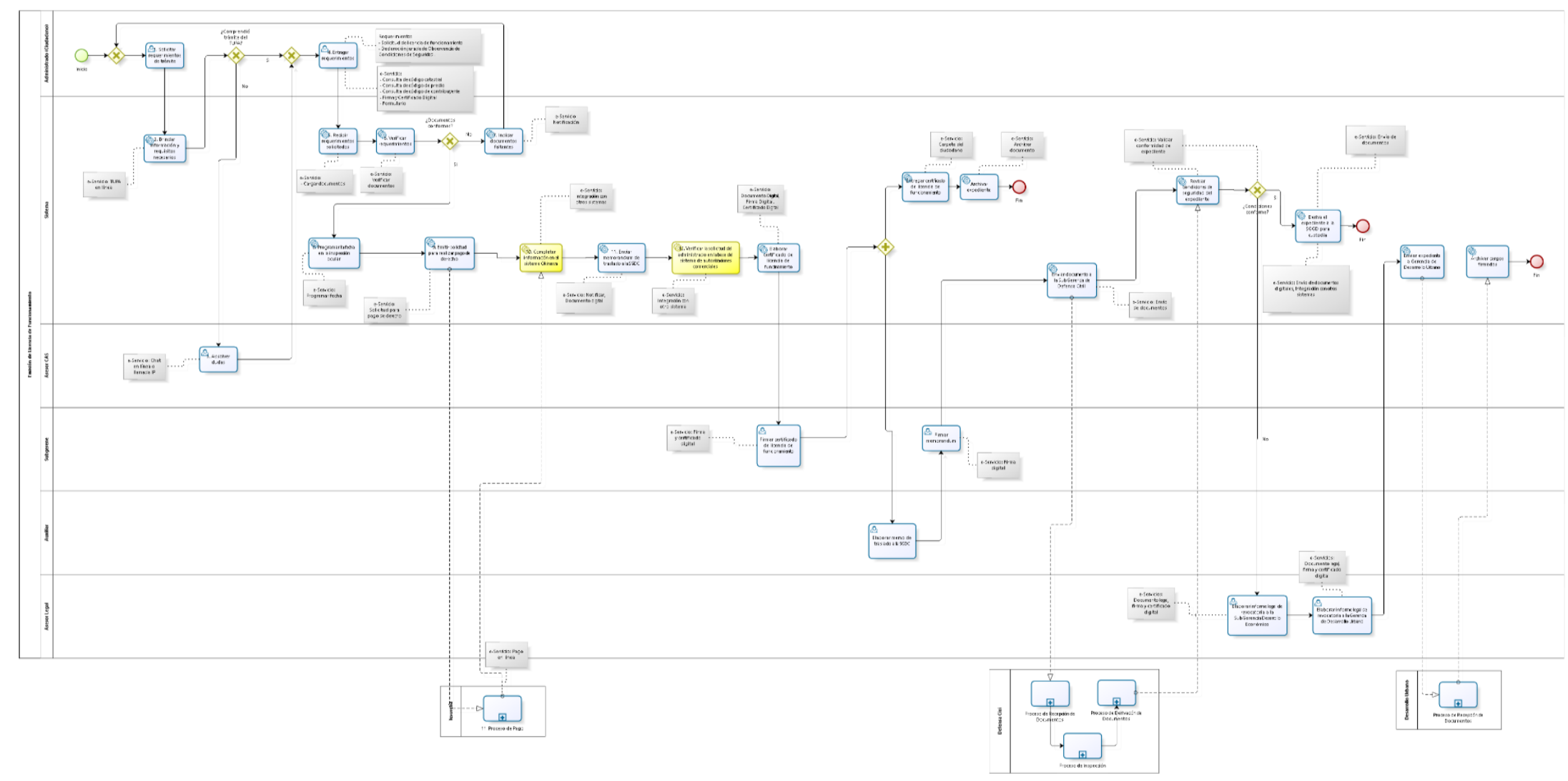


Fuente : Elaboración Propia

Anexo 3 : Caso de Uso - Contacto con el Ciudadano

Figure 23: Caso de Uso 1

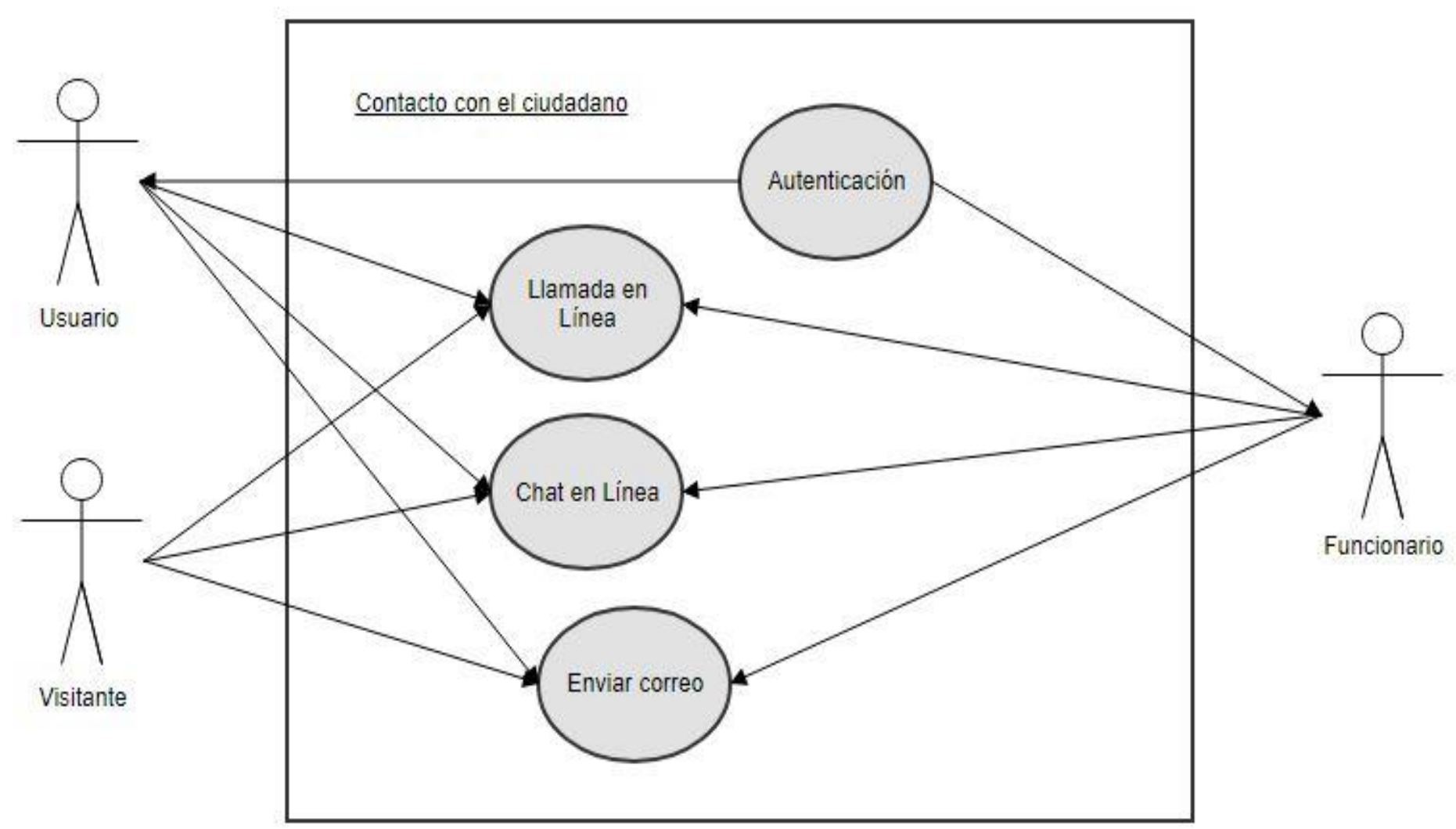

[143] 
Fuente : Elaboración Propia

Anexo 4 : Caso de Uso - Información Municipal

Figure 24: Caso de Uso 2

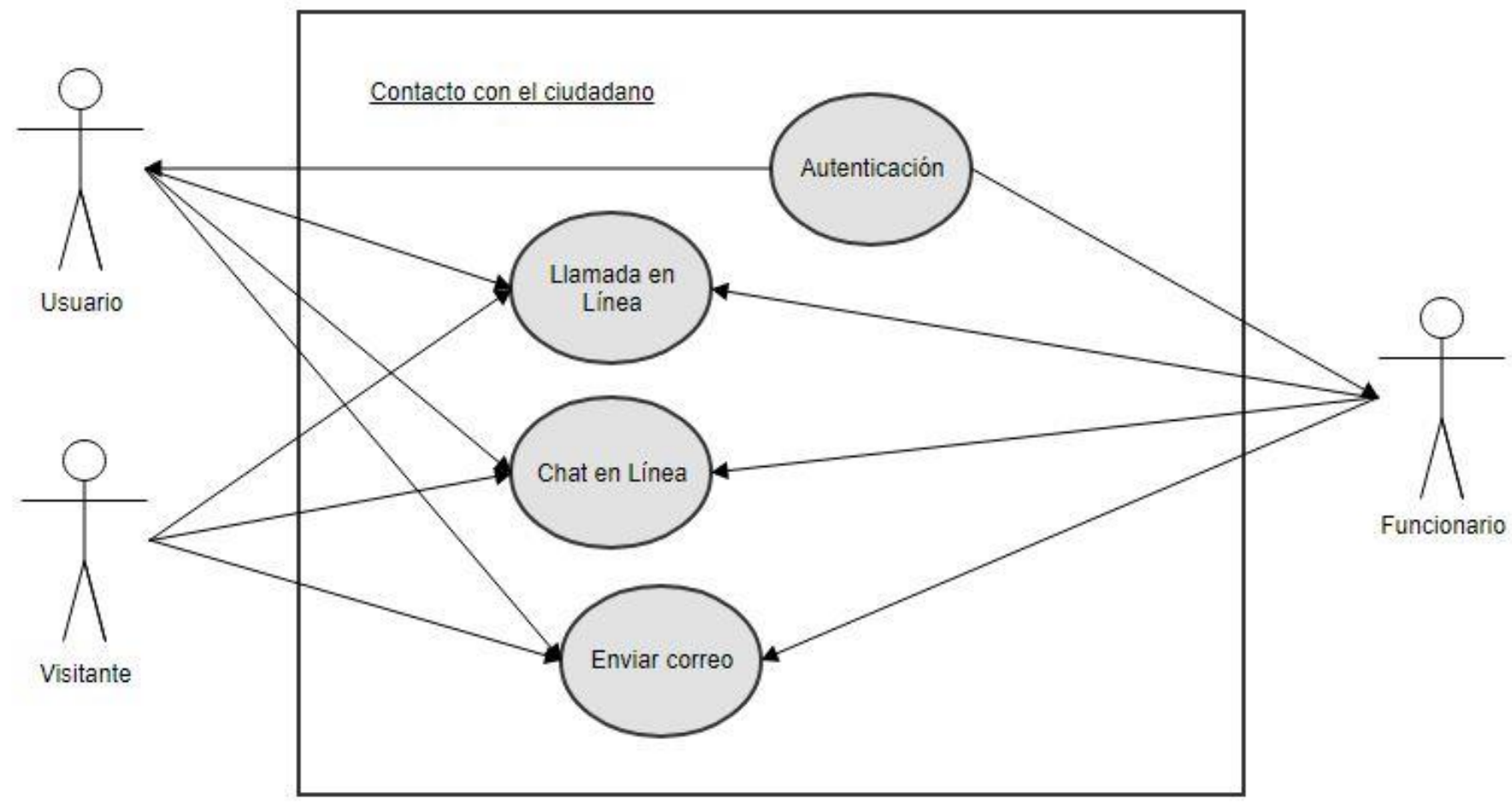

[144] 
Fuente : Elaboración Propia

Anexo 5: Caso de Uso - Trámite Municipal 
Figure 25: Caso de Uso 3

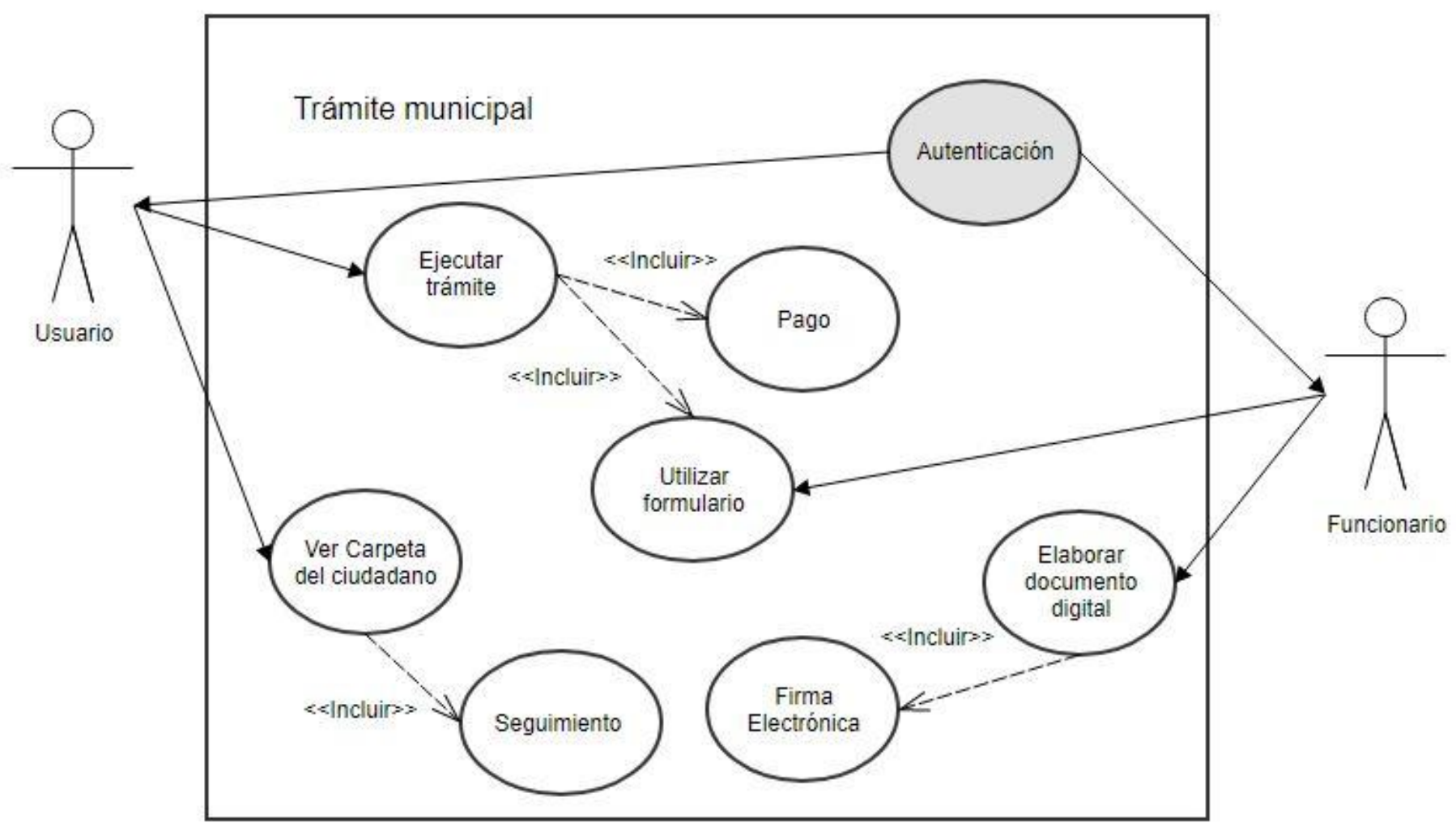

Fuente : Elaboración Propia

\section{Anexo 6: Principios de Negocio}


Figure 26: Principios de Negocio

\begin{tabular}{|c|c|c|c|c|c|c|}
\hline \multicolumn{7}{|c|}{ Principios de Negocio } \\
\hline ID & Nombre & Declaración & Fundamento & Implicaciones & Fecha & Creador \\
\hline PRN_BU_01 & Cumplimiento de la ley & $\begin{array}{l}\text { Definir políticas, procesos y procedimientos que } \\
\text { faciliten el crecimiento de la gestión de TI de la } \\
\text { municipalidad. }\end{array}$ & $\begin{array}{l}\text { La municipalidad debe cumplir con las leyes, } \\
\text { políticas y regulaciones propuestas por el estado } \\
\text { peruano. }\end{array}$ & $\begin{array}{l}\text { 1. Estar al tanto de las normas, políticas o } \\
\text { regulaciones que decrete el estado peruano } \\
\text { 2. Se ajustarán los procesos para el } \\
\text { cumplimiento de las leyes. }\end{array}$ & 01/09/2017 & $\begin{array}{r}\text { Raphael } \\
\text { Hinostroza }\end{array}$ \\
\hline PRN_BU_02 & Responsabilidad de TI & $\begin{array}{l}\text { El área de Tl es responsable de la propiedad e } \\
\text { implementación de los procesos e } \\
\text { infraestructura de TI, las cuales permiten que las } \\
\text { soluciones satisfagan los requisitos definidos } \\
\text { por el usuario con el cumplimiento la } \\
\text { funcionalidad, los niveles de servicio, costo y } \\
\text { tiempo de entrega. }\end{array}$ & $\begin{array}{l}\text { Alinear eficientemente las expectativas con las } \\
\text { capacidades del área. Implementando soluciones } \\
\text { eficientes y eficaces que tienen costos razonables y } \\
\text { con claros beneficios. }\end{array}$ & $\begin{array}{l}\text { 1. La función de TI debe definir los procesos } \\
\text { para gestionar las expectativas de las } \\
\text { unidades municipales. } \\
\text { 2. Implementar las arquitecturas de } \\
\text { aplicaciones, datos y tecnología para } \\
\text { brindar soluciones integradas de calidad y } \\
\text { maximizar los resultados. }\end{array}$ & 01/09/2017 & $\begin{array}{l}\text { Raphael } \\
\text { Hinostroza }\end{array}$ \\
\hline PRN_BU_03 & Orientación a los servicios & $\begin{array}{l}\text { Establecer los servicios que ofrece la } \\
\text { municipalidad, los cuales comprenden las } \\
\text { actividades de diferentes áreas. }\end{array}$ & $\begin{array}{l}\text { Los servicios ofrece a la municipalidad una } \\
\text { agilidad en sus procesos y dejar de lado el uso del } \\
\text { papel. }\end{array}$ & $\begin{array}{l}\text { 1. Identificar el objetivo del servicio y las } \\
\text { áreas que intervienen. } \\
\text { 2. Identificar las reglas o leyes existentes } \\
\text { para la aplicación de los mismo. }\end{array}$ & 01/09/2017 & $\begin{array}{l}\text { Allison } \\
\text { Garcia }\end{array}$ \\
\hline PRN_BU_04 & $\begin{array}{l}\text { Cambios basados en } \\
\text { requerimientos }\end{array}$ & $\begin{array}{l}\text { Solo para necesidades del negocio se procederá } \\
\text { a realizar cambios en las aplicaciones y la } \\
\text { tecnología. }\end{array}$ & $\begin{array}{l}\text { Asegurar que para cualquier cambio propuesto, la } \\
\text { información es el soporte de las operaciones del } \\
\text { negocio. }\end{array}$ & $\begin{array}{l}\text { 1. Las mejoras o cambios requeridos deben } \\
\text { estar documentados. } \\
\text { 2. Los cambios deberán ser analizados } \\
\text { minuciosamente. }\end{array}$ & 01/09/2017 & $\begin{array}{l}\text { Allison } \\
\text { Garcia }\end{array}$ \\
\hline PRN_BU_05 & Negocio sin fines de lucro & $\begin{array}{l}\text { El objetivo principal de la municipalidad debe } \\
\text { ser el bienestar social de sus ciudadanos. }\end{array}$ & $\begin{array}{l}\text { La municipalidad no busca un beneficio económico } \\
\text { sino que su principal objetivo es el beneficio para } \\
\text { sus ciudadanos. }\end{array}$ & $\begin{array}{l}\text { 1. Los servicios ofrecidos deben cumplir con } \\
\text { las necesidades del cliente. } \\
\text { 2. Las mejoras y/o cambios realizados deben } \\
\text { ser orientados al bienestar de los } \\
\text { ciudadanos y no para el beneficio } \\
\text { económico de la municipalidad. }\end{array}$ & 01/09/2017 & $\begin{array}{l}\text { Allison } \\
\text { Garcia }\end{array}$ \\
\hline
\end{tabular}

Fuente : Elaboración Propia

\section{Anexo 7: Principios de Datos}


Figure 27: Principios de Datos

\begin{tabular}{|c|c|c|c|c|c|c|}
\hline \multicolumn{7}{|c|}{ Principios de Datos } \\
\hline 1D & Nombre & Declaración & Fundamento & Implicaciones & Fecha & Creador \\
\hline PRN_IN_01 & $\begin{array}{l}\text { Los datos son un activo que tiene } \\
\text { valor para la municipalidady, en } \\
\text { consecuencia, se gestiona. }\end{array}$ & $\begin{array}{l}\text { Los datos son recursos valiosos para la municipalidad ya } \\
\text { que son medibles. Esto, además de tenerlos de manera } \\
\text { oportuna y precisa, facilita a la toma de decisiones. La } \\
\text { mayoría de los activos de la municipalidad son } \\
\text { gestionados con cuidado y los datos no deben ser la } \\
\text { excepción. Por último, se deben manejar con cuidado } \\
\text { para asegurarse su ubicación, que se pueda confiar en su } \\
\text { exactitud y se oueda obtener en el momento oue se. }\end{array}$ & $\begin{array}{l}\text { Los datos son recursos valiosos para la municipalidad ya que } \\
\text { son medibles. Esto, además de tenerlos de manera oportuna y } \\
\text { precisa, facilita a la toma de decisiones. La mayoría de los } \\
\text { activos de la municipalidad son gestionados con cuidado y los } \\
\text { datos no deben ser la excepción. Por último, se deben manejar } \\
\text { con cuidado para asegurarse su ubicación, que se pueda } \\
\text { confiar en su exactitud y se pueda obtener en el momento que } \\
\text { senecesite. }\end{array}$ & $\begin{array}{l}\text { 1. Los administradores deben tener l la autoridad y los medios para } \\
\text { gestionar los datos de los que son responsables. } \\
\text { 2. El papel de administrador de datos es critico porque los datos } \\
\text { obsoletos, inexactos o incoherentes se podrian pasar a los funcionarios } \\
\text { municipales y afectar negativamente a las decisiones. } \\
\text { 3. Puesto que los datos es un activo de valor para toda la municipalidad, } \\
\text { los administradores de datos responsables de gestionar } \\
\text { adecuadamente los datos deben ser asignados a nivel de emoresa. }\end{array}$ & 01/09/2017 & \begin{tabular}{|c} 
Raphael \\
Hinostroza
\end{tabular} \\
\hline PRN_IN_02 & $\begin{array}{l}\text { Vocabulario común y definición } \\
\text { de datos }\end{array}$ & $\begin{array}{l}\text { El dato se define constantemente en toda la } \\
\text { municipalidad, y las definiciones son comprensibles } y \\
\text { disponible para todos los usuarios. }\end{array}$ & $\begin{array}{l}\text { Los datos que se utilizará en el desarrollo de aplicaciones debe } \\
\text { tener una definición común a través de la entidad para permitir } \\
\text { el intercambio de datos. Un vocabulario común facilitará la } \\
\text { comunicación y permitirá el diálogo eficaz entre aplicaciones. } \\
\text { Además, se requiere para interconectar sistemas y cambio de } \\
\text { datos. }\end{array}$ & $\begin{array}{l}\text { 1. La municipalidad debe establecer el vocabulario común inicial para el } \\
\text { negocio. Las definiciones serán utilizadas de manera uniforme en toda } \\
\text { la entidad. } \\
\text { 2. Siempre que se requiera una nueva definición de algún dato, se debe } \\
\text { definir según las normas o reglas planteadas en el glosario de datos. } \\
\text { 3. Se deben asignar las responsabilidades del administrador de datos. }\end{array}$ & 01/09/2017 & $\begin{array}{l}\text { Raphael } \\
\text { Hinostroza }\end{array}$ \\
\hline PRN_IN_03 & Los datos son compartidos & $\begin{array}{l}\text { Los usuarios tienen acceso a los datos que se comparten } \\
\text { entre las diferentes áreas para llevar a cabo sus labores. }\end{array}$ & $\begin{array}{l}\text { El contar con acceso a estos datos es de suma importancia } \\
\text { para la toma de decisiones de la municipalidad. Además de } \\
\text { evitar la duplicidad de datos en la organización. }\end{array}$ & $\begin{array}{l}\text { 1. Se debe establecer políticas, normas y procedimientos para la } \\
\text { gestión de datos y el acceso a los mismo, los cuales deben ser divulgado } \\
\text { a todos los empleados de la municipalidad. } \\
\text { 2. Desarrollar un gestor de almacenamiento de datos. }\end{array}$ & $01 / 09 / 2017$ & $\begin{array}{l}\text { Allison } \\
\text { Garcia }\end{array}$ \\
\hline PRN_IN_04 & $\begin{array}{l}\text { Restricción de datos } \\
\text { confidenciales }\end{array}$ & $\begin{array}{l}\text { La municipalidad cuenta con cierta información } \\
\text { confidencial que no puede ser compartida abiertamente } \\
\text { al público en general. }\end{array}$ & $\begin{array}{l}\text { Es necesario establecer datos que son confidenciales y no } \\
\text { pueden ser compartidas abiertamente a cualquier persona, } \\
\text { para el cual se requiere ciertas restricciones y permisos. }\end{array}$ & $\begin{array}{l}\text { 1. Conocimiento de la ley № } 29733 \text { - Ley de protección de datos } \\
\text { personales. } \\
\text { 2. Se debe establecer roles que cuenten con acceso a cierta información } \\
\text { confidencial. } \\
\text { 3. Cada usuario debe contar con un usuario y contraseña único y } \\
\text { personal. }\end{array}$ & $01 / 09 / 2017$ & $\begin{array}{l}\text { Allison } \\
\text { Garcia }\end{array}$ \\
\hline PRN_IN_05 & Datos públicos & $\begin{array}{l}\text { Los datos que las municipalidad son de acceso público } \\
\text { para quienes lo requieran. }\end{array}$ & $\begin{array}{l}\text { Los datos que una municipalidad maneja son de acceso } \\
\text { público, ya que al ser una entidad pública existe una ley que } \\
\text { indica esto. }\end{array}$ & $\begin{array}{l}\text { 1. Conocimiento de la ley № } 27806 \text { - Ley de Transparencia y Acceso de la } \\
\text { Información Pública. } \\
\text { 2. Los datos son públicos, al menos que exista una ley que lo restrinia. }\end{array}$ & $01 / 09 / 2017$ & $\begin{array}{l}\text { Raphael } \\
\text { Hinostroza }\end{array}$ \\
\hline
\end{tabular}

Fuente : Elaboración Propia

\section{Anexo 8: Principios de Aplicación}


Figure 28: Principios de Aplicación

\begin{tabular}{|c|c|c|c|c|c|c|}
\hline \multicolumn{7}{|c|}{ Principios de Aplicaciones } \\
\hline $\mathrm{ID}$ & Nombre & Declaración & $\begin{array}{l}\text { Fundamento } \\
\text {. }\end{array}$ & Implicaciones & Fecha & Creador \\
\hline PRN_AP_01 & Facilidad de uso & $\begin{array}{l}\text { Sistema intuitivos para el usuario sin necesidad } \\
\text { de una capacitación exahustiva. }\end{array}$ & $\begin{array}{l}\text { La facilidad de uso permite una } \\
\text { navegabilidad agradable para el usuario, } \\
\text { tanto los sistemas que interactúan con } \\
\text { funcionarios o como los sistemas } \\
\text { individuales. }\end{array}$ & $\begin{array}{l}\text { 1. Definir estándares de diseño de } \\
\text { aplicaciones. } \\
\text { 2. Realizar pruebas con usuarios que no hayan } \\
\text { tenido contacto con el sistema antes de que } \\
\text { salga a producción. } \\
\text { 3. Contar con el sistema con al menos dos } \\
\text { idiomas para el usuario, si es necesario. }\end{array}$ & 01/09/2017 & $\begin{array}{l}\text { Allison } \\
\text { Garcia }\end{array}$ \\
\hline PRN_AP_02 & Tecnología independiente & $\begin{array}{l}\text { Las aplicaciones de la municipalidad son } \\
\text { independientes de una tecnología específica, } \\
\text { por lo tanto pueden operar en varias } \\
\text { plataformas tecnológicas. }\end{array}$ & $\begin{array}{l}\text { La tecnología independiente permite que } \\
\text { las aplicaciones seleccionadas sean } \\
\text { desarrolladas y operadas de la manera } \\
\text { más rentable y oportuna. }\end{array}$ & $\begin{array}{l}\text { 1. Desarrollar interfaces entre los sistemas } \\
\text { que permita a las aplicaciones interoperar } \\
\text { con las aplicaciones desarrolladas en la } \\
\text { Arquitectura Empresarial. } \\
\text { 2. Definir estándares de soporte a la } \\
\text { portabilidad. }\end{array}$ & $01 / 09 / 2017$ & $\begin{array}{l}\text { Allison } \\
\text { Garcia }\end{array}$ \\
\hline PRN_AP_03 & Interoperabilidad & $\begin{array}{l}\text { Las aplicaciones deben comunicarse entre ellas } \\
\text { de una manera ágil. }\end{array}$ & $\begin{array}{l}\text { Los estándares para la interoperabilidad } \\
\text { permiten la conexión de varias } \\
\text { aplicaciones y facilitan la integración para } \\
\text { una transferencia de información eficaz. }\end{array}$ & $\begin{array}{l}\text { 1. Los estándares de interoperabilidad serán } \\
\text { seguidos a menos que haya una razón de } \\
\text { negocios para implementar una solución no } \\
\text { estándar. } \\
\text { 2. Las aplicaciones existentes deben ser } \\
\text { identificadas y documentadas. }\end{array}$ & 01/09/2017 & $\begin{array}{l}\text { Allison } \\
\text { Garcia }\end{array}$ \\
\hline
\end{tabular}

Fuente : Elaboración Propia

\section{Anexo 9: Principios de Tecnología}


Figure 29: Principios de Tecnología

\begin{tabular}{|c|c|c|c|c|c|c|}
\hline \multicolumn{7}{|c|}{ Principios de Tecnología } \\
\hline$\overline{\text { ID }}$ & Nombre & Declaración & Fundamento & Implicaciones & Fecha & Creador \\
\hline PRN_TI_O1 & Alta disponibilidad & $\begin{array}{l}\text { Software de servicio municipal y Hardware } \\
\text { disponible } 24 \times 7 \text {. }\end{array}$ & $\begin{array}{l}\text { Los servicios municipales deben ser } \\
\text { accedidos por la ciudadanía en cualquier } \\
\text { momento, si así lo requiere. }\end{array}$ & $\begin{array}{l}\text { 1. Contar con un equipo de soporte las } 24 \times 7 . \\
\text { 2. Mantenimiento periódico del hardware. } \\
\text { 3. Elaborar y publicar SLA. }\end{array}$ & 01/09/2017 & $\begin{array}{c}\text { Rahael } \\
\text { Hinostroza }\end{array}$ \\
\hline PRN_TI_O2 & Interoperabilidad & $\begin{array}{l}\text { El Software y hardware deben ajustarse a las } \\
\text { normas definidas que promueven la } \\
\text { interoperabilidad de los datos, las aplicaciones y } \\
\text { la tecnologia }\end{array}$ & $\begin{array}{l}\text { Las normas ayudan a garantizar la } \\
\text { coherencia, mejorando así la capacidad de } \\
\text { gestionar los sistemas, mejorar la } \\
\text { satisfacción del usuario y proteger las } \\
\text { inversiones de Tl existentes, maximizando asi } \\
\text { la rentabilidad de la inversión y la reducción } \\
\text { de costes. Los estándares para la } \\
\text { interoperabilidad, además, ayudan a } \\
\text { asegurar la conexión de varios sistemas, y } \\
\text { facilitan la integración de las entidades } \\
\text { gubernamentales para una transferencia de } \\
\text { información eficaz. }\end{array}$ & $\begin{array}{l}\text { 1. Los estándares de interoperabilidad y } \\
\text { estándares de la industria serán seguidos a menos } \\
\text { que haya una razón de negocios para implementar } \\
\text { una solución no estándar. } \\
\text { 2. Las plataformas existentes deben ser } \\
\text { identificadas y documentadas. } \\
\text { 3. Cumplimiento del decreto legislativo que } \\
\text { aprueba diversas medidas de simplificación } \\
\text { administrativa }\end{array}$ & |01/09/2017 & $\begin{array}{l}\text { Rahael } \\
\text { Hinostroza }\end{array}$ \\
\hline PRN_TI_03 & Acuerdo de Niveles de Servicio & $\begin{array}{l}\text { La prestación de los servicios se debe negociar } \\
\text { mediante un Acuerdo de Nivel de Servicio. Esto con } \\
\text { el propósito de llegar a un acuerdo de } \\
\text { expectativas. }\end{array}$ & \begin{tabular}{|l|} 
El Acuerdo de Nivel de Servicios establece un \\
acuerdo entre elproveedor de TI con la \\
municipalidad, los servicios ofrecidos deben \\
contar con un nivel para poder asegurar la \\
calidad de dicho servicio, los aspectos \\
relacionados son tiempo de respuesta, \\
disponibilidad horaria, documentación \\
disponible, personal asignado al servicio, \\
entre otros.
\end{tabular} & $\begin{array}{l}\text { 1. Contar con un manual de políticas y lineamientos } \\
\text { de proceso. } \\
\text { 2. Establecer el servicio ofrecido. } \\
\text { 3. Establecer los costos incurridos en la prestación } \\
\text { del servicio. } \\
\text { 4. Establecer el aporte de las Tecnologías de } \\
\text { Información al cumplimiento de los objetivos de la } \\
\text { municipalidad. }\end{array}$ & |01/09/2017 & $\begin{array}{l}\text { Allison } \\
\text { Garcia }\end{array}$ \\
\hline PRN_TI_O4 & $\begin{array}{l}\text { Administración de catálogo de } \\
\text { servicios }\end{array}$ & $\begin{array}{l}\text { Los servicios de Tl que preste la organización } \\
\text { informática deberán estar definidos en el catálogo } \\
\text { de servicios con su respectivo atributos. }\end{array}$ & $\begin{array}{l}\text { El cátalogo de servicios sirve para definir los } \\
\text { servicios de Tl que se vayan a solicitar, este } \\
\text { debe contener atributos. Con este catálogo } \\
\text { se podrán generar nuevas ofertas de servicio } \\
\text { de acuerdo a las necesidades. }\end{array}$ & $\begin{array}{l}\text { 1. Contar con un manual de Políticas y Lineamientos } \\
\text { de proceso. } \\
\text { 2. Los servicios deben estar definidos con sus } \\
\text { atributos correspondientes. } \\
\text { 3. Los atributos de los servicios son: Niveles de } \\
\text { servicio, público objetivo, costo y alcance. }\end{array}$ & 01/09/2017 & $\begin{array}{l}\text { Allison } \\
\text { Garcia }\end{array}$ \\
\hline
\end{tabular}

Fuente : Elaboración Propia

\section{Anexo 10: Principios de Seguridad}


Figure 30: Principios de Seguridad

\begin{tabular}{|c|c|c|c|c|c|c|}
\hline \multicolumn{7}{|c|}{ Principios de Seguridad } \\
\hline ID & Nombre & Declaración & Fundamento & Implicaciones & Fecha & Creador \\
\hline PRN_SE_01 & Integridad de datos & $\begin{array}{l}\text { La información de la municipalidad no sufre } \\
\text { alteraciones o modificaciones. }\end{array}$ & $\begin{array}{l}\text { La empresa debe almacenar información de primera } \\
\text { mano, cuya modificación puede poner en juego la } \\
\text { integridad de los datos. }\end{array}$ & $\begin{array}{l}\text { 1. No tomar decisiones en base a data incorrecta } \\
\text { 2. Implementar un proceso de validación de } \\
\text { información. } \\
\text { 3. Manejar roles y permisos para modificación de } \\
\text { información. }\end{array}$ & 01/09/2017 & $\begin{array}{l}\text { Raphael } \\
\text { Hinostroza }\end{array}$ \\
\hline PRN_SE_02 & Seguridad de datos & $\begin{array}{l}\text { Los datos están protegidos del uso no } \\
\text { autorizado y la divulgación. }\end{array}$ & $\begin{array}{l}\text { El intercambio abierto y la divulgación de la } \\
\text { información debe equilibrarse con la necesidad de } \\
\text { restringir la disponibilidad de la información } \\
\text { clasificada y sensible. }\end{array}$ & \begin{tabular}{|l|} 
1. Cumplimiento de la ley № 29733 - Ley de \\
protección de datos personales \\
2. Con el fin de proveer adecuadamente el \\
acceso a la información mientras se mantiene la \\
información sensible segura, las necesidades de \\
seguridad deben ser identificadas y \\
desarrolladas a nivel de datos, no el nivel de \\
aplicación.
\end{tabular} & 01/09/2017 & $\begin{array}{l}\text { Allison } \\
\text { Garcia }\end{array}$ \\
\hline PRN_SE_03 & $\begin{array}{l}\text { Perímetros de seguridad } \\
\text { informática }\end{array}$ & $\begin{array}{l}\text { Protección del sistema de información de la } \\
\text { municipalidad. }\end{array}$ & $\begin{array}{l}\text { La municipalidad debe contar con seguridad } \\
\text { informática, la cual se encarga de diseñar las } \\
\text { normas, procedimientos, métodos y técnicas } \\
\text { destinados a conseguir un sistema de información } \\
\text { seguro y confiable. }\end{array}$ & $\begin{array}{l}\text { 1. Establecer una serie de estándares, protocolos } \\
\text { y métodos para evitar riesgos de información. } \\
\text { 2. Establecer reglas, herramientas y leyes para } \\
\text { minimizar los posibles riesgos a la } \\
\text { infraestructura o a la información. }\end{array}$ & $01 / 09 / 2017$ & $\begin{array}{l}\text { Allison } \\
\text { Garcia }\end{array}$ \\
\hline
\end{tabular}

Fuente : Elaboración Propia

\section{Anexo 11: Misión}


Figure 31: Misión Municipalidad de Miraflores

\section{Declaración de la Misión}

Brindar servicios públicos a través de una gestión moderna y eficiente, con el fin de entregar a los ciudadanos un lugar grato para desarrollarse y vivir.

Fuente : Municipalidad de Miraflores

\section{Anexo 12: Sponsor de la Organización}

Figure 32: Sponsor

\begin{tabular}{|c|c|c|c|c|c|}
\hline \multicolumn{6}{|c|}{ Sponsor de la Organización } \\
\hline ID & Nombre & Organización & Posición & Email & Teléfono \\
\hline SPS_01 & Roberto Hipolito Gómez Baca & Municipalidad de Santiago de Surco & Alcalde & alcaldia@munisurco.gob.pe & 411-5560 Anexo 2204 \\
\hline SPS_02 & Waldo Felipe Olivos Rengifo & Municipalidad de Santiago de Surco & Gerente Municipal & gm@munisurco.gob.pe & $\begin{array}{l}\text { 411-5560 Anexos: } 2207 \text { - } \\
2208\end{array}$ \\
\hline SPS_03 & Héctor Luis Santivañez Cotera & Municipalidad de Santiago de Surco & Gerente de Desarrollo Económico & gde@munisurco.gob.pe & $\begin{array}{c}\text { 411-5560 Anexos: } 1251 \text { - } \\
1252\end{array}$ \\
\hline SPS_04 & $\begin{array}{c}\text { Milagros Pamela Arteaga } \\
\text { Delgado }\end{array}$ & Municipalidad de Santiago de Surco & Gerente de Desarrollo Urbano & gdu@munisurco.gob.pe & $\begin{array}{l}\text { 411-5560 Anexos: } 2101 \text { - } \\
2102\end{array}$ \\
\hline SPS_05 & Rosa María Ita Martínez & Municipalidad de Santiago de Surco & Subgerente de Licencias y Habilitación & sglh@munisurco.gob.pe & $\begin{array}{l}411-5560 \text { Anexos: } 2107- \\
2108 \\
\end{array}$ \\
\hline SPS_06 & & & & & \\
\hline
\end{tabular}

Fuente : Elaboración Propia

\section{Anexo 13: Objetivos}


Figure 33: Objetivos

\begin{tabular}{|c|c|c|c|}
\hline \multicolumn{4}{|c|}{ Objetivos } \\
\hline ID & Nombre del Objetivo & Tipo & Indicador \\
\hline \multirow{3}{*}{ OBJ_01 } & \multirow{3}{*}{ Fortalecer la seguridad ciudadana. } & \multirow{3}{*}{ Estratégico } & Disminuir en a un $20 \%$ el nivel de percepción de la inseguridad ciudadana. \\
\hline & & & Disminuir a un $10 \%$ el ratio de victimización. \\
\hline & & & Disminuir a un $50 \%$ el porcentaje de accidentes de tránsito en los puntos negros identificados. \\
\hline \multirow{4}{*}{$\mathrm{OBJ} \_02$} & \multirow{4}{*}{ Asegurar la calidad ambiental de la ciudad. } & \multirow{4}{*}{ Estratégico } & Aumentar a un $5 \%$ el porcentaje de residuos sólidos inogánicos domiciliarios destinados a reciclaje. \\
\hline & & & Disminuir a un $23.5 \mu \mathrm{g} / \mathrm{m} 3$ el nivel de concentración de material particulado PM 2,5 . \\
\hline & & & Aumentar a un $6.0 \mathrm{~m} 2 /$ hab la superficie de área verde pública per cápita. \\
\hline & & & Aumentar a un $70 \%$ el porcentaje de agua de canal y agua tratada para la irrigación de las áreas verdes. \\
\hline OBJ_03 & Reducir la vulnerabilidad del riesgo de desastres del distrito. & Estratégico & Aumentar a un $35 \%$ el porcentaje de la población con capacidad de respuesta ante emergencias y desastres. \\
\hline \multirow{3}{*}{ OBJ_04 } & \multirow{3}{*}{ Lograr el crecimiento ordenado de la ciudad. } & \multirow{3}{*}{ Estratégico } & Reducir a un $34 \%$ el porcentaje de condición de terreno rústico y semi-rústico. \\
\hline & & & Disminuir el tiempo promedio de circulación vehicular en hora punta a 11 minutos. \\
\hline & & & Aumentar a un $5 \%$ el porcentaje de ejecución presupuestal del gasto en infraestructura vial. \\
\hline OBJ_05 & Promover el desarrollo económico de la ciudad. & Estratégico & Aumentar a 23342 establecimientos con licencias de funcionamiento activas. \\
\hline OBJ_06 & Fortalecer el desarrollo humano de la población. & Estratégico & Aumentar a 0,79 el índice de desarrollo humano (IDH). \\
\hline OBJ_07 & $\begin{array}{l}\text { Mejorar la calidad y el acceso de los servicios de educación y salud de la } \\
\text { población. }\end{array}$ & Estratégico & $\begin{array}{l}\text { Aumentar a } 81 \% \text { el porcentaje de estudiantes de } 2^{\circ} \text { grado de primaria de instituciones educativas que se } \\
\text { encuentran en el nivel satisfactorio en comprensión lectora. } \\
\text { Aumentar a } 48 \% \text { el porcentaje de estudiantes de } 2^{\circ} \text { grado de primaria de instituciones educativas que se } \\
\text { encuentran enel nivel satisfactorio en matemáticas. } \\
\text { Aumentar a } 51 \% \text { el porcentaje de estudiantes de } 2^{\circ} \text { grado de secundaria de instituciones educativas que se } \\
\text { encuentran en el nivel satisfactorio en comprensión lectora. } \\
\text { Aumentar a } 34 \% \text { el porcentaje de estudiantes de } 2^{\circ} \text { grado de secundaria de instituciones educativas que se } \\
\text { encuentran en el nivel satisfactorio en matemáticas } \\
\text { Aumentar a } 90 \% \text { el porcentaje de población afiliada a algún tipo de seguro de salud. }\end{array}$ \\
\hline \multirow{3}{*}{ OBJ_08 } & \multirow{3}{*}{ Mejorar la gobernanza de la ciudad. } & \multirow{3}{*}{ Estratégico } & Aumentar a 266 agentes participantes del proceso de presupuesto participativo. \\
\hline & & & Aumentar a 7 el nivel de cumplimiento de información publicada en el portal de transparencia. \\
\hline & & & Aumentar a $65 \%$ el porcentaje de atención de solicitudes, quejas, reclamos y sugerencias finalizadas. \\
\hline
\end{tabular}

Fuente : Elaboración Propia

\section{Anexo 14: Requerimientos}


Figure 34: Requerimientos

\begin{tabular}{|c|c|c|}
\hline \multicolumn{3}{|r|}{ Requerimientos } \\
\hline ID & Tipo & Requerimiento \\
\hline REQ_01 & Funcional & El sistema enviará una notificación cuando se registre alguna solicitud de emisión de licencia de funcionamiento. \\
\hline REQ_02 & Funcional & El sistema debe poder comunicarse con todas las áreas de la municipalidad para que éstas puedan estar integradas. \\
\hline REQ_03 & Funcional & $\begin{array}{l}\text { El jefe del área de recursos humanos debe ser capaz de actualizar el listado de empleados que existe en la organización, indicando los nuevos } \\
\text { ingresantes, nuevos puestos y salidas. }\end{array}$ \\
\hline REQ_04 & Funcional & Para la realización de trámites, el sistema solicitará el registro del usuario. \\
\hline REQ_05 & Funcional & El sistema otorgará a cada solicitud un único identificador de trámite. \\
\hline REQ_06 & Funcional & Se debe verificar que la documentación necesaria para iniciar el trámite esté correcta y completa cumpliendo con las leyes y normas establecidas. \\
\hline REQ_07 & Funcional & Se debe contar con una asesoría en línea disponible al ciudadano cuando este lo requiera. \\
\hline REQ_08 & Funcional & Para la emisión de la licencia de funcionamiento es necesario que defensa civil realice una inspección del establecimiento. \\
\hline REQ_09 & No Funcional & $\begin{array}{l}\text { El plazo máximo para la emisión de la licencia de funcionamiento debe ser de } 7 \text { días hábiles luego de haber presentado correctamente todos los } \\
\text { requisitos. }\end{array}$ \\
\hline REQ_10 & No Funcional & $\begin{array}{l}\text { La licencia de funcionamiento emitida solo es válida en el distrito en que se solicitó la emisión, más no si el solicitante desea abrir el mismo negocio en } \\
\text { otro distrito. }\end{array}$ \\
\hline REQ_11 & No Funcional & $\begin{array}{l}\text { La licencia de funcionamiento tiene un tiempo indeterminado pero en caso se cesen las actividades del negocio se debe informar inmediatamente a la } \\
\text { municipalidad. }\end{array}$ \\
\hline REQ_12 & No Funcional & En caso se desee cambiar el local de establecimiento del negocio se debe solicitar una nueva licencia de funcionamiento. \\
\hline REQ_13 & Funcional & Los usuarios deben ingresar al sistema con usuario y contraseña. \\
\hline REQ_14 & Funcional & Se deben asignar los permisos correspondientes al rol de cada usuario. \\
\hline REQ_15 & No Funcional & La actualización de los datos modificados en la base de datos debe ser en menos de 3 segundos. \\
\hline REQ_16 & No Funcional & Los permisos de acceso al sistema correspondiente a cada rol solo podrán ser cambiados por el administrador de acceso a datos. \\
\hline
\end{tabular}

Fuente : Elaboración Propia

\section{Anexo 15: Roles}


Figure 35: Roles

\begin{tabular}{|l|l|l|l|}
\hline \multicolumn{2}{|c|}{ Área } & \multicolumn{1}{c}{ Rombre del Rol } & Nombre de Usuario \\
\hline ID & \multicolumn{1}{|c|}{ Roles } & Rosa María Ita Martínez \\
\hline RESP_PYP_01 & $\begin{array}{l}\text { Gerencia de Desarrollo Urbano } \\
\text { Subgerencia de Desarrollo }\end{array}$ & Asesor CAS & Milagros Pamela Arteaga Delgado \\
\hline RESP_PYP_02 & $\begin{array}{l}\text { Gerencia de Desarrollo Urbano } \\
\text { Subgerencia de Desarrollo }\end{array}$ & Subgerente & Eva Rocío Cubillas Quispe \\
\hline RESP_PYP_03 & $\begin{array}{l}\text { Gerencia de Desarrollo Urbano } \\
\text { Subgerencia de Desarrollo } \\
\text { Económico }\end{array}$ & Auxiliar & Edwin Jim Valdivia Devoto \\
\hline RESP_PYP_04 & Gerencia de Asesoría Jurídica & Asesor Legal & Allison García Girón \\
\hline RESP_PYP_05 & Equipo de Proyecto & Analista Funcional & Alejandro Delgado Ledesma \\
\hline RESP_PYP_06 & Equipo de Proyecto & Especialista en Infraestructura & Daniel Dueñas Zamorano \\
\hline RESP_PYP_07 & Equipo de Proyecto & Desarrollador & Raphael Hinostroza Lozada \\
\hline RESP_PYP_08 & Equipo de Proyecto & Administrador de Base de Datos & Edgar Díaz \\
\hline RESP_PYP_09 & Equipo de Proyecto & Jefe de Proyecto & \\
\hline
\end{tabular}

Fuente : Elaboración Propia

\section{Anexo 16: Roles - Responsabilidades (1)}


Figure 36: Roles - Responsabilidades (1)

\begin{tabular}{|c|c|c|c|}
\hline \multicolumn{4}{|r|}{ Responsabilidades } \\
\hline ID & Área & Nombre del Rol & Responsabilidad \\
\hline RESP_PYP_01 & $\begin{array}{l}\text { Gerencia de Desarrollo Urbano } \\
\text { Subgerencia de Desarrollo } \\
\text { Económico }\end{array}$ & Asesor CAS & 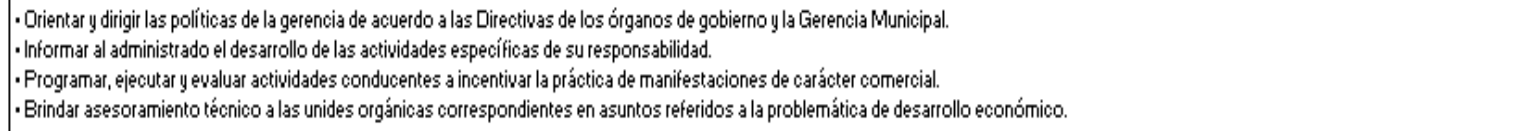 \\
\hline RESP_PYP_02 & $\begin{array}{l}\text { Gerencia de Desarrollo Urbano } \\
\text { Subgerencia de Desarrollo } \\
\text { Económico }\end{array}$ & Subgerente & 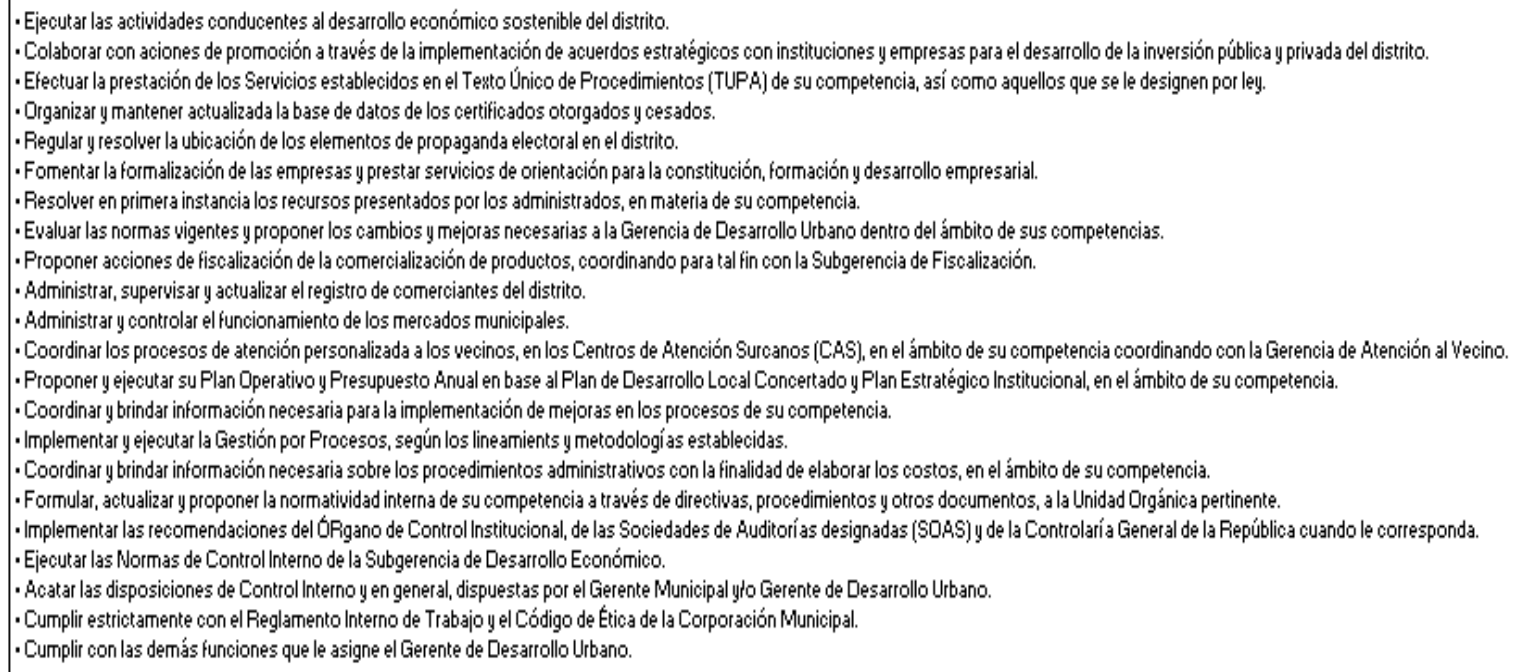 \\
\hline RESP_PYP_03 & $\begin{array}{l}\text { Gerencia de Desarrollo Urbano } \\
\text { Subgerencia de Desarrollo } \\
\text { Económico }\end{array}$ & Ausiliar & 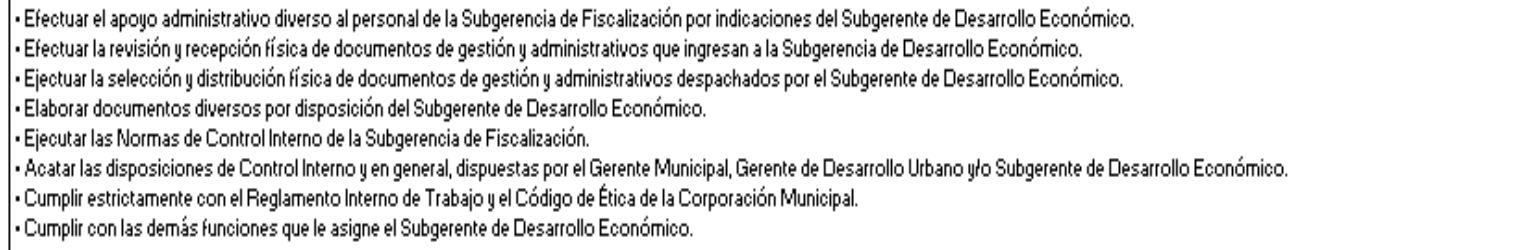 \\
\hline
\end{tabular}

Fuente : Elaboración Propia

\section{Anexo 17: Roles - Responsabilidades (2)}


Figure 37: Roles - Responsabilidades (2)

\begin{tabular}{|c|c|c|c|}
\hline RESP_PYP_04 & Gerencia de Desarrollo Urbano & Asesorlegal & 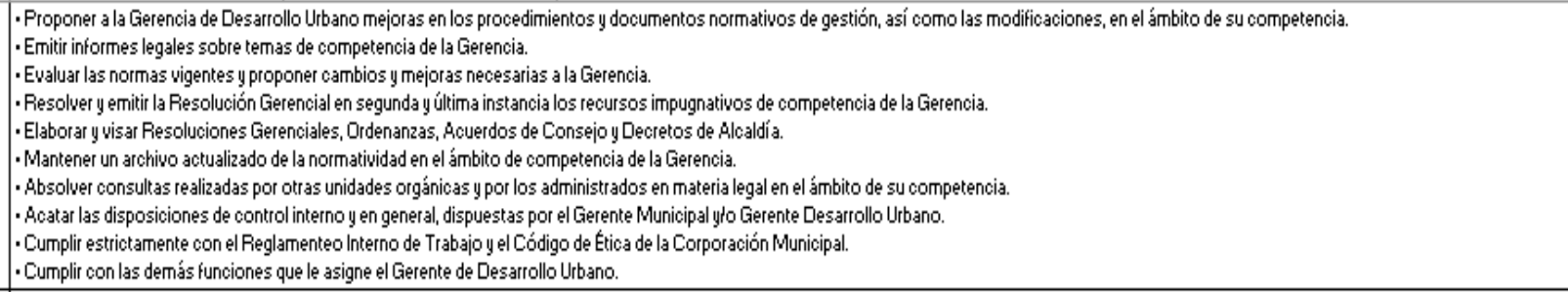 \\
\hline RESP_PYP_05 & Equipo de Proyecto & Anabista Funcional & 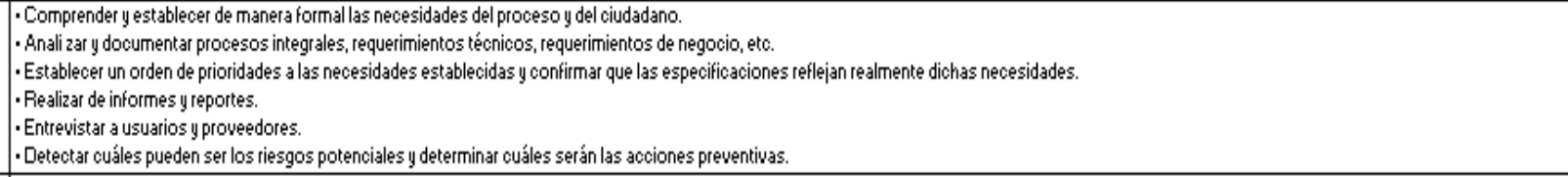 \\
\hline RESP_PYP_06 & Equipo de Proyecto & Especialista en Infraestructura & $\begin{array}{l}\text { - Gestionar el entorno físico donde se encuentra ubicada la infraestructura de TI. } \\
\text { - Disen̂ar componentes de infraestructura y sistemas necesarios. } \\
\text { - Disen̂ar y yerificar las coneviones IP. } \\
\text { - Rea alizar las configuración de puertos adecuadamente. }\end{array}$ \\
\hline RESP_PYP 07 & Equipo de Proyecto & Desamollador & 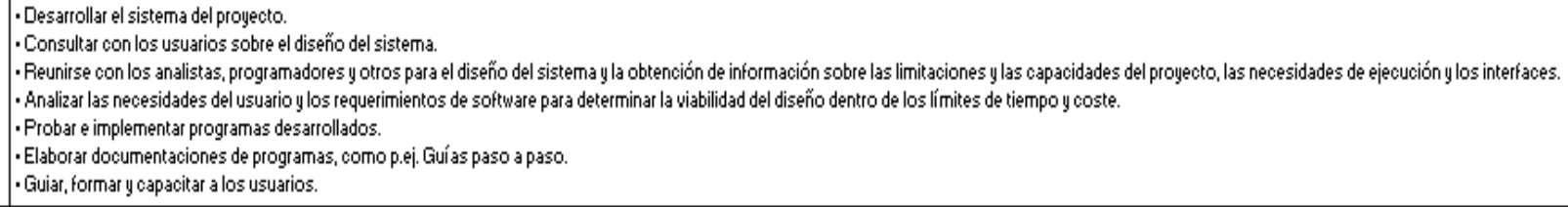 \\
\hline RESP_PYP_08 & Equipo de Proyecto & Aloministrador de Base de Datos & 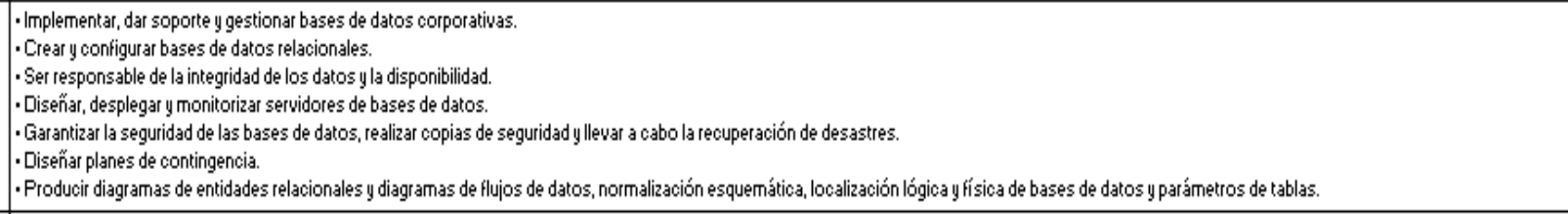 \\
\hline RESP_PYP_09 & Equipo de Proyecto & Wefe de Proyecto & 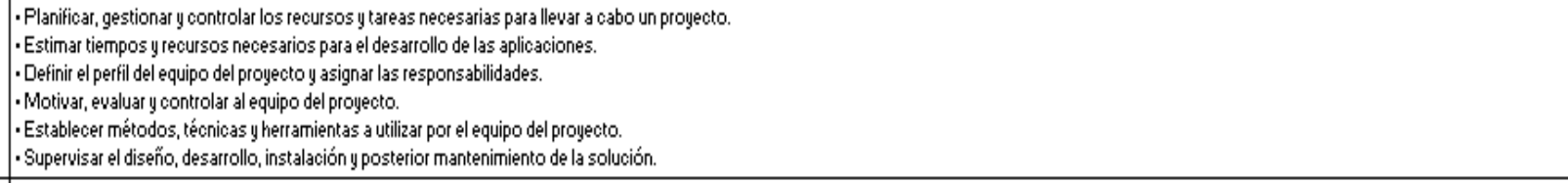 \\
\hline
\end{tabular}

Fuente : Elaboración Propia 


\section{Anexo 18: Cuestionario de Evaluación para TI}

Evaluación del Modelo de Mejora de eServicios Municipales

Nombre:

Municipalidad:

Cargo:

Cuestionario:

Ingrese los números de los documentos en la casilla que considere conveniente.

1. ¿Consideras que el documento ayudaría a su municipalidad a implementar correctamente el Gobierno Electrónico Municipal?

\begin{tabular}{|c|l|l|l|l|l|l|l|l|l|}
\hline P/A & 1 & 2 & 3 & 4 & 5 & 6 & 7 & 8 & 9 \\
\hline 5 & & & & & & & & & \\
\hline 4 & & & & & & & & & \\
\hline 3 & & & & & & & & & \\
\hline 2 & & & & & & & & & \\
\hline 1 & & & & & & & & & \\
\hline
\end{tabular}

Comentarios

2. ¿Considera que sería difícil para la municipalidad ingresar la información que solicita el documento?

\begin{tabular}{|c|l|l|l|l|l|l|l|l|l|}
\hline P/A & 1 & 2 & 3 & 4 & 5 & 6 & 7 & 8 & 9 \\
\hline 5 & & & & & & & & & \\
\hline 4 & & & & & & & & & \\
\hline 3 & & & & & & & & & \\
\hline 2 & & & & & & & & & \\
\hline 1 & & & & & & & & & \\
\hline
\end{tabular}

Comentarios 
3. Si hubiera algún proyecto nuevo para el área ¿El documento aumentaría las posibilidades de una implementación exitosa?

\begin{tabular}{|c|l|l|l|l|l|l|l|l|l|}
\hline P/A & 1 & 2 & 3 & 4 & 5 & 6 & 7 & 8 & 9 \\
\hline 5 & & & & & & & & & \\
\hline 4 & & & & & & & & & \\
\hline 3 & & & & & & & & & \\
\hline 2 & & & & & & & & & \\
\hline 1 & & & & & & & & & \\
\hline
\end{tabular}

\section{Comentarios}

4. Respecto al esquema propuesto. ¿Considera que incentivaría la implementación de del Gobierno Electrónico Municipal en el Perú?

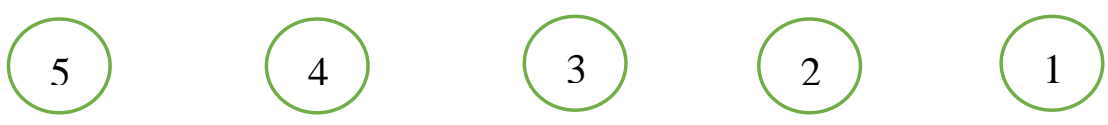

Comentarios

5. ¿Utilizaría el presente esquema en la municipalidad donde trabaja?

\section{5}

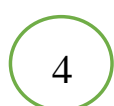

3

Comentarios

Firma 


\section{Anexo 19: Cuestionario de Evaluación para Funcionario}

Evaluación de la propuesta de emisión de licencias de funcionamiento web

Nombre:

Municipalidad:

Cargo:

1. ¿Considera que la propuesta presentada disminuye la carga procesal de los funcionarios?

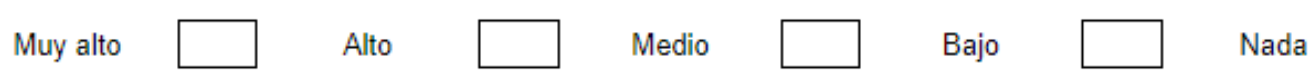

¿Por qué?

2. ¿Considera que la propuesta presentada facilitaría al ciudadano a realizar sus trámites?

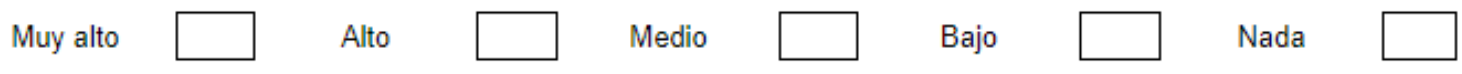

¿Por qué?

3. ¿Considera que la propuesta presentada contribuye a mejorar la relación entre el ciudadano y la municipalidad?

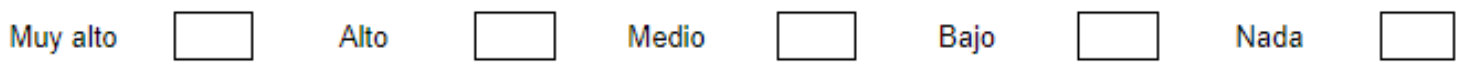

¿Por qué?

4. ¿Considera que la propuesta presentada contribuye a que los procesos de la municipalidad sean más transparentes para el ciudadano?

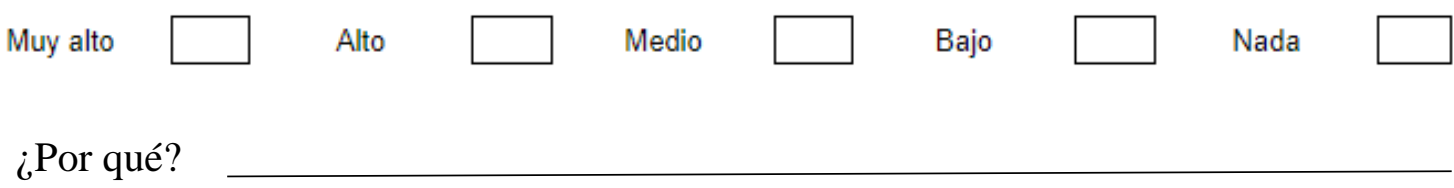


5. En general, ¿cómo considera la propuesta?

Muy buena $\square$ Buena $\square$ Regular $\square$ Mala $\square$ Muy Mala $\square$
¿Por qué?

Firma 


\section{Anexo 20: Cuestionario de Evaluación para Ciudadano}

Evaluación de la propuesta de emisión de licencias de funcionamiento web

Nombre:

Local:

Dirección:

1. ¿Considera que la propuesta presentada le facilita solicitar una licencia de funcionamiento?

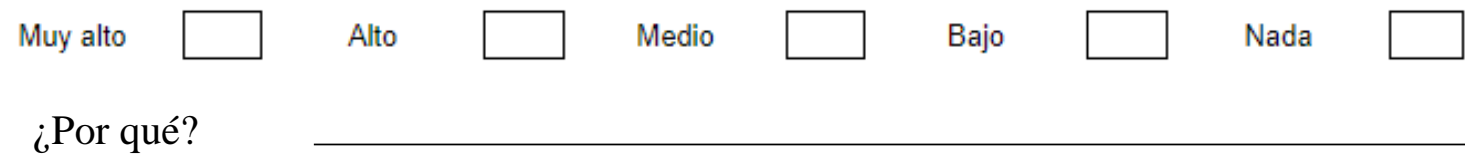

2. ¿Considera que la municipalidad debería utilizar una solución como esta?

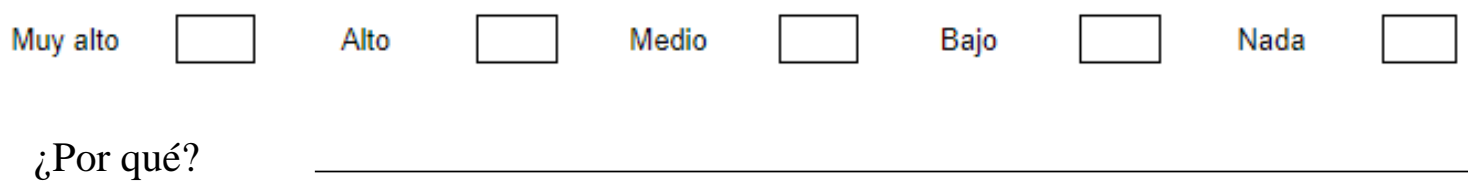

3. ¿Considera que la propuesta presentada contribuye a mejorar la relación entre el ciudadano y la municipalidad?

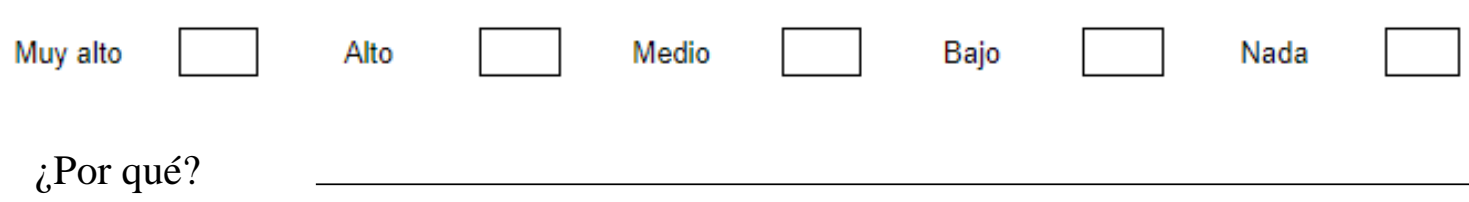

4. ¿Considera que la propuesta beneficiaría los ciudadanos?

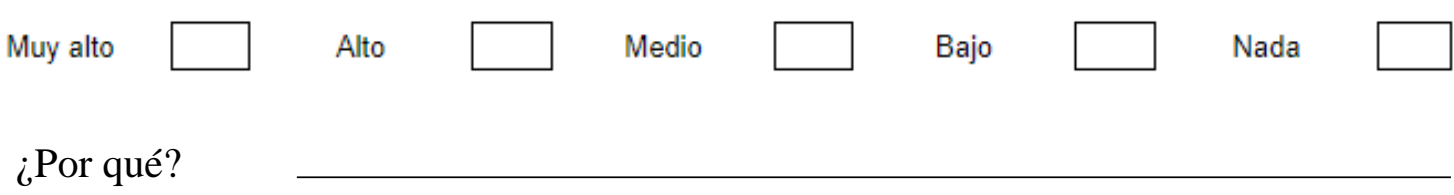

5. En general, ¿cómo considera la propuesta?

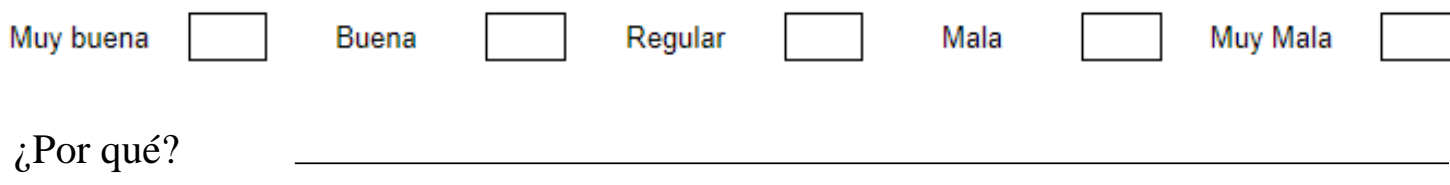




\section{Anexo 21: Trámite Documentario}

Figure 38: Trámite Dcoumentario

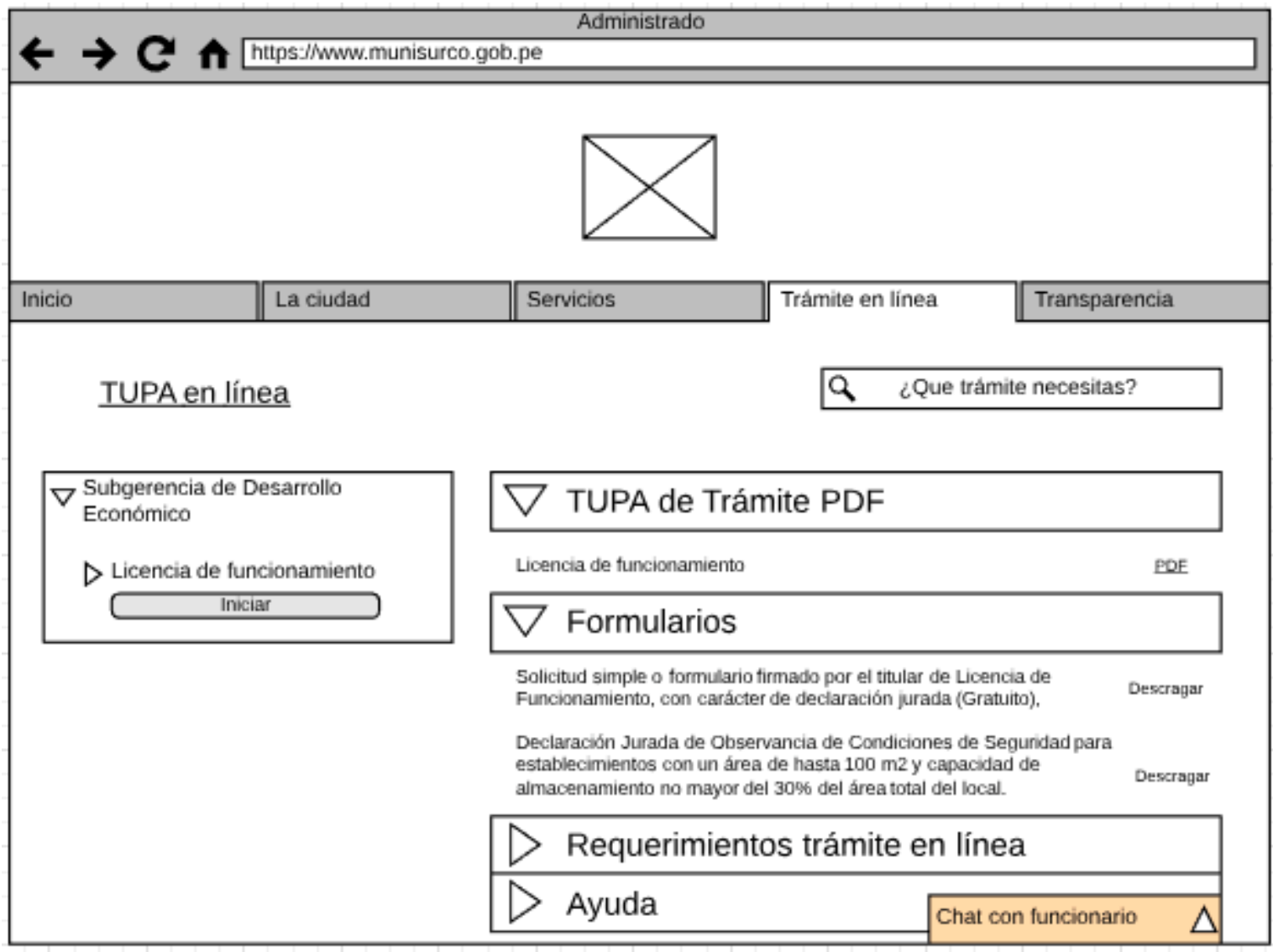

Fuente : Elaboración Propia 


\section{Anexo 22: Licencia de Funcionamiento}

Figure 39: Licencia de Funcionamiento

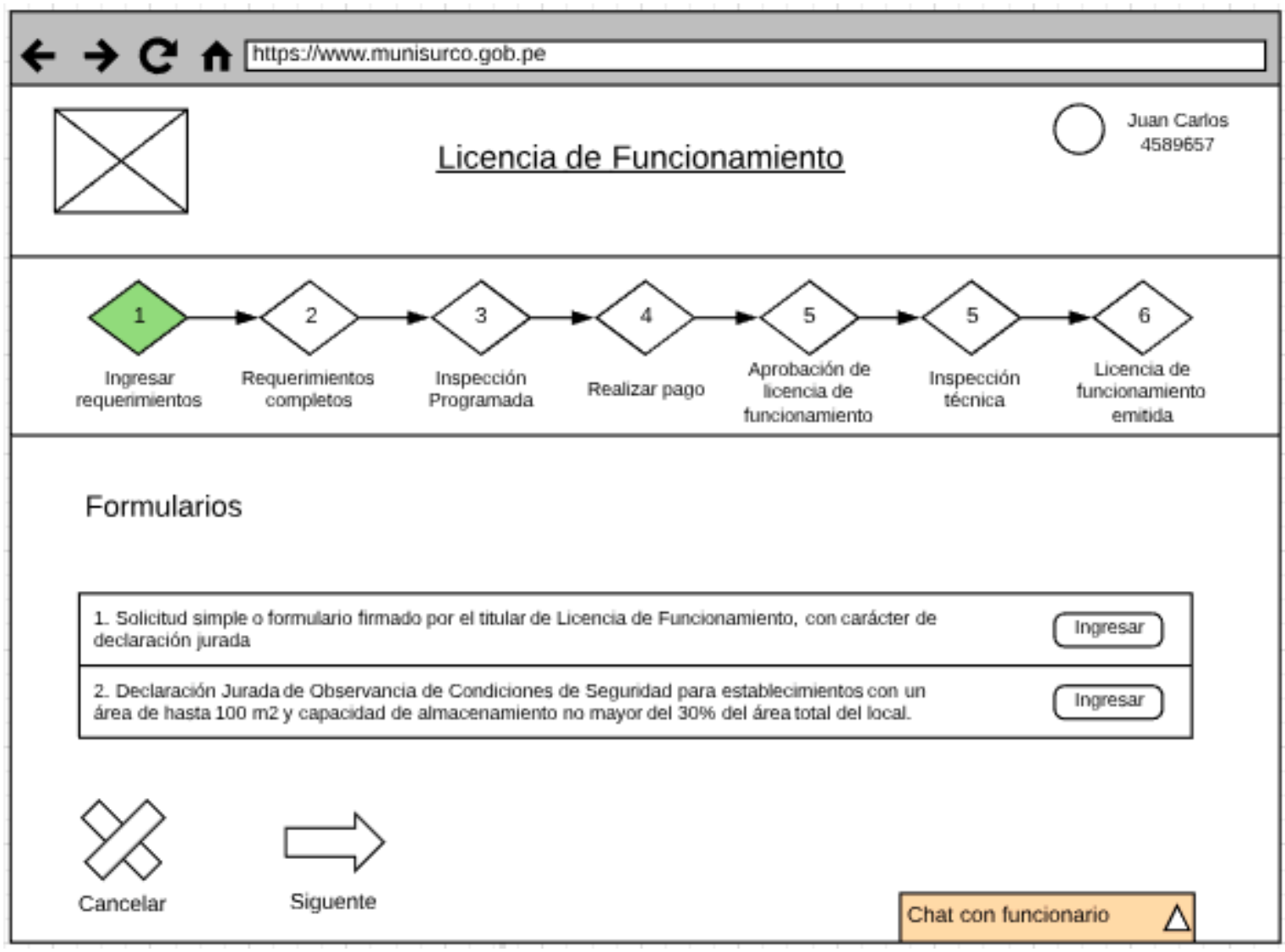

Fuente : Elaboración Propia 


\section{Anexo 22: Declaración Jurada de Observancia de Condiciones de Seguridad - Parte 1}

Figure 40: Declaración Jurada

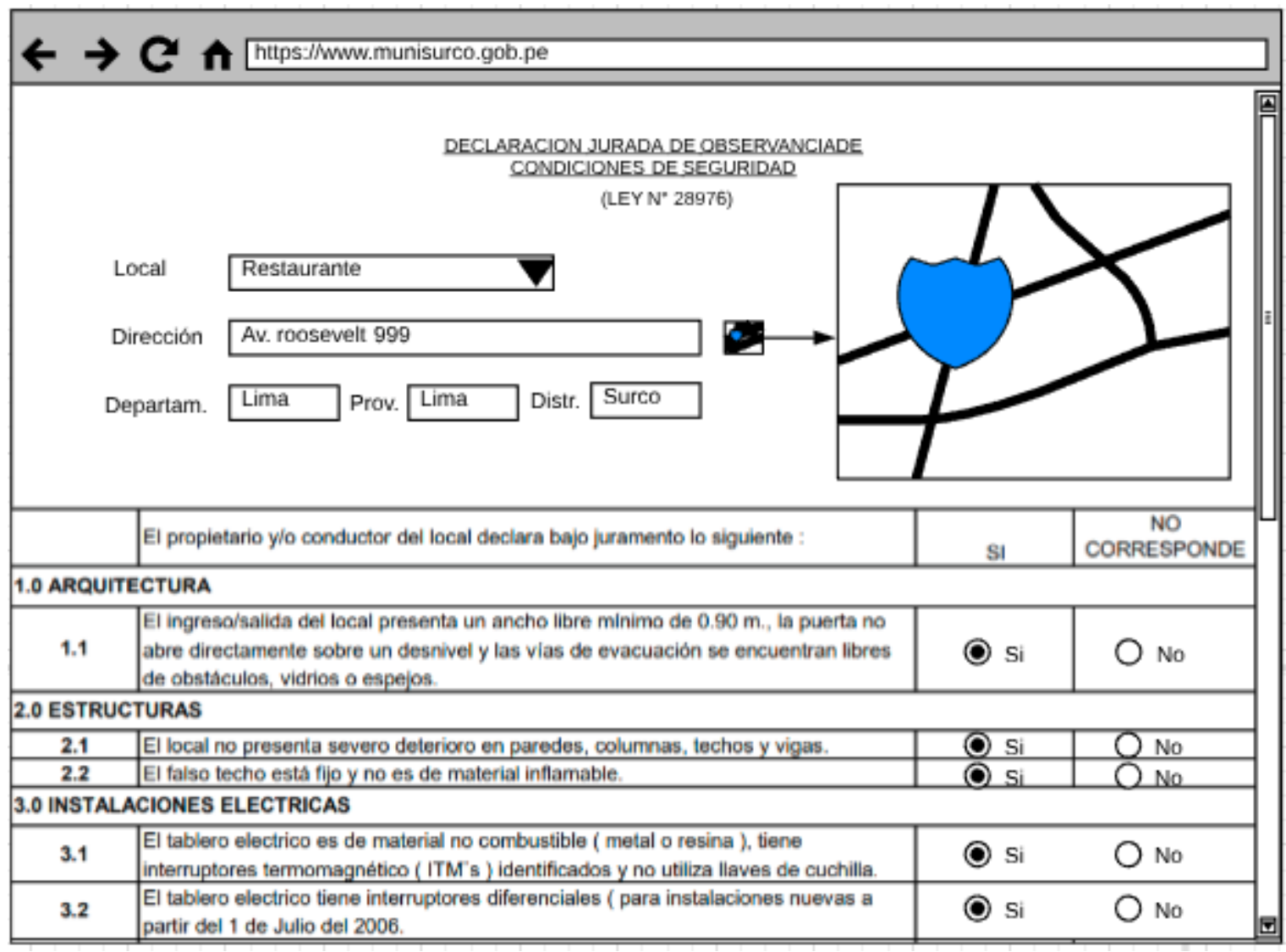

Fuente : Elaboración Propia 


\section{Anexo 23: Declaración Jurada de Observancia de Condiciones de Seguridad - Parte 2}

Figure 41: Declaración Jurada (2)

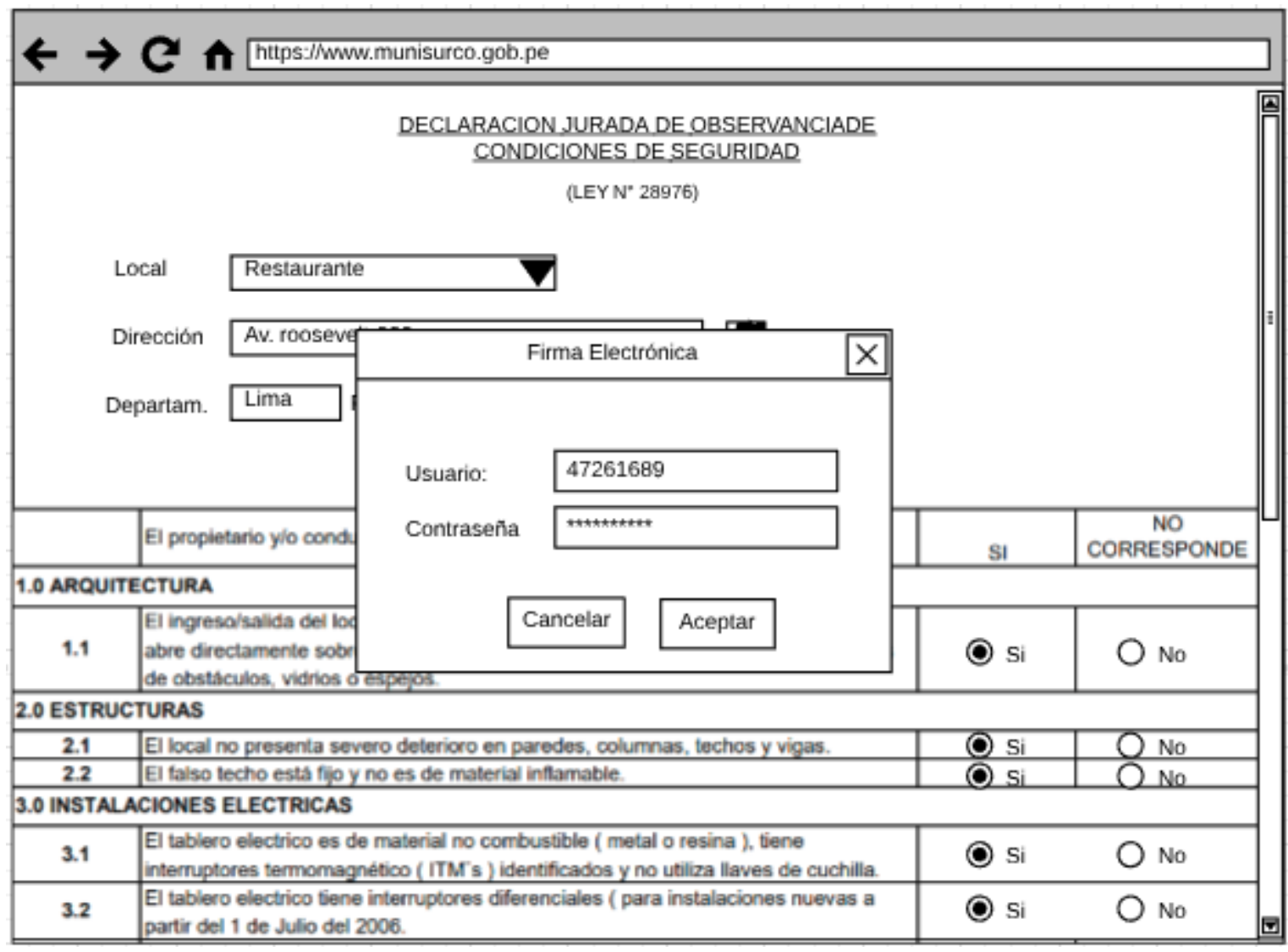

Fuente : Elaboración Propia 


\section{Anexo 23: Solicitud de Declaración Jurada para Obtener Licencia Municipal de Funcionamiento}

Figure 42: Solicitud de Declaración Jurada

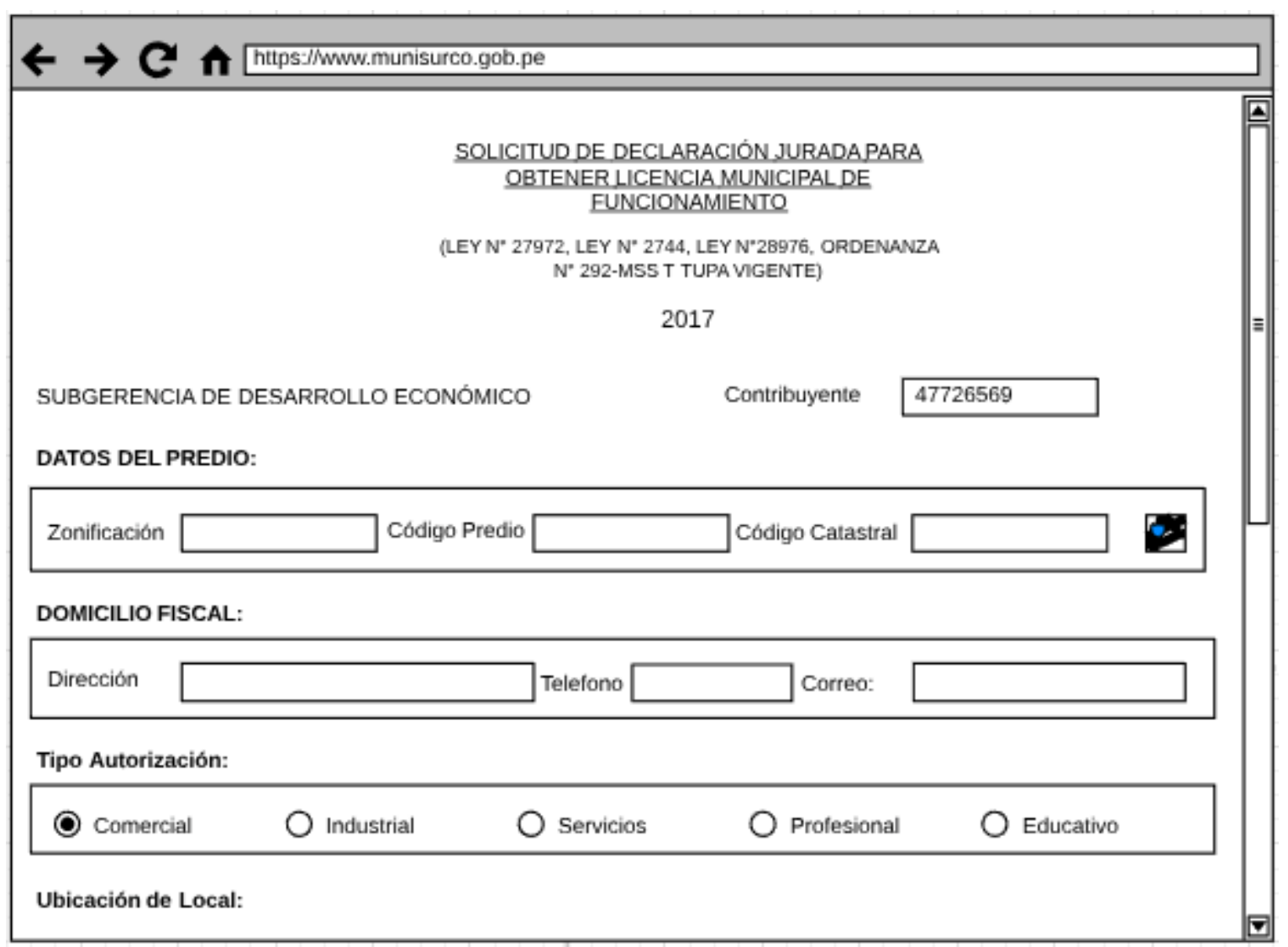

Fuente : Elaboración Propia 


\section{Anexo 23: Licencia de Funcionamiento - Parte 1}

Figure 43: Licencia de Funcionamiento

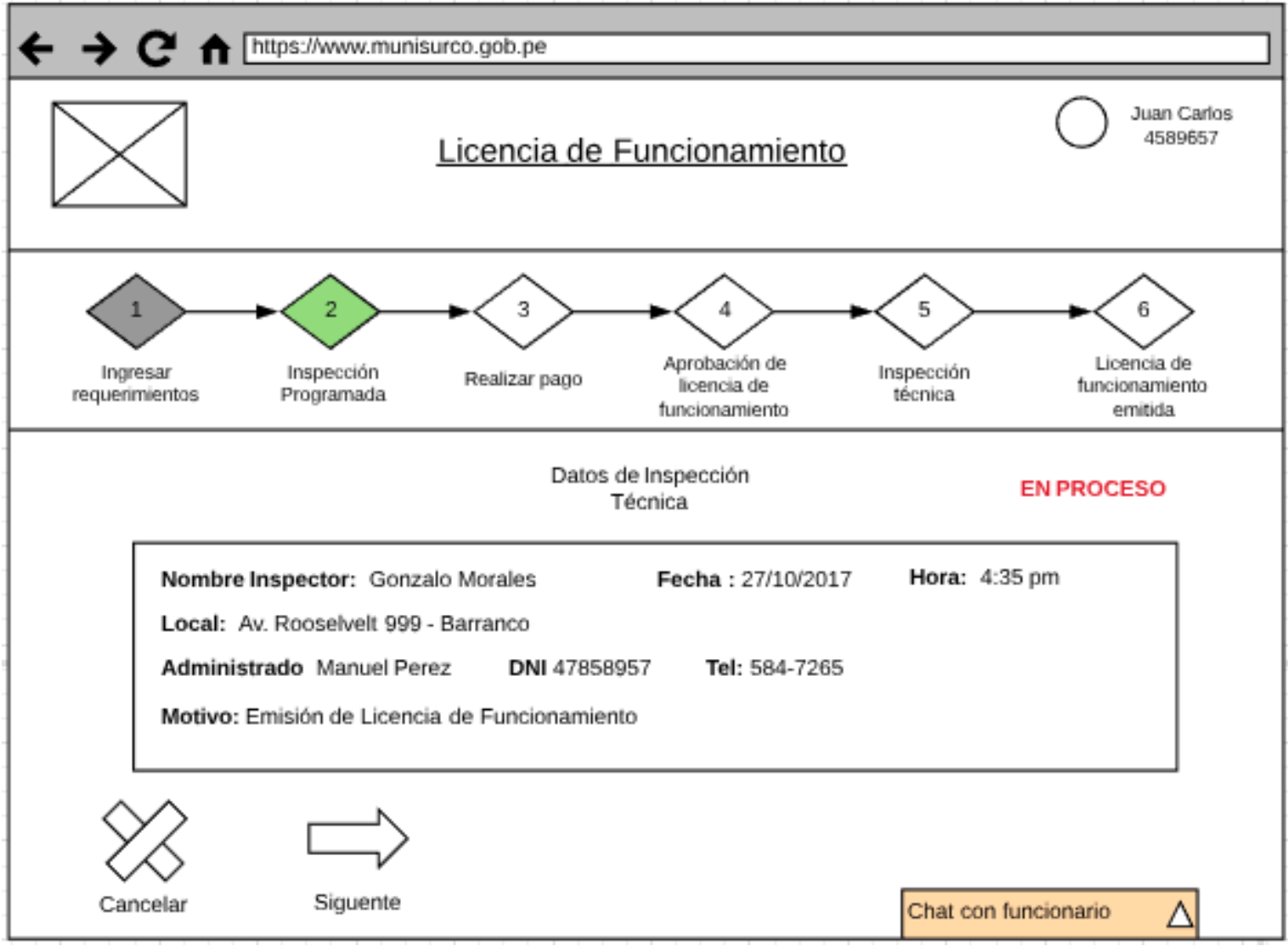

Fuente : Elaboración Propia 


\section{Anexo 24: Licencia de Funcionamiento - Parte 2}

Figure 44: Licencia de Funcionamiento (2)

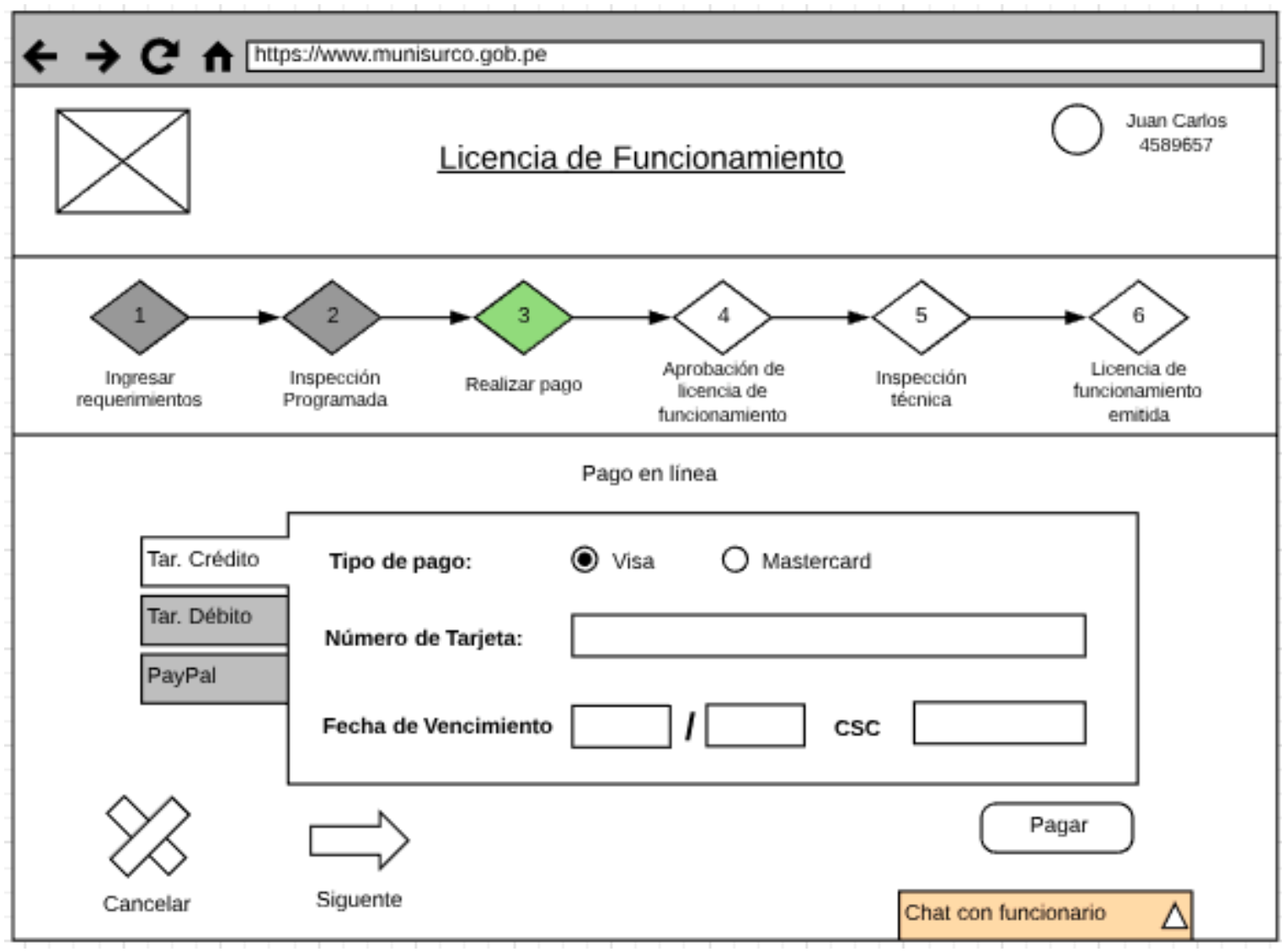

Fuente : Elaboración Propia 


\section{Anexo 24: Licencia de Funcionamiento - Parte 3}

Figure 45: Licencia de Funcionamiento (3)

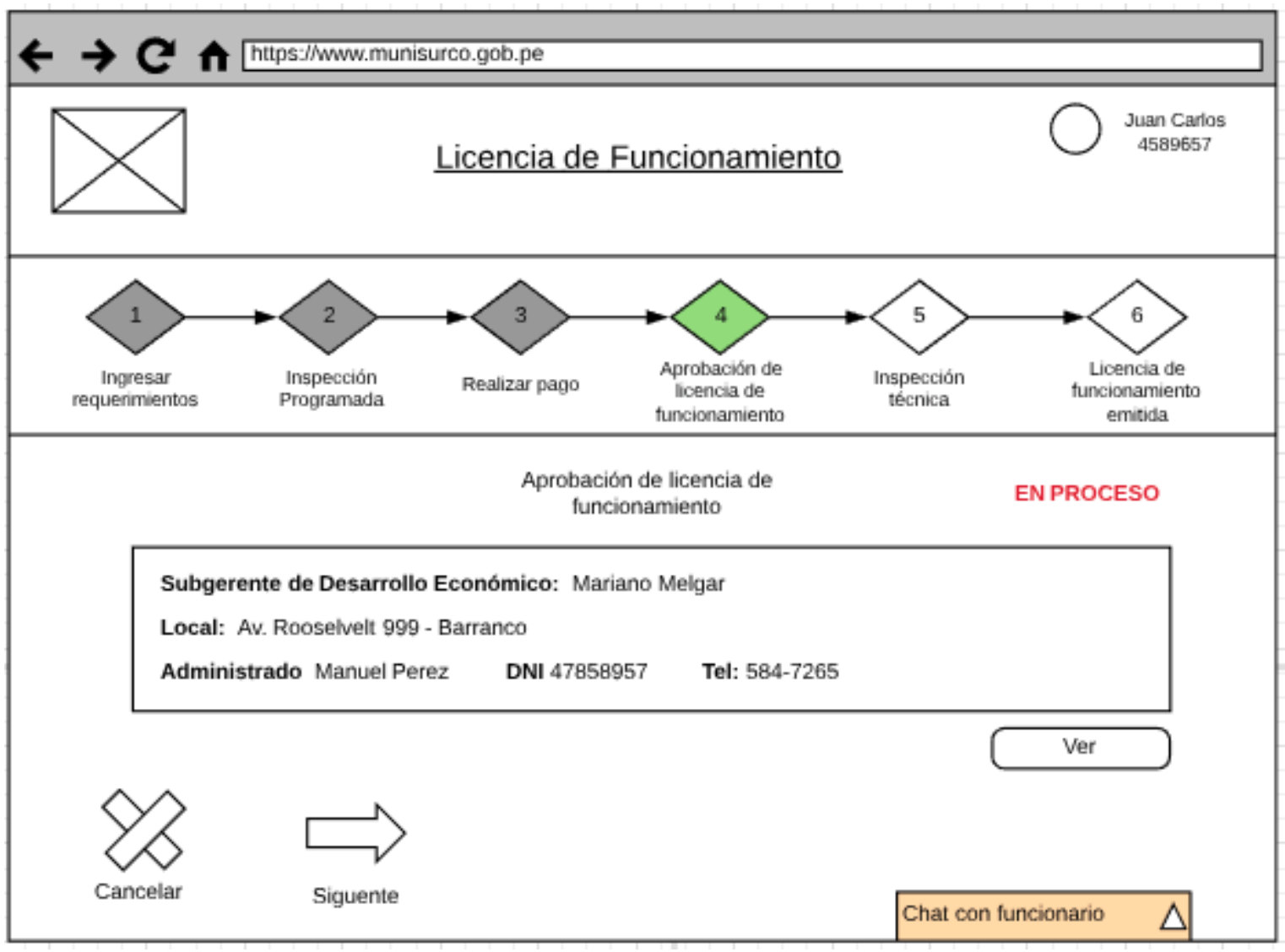

Fuente : Elaboración Propia 


\section{Anexo 24: Licencia de Funcionamiento - Parte 4}

Figure 46: Licencia de Funcionamiento (4)

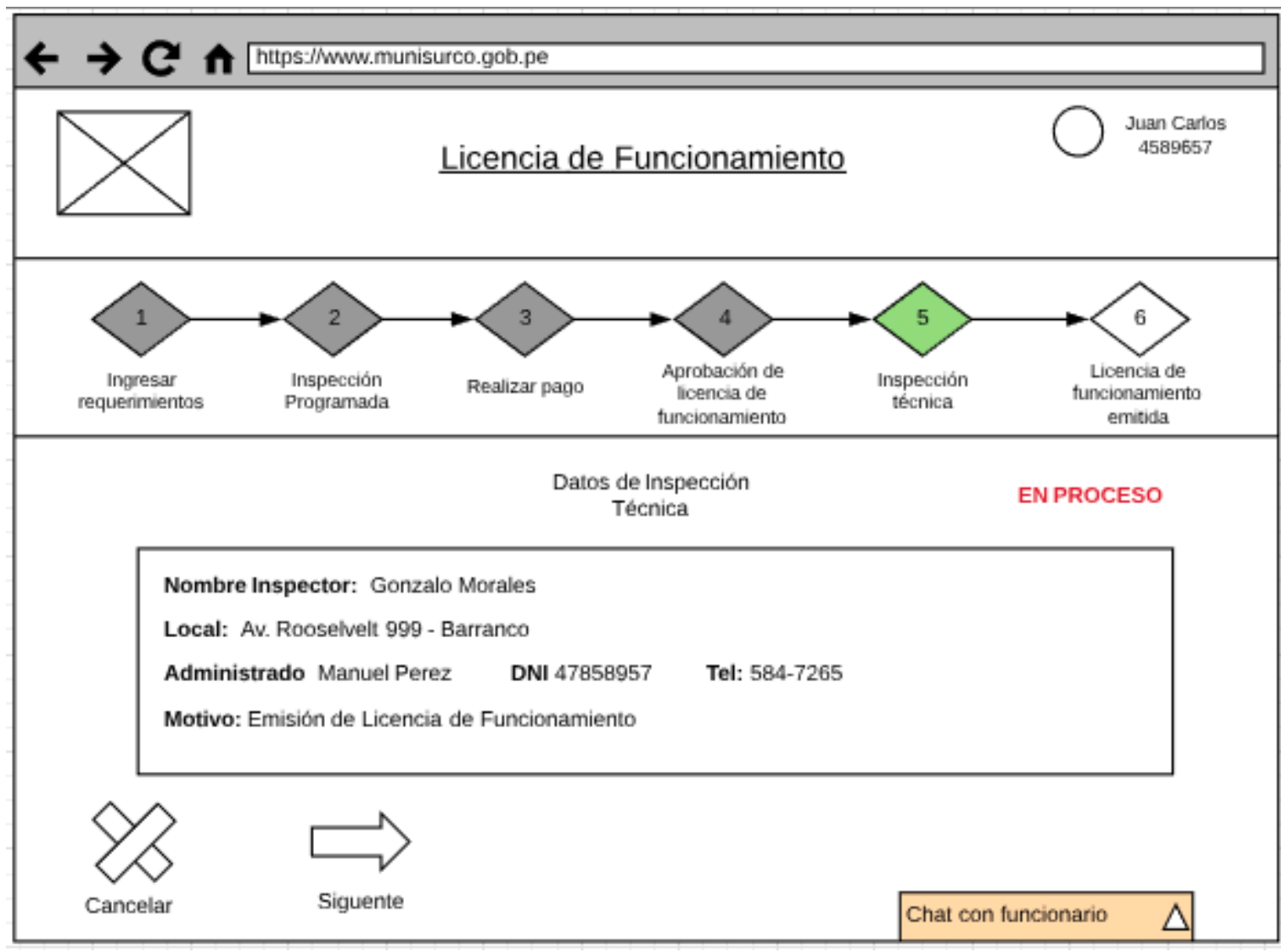

Fuente : Elaboración Propia 


\section{Anexo 24: Licencia de Funcionamiento - Parte 5}

Figure 47: Licencia de Funcionamiento (5)

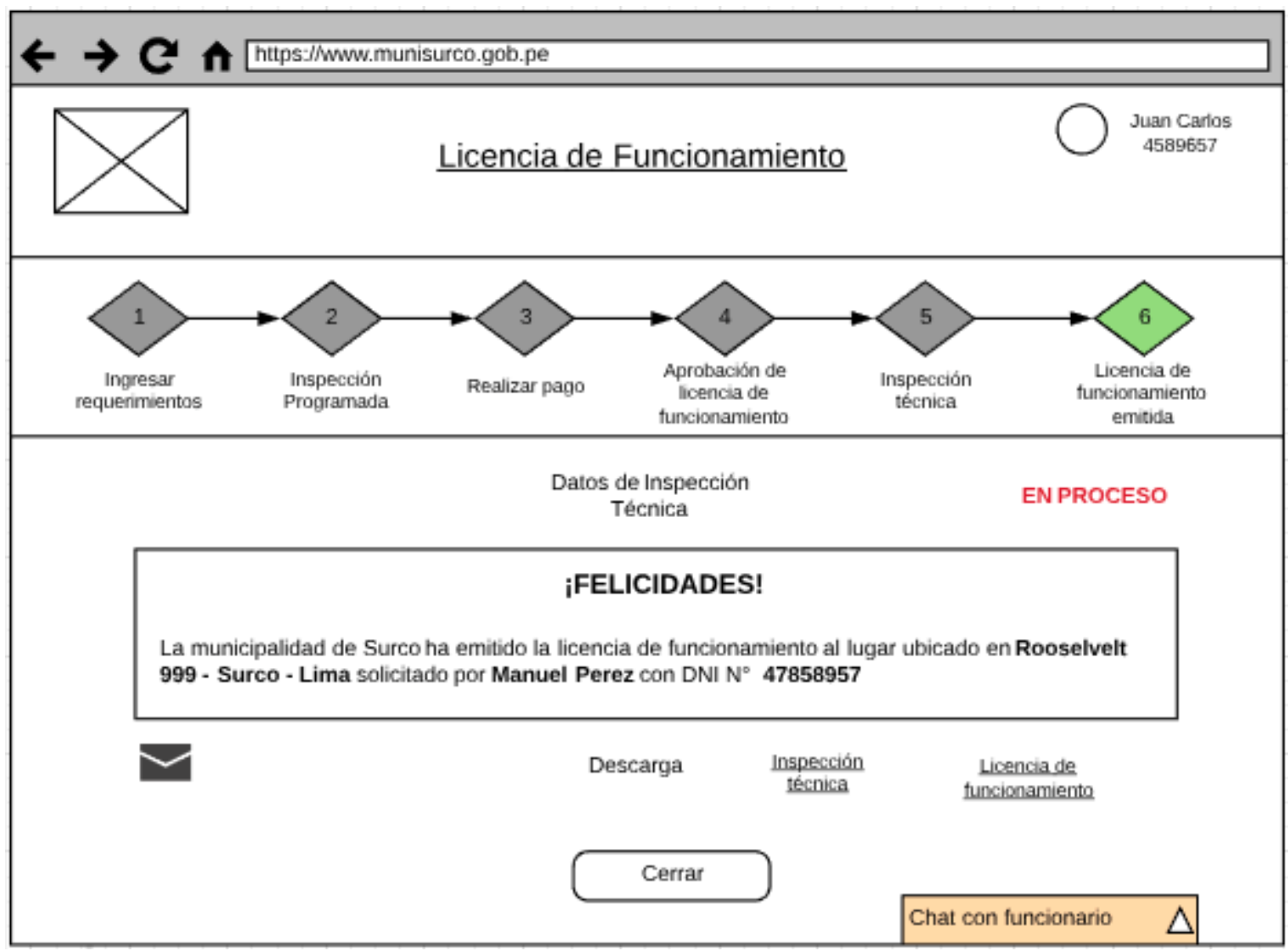

Fuente : Elaboración Propia 


\section{Anexo 24: Chat en Línea - Parte 1}

Figure 48: Chat en Línea

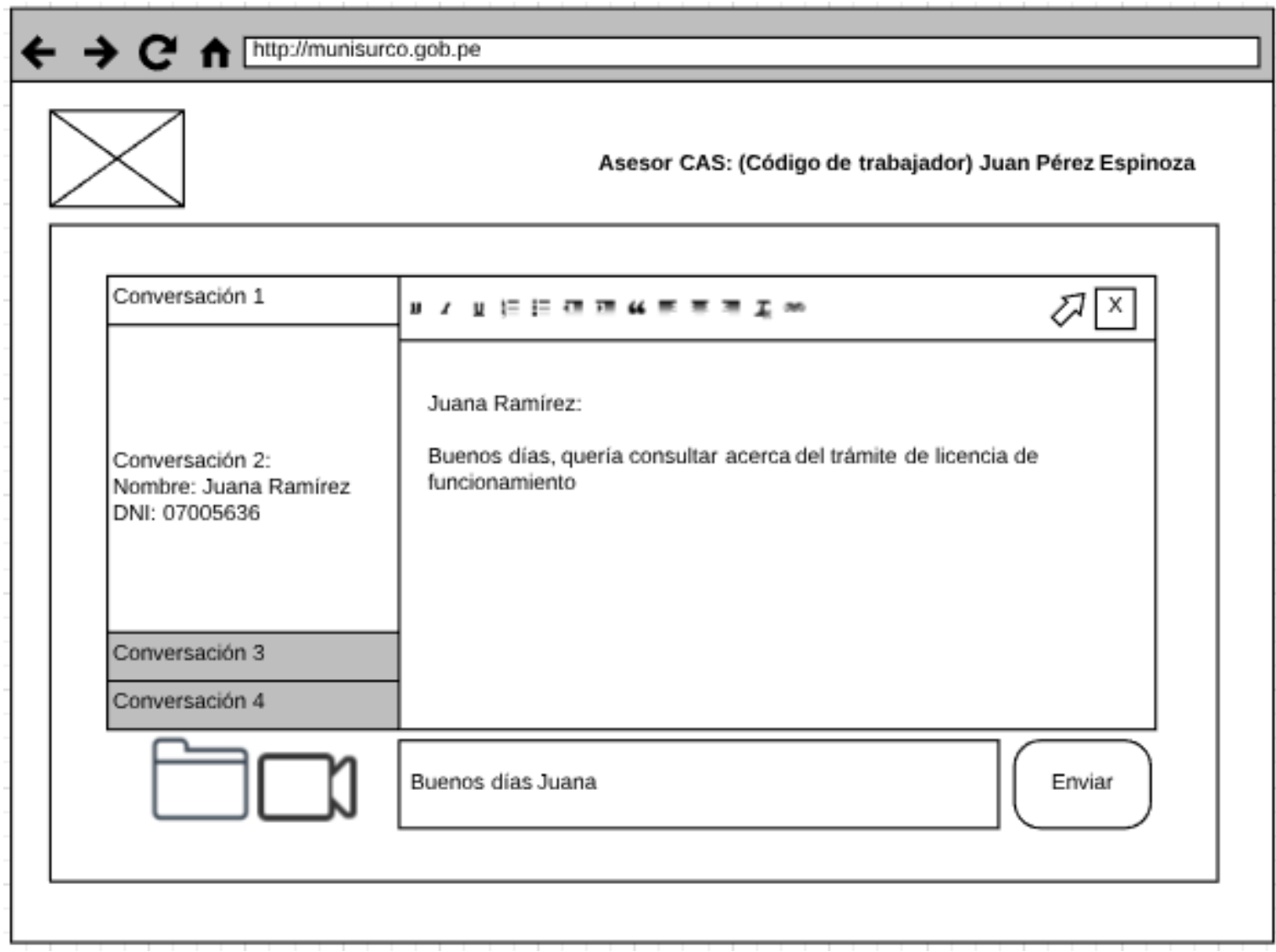

Fuente : Elaboración Propia 


\section{Anexo 24: Chat en Línea - Parte 2}

Figure 49: Chat en Línea (2)

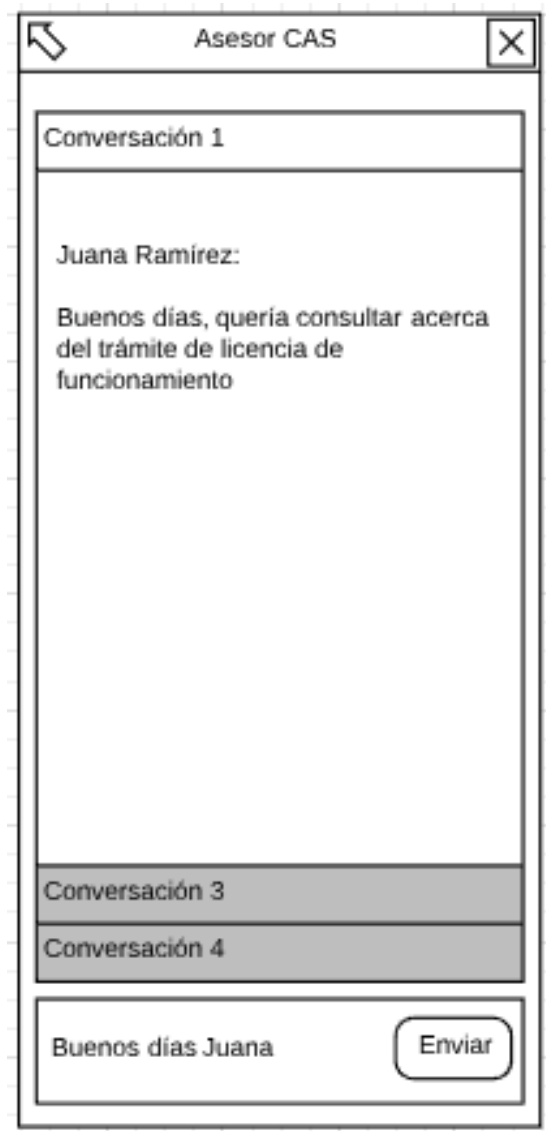

Fuente : Elaboración Propia 


\section{Anexo 24: Firma de Certificado}

Figure 50: Firma de Certificado

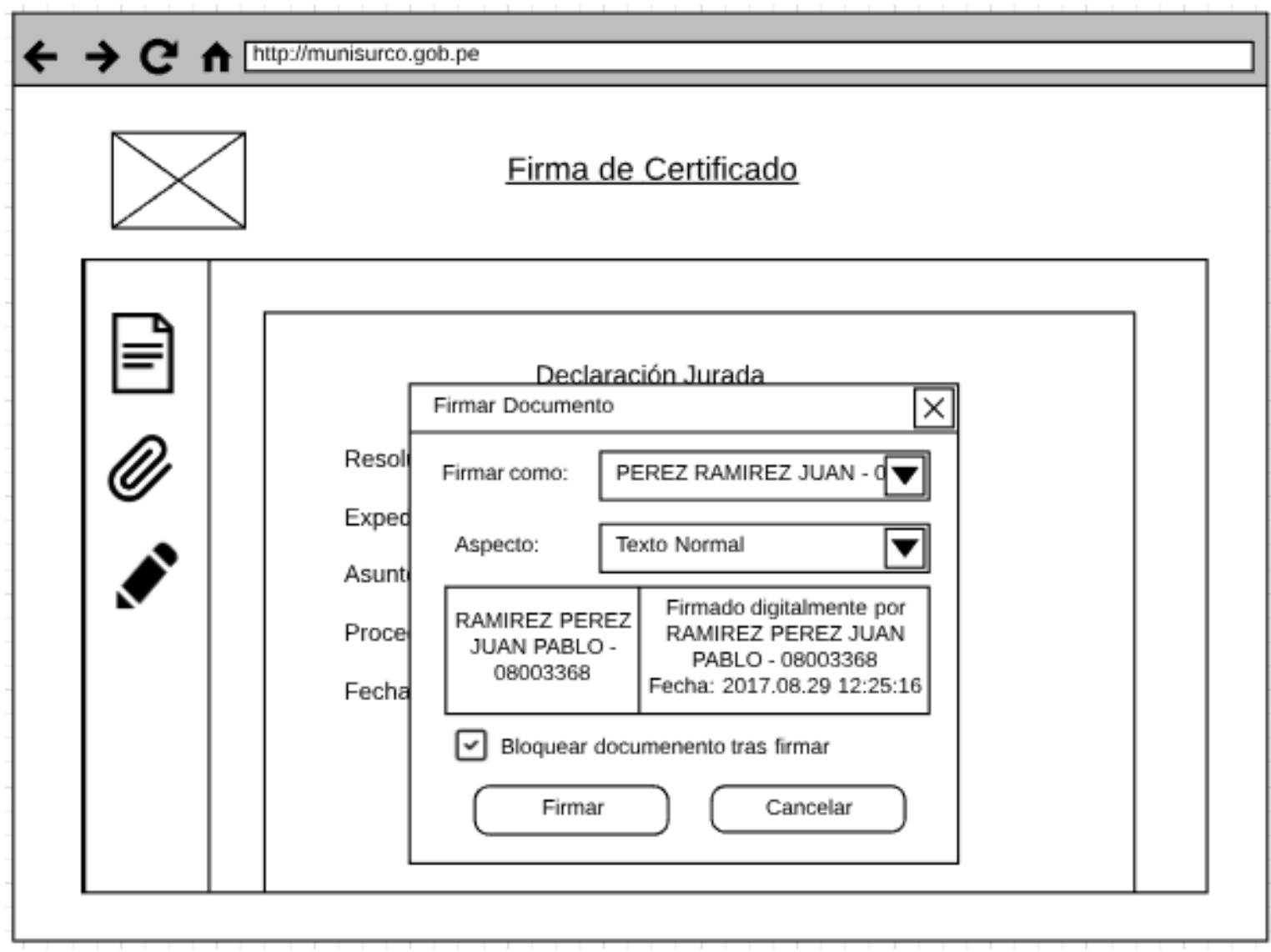

Fuente : Elaboración Propia 


\section{Anexo 24: Memorandum}

Figure 51: Memorandum

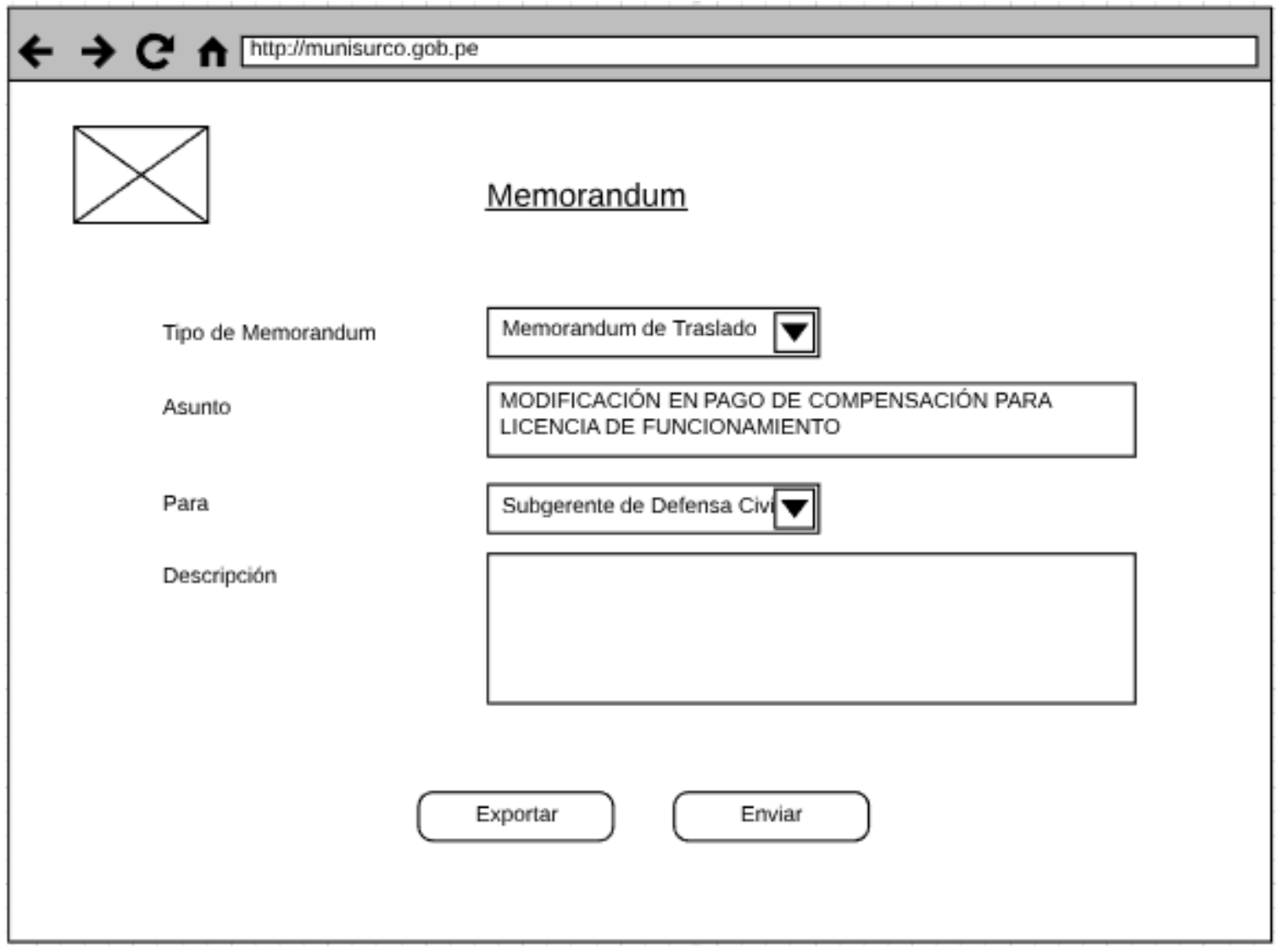

Fuente : Elaboración Propia 


\section{Anexo 24: Elaborar Documento}

Figure 52: Elaborar Documento

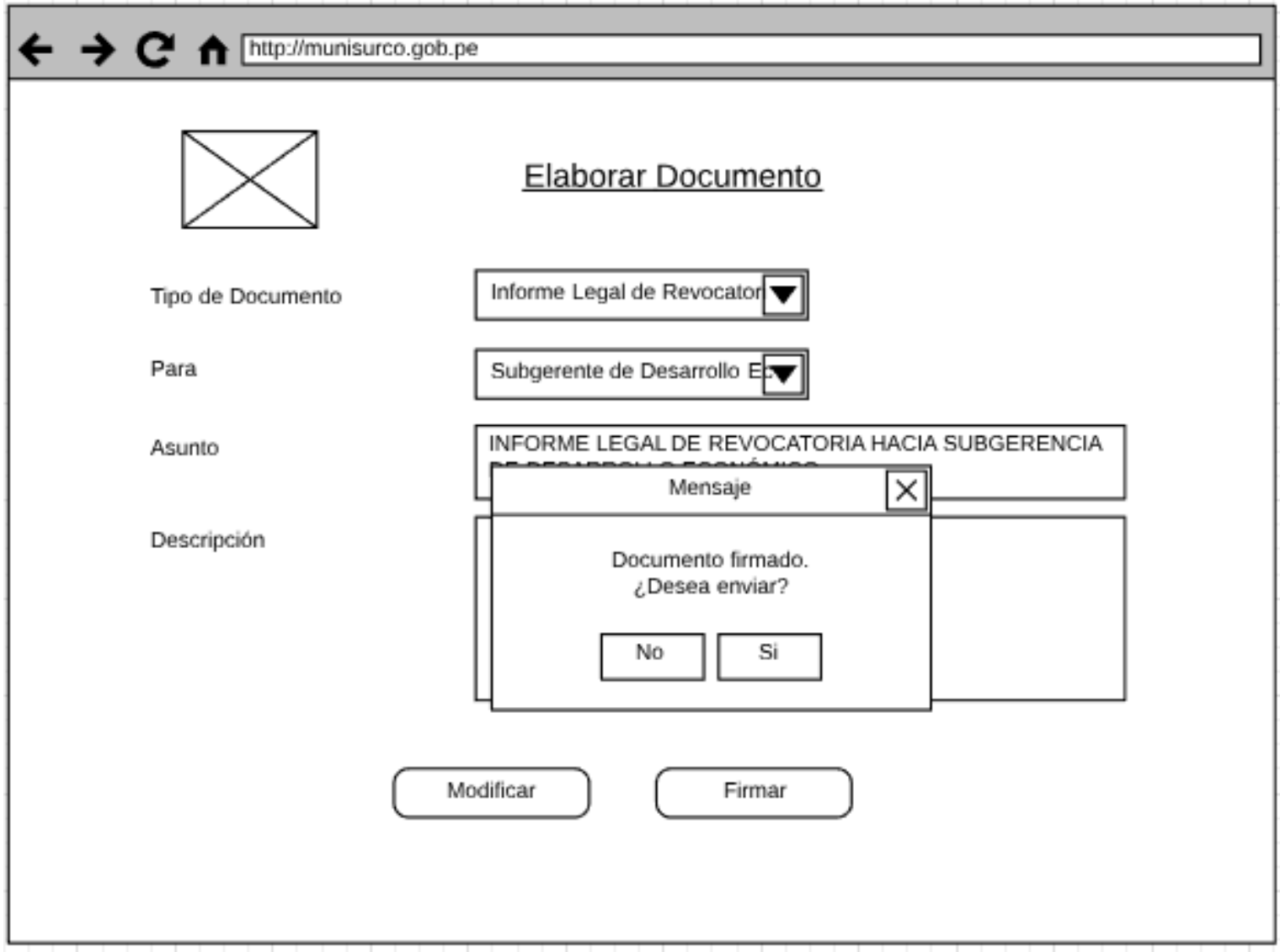

Fuente : Elaboración Propia 


\section{Referencias Bibliográficas}

En esta sección, se describirá la bibliografía usada para el desarrollo del presente documento:

Arango, M., Londoño, J. \& Zapata, J. 2010. Arquitectura Empresarial - Una Visión General. Revista Ingenierías Universidad de Medellín. Colombia.

Areej AlHogail. 2015. Diseño y validación del marco de cultura de seguridad de la información.

CIO@GOV. 2016. Arquitectura Empresarial. El camino hacia un gobierno integrado.

Definición ABC. Definición de Municipalidad. 2016. Sitio Web: http://www.definicionabc.com/general/municipalidad.php

Definición de. Definición de municipalidad. 2016. Sitio Web: http://definicion.de/municipalidad/

Es.wikipedia.org. Gobierno local. 2016. Sitio Web: https://es.wikipedia.org/wiki/Gobierno_local

Enrique Bonsón, Sonia Royo, Melinda Ratkai. 2014. Participación de los ciudadanos en los sitios de Facebook de los gobiernos locales. Un análisis empírico: El impacto de los diferentes tipos de medios y contenidos en Europa Occidental.

Filipe Sá, Álvaro Rocha, Joaquim Gonçalves, Manuel Pérez Cota. 2016. Modelo para la Calidad de los Servicios en Línea del Gobierno Local.

Hai Wanga, Shouhong Wang. 2013. Mapa ontológico de la arquitectura orientada a servicios para servicios de administración compartidos.

Jie Lu, Dianshuang Wu, Mingsong Mao, Wei Wang, Guangquan Zhang. 2015. Sistema de recomendación de desarrollos de aplicaciones: una encuesta.

Josey, A., Harrison, R., Homan, P., Rouse, M., Van Sante, T.,Turner, M. \& Van der Merwe, P. 2013. TOGAF Versión 9.1 Guía de Bolsillo. Zaltbommel.

Kaja J. Fietkiewicz, Agnes Mainka, Wolfgang G. Stock. 2016. La administración electrónica en las ciudades de la sociedad del conocimiento. Una investigación empírica de los sitios web gubernamentales de Smart Cities.

Lu, J. 2001. Medición de los costos y beneficios de las aplicaciones de comercio electrónico y la satisfacción del cliente. Actas de la $2^{\text {a }}$ Conferencia Internacional de la Web. 
Molano. 2015 ¿Qué es Arquitectura Empresarial? Sitio Web: https://colombiadigital.net/actualidad/articulos-informativos/item/8123-que-es-arquitecturaempresarial.html

Molano 2015. ¿Qué es Togaf? Sitio Web: https://colombiadigital.net/actualidad/articulosinformativos/item/8163-que-es-togaf.html

Opengroup.org. TOGAF®, an Open Group standard | The Open Group. 2016. Sitio Web: https://www.opengroup.org/togaf/

Petnji Yaya Luc Honore, Marimon Frederic, Casadesus Marti. 2012. Investigando Discrepancias entre E-Services: Implementación o No - Iso 9001: Perspectivas de los Clientes en el Ejemplo de los Servicios Electrónicos en Cataluña (España).

Po-Ling Sun, Cheng-Yuan Ku, Dong-Her Shih. 2013. Un marco de implementación para EGovernment 2.0

Project Management Institute, Inc. 2013. Guía de los Fundamentos para la Dirección de Proyectos (guía del PMBOK).

Slideshare. 2010. e-Gobierno (e-government). Sitio Web: http://es.slideshare.net/hugoces/egobierno-egovernment.

Unesco. Gobernabilidad Electrónica Fortalecimiento de capacidades de la gobernabilidad electrónica. Sitio Web: http://portal.unesco.org/ci/en/files/14896/11412266495egovernance.pdf/e-governance.pdf

Zhao Huang, Morad Benyoucef. 2014. Facilidad de uso y la credibilidad de los sitios web de gobierno electrónico. 